Departamento de Ingeniería Topográfica y Cartografía Escuela Técnica Superior de Ingenieros en Topografía, Geodesia y Cartografía

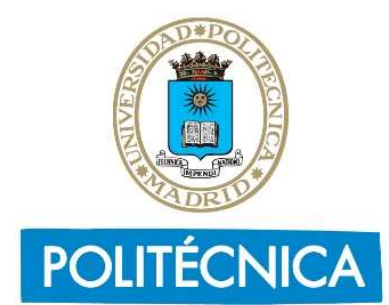

“Ingeniamos el futuro"

\title{
Contribución a la mejora de la expresión gráfica de las cartas aeronáuticas
}

TESIS DOCTORAL

Javier Moya Honduvilla | AUTOR Ingeniero en Geodesia y Cartografía

Dr. Miguel Ángel Bernabé Poveda | DIRECTOR Doctor en Filosofía y Ciencias de la Educación 

El Tribunal de la Tesis Doctoral, nombrado por el Magnífico y Excelentísimo Sr. Rector de la Universidad Politécnica de Madrid,

\section{POLITÉCNICA} con fecha de 18 de enero de 2016, integrado por:

“Ingeniamos el futuro"

Presidente: Dr. Alfredo Llanos Viña - Universidad Politécnica de Madrid - UPM

Secretario: Dr. Rufino Pérez Gómez - Universidad Politécnica de Madrid - UPM

Vocal 10: Dr. Francisco Javier Escobar Martínez - Universidad de Alcalá - UAH

Vocal 20: Dr. Yusef Hassan Montero - Universidad Internacional de La Rioja - UNIR

Vocal 30: Dr. Xavier Prats Menéndez - Universitat Politècnica de Catalunya - UPC

Suplente 10: Dr. Luis Delgado Muñoz - University of Westminster - Londres, Reino Unido

Suplente 20: Dr. José Jesús Reyes Núñez - Eotvos Lorand University - Budapest, Hungría

Realizado el acto de defensa y lectura de tesis el día 27 de enero de 2016,

decide otorgar a la tesis doctoral presentada la calificación de:

EL PRESIDENTE

EL VOCAL $1^{\circ}$

EL VOCAL $2^{\circ}$

EL SECRETARIO 
IV ] UNIVERSIDAD POLITÉCNICADE MADRID 

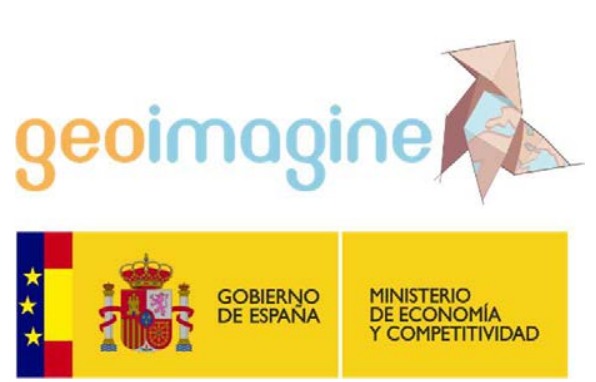

Parte de esta esta tesis doctoral ha sido apoyada mediante financiación pública en el marco del Programa Estatal de Promoción del Talento y su Empleabilidad, incluido en el Plan Estatal de Investigación Científica, Técnica y de Innovación 2013-2016. 
'Per aspera ad astra'

a las estrellas por el camino más difícil

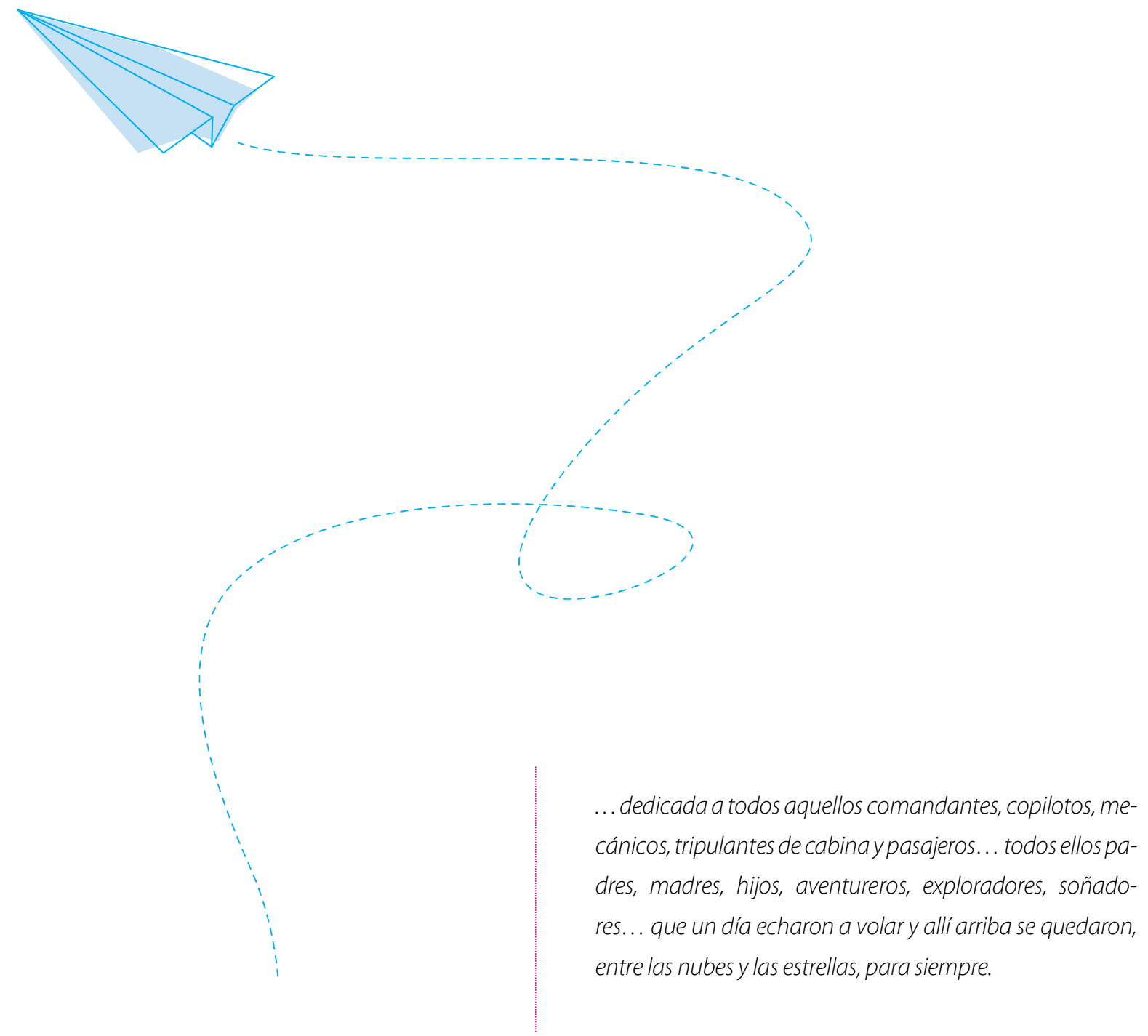


Agradecimientos

la razón por la cual ésta tesis está redactada en primera persona del plural

Al Colegio Oficial de Pilotos de la Aviación Comercial (COPAC), a la Asociación Española de Pilotos de Aeronaves Ligeras (AEPAL) y al Sindicato Español de Pilotos de Líneas Aéreas (SEPLA), por facilitarnos el contacto con todos sus asociados a la hora de descubrir el uso en vuelo real de los distintos aparejos cartográficos objeto de la investigación.

A los comandantes Pablo Puche -Gestair- y Marcos Arranz -Air Europa- por ayudarnos desinteresadamente y encaminarnos con acierto en los pasos iniciales de la tesis doctoral. A Carmelo Garrido, de la Asociación Española de Pilotos de Aeronaves Ligeras (AEPAL), por aportarnos el valioso punto de vista de los usuarios de aeronaves ligeras. A Carmen de Cima y Esther Maseda, del Servicio de Publicaciones de AENA, por acompañarnos en nuestra accidentada -pero finalmente victoriosa- aventura editorial. A José Yépez, del Instituto Espacial Ecuatoriano (IEE), por abrirnos las puertas de la Fuerza Aérea Ecuatoriana (FAE) y facilitarnos el trabajo con sus compañeros de promoción.

A Willington Siabato, por enrolarme en el inicio de los tiempos a su equipo de trabajo en el convenio con AENA, y después por su ilimitada generosidad. A Alberto Fernández, por demostrarnos que el talento siempre vence a los mediocres. A Iván Moya, por ayudar a hacer posible que inferir conclusiones de las mil y una opiniones de casi 300 pilotos fuera un simple juego de consultas SQL. A María Ester González, por la inestimable ayuda prestada en Quito en la recogida de datos. A Isaac Pozo, por seguir ahí, remando encadenado en las galeras del barco pirata de Geoimagine -que volar no vuela pero flotar, flota-. A Teresa Iturrioz, por los cafés compartidos y por no permitir que asuntos tontos y banales nos impidan seguir siendo librepensadores. A Miguel Ángel Manso por la iluminación que supuso descubrir la sencilla pero brillante estructura metodológica de su tesis doctoral. A Antonio Vázquez por acompañarme -calendario y calculadora en mano- en los últimos pasos dados, facilitándome todos los trámites burocráticos finales.

Y finalmente a mi Director de Tesis, Miguel Ángel Bernabé, por mil y una razones. Pero sobre todo, por dejarme volar hacia donde a mí me diera la gana -en la jerga de esta tesis doctoral, bajo reglas de Vuelo Visual-. 


\section{RESUMEN}

Según la Organización de Aviación Civil Internacional (OACI), las cartas aeronáuticas son un medio adecuado para el suministro de información aeronáutica de manera manejable, condensada y coordinada. Sobre esta cartografía temática los editores autorizados sintetizan datos específicos relacionados con la orientación espacial y la salvaguarda de la seguridad del vuelo. En consecuencia, se postulan como un recurso de referencia básico para la planificación, el control de tránsito aéreo y la propia navegación aérea.

Mediante una indagación inicial, en la cual participaron más de 250 pilotos españoles de aviación civil, se revelaron múltiples ineficiencias en el sistema de comunicación gráfica de las cartas aeronáuticas. Su constatación nos lleva a plantear, como punto de partida, que las innovaciones metodológicas que puedan ser alcanzadas, en lo referente a la expresión gráfica de los modelos cartográficos para la navegación aérea, tendrán plena actualidad y recorrido en el contexto conceptual, tecnológico y científico de la información aeronáutica.

En consecuencia, se plantea la necesidad de proponer estrategias o pautas de simbolización basadas en el estudio de la interferencia entre conjuntos de símbolos agrupados en distintos ámbitos o niveles de significado o realidad. El fin último es conseguir, en el caso de las cartas aeronáuticas complejas, una carga visual adecuada y ponderada que facilite y mejore la percepción e interpretación durante las labores de vuelo visual. Este propósito se ha materializado en el diseño de una serie de prototipos que tratan así de mejorar la comunicabilidad de las cartas aeronáuticas complejas, en términos de comprensión y legibilidad del mensaje portado. Para alcanzar este objetivo, la metodología propuesta ha sido dividida en tareas sucesivas: (a) caracterizar la utilización práctica de la información geo-aeronáutica, (b) concretar un conjunto limitado de cartas estereotipadas, (c) diseñar y aplicar una metodología para el análisis de la eficiencia comunicacional, (d) determinar la influencia perceptual provocada por la combinación de variables visuales en la representación y, finalmente, (e) el diseño y evaluación de un prototipo de mejora.

Una vez analizado un conjunto Cartas de Aproximación Visual (VAC) vigentes de ediciones características de distintas regiones y continentes, se ha constatado que la observancia de los distintos principios relativos a factores humanos es manifiestamente mejorable. Adicionalmente existe una llamativa diversidad al respecto entre las series de los distintos Servicios de Información Aeronáutica (AIS) autorizados; este hecho se ha sistematizado mediante una escala de grados, permitiendo así calcular la intensidad de cambio o diferencia existente en cada uno de los símbolos analizados con respecto a la especificación simbólica recomendada de $\mathrm{OACl}$.

A partir de la sistematización anterior, se ha alcanzado un estereotipado de tendencias de simbolización, permitiendo así elaborar una serie de modelos de representación cartográfica estereotipo. Aplicando algoritmos de saliencia, se han calculado las capacidades de prominencia visual y de atención temprana de cada uno de ellos. A su vez, mediante técnicas de seguimiento ocular, se han cotejado las cualidades comunicativas calculadas de forma teórica con las medidas en una actividad de lectura e interpretación, en la que participaron pilotos militares y profesionales de la información geográfica. 
Los resultados obtenidos permiten afirmar que es factible predecir de forma básica las capacidades de atención temprana de los objetos gráficos que componen una carta aeronáutica, posibilitando dirigir de forma planificada la atención visual del lector hacia determinados elementos y símbolos, según el propósito que tenga cada carta en particular. Adicionalmente se ha constatado que una adecuación en términos de contraste relacional y combinatoria de variables visuales mejora la eficiencia de los recorridos visuales, optimiza la duración de las fijaciones oculares y, como resultado, se reduce el tiempo de adquisición de la información en la lectura de las cartas aeronáuticas.

En consecuencia, tomando en consideración los requerimientos de factores humanos como parámetros de calidad para que el lenguaje gráfico alcance una comunicabilidad adecuada, podemos afirmar que puede mejorarse la eficiencia comunicacional de las cartas aeronáuticas, en términos de velocidad, claridad y cantidad de información que se puede ser percibida y procesada con respecto al desempeño humano óptimo.

Palabras clave: expresión gráfica, cartografía aeronáutica, historia de la aviación, navegación aérea, información geo-aeronáutica, modelos cartográficos, OACI (ICAO), estereotipado de la representación gráfica, usabilidad, factores humanos, semiología gráfica, evaluación de la comunicabilidad, variables visuales, saliencia, inferencia perceptual, eye-tracking, métricas de seguimiento ocular. 


\section{ABSTRACT}

According to the International Civil Aviation Organization (ICAO), aeronautical charts provide a convenient medium for supplying navigation information in a manageable, condensed and coordinated manner. Throughout these thematic maps, authorised publishers synthesize specific information related to spatial orientation and flight safety. Thus, they can be described themselves as the main reference for planning, air traffic control and navigation purposes.

250 Spanish civil aviation pilots participated in an initial inquiry that revealed several inefficiencies in the graphic communication of aeronautical charts. As starting point, these facts are strikingly relevant today from a conceptual, technological and scientific view. Moreover, they lead to regard some methodological innovations that could be achieved with respect the graphic expression of cartographic models in the air navigation field.

Subsequently, it is needed to propose new strategies and rules for symbology based on the interference studies within of set of symbols grouped in diverse situations or significance levels. In the case of complex aeronautical charts, the ultimate aim is to achieve a proper and well-considered visual load improving the perception and interpretation during visual flight conditions. As a matter of fact, several prototypes was designed aiming to improve the communication in complex aeronautical charts in terms of comprehension and legibility of the carried message. The proposed methodology was divided in subsequent tasks: (a) characterize the practical usage of aeronautical geo-information, (b) specify a reduced set of stereotypical charts, (c) design and apply a methodology to analyze the communicational efficiency, (d) determine the perceptual influence of visuals variables in the graphic representation, and finally (e) design and assess an enhanced prototype.

Following the analysis of a representative set of Visual Approach Charts from diverse regions and continents, it was confirmed the need to improve the observational principles related to human factors. In this respect, there is a remarkable differences within the diverse official Aeronautical Information Services. A grading scale was designed with the aim to classify systematically the differences in every single symbol, which were analysed with respect the recommended specification of ICAO.

Following the previous systematization, stereotypical trends of the symbolization were achieved and led into a set of stereotyped models of cartographic representation. It is possible to calculate each of the capabilities of visual prominence and early attention when applying saliency algorithms. At the same time, the communicational skills calculated with eye-tracking were later cross-checked with the measures taken from an interpretation experiment involving military pilots and geo-information experts. 
The obtained results confirm the feasibility to achieve a basic prediction of the capability of early attention to graphical objects in the aeronautical chart. Thus, the reader's visual attention can be addressed through the main elements and symbols of the chart. In addition, the adaptation of relational contrast and the combination of visual variable may enhance the efficiency of visual pathways, together with the optimization of the ocular focus. As a matter of fact, it is reduced the time needed to the read the information from the aeronautical charts.

It had proved possible to conclude that the requirements of human factors represent a parameter of quality influencing the graphical communication. Therefore, communicational efficiency of aeronautical charts can be improved by the influence of the optimal human performance; with respect of quickness, clarity and quantity of the information perceived and processed.

Key words: graphic expression, aeronautical cartography, history of aviation, air navigation, aeronautical geoinformation, cartographical models, ICAO, stereotyped graphic representation, usability, human factors, Graphic Semiotics, communicability assessment, visual variables, saliency, perceptual inference, eye-tracking. 


\section{ESQUEMA DE CONTENIDOS}

\section{Si el tiempo vale su peso en oro... .}

Si no se dispone excesivo tiempo para leer la tesis o, simplemente se requiere conocer directamente los rasgos, resultados y conclusiones más generales, en forma de primera mirada recomendamos acercarse a las motivaciones y al plan de trabajo a través del capítulo de introducción. Adicionalmente, al final de los capítulos del cuerpo de la tesis se disponen de síntesis que resumen de forma muy abreviada todos los pasos de las metodologías que se han ido desarrollado. Como no podía ser menos, en el capítulo de conclusiones se presentarán las aportaciones originales, se discutirán los resultados, se revisará las preguntas de investigación y, finalmente, se identificarán nuevos caminos por explorar.

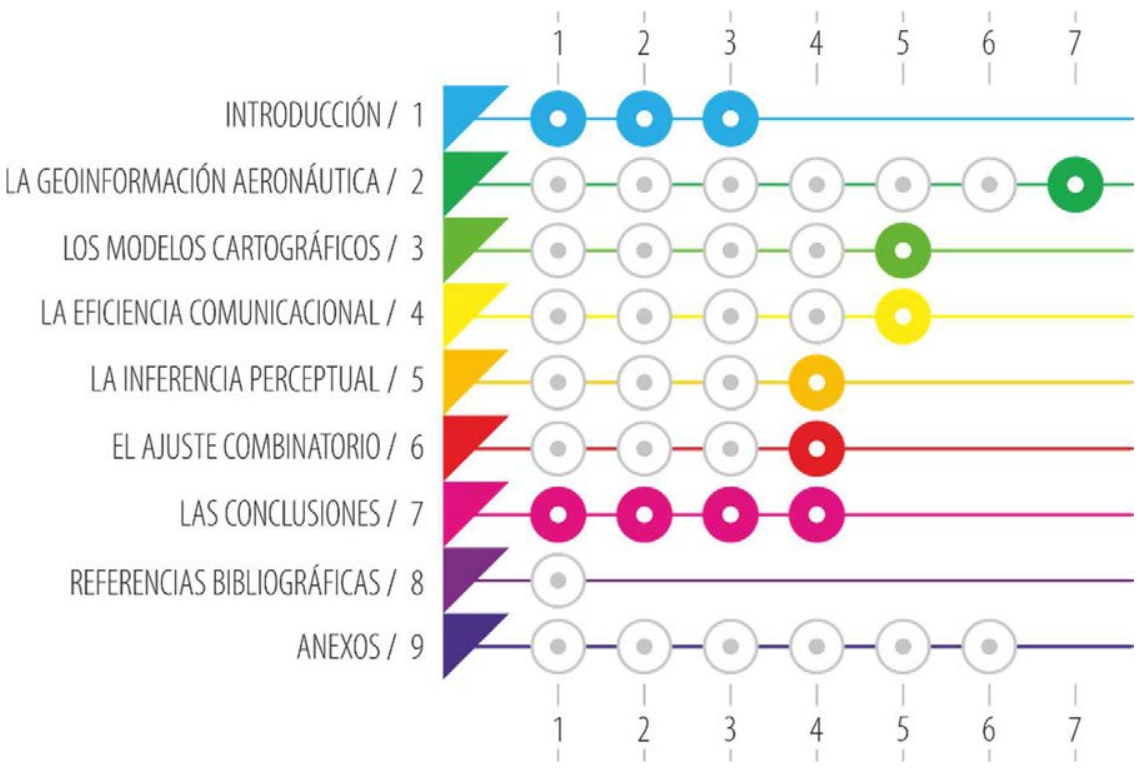

\section{Si se quieren conocer los antecedentes y lo último al respecto... .}

El esquema habitual de una tesis suele disponer el estado del arte concentrado únicamente en su tramo inicial. Sin embargo, y debido a la multiplicidad de temáticas y aspectos que son transitados en este trabajo, proponemos distribuir el contenido del estado del conocimiento y la valoración de los antecedentes científicos en determinadas secciones, todas ellas localizadas en la primera mitad de la tesis. Se aspira así a enmarcar la investigación propia cuando así se requiera. 


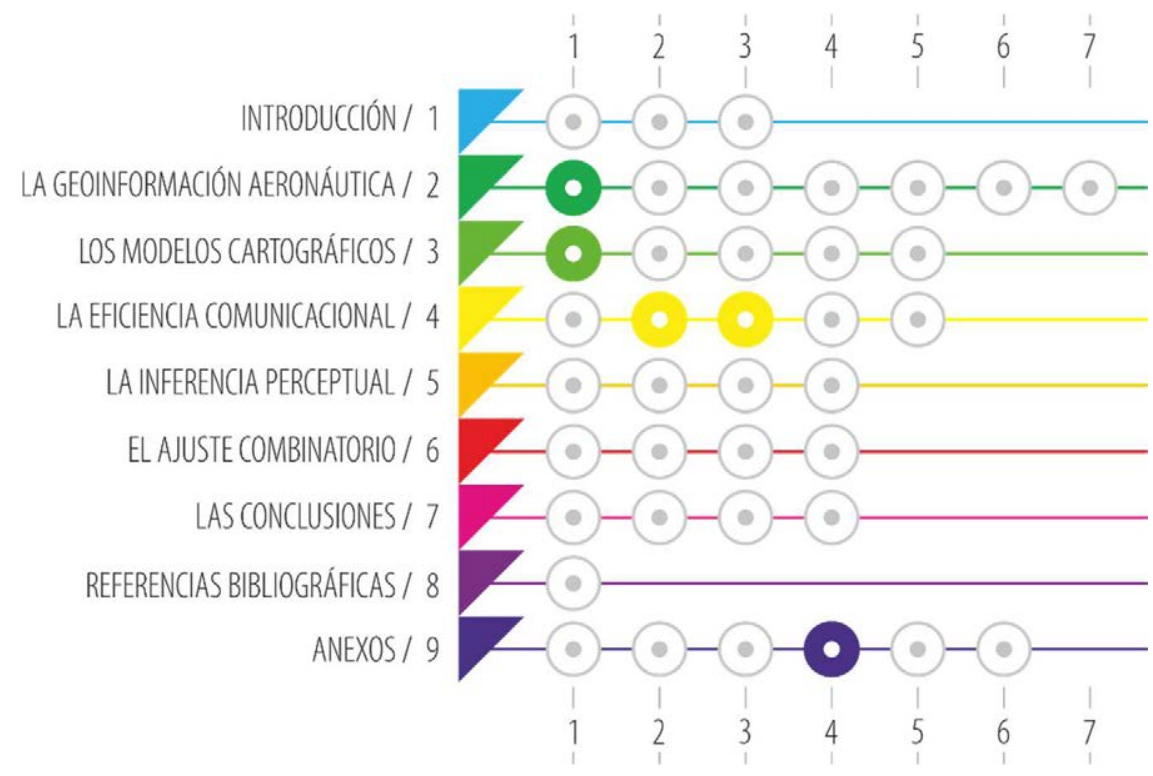

Si se requiere conocer la investigación original de esta tesis.. .

El cuerpo central de la tesis se distribuye por una serie concreta de secciones, en las cuales se desarrolla la investigación de carácter original efectuada: se presenta la metodología propuesta y los métodos empleados, se detallan y analizan los materiales y datos obtenidos, etc. Finalmente, los resultados serán discutidos desde un punto de vista crítico, justificando cómo éstos van a apoyar o no la tesis inicial propuesta.

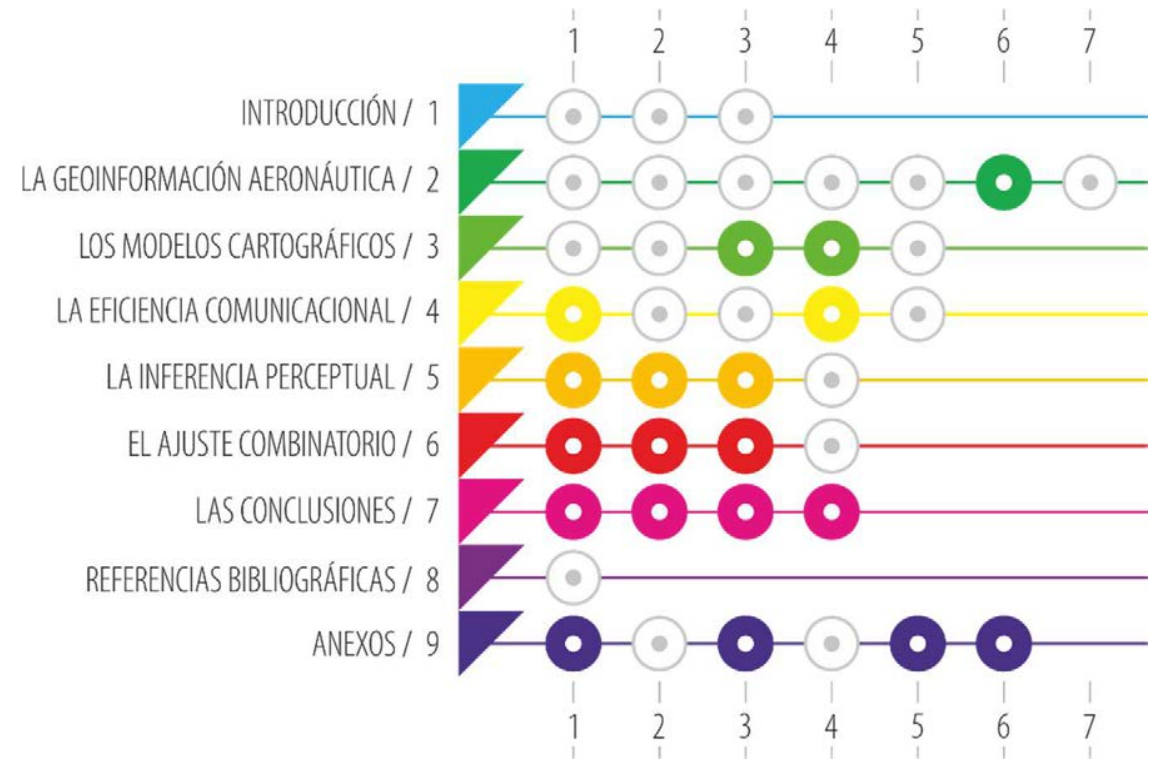




\section{Si una vez leída la tesis se aspira a conocer más...}

Determinadas secciones hacen referencia, en parte, a conocimientos, razonamientos o deducciones que, si bien son interesantes, creemos que pueden considerarse en cierta manera como adicionales al núcleo de la tesis. Por ello, con el objeto de no distraer en exceso el hilo argumental, diversas partes del texto reconducirán al lector hacia los anexos cuando se requiera más información acerca de una cuestión o contenido concreto de especial interés, bien sea propio o de terceros. Por otra parte, esta tesis doctoral contiene 775 citas a 365 textos o trabajos de referencia. Si llegado el caso se requiere indagar sobre una obra de interés, cualquiera de ellas podrá encontrarse convenientemente reseñada en el capítulo de referencias bibliográficas.

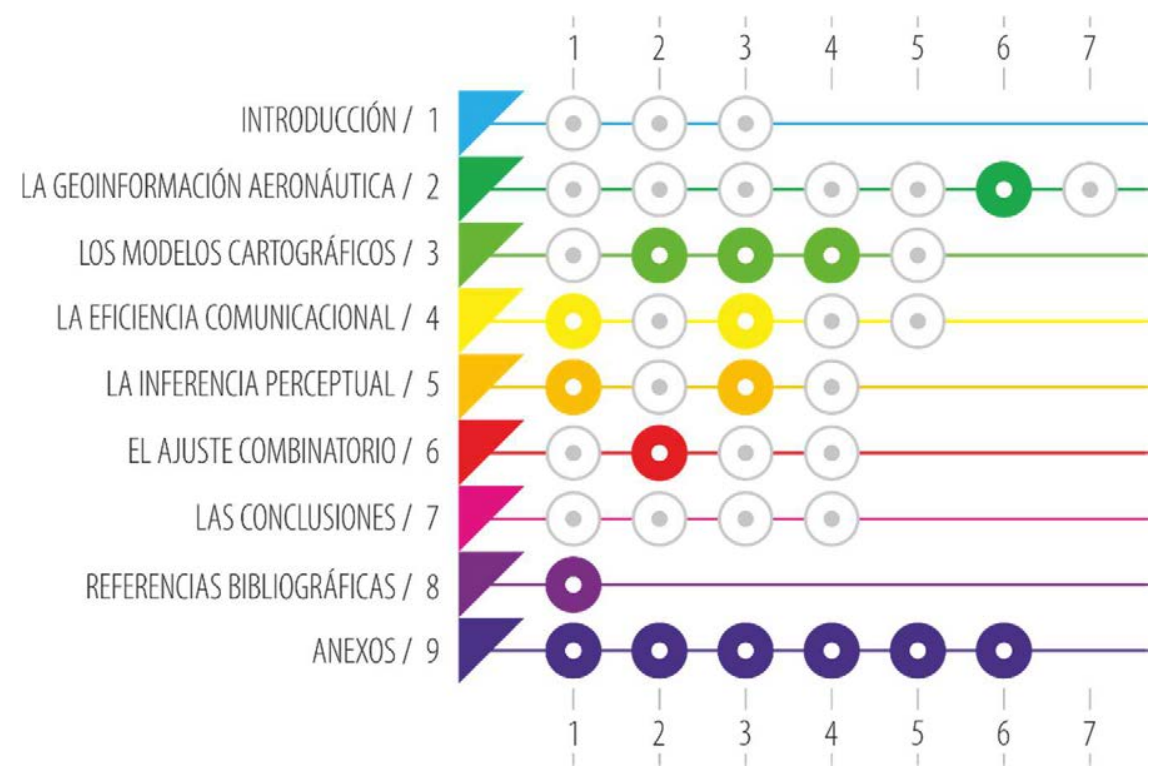

\section{Si se realiza una aproximación desde el ámbito de la geografía. . .}

Si esta tesis se aborda partiendo de un perfil relacionado con el ámbito de la semiótica gráfica y la redacción cartográfica, posiblemente existan términos, expresiones, circunstancias y necesidades que un lector extraño al entorno aeronáutico desconozca a priori, dificultándole en buena medida la comprensión del trabajo realizado. Para facilitar este conocimiento tan especializado a quienes se acerquen a esta tesis desde un conocimiento previo puramente geográfico, se han dedicado algunas secciones a aportar una serie de nociones básicas relacionadas con el ámbito de la información aeronáutica. 


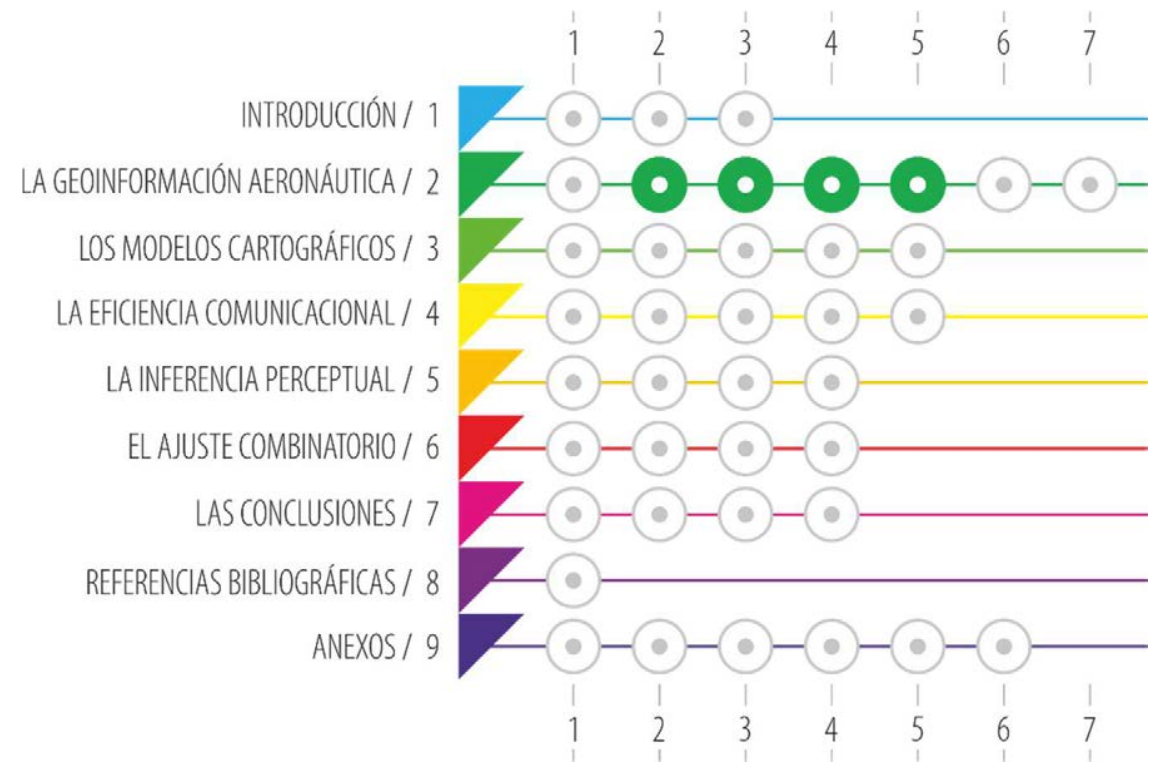

\section{0 si la aproximación parte desde mundo de la aviación...}

Por el contrario, si el acercamiento a esta disertación proviene desde un perfil eminentemente aeronáutico, hemos reservado algunas de las secciones para aportar cuestiones semióticas y de expresión gráfica que consideramos básicas. En definitiva, tratamos así de posicionar en igualdad de condiciones a los perfiles geográfico y aeronáutico para comenzar a generar, conjuntamente, la aportación de conocimiento propio y novedoso que toda tesis doctoral requiere.

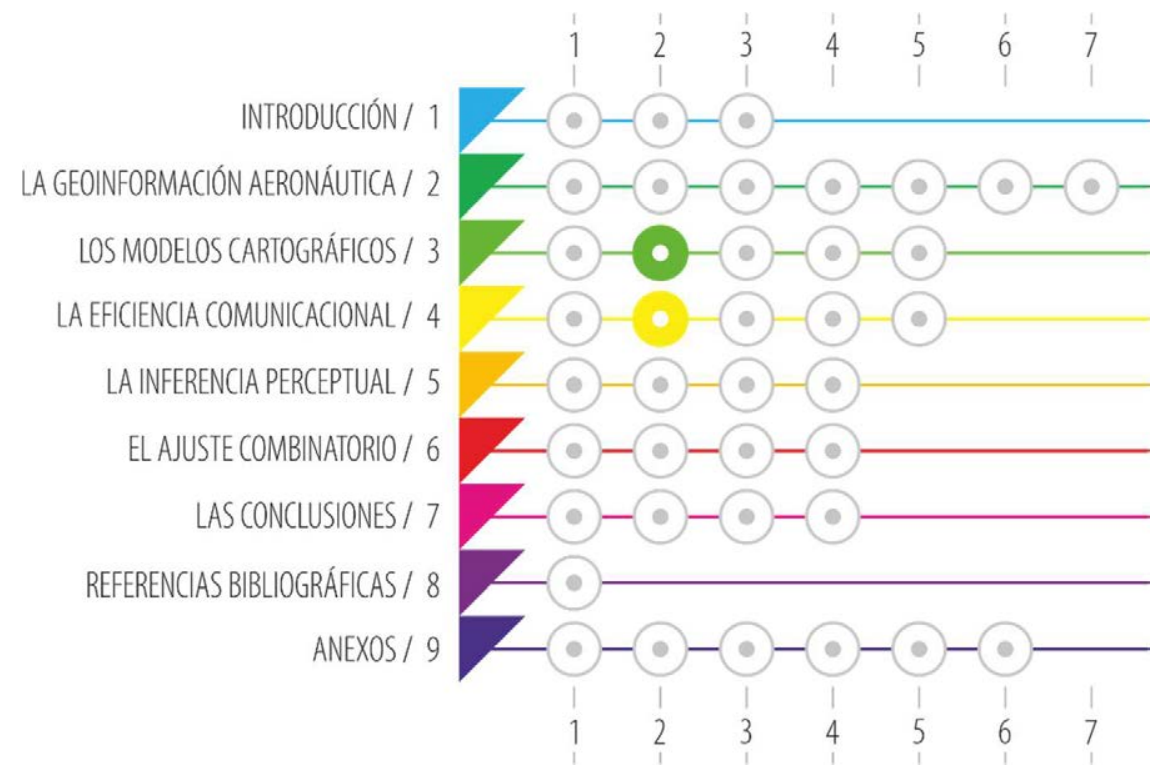




\section{ÍNDICE DE CONTENIDOS}

1. INTRODUCCIÓN ................................................................39

1.1. ANTECEDENTES Y ESTADO GENERAL DE LA CUESTIÓN ................................................39

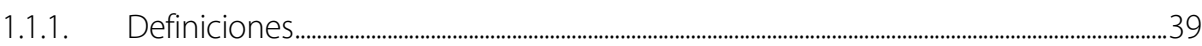

1.1.2. Normalización y transición al entorno digital .........................................................................40

1.1.3. Planes de interoperabilidad y programas actuales ..........................................................41

1.1.4. Líneas de investigación en el campo de la visualización de la IGA............................42

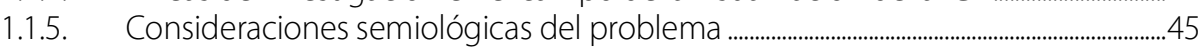

1.1.6. División del problema.........................................................................................................46

1.2. OBJETIVOS DE LA TESIS Y CUESTIONES DE INVESTIGACIÓN.......................................47

1.2.1. Hipótesis ..........................................................................................................................................4

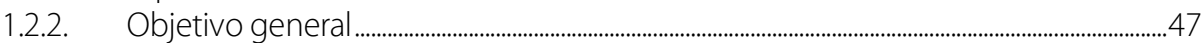

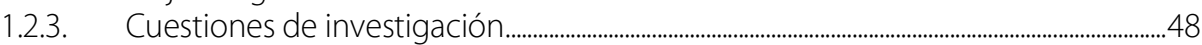

1.2.4. Objetivos específicos .............................................................................................................................4

1.3. METODOLOGÍA ..............................................................................................................4

1.4. RESULTADOS PREVISTOS ………………………………………………………………...... 51

2. LA GEOINFORMACIÓN AERONÁUTICA .................................55

2.1. 110 AÑOS EN EL CIELO .................................................................................................5

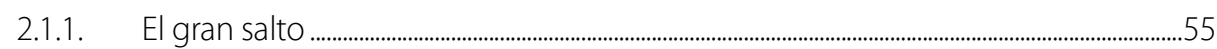

2.1.2. La especialización.........................................................................................................................59

2.1.3. La batalla....................................................................................................................................62

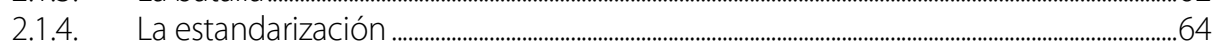

2.1.5. La presurización .........................................................................................................................65

2.1.6. Los trazos luminosos .....................................................................................................................67

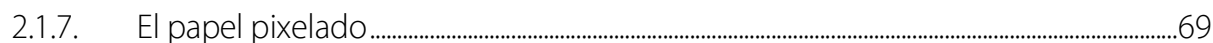

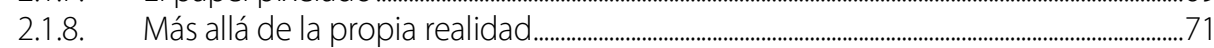

2.2. LA NAVEGACIÓN AÉREA ..............................................................................................

2.2.1. La determinación de la posición de una aeronave..........................................................76

2.2.2. Los métodos de navegación autónomos ..............................................................................77

2.2.3. Los métodos de navegación asistidos ...........................................................................79

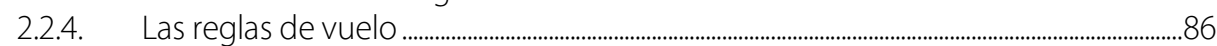

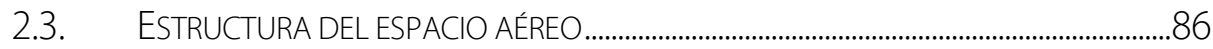

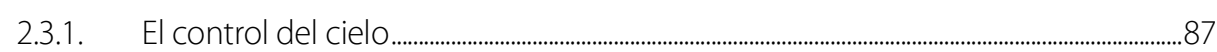

2.3.2. Las regiones de información de vuelo.........................................................................................89

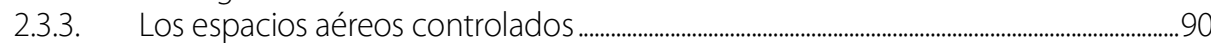




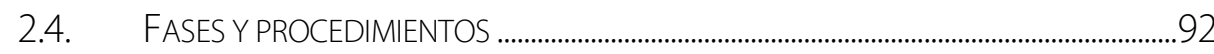

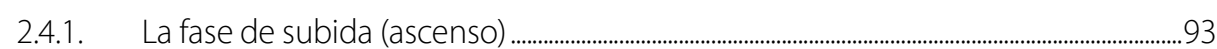

2.4.2. La fase de crucero (en ruta) ................................................................................................................... 94

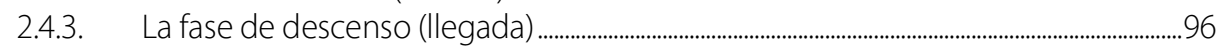

2.4.4. Las fases de aproximación y aterrizaje.....................................................................................97

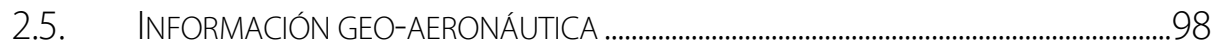

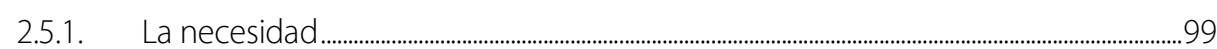

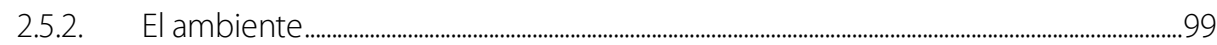

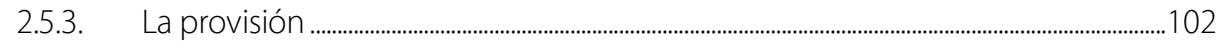

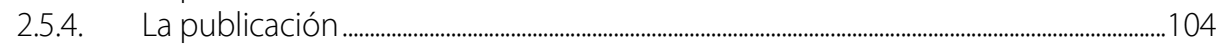

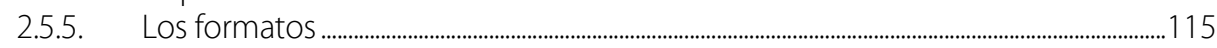

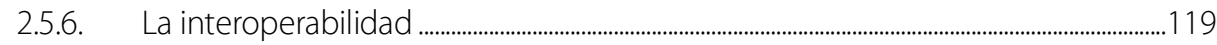

2.6. CARACTERIZACIÓN DEL USO PRÁCTICO DE LA INFORMACIÓN ................................ 121

2.6.1. Los aspectos de interés y el instrumento de evaluación ....................................................123

2.6.2. El propósito de la escala......................................................................................................................... 125

2.6.3. La definición, redacción, ordenación y codificación de ítems .......................................127

2.6.4. El formato y la programación del cuestionario ..........................................................................130

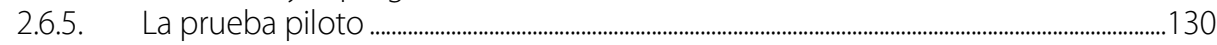

2.6.6. El plan de difusión y recogida de datos ..................................................................................131

2.6.7. La representatividad y fiabilidad del estudio ........................................................................131

2.6.8. La explotación de datos ........................................................................................................................132

2.6.9. El perfil general de las tripulaciones y sus aeronaves..........................................................133

2.6.10. Utilización de los elementos de información geográfica en vuelo ...........................136

2.6.11. Evaluación de características semiológicas, de usabilidad y de eficiencia............139

2.6.12. Resolución de aspectos de interés...................................................................................................146

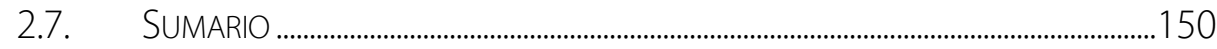

3. LOS MODELOS CARTOGRÁFICOS................................. 153

3.1. ESTANDARIZACIONES Y RECOMENDACIONES........................................................ 155

3.1.1. El Anexo 4 del Convenio de Aviación Civil Internacional...............................................1.155

3.1.2. Otros documentos $\mathrm{OACl}$ de orientación y ayuda.............................................................159

3.1.3. Las directrices particulares en el ámbito digital ....................................................................160

3.1.4. El nuevo contexto de servicios y aplicaciones .........................................................................161

3.2. GRAFISMO DE LA INFORMACIÓN AERONÁUTICA ........................................................163

3.2.1. La representación .................................................................................................................................. 164

3.2.2. La simbolización ............................................................................................................................. 165

3.2.3. Los aspectos operacionales ..................................................................................................... 165

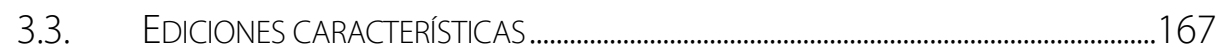

3.3.1. Análisis preliminar de ediciones $\mathrm{OACl}$..........................................................................................168

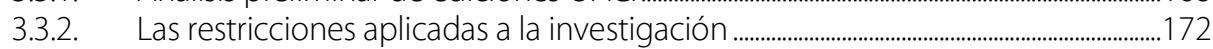

3.3.3. Listado de ediciones características .......................................................................................... 174 
3.4. EVALUACIÓN Y ESTEREOTIPADO DE TENDENCIAS ...............................................178

3.4.1. El análisis de especificaciones simbólicas...........................................................178

3.4.2. La composición de modelos de simbología estereotipada........................................185

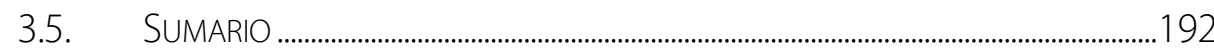

4. LA EFICIENCIA COMUNICACIONAL.....................................195

4.1. FACTORES HUMANOS EN LA COMUNICACIÓN CARTOGRÁFICA ...........................197

4.1.1. El modelo conceptual de los factores humanos ..............................................................198

4.1.2. Las implicaciones de los errores de edición, lectura e interpretación ......................199

4.1.3. Los componentes y factores implicados en la lectura de cartas ...............................204

4.1.4. Listado de conceptos de eficiencia comunicacional .................................................208

4.2. ERGONOMÍA DE LA COMUNICACIÓN VISUAL.......................................................2.

4.2.1. La comunicación y la ergonomía cognitiva ........................................................................211

4.2.2. La incertidumbre gramatical de la imagen .........................................................................211

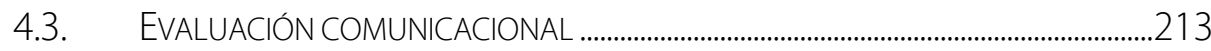

4.3.1. Las metodologías de evaluación de los sistemas de comunicación......................213

4.3.2. La atención visual y el seguimiento de ojos ................................................................215

4.3.3. Evaluación cartográfica mediante técnicas de eye-tracking ..........................................221

4.3.4. Bondades, incertidumbres y limitaciones.........................................................................228

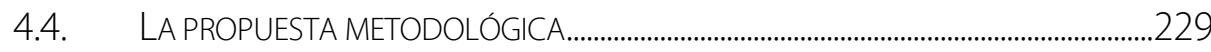

4.4.1. Localización del ámbito geográfico de evaluación ...................................................230

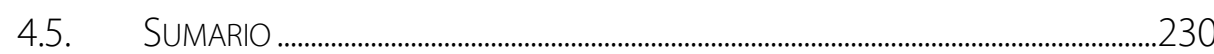

5. LA INFERENCIA PERCEPTUAL ......................................233

5.1. MOTIVACIONES Y PLANTEAMIENTO METODOLÓGICO.............................................235

5.1.1. La selección del problema comunicacional ...........................................................235

5.1.2. El marco de evaluación y los niveles de abstracción simbólica..............................236

5.1.3. La organización de la percepción visual...........................................................................239

5.1.4. El ajuste de variables visuales.................................................................................................241

5.1.5. El diseño de materiales (estímulos) .................................................................................243

5.1.6. La verificación de saliencia y atención visual ..................................................................248

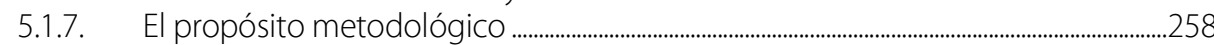

5.2. DISEÑO Y ADMINISTRACIÓN DEL ESTUDIO..........................................................2

5.2.1. Grupos de evaluación ..............................................................................................................259

5.2.2. Tareas y diseño de las pruebas..........................................................................................260

5.2.3. Planificación de la visualización de estímulos....................................................................263

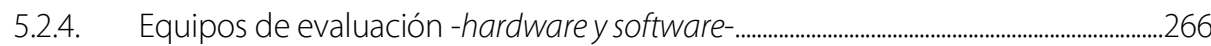


5.3. EVALUACIÓN Y RESULTADOS ..............................................................................2.

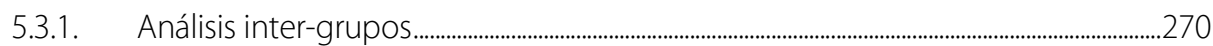

5.3.2. Análisis por modelos cartográficos .....................................................................................272

5.3.3. Análisis por tareas realizadas .......................................................................................................275

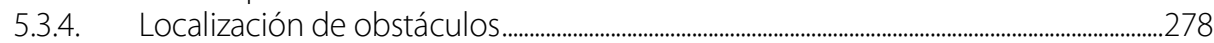

5.3.5. Selección de recorridos por carretera ......................................................................................283

5.3.6. Comparación de atributos de altura...........................................................................................288

5.3.7. Localización de aeropuertos / aeródromos ......................................................................295

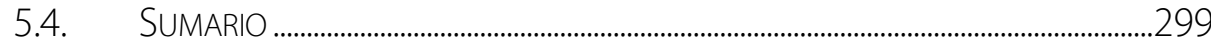

6. EL AJUSTE COMBINATORIO..............................................301

6.1. CONSIDERACIONES ACERCA DEL ESTUDIO ..................................................................302

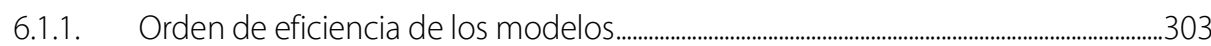

6.1.2. Modelos de Bourdeaux Merignac.....................................................................................305

6.1.3. Modelos de Madrid Cuatro Vientos...................................................................................306

6.2. INCORPORACIÓN DE AJUSTES..................................................................................307

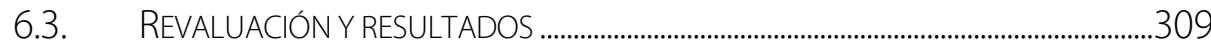

6.3.1. Administración del estudio ...............................................................................................309

6.3.2. Resultados y comparación .............................................................................................................310

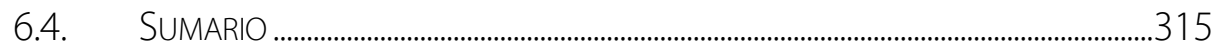

7. LAS CONCLUSIONES...............................................................317

7.1. APORTACIONES ORIGINALES......................................................................................317

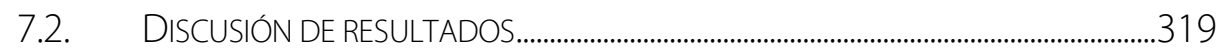

7.2.1. Con respecto a la geo-información aeronáutica ...................................................320

7.2.2. Con respecto a los modelos cartográficos .........................................................................322

7.2.3. Con respecto a la eficiencia comunicacional ...............................................................324

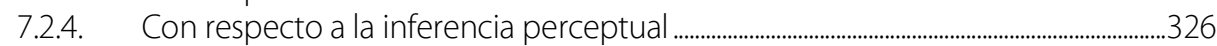

7.3. REVISIÓN DE LAS PREGUNTAS DE INVESTIGACIÓN E HIPÓTESIS..............................329

7.3.1. Particularidades del uso práctico de la cartografía aeronáutica...............................330

7.3.2. Conformidad con las normas y métodos recomendados por OACl.......................332

7.3.3. Homogeneidad de estilos gráficos en las ediciones AIS ............................................332

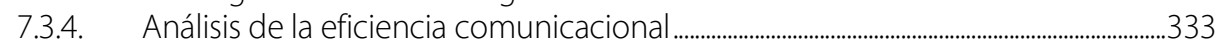

7.3.5. Modificación de la efectividad del mensaje cartográfico .............................................334

7.3.6. Especificación combinatoria de variables visuales............................................................335

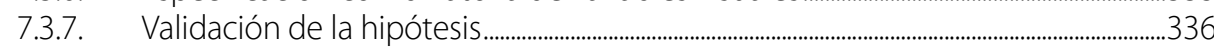

7.4. TRABAJOS FUTUROS ............................................................................................... 
9. ANEXOS

9.1. INFORMACIÓN COMPLEMENTARIA A LA CARACTERIZACIÓN DEL USO PRÁCTICO DE

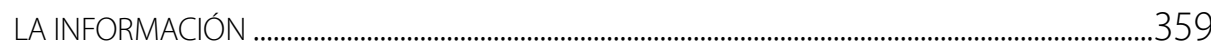

9.1.1. Consideraciones adicionales acerca del instrumento de evaluación......................359

9.1.2. Contenido del cuestionario.......................................................................................................

9.1.3. Codificación de respuestas a través de escalas ......................................................................361

9.1.4. Formato del cuestionario .....................................................................................................................

9.1.5. Principios considerados en la creación de formularios .......................................................364

9.1.6. Diagrama de entidad/relación y conexión de la base de datos.....................................366

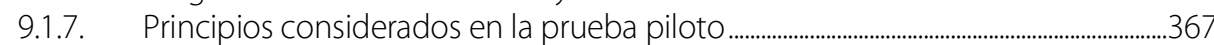

9.1.8. Formularios Web publicados para la recogida de información ...................................370

9.1.9. Particularidades del plan de difusión ............................................................................................381

9.1.10. Estimación de la representatividad de la muestra...........................................................384

9.1.11. Evaluación de la fiabilidad de la metodología propuesta ..............................................386

9.1.12. Metodología de creación automatizada de consultas ......................................................389

9.1.13. Tipología y cuantificación de las aeronaves del estudio ..................................................392

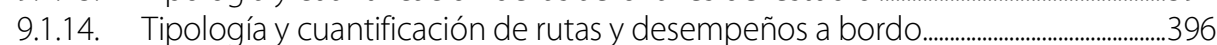

9.1.15. Consideraciones adicionales acerca del uso de formatos a bordo.............................397

9.1.16. Valoración semiológica y de usabilidad: cartas en papel....................................................400

9.1.17. Valoración semiológica y de usabilidad: displays de navegación.................................404

9.1.18. Valoración semiológica y de usabilidad: cartas digitales..................................................410

9.1.19. Eficiencias e ineficiencias del formato de cartas en papel .............................................4 415

9.1.20. Eficiencias e ineficiencias del formato de displays de navegación...............................419

9.1.21. Eficiencias e ineficiencias del formato de cartas digitales ...............................................423

\subsection{INFORMACIÓN COMPLEMENTARIA AL GRAFISMO DE LA INFORMACIÓN} AERONÁUTICA

9.2.1. Representación de los fenómenos geográficos en relación con sus características.

9.2.2. Clasificación de los símbolos aeronáuticos según niveles de abstracción............430

\subsection{INFORMACIÓN COMPLEMENTARIA AL ANÁLISIS DE LAS ESPECIFICACIONES} SIMBÓLICAS

9.3.1. Análisis de caracterización $\mathrm{OACl}$ de fenómenos y abstracción simbólica ...........431

9.3.2. Cotejo gráfico de diferencias entre la simbología de ediciones características y la especificación $\mathrm{OACl}$.

9.3.3. Análisis de tendencias existentes en la simbolización de las ediciones características 439

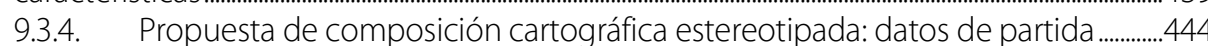

9.3.5. Propuesta de composición cartográfica estereotipada: modelos finales..............447

9.4. INFORMACIÓN COMPLEMENTARIA A LOS FACTORES HUMANOS EN LA COMUNICACIÓN CARTOGRÁFICA.

9.4.1. Factores humanos de interés desde el punto de vista de los sistemas electrónicos de visualización de datos

9.4.2. Conceptos fundamentales de factores humanos aplicados a la representación visual de la información.

9.4.3. Métricas de seguimiento ocular 457 
9.5. INFORMACIÓN COMPLEMENTARIA A LA MOTIVACIÓN Y PLANTEAMIENTO METODOLÓGICO. .460

9.5.1. Modelos estereotipo enfocados a la orientación visual y a la navegación ..........460

9.5.2. Análisis de la prominencia visual de los modelos cartográficos ................................463

9.5.3. Análisis ANOVA de comparación inter-grupos .................................................................470

9.5.4. Análisis de dispersión y simetría de los datos................................................................472

9.6. INFORMACIÓN COMPLEMENTARIA A LA INCORPORACIÓN DE AJUSTES................473

9.6.1. Propuesta de composición estereotipada modificada: modelos finales..............474 


\section{ÍNDICE DE FIGURAS}

Figura 2-1: Página del logbook o diario de vuelo en la que se documenta el primer circuito de vuelo circular realizado por los hermanos Wright el 20 de septiembre de 1904 (Winchester, 2004a)

Figura 2-2: Carta de navegación de 1918 para el trayecto Washington-Norfolk (EE.UU.) además de ciudades, vías de comunicación, bases y depósitos, se indican los lugares de aterrizaje clasificados en buenos, malos e indiferentes. Proporción real: 1×3,1 (National Air and Space Museum, Washington, D.C.). .60

Figura 2-3: Carta de 1928 destinada a la ruta aérea entre Greensboro y Richmond (EE.UU.) balizada a través de aerofaros. Proporción real: 1×3. (National Air and Space Museum, Washington, D.C.) 61

Figura 2-4: Prototipo de carta instrumental de 1948 para el trayecto Chicago-Nueva York (EE.UU.) en la que por primera vez se simbolizan los procedimientos de radionavegación VOR. Proporción real: 3×1 (National Air and Space Museum, Washington, D.C.)

Figura 2-5: Comparativa parcial entre la carta de navegación de 1933 utilizada por la tripulación del Cuatro Vientos para realizar la travesía atlántica (Museo de Aeronáutica y Astronáutica de Madrid) y una carta aeronáutica japonesa de 1943, centrada en la isla de Taiwán -antigua Formosa- (Geographiclamacicus Antique Maps). 63

Figura 2-6: Mapa móvil de navegación en formato papel, integrado en la instrumentación de un HS-121 Trident (Steve Petch, Airliners.net) .66

Figura 2-7: Publicidad del Ferranti Moving Map Display en revistas de la época. Alrededor de 1965 hacían acto de presencia los primeros anuncios comerciales de pantallas de mapas móviles en las revistas especializadas de la industria aeronáutica, las cuales recogían los primeros requerimientos de ICAO y EUROCONTROL acerca de las pantallas gráficas de navegación (International, 1965a)..

Figura 2-8: Prototipo de PFD y ND de Thomson-CSF propuesto para equipar al Airbus A310 (International, 1980)...

Figura 2-9: Cotejo de una hoja actual de la carta aeronáutica-OACl 1:500.000 publicada por Aena y su equivalente digital desplegado en un prototipo visor interoperable de cartografía aeronáutica on-line sobre un dispositivo electrónico portable iPad (Moya y Bernabé, 2011) . .70

Figura 2-10: Visualización del Primary Flight Display (PFD) de un Boeing B737-800 en aproximación al Aeropuerto Internacional de San Francisco a través de un dispositivo Head-up Display (HUD) (Brett B. Despain, Airliners.net). . .73

Figura 2-11: Sistema de Visión Sintética asociada a la pantalla de vuelo primario (SV-PFD dispuesto a bordo de una aeronave Gulfstream (Ververs et al., 2011) .. .74

Figura 2-12: Ejes implicados en la determinación de la actitud de una aeronave (Moya y Bernabé, 2011).. 
Figura 2-13: Componentes del ángulo de deriva en una navegación con viento cruzado (figura propia a partir de Pérez (2003)). . .78

Figura 2-14: Distintas trayectorias con viento lateral, al utilizar un equipo NDB/ADF o una radioayuda VOR, respectivamente (figura propia a partir de Pérez (2003)) . .80

Figura 2-15: Ejemplo de navegación radial asistida con estaciones VOR/DME (Moya y Bernabé, 2011).

Figura 2-16: Esquema de triangulación de la red de satélites GPS para el posicionamiento tridimensional de una aeronave (Moya y Bernabé, 2011). . .82

Figura 2-17: Indicaciones de desviación al establecerse en una senda de planeo del sistema ILS (Moya y Bernabé, 2011) 84

Figura 2-18: Distintas respuestas de un indicador luminoso PAPI a pie de pista (Moya y Bernabé, 2011). . .85

Figura 2-19: Centro de Control de tráfico de Los Ángeles en 1956. La cobertura radar ATC en EE.UU era extremadamente limitada. Por ello los aviones comerciales informaban de su posición aproximada a los controladores y estos a su vez realizaban estimaciones del tiempo de llegada a la siguiente posición (LostFlights Archive Photo). .. .88

Figura 2-20: Las tres Regiones de Información de Vuelo -denominadas Madrid, Barcelona y Canarias- de responsabilidad española (figura propia a partir de (Aena, 2013a)). .. .89

Figura 2-21: Esquema de las estructuras normalizadas del Espacio Aéreo Controlado (figura propia a partir de Calvo (2000) y Sáez et al. (2002)). 90

Figura 2-22: Esquema de las fases de vuelo bajo reglas IFR instrumentales (ICAO, 2005b; Moya y Bernabé, 2011) .. .93

Figura 2-23: Puntos significativos y de notificación en una ruta de crucero o ATS (Moya y Bernabé, 2011)

Figura 2-24: Diferencia entre una ruta convencional y una ruta RNAV (Moya y Bernabé, 2011).

Figura 2-25: Procedimiento de espera por congestión de tráfico (Moya y Bernabé, 2011)...96

Figura 2-26: Segmentos y puntos fijos de la fase de aproximación (figura propia a partir de (ICAO, 2006b))

Figura 2-27: Maniobra de aproximación frustrada (Moya y Bernabé, 2011). .98

Figura 2-28: Esquema general de paneles de control e indicación de la serie A319/320/321. (Airbus, 1998) .101

Figura 2-29: Plano de aeródromo - OACI. ADC - LEGT. (Aena 2013a) .110

Figura 2-30: Carta de salida normalizada por instrumentos (SID) - OACI. SID 1 / RWY 10 - LEBB. (Aena, 2013a).

Figura 2-31: Plano de obstáculos de aeródromo (tipo A) - OACI. AOC/1 - LEGR. (Aena, 2013a) 
Figura 2-32: Cartas de Radionavegación - Espacio Aéreo Inferior -Península- ENR 6.1.1. (Aena, 2013a). 113

Figura 2-33: Carta de aproximación por instrumentos - OACI. IAC/9 ILS Z RWY 18R - LEMD. (Aena, 2013a)

Figura 2-34: Carta de aproximación visual - OACI. VAC/1 - LEXJ. (Aena, 2013a). .115

Figura 2-35: Pantalla Primaria de Vuelo (PFD) - derecha- y Display de Navegación (ND) izquierda-. El modo y alcance visualizados son ARC y 320 millas náuticas respectivamente. (Florian Sindermann, Airliners.net). .118

Figura 2-36: Leyenda de componentes y tipo de relaciones entre componentes considerados (figura propia). 125

Figura 2-37: Esquema relacional de componentes y factores considerado en el estudio (figura propia) 126

Figura 2-38: Esquema del flujo personalizado de preguntas. (pa) cartas papel, (nd) displays de navegación, (dg) cartas digitales, (s) registro en la base de datos (figura propia)........129

Figura 2-39: Usos principales a los que se destinan las aeronaves (figura propia). .135

Figura 2-40: Formatos de cartas utilizados a bordo según la frecuencia de uso de la aeronave (figura propia) 137

Figura 2-41: Formatos de cartas utilizados a bordo respecto al perfil general del piloto. Los porcentajes agregados totales son del 97\% en cartas papel, $48 \%$ en cartas digitales y del $61 \%$ en el caso de los displays de navegación (figura propia). 138

Figura 3-1: Símbolos de aeródromos-OACl, extracto. (ICAO, 2009a). .158

Figura 3-2: Símbolos de clasificación y restricciones del espacio aéreo. (ICAO, 2009a)..........158

Figura 3-3: Guía de color-OACl: tintas hipsométricas, extracto. (ICAO, 2009a) 159

Figura 3-4: Aplicación AWE de información meteorológica aeronáutica basada en símbolos dinámicos (Spirkovska y Lodha, 2002) 162

Figura 3-5: Comparativa simbológica entre cartas de aproximación visual (VAC) españolas y francesas (Moya, Siabato, y Bernabé, 2012) 170

Figura 3-6: Algunos de los símbolos de cartas FAA/NACO no contemplados por OACI (Moya, Siabato, et al., 2012) .171

Figura 3-7: Extractos cartas VAC. a) N'Djamena-FTTJ (Asecna/Chad), b) Belém-SBBE (Brasil). .175

Figura 3-8: Extractos cartas VAC. a) Curicó-SCIC (Chile), b) Valencia-LEVC (España). . .176

Figura 3-9: Extractos cartas VAC. a) Toulouse-LFBO (Francia), b) Maastricht-EHMK (Holanda). .176

Figura 3-10: Extractos cartas VAC. a) Zúrich-LSZH (Suiza), b) Anchorage-PANC (USA). 177

Figura 3-11: Extractos cartas VAC. a) México DF-MMMX (México), b) Reykjavik-BIRK (Islandia) 
Figura 3-12: Extractos cartas VAC. a) Eilat-ETH (Israel), b) Seúl-RKSS (Corea del Sur) 178

Figura 3-13: Código utilizado para el análisis de la caracterización OACl de fenómenos y abstracción simbólica (figura propia) 180

Figura 3-14: Síntesis de los resultados del análisis de la caracterización OACl de fenómenos y abstracción simbólica (figura propia). . .180

Figura 3-15: Código utilizado para el análisis del cambio o diferencia existente en cada uno de los símbolos analizados con respecto a la especificación recomendada de OACI (figura propia). .183

Figura 3-16: Carta de Aproximación Visual (VAC) de Bourdeaux Merignac (LFBD) -arriba- y carta de Aproximación Visual (VAC) de Madrid Cuatro Vientos (LECU) -abajo-. Cartas originales. (SIA, Francia y AENA, España).. 187

Figura 3-17: Capas de información base ya estereotipadas de la carta VAC de Burdeos (LFBD) -arriba-y de la carta VAC de Madrid Cuatro Vientos (LECU) -abajo- (figura propia)...188

Figura 3-18: Adición de nuevas capas con simbolización estereotipada. Arriba carta VAC de Burdeos (LFBD), y abajo carta VAC de Madrid Cuatro Vientos (LECU) (figura propia).189

Figura 3-19: Capas de información aeronáutica con simbolización estereotipada. Arriba carta VAC de Burdeos (LFBD), y abajo carta VAC de Madrid Cuatro Vientos (LECU) (figura propia).. 190

Figura 3-20: Extractos de los modelos de simbología estereotipada propuestos. Arriba carta VAC estereotipada de Burdeos (LFBD), y abajo carta VAC estereotipada de Madrid Cuatro Vientos (LECU) (figura propia). 191

Figura 4-1: Modelo SHEL modificado por Hawkings (ICAO, 1998b). .198

Figura 4-2: Infografía del accidente del Monte Oiz de 1985 (De Velasco y Alonso, 2008)...201

Figura 4-3: Extracto de la carta de Aproximación por Instrumentos - OACl / ILS RWY 30 del Aeropuerto de Bilbao -editada en Julio de 1984- supuestamente utilizada por la tripulación accidentada (España, 1985; Iberia, 1985). Se indica en rojo la posición aproximada del Monte Oiz -3.386 pies de altura, no representado-y la representación de la Altitud Mínima del Sector (MSA). 201

Figura 4-4: Extracto de la carta de Aproximación por Instrumentos - OACI / ILS RWY 30 del Aeropuerto de Bilbao -editada en Noviembre de 1981- del Servicio de Información Aeronáutica -actual AlS de Aena-y que era oficial en el momento del accidente (España, 1985). Se indica en rojo la posición aproximada del Monte Oiz, de 3.386 pies de altura no representado- y la representación de la Altitud Mínima del Sector (MSA) 202

Figura 4-5: Extracto de la carta de Aproximación por Instrumentos - OACl / LOC Z RWY 30 del Aeropuerto de Bilbao, que es oficial en la actualidad (Aena, 2013a). Se indica en rojo la posición del Monte Oiz y la representación de la Altitud Mínima del Sector (MSA)..203

Figura 4-6: Modelo de error humano denominado 'del queso suizo'. Adaptado de (Reason (1990), 2000)). 203

Figura 4-7: Modelo de interacción de factores humanos de Meister (1971) adaptado para funciones de formación en la FAA (figura propia a partir de (R. R. Gray et al., 2007)).205 
Figura 4-8: Comparativa parcial del plano esquemático del Metro de Madrid. Izquierda plano oficial de Rafael Sañudo (2007-2013) y derecha plano oficial actual (2013-2015), basado en el diseño clásico de Alberto Corazón (Madrid, 2015). .214

Figura 4-9: Técnica de pupila brillante con infrarrojos -arriba, izquierda-, técnica de pupila oscura -arriba, centro- y segmentación de la imagen -arriba, derecha- para la determinación del centro de la córnea y reflejo de la pupila -abajo, centro- (Meunier, 2009). 218

Figura 4-10: Comparativa de recorridos y fijaciones sobre un mismo mapa estático a través de un dispositivo de seguimiento ocular SIM Red 250 -en rojo- y un dispositivo EyeTribe en azul-. En ambos casos se utilizó una frecuencia de muestreo de $60 \mathrm{~Hz}$ (Popelka y Brychtova, 2015)...

Figura 4-11: Áreas de Interés (AOI) definidas por Anders -en su investigación- en el cockpit de un Airbus A330. Adaptado de (Anders, 2001) sobre fotografía original de (Janco Nagelhout, Airliners.net)

Figura 4-12: Resultado inicial del porcentaje de atención de los pilotos sobre las Áreas de Interés (AOI). Sobre el área de mayor atención -Pantalla Primaria de Vuelo (PFD)- se realiza una segmentación de porcentaje para cada una de sus secciones (Anders, 2001)

Figura 5-1: Orden o jerarquía compositiva que poseen los niveles de abstracción simbólica en la compilación cartográfica de la carta VAC estereotipada propuesta para Bordeaux Mérignac (figura propia). .239

Figura 5-2: Extractos de los modelos de simbología estereotipada adaptados para las labores de orientación en vuelo visual. Arriba carta VAC adaptada para Burdeos Merignac (LFBD), y abajo carta VAC adaptada para Madrid Cuatro Vientos (LECU) (figura propia). .246

Figura 5-3: Extractos de los modelos de simbología estereotipada adaptados para las labores de navegación. Arriba carta VAC adaptada para Burdeos Merignac (LFBD), y abajo carta VAC adaptada para Madrid Cuatro Vientos (LECU) (figura propia). 247

Figura 5-4: Predicción de la disposición de puntos focales de atención-por orden de relevanciapara cada una de las cartas propuestas de Burdeos Merignac, según el modelo de atención visual de Itti et al. (1998) (figura propia). 250

Figura 5-5: Predicción de la disposición de puntos focales de atención-por orden de relevanciapara cada una de las cartas propuestas de Madrid Cuatro Vientos, según el modelo de atención visual de Itti et al. (1998) (figura propia). 251

Figura 5-6: Mapas combinados de prominencia visual correspondientes a la carta original y a los modelos estereotipados de Burdeos Merignac (LFBD) (figura propia). .256

Figura 5-7: Mapas combinados de prominencia visual correspondientes a la carta original y a los modelos estereotipados de Madrid Cuatro Vientos (LECU) (figura propia).............257

Figura 5-8: Oficial de la FAE realizando la evaluación de modelos cartográficos en la Base Aérea Mariscal Sucre de Quito (fotografía propia). 260

Figura 5-9: Visualización de estímulos: uno de los participantes en el experimento realizando la correspondiente tarea propuesta sobre el mapa estereotipado de Madrid Cuatro Vientos (fotografía propia). 
Figura 5-10: Reparto y secuencia de estímulos entre grupos de participantes (figura propia).

Figura 5-11: Secuencia de estímulos y tareas proporcionada a los participantes, por grupos de evaluación

Figura 5-12: Secuencia final de estímulos. Los modelos BE-O, BE-N, ME-O y ME-N se presentan rotados $180^{\circ}$ a los evaluadores, pero conservando la comprensibilidad de textos y símbolos puntuales (figura propia)

Figura 5-13: Comparativa entre el modelo inicial de simbología estereotipada para orientación -izquierda-y el modelo editado -rotado 180- que finalmente es trasladado a la evaluación-derecha- (figura propia).

Figura 5-14: Dispositivo de seguimiento ocular EyeTribe modelo ET1000 utilizado en la investigación. Una vez adquirido, las primeras valoraciones de rendimiento se realizaron a través de la visualización de antiguas cartas de radio-ayudas del Ministerio de Aire español. La que aparece en la imagen está datada con fecha de abril de 1958 (fotografía propia)

Figura 5-15: Variabilidad en la medida, con un intervalo de confianza de la media del 95\%, para las variables seleccionadas. En rojo pilotos militares, en azul personal del IGM (figura propia). .272

Figura 5-16: Tomando en consideración el conjunto total de tareas, valores medios obtenidos -con un intervalo de confianza del 95\%- en cada modelo cartográfico para cada una de las cuatro métricas de seguimiento ocular seleccionadas (figura propia). .274

Figura 5-17: Análisis gráfico de los valores de métricas oculares registrados con respecto a tareas individualizadas. En rojo pilotos militares, en azul personal del IGM (figura propia). .276

Figura 5-18:Tomando en consideración la tarea de localización de obstáculos, valores medios obtenidos -con un intervalo de confianza del 95\%- en cada modelo cartográfico para cada una de las cuatro métricas de seguimiento ocular seleccionadas (figura propia).

Figura 5-19: Mapas de atención de Burdeos Merignac (LFBD) para la localización de obstáculos: prevalencia en la selección y atención visual en la búsqueda (figura propia)

Figura 5-20: Mapas de atención de Madrid Cuatro Vientos (LECU) para la localización de obstáculos: prevalencia en la selección y atención visual de la búsqueda (figura propia)

Figura 5-21: Tomando en consideración la tarea de selección de recorridos, valores medios obtenidos -con un intervalo de confianza del 95\%- en cada modelo cartográfico para cada una de las cuatro métricas de seguimiento ocular seleccionadas (figura propia).

Figura 5-22: Cartas de Burdeos Merignac (LFBD): recorridos seleccionados por los participantes -pilotos en rojo, personal IGM en azul-y atención visual de la búsqueda (figura propia)

Figura 5-23: Cartas de Madrid Cuatro Vientos (LECU): recorridos seleccionados por los participantes -pilotos en rojo, geógrafos en azul-y atención visual de la búsqueda (figura propia). 
Figura 5-24:Tomando en consideración la tarea de localización del obstáculo +/- alto, valores medios obtenidos -con un intervalo de confianza del 95\%- en cada modelo cartográfico para cada una de las cuatro métricas de seguimiento ocular seleccionadas (figura propia) .288

Figura 5-25: Porcentajes de error -en el primer intento- en la localización del obstáculo requerido en cada carta (figura propia). .289

Figura 5-26: Cartas de Burdeos Merignac (LFBD); prevalencia en la selección de obstáculos, siendo la fila superior la correspondiente a pilotos y la inferior al personal IGM (figura propia) .291

Figura 5-27: Cartas de Madrid Cuatro Vientos (LECU); prevalencia en la selección de obstáculos, fila superior la correspondiente a pilotos y la inferior al personal IGM (figura propia) .292

Figura 5-28: Cartas de Burdeos Merignac (LFBD); atención visual en la comparación: fila superior la correspondiente a pilotos y la inferior al personal IGM (figura propia)....293

Figura 5-29: Mapas de atención de Madrid Cuatro Vientos (LECU); atención visual en la comparación: fila superior pilotos y fila inferior personal IGM (figura propia). .294

Figura 5-30: Tomando en consideración la tarea de localización de aeropuertos/aeródromos, valores medios obtenidos -con un intervalo de confianza del 95\%- en cada modelo cartográfico para cada una de las cuatro métricas de seguimiento ocular seleccionadas (figura propia) .295

Figura 5-31: Cartas de Burdeos Merignac (LFBD); para grupo de pilotos, prevalencia en la selección de aeropuertos -superior-y atención visual en la búsqueda -inferior- (figura propia).

Figura 5-32: Cartas de Madrid C. Vientos (LECU); para grupo de pilotos, prevalencia en la selección de aeropuertos -superior-y atención visual en la búsqueda -inferior- (figura propia). .298

Figura 6-1: Prelación de eficiencia comunicacional de los modelos evaluados-considerando el conjunto de tareas realizadas-. Cuanto menor sea el valor de la puntuación, mejor será el modelo. En consecuencia, para cada una de las dos regiones, el color verde indicaría el modelo con el que se ha conseguido mayor eficiencia, mientras que el rojo indicaría el menos favorable (figura propia). 303

Figura 6-2: Prelación de eficiencia comunicacional de los modelos evaluados -considerando el conjunto de tareas realizadas-. En esta ocasión, las puntuaciones han sido ponderadas en función de las métricas: un 40\% la duración de las pruebas y la longitud de los recorridos entre fijaciones, y un $10 \%$ el resto (figura propia). .304

Figura 6-3: Orden de eficiencia de los modelos cartográficos evaluados, considerando las tareas realizadas tanto en conjunto como individualmente. Cuanto menor sea el valor de la puntuación, mejor resultado se ha obtenido en las pruebas (figura propia).....305

Figura 6-4: Orden de eficiencia de los modelos cartográficos evaluados, considerando las tareas realizadas tanto en conjunto como individualmente. En este caso las puntuaciones han sido ponderadas en función de las métricas: un 40\% la duración de las pruebas y la longitud de los recorridos entre fijaciones, y un 10\% el resto. Cuanto menor sea el valor de la puntuación, mejor resultado se ha obtenido en las pruebas (figura propia) 
Figura 6-5: Carta estereotipada de Madrid Cuatro Vientos inicial -izquierda- y carta modificada -derecha-, en la que se ha tratado de mejorar, con pequeñas adaptaciones, tanto la atención focal sobre los elementos de interés como el contraste de los objetos con el fondo (figura propia). 308

Figura 6-6: Secuencia final de estímulos. Con respecto al estudio anterior, se sustituyen los modelos BO y MO por los ajustados BA y MA, respectivamente (figura propia)..........310

Figura 6-7: Variabilidad en la medida, con un intervalo de confianza de la media del 95\%, para las variables seleccionadas. En rojo pilotos militares, en azul personal del IGM y en amarillo alumnos (figura propia). .312

Figura 6-8: Análisis gráfico de los valores de métricas oculares registrados con respecto a tareas individualizadas. En rojo pilotos militares, en azul personal del IGM y en amarillo alumnos de la UPM (figura propia). .314

Figura 9-1: Traslación de los aspectos de interés a medir al lenguaje del cuestionario (figura propia) .361

Figura 9-2: Diagrama de Entidad/Relación de la base de datos asociada al sistema de formularios (figura propia). .366

Figura 9-3: Portal Web del Convenio Aena-UPM, desde el cual se centraliza el acceso a la encuesta (www.aena-upm.es) 367

Figura 9-4: Extracto del informe asociado a la prueba piloto (figura propia) .369

Figura 9-5: Registro temporal de incorporación de encuestas en la Base de Datos. Las notas superpuestas hacen referencia a los distintos contactos realizados con las organizaciones que colaboraron en la difusión del estudio (figura propia) .383

Figura 9-6: Visualización del contenido de la tabla aeronaves, designada en el modelo Entidad/Relación para almacenar el tipo, fabricante y modelo de aeronaves que los pilotos encuestados declaran utilizar (figura propia). .389

Figura 9-7: Tipología y frecuencia de uso de aeronaves (figura propia). .393

Figura 9-8: Airbus A320-211 y Boeing 737-800 NG respectivamente (Krzysztof Kaczala / D.R. JetPhotos.net). .394

Figura 9-9: Cessna C172 y Piper PA 28 respectivamente (Radial 360 / Óscar Laborda, Airliners.net) .394

Figura 9-10: Tecnam P96 y Rans Coyote II respectivamente (Manolo Aldama / Sergio Morchon, flickr.com). 395

Figura 9-11: Autogiro ELA-07 y Eurocopter AS 350 respectivamente (Pasley Aviation Photography / José Lojo, flickr.com). .395

Figura 9-12: Tipología de rutas a las que son destinadas las aeronaves (figura propia).........396

Figura 9-13: Desempeños como tripulación en las aeronaves (figura propia). 397

Figura 9-14: Preferencia de proveedores de cartas, porcentajes significativos (figura propia). 
Figura 9-15: Frecuencia de displays de navegación existentes en las aeronaves utilizadas, porcentajes significativos (figura propia). .399

Figura 9-16: Uso a bordo de dispositivos personales (PDA, Tablet PC, PC Portátil, etc.) para la consulta de cartografía, programas, etc. (figura propia) 400

Figura 9-17: Valoración de los problemas con el espacio necesario en el cockpit para poder manejar las cartas en papel sin mayor dificultad (figura propia). 401

Figura 9-18: Valoración de la adecuación del volumen y densidad de información para encontrar con rapidez la información que se necesita (figura propia). 401

Figura 9-19: Valoración de la adecuación de la representación de los límites de velocidad, altitud y sectorización del espacio aéreo (figura propia). .402

Figura 9-20: Valoración de la adecuación de la representación de la orografía y los obstáculos del terreno (figura propia) .402

Figura 9-21: Valoración de la dificultad para interpretar zonas de la carta con gran densidad de datos y simbología (figura propia). .403

Figura 9-22: Valoración de la eficacia del diseño de las cartas VFR para orientarse correctamente a partir del cotejo de referencias visuales (figura propia). .403

Figura 9-23: Incidencias a bordo debido a problemas de uso y/o interpretación de cartas en papel (figura propia). 404

Figura 9-24: Valoración de la adecuación de la visibilidad del Display de Navegación (ND, mapa móvil) para cualquier condición de luz ambiental en cabina (figura propia)..405

Figura 9-25: Valoración de la adecuación del volumen y densidad de información del Display de Navegación (ND) para su correcta interpretación figura (propia). .406

Figura 9-26: Valoración de la adecuación para las necesidades de navegación de los modos de visualización del selector de la unidad de control del Display de Navegación (ND) (figura propia). .406

Figura 9-27: Valoración de la adecuación para las necesidades de visualización de los valores de alcance del selector de escala del Display de Navegación (ND) (figura propia)...407

Figura 9-28: Valoración de la posibilidad de ejecutar rutas con seguridad guiándose exclusivamente-sin control automático- a través del Display de Navegación (ND) (figura propia) .408

Figura 9-29: Valoración de la adecuación y claridad de la representación orográfica del terreno en el Display de Navegación (ND) para una navegación segura a baja altitud (figura propia) .408

Figura 9-30: Incidencias a bordo en el uso de Displays de Navegación (ND) debido a dificultades de interpretación y anomalías técnicas (figura propia) 409

Figura 9-31: Valoración de la adecuación de la visibilidad de la pantalla para cualquier condición de luz ambiental en cabina (figura propia). 410

Figura 9-32: Valoración de la mayor eficiencia de la cartografía digital con respecto a la utilización de colecciones equivalente de cartas en formato papel (figura propia)..411 
Figura 9-33: Valoración de la posibilidad de manejar el dispositivo sin dificultad y con seguridad para control de vuelo: espacio suficiente, apoyo estable, etc. (figura propia).

Figura 9-34: Valoración de la adecuación y funcionalidad del interfaz de los programas de estos dispositivos sin interferir claramente en labores de pilotaje (figura propia).......412

Figura 9-35: Valoración de la mayor eficacia de programas con gran cantidad de opciones con respecto a equivalentes sin apenas posibilidad de interacción (figura propia) 413

Figura 9-36: Valoración de la utilidad del uso de dispositivos digitales personales a bordo para la solución de carencias de los mapas en papel y displays de navegación (figura propia).

Figura 9-37: Incidencias a bordo en el uso de Displays de Navegación (ND) debido a dificultades de interpretación, manejo, anomalías técnicas y cobertura GPS (figura propia)

Figura 9-38: Aspectos considerados como más positivos de las cartas en papel para su uso en labores de navegación (figura propia). 416

Figura 9-39: Aspectos considerados como más negativos de las cartas en papel para su uso en labores de navegación (figura propia). .419

Figura 9-40: Aspectos considerados como más positivos de los displays de navegación (ND) para su uso en labores de navegación (figura propia).

Figura 9-41: Aspectos considerados como más negativos de los displays de navegación (ND) para su uso en labores de navegación (figura propia).

Figura 9-42: Aspectos considerados como más positivos de los dispositivos para consulta de cartas digitales para su uso en labores de navegación (figura propia). .424

Figura 9-43: Aspectos considerados como más negativos de los dispositivos para consulta de cartas digitales para su uso en labores de navegación (figura propia). .426

Figura 9-44: Código utilizado para el análisis de la caracterización OACl de fenómenos y abstracción simbólica (figura propia)

Figura 9-45: Carta de Aproximación Visual (VAC) de Bourdeaux Merignac (LFBD). Carta original. (Service de L'information Aeronautique, Francia) 445

Figura 9-46: Carta de Aproximación Visual (VAC) de Madrid Cuatro Vientos (LECU). Carta original. (AENA, España). 446

Figura 9-47: Carta de Aproximación Visual (VAC) de Bourdeaux Merignac (LFBD). Composición simbológica estereotipada (figura propia). . .447

Figura 9-48: Carta de Aproximación Visual (VAC) de Madrid Cuatro Vientos (LECU). Composición simbológica estereotipada (figura propia). 448

Figura 9-49: Carta de Aproximación Visual (VAC) de Bourdeaux Merignac (LFBD). Composición simbológica estereotipada enfocada a la orientación visual (figura propia). 461

Figura 9-50: Carta de Aproximación Visual (VAC) de Madrid Cuatro Vientos (LECU). Composición simbológica estereotipada enfocada a la navegación instrumental (figura propia). 462 
Figura 9-51: Estudio de saliencia visual de la carta VAC de Burdeos Merignac. De izquierda a derecha y de arriba abajo: Carta original, predicción de las 10 primeras fijaciones y recorrido entre ellas, mapa combinado de prominencia y representaciones corticales de color, orientación e intensidad (figura propia). 463

Figura 9-52: Estudio de saliencia visual de la carta VAC estereotipada de Burdeos Merignac. De izquierda a derecha y de arriba abajo: Carta original, predicción de las 10 primeras fijaciones y recorrido entre ellas, mapa combinado de prominencia y representaciones corticales de color, orientación e intensidad (figura propia). .464

Figura 9-53: Estudio de saliencia visual de la carta VAC estereotipada enfocada a la orientación de Burdeos Merignac. De izquierda a derecha y de arriba abajo: Carta original, predicción de las 10 primeras fijaciones y recorrido entre ellas, mapa combinado de prominencia y representaciones corticales de color, orientación e intensidad (figura propia). .465

Figura 9-54: Estudio de saliencia visual de la carta VAC estereotipada orientada a la navegación de Burdeos Merignac. De izquierda a derecha y de arriba abajo: Carta original, predicción de las 10 primeras fijaciones y recorrido entre ellas, mapa combinado de prominencia y representaciones corticales de color, orientación e intensidad (figura propia). .466

Figura 9-55: Estudio de saliencia visual de la carta VAC de Madrid Cuatro Vientos. De izquierda a derecha y de arriba abajo: Carta original, predicción de las 10 primeras fijaciones y recorrido entre ellas, mapa combinado de prominencia y representaciones corticales de color, orientación e intensidad (figura propia). .467

Figura 9-56: Estudio de saliencia visual de la carta VAC estereotipada de Madrid Cuatro Vientos. De izquierda a derecha y de arriba abajo: Carta original, predicción de las 10 primeras fijaciones y recorrido entre ellas, mapa combinado de prominencia y representaciones corticales de color, orientación e intensidad (figura propia).. 468

Figura 9-57: Estudio de saliencia visual de la carta VAC estereotipada enfocada a la orientación de Madrid Cuatro Vientos. De izquierda a derecha y de arriba abajo: Carta original, predicción de las 10 primeras fijaciones y recorrido entre ellas, mapa combinado de prominencia y representaciones corticales de color, orientación e intensidad (figura propia). .469

Figura 9-58: Estudio de saliencia visual de la carta VAC estereotipada enfocada a la navegación de Madrid Cuatro Vientos. De izquierda a derecha y de arriba abajo: Carta original, predicción de las 10 primeras fijaciones y recorrido entre ellas, mapa combinado de prominencia y representaciones corticales de color, orientación e intensidad (figura propia). 470

Figura 9-59: Diagrama de caja y bigotes para las variables duración de las pruebas y promedio de duración de las fijaciones (figura propia). .472

Figura 9-60: Diagrama de caja y bigotes para las variables número de fijaciones por segundo y longitud de recorridos entre fijaciones (figura propia). .473

Figura 9-61: Carta de Aproximación Visual (VAC) de Bourdeaux Merignac (LFBD). Composición simbológica estereotipada ajustada (figura propia)

Figura 9-62: Carta de Aproximación Visual (VAC) de Madrid Cuatro Vientos (LECU). Composición simbológica estereotipada ajustada (figura propia). 475 


\section{ÍNDICE DE TABLAS}

Tabla 2-1: Tipos de reservas del espacio aéreo (Aena, 2013a) 92

Tabla 2-2: Partes en las que se divide una publicación AIP (Aena, 2013b). .105

Tabla 2-3: Cartas de publicación obligatoria disponibles en la AIP-España (Aena, 2013a)...106

Tabla 2-4: Cartas de publicación condicional disponibles en la AIP-España (Aena, 2013a) 107

Tabla 2-5: Cartas de publicación opcional disponibles en la AIP-España (Aena, 2013a)........108

Tabla 2-6: Grupos de cartas OACI según su utilización principal (ICAO, 1992) 109

Tabla 2-7: Aspectos relacionados con las relaciones generales 123

Tabla 2-8: Aspectos relacionados con las preferencias y especializaciones .123

Tabla 2-9: Aspectos relacionados con la adecuación de la representación e interpretación 124

Tabla 2-10: Aspectos relacionados con las condiciones ambientales. .124

Tabla 3-1: Listado de ediciones características seleccionadas. 175

Tabla 3-2: Agrupación temática de los fenómenos susceptibles de ser representados en las cartas VAC. 179

Tabla 3-3: Pautas y tendencias estereotipadas de la caracterización simbológica del conjunto de ediciones características (elaboración propia). 185

Tabla 4-1: Componentes y factores implicados en el modelo adaptado de Meister (1971) (R R. Gray et al., 2007). 206

Tabla 4-2: Componentes y factores implicados en la interacción de un piloto con una carta aeronáutica en formato papel (elaboración propia). 208

Tabla 5-1: Agrupación temática del conjunto de fenómenos susceptibles de ser representados en las cartas VAC (elaboración propia). .238

Tabla 5-2: Orden o jerarquía compositiva reclasificada por segregación de fondo y figura de las variaciones de modelos estereotipados, adaptados a orientación en vuelo visual y navegación, respectivamente (elaboración propia). .244

Tabla 5-3: Reformulación transversal -por segregación de fondo y figura- de variables visuales aplicada a los modelos estereotipados adaptados a orientación en vuelo visual y navegación, respectivamente (elaboración propia) .246

Tabla 5-4: Prelación -orden de relevancia visual- y tipología de los símbolos sobre los que se sitúan los 10 primeros puntos focales de atención en las cartas de Burdeos Merignac (elaboración propia). .252 
Tabla 5-5: Prelación -orden de relevancia visual- y tipología de los símbolos sobre los que se sitúan los 10 primeros puntos focales de atención en las cartas de Madrid Cuatro Vientos (elaboración propia). .253

Tabla 5-6: Descripción de tareas propuestas en el estudio. 261

Tabla 5-7: Codificación de estímulos y tareas. .264

Tabla 5-8: Especificaciones declaradas del dispositivo de seguimiento EyeTribe modelo ET1000. .267

Tabla 5-9: Valores de media, media recortada al 95\% de intervalo de confianza y desviación típica (para cada uno de los modelos cartográficos) de las variables duración de las pruebas, promedio de duración de las fijaciones, número de fijaciones por segundo y longitud de recorridos entre fijaciones, respectivamente. .273

Tabla 6-1: Comparativa de estadísticos descriptivos de las variables de seguimiento ocular de interés, entre grupos de evaluación. 311

Tabla 6-2: Valores de media, media recortada al 95\% de intervalo de confianza y desviación típica (para cada uno de los modelos cartográficos) de las variables seleccionadas.313

Tabla 9-1: Análisis de la caracterización $\mathrm{OACl}$ de fenómenos y abstracción simbólica (elaboración propia).

Tabla 9-2: Cotejo gráfico completo de diferencias e intensidad del cambio entre la simbología de ediciones características de 5 países europeos y la especificación OACI (elaboración propia) 438

Tabla 9-3: Factores de interés desde el punto de vista de los sistemas electrónicos de visualización de datos (R. R. Gray et al., 2007). 450

Tabla 9-4: Estadísticos descriptivos y análisis ANOVA de un factor para las variables dependientes duración de las pruebas, promedio de duración de las fijaciones, número de fijaciones por segundo y longitud de recorridos entre fijaciones, respectivamente. 


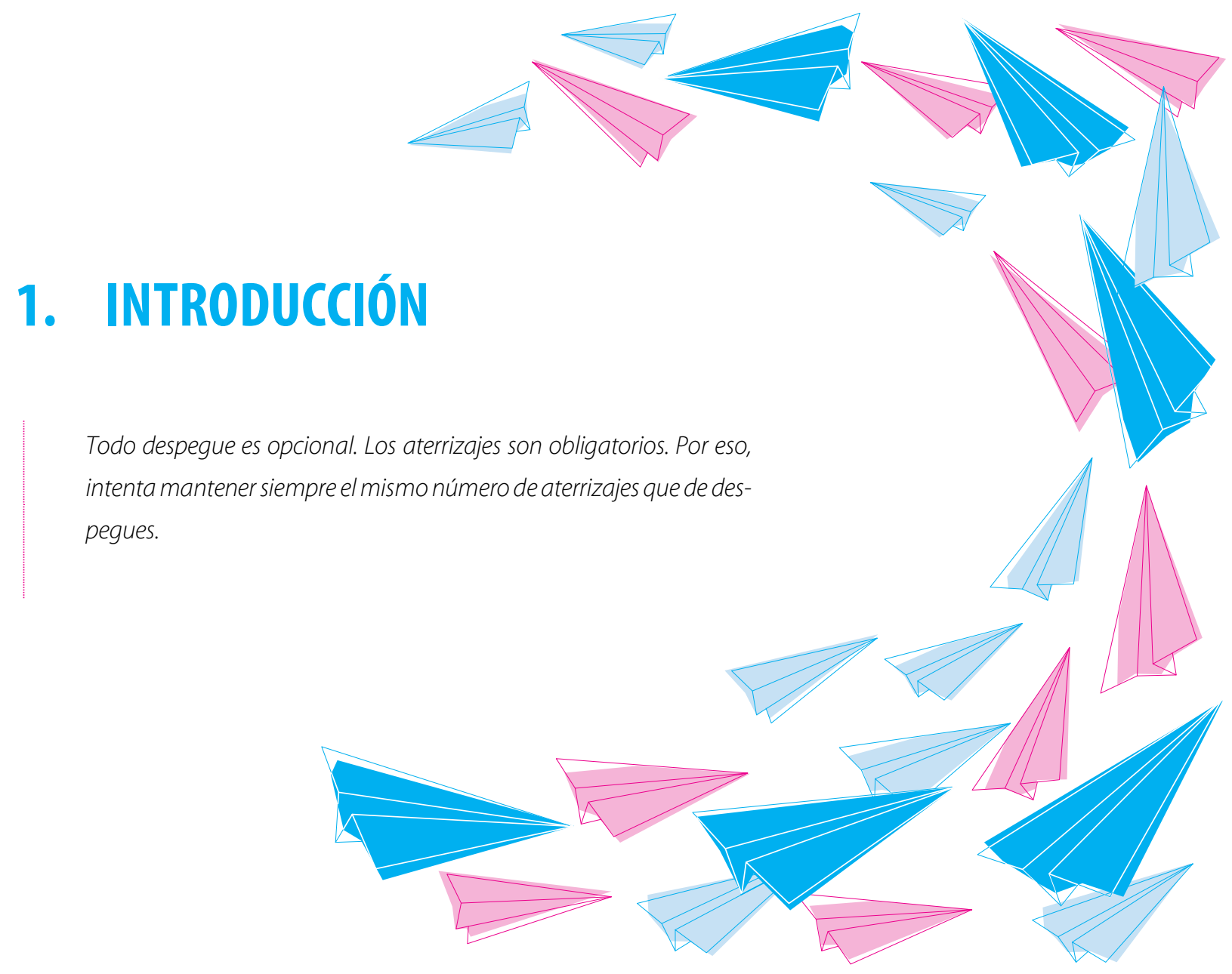

Esta propuesta de tesis doctoral plantea la ideación de un prototipo que mejore la comunicabilidad de las cartas aeronáuticas complejas, a partir del estudio relacional de la influencia perceptual producida por la combinación de las variables visuales aplicadas a los distintos niveles de representación.

\subsection{ANTECEDENTES Y ESTADO GENERAL DE LA CUESTIÓN}

\subsubsection{Definiciones}

Según define la Organización de Aviación Civil Internacional (OACl), los datos aeronáuticos son 'la representación de hechos, conceptos o instrucciones aeronáuticas de manera formalizada que permita (sic) que se comuniquen, interpreten o procesen' (ICAO, 2004). El resultado sintetizado de la agrupación, análisis y formateo de datos aeronáuticos indispensables para la navegación aérea es lo que ha de considerarse Información Aeronáutica. 
Los llamados Servicios de Información Aeronáutica (AIS) de cada Estado son los encargados de recopilar, verificar y difundir la información aeronáutica a través de los medios que se consideren convenientes. El objetivo final es lograr la adecuada provisión de información necesaria para la seguridad, regularidad y eficiencia de la navegación aérea a todos los usuarios del sistema que asíl lo requieran, dentro de un área de cobertura definida (ICAO, 2004).

Para este propósito, las cartas aeronáuticas son un medio adecuado para suministrar esta información de manera manejable, condensada y coordinada, siendo así un recurso de referencia básico para la planificación, el control de tránsito aéreo y la navegación (ICAO, 2012a). Sobre esta cartografía temática queda sintetizada la información aeronáutica que permite aportar a las tripulaciones datos específicos relacionados con la orientación espacial y la salvaguarda de la seguridad del vuelo. Algunos de los datos usualmente codificados son la descripción de la orografía y la situación de los obstáculos para la navegación aérea, la localización espacial de zonas peligrosas, restringidas y prohibidas, la posición y frecuencias identificativas de las radioayudas a la navegación diseminadas por el territorio, los límites operativos de altitud y velocidad, y otras secundarias. (ICAO, 2009a)

\subsubsection{Normalización y transición al entorno digital}

Es a partir del Convenio sobre Aviación Civil Internacional firmado en 1944 por 52 estados (ICAO, 1944) cuando comenzaron a establecerse de forma definitiva las actuales obligaciones para los Estados en materia de generación, mantenimiento y difusión de determinados tipos de cartas aeronáuticas. Las directrices de producción y difusión de cartas aeronáuticas se recogen formalmente en el denominado Anexo 4 del citado Convenio (AN/4), normalizando para ello su cobertura, formato, identificación dentro de una determinada serie y contenidos, incluyendo también la simbología normalizada y el color (ICAO, 2009a).

La evolución de los datos aeronáuticos suministrados en mapas tradicionales en formato papel hacia un entorno digital es consecuencia de la carrera por la automatización de los sistemas de pilotaje de la industria aeronáutica civil (International, 1965b); a mediados de los años 70 comienzan a comercializarse los primeros datos aeronáuticos digitales (C. Jeppesen, 2012a) que alimentan a los Sistemas de Gestión y Guía de Vuelo Automático o Flight Management Guidance Computer System (FMGCS), presentes en cualquier aeronave comercial moderna. Paralelamente, el uso de los Sistemas de Información Geográfica (SIG) permitió a las oficinas responsables de la información aeronáutica de cada estado, denominadas Aeronautical Information Service (AIS), mejorar la gestión e integración de gran cantidad de datos de diferentes fuentes, automatizando en buena medida los procesos cartográficos y personalizando sus series de cartas. En consecuencia, los sistemas SIG dieron lugar a la producción eficiente de cartas de navegación aérea de cualquier escala, orientación y proyección, a través del uso de elementos inteligentes que se actualizan automáticamente basándose en el contenido de una geodatabase asociada (McGaugh, 2004).

La apertura del Sistema de Posicionamiento Global GPS para uso civil (Pace, 1995; Schroeer, 2000) y la aparición de nuevos soportes tecnológicos, ha permitido crear entornos apropiados para la presentación electrónica de 
cartas aeronáuticas en el puesto de pilotaje (ICAO, 2012a; Moya y Bernabé, 2011). Actualmente está generalizado el uso a bordo de diferentes dispositivos que, o bien han sido ideados y certificados exclusivamente para la gestión de información y de cartografía aeronáutica electrónica en vuelo como los Maletines Electrónicos de Vuelo o Electronic Flight Bag (EFB) (FAA, 2003a; Norris, 2001), o por sus cualidades de propósito general, portabilidad y manejo táctil son susceptibles de ser aprovechados como aparejo de vuelo en la cabina de pilotaje, lo que también extiende el uso de las cartas aeronáuticas digitales a la aviación de negocios, deportiva y de ultraligeros. Como ocurre en el caso de los EFB, estos dispositivos comienzan también a certificarse para el uso en la operativa de vuelos comerciales en distintas fases de vuelo (FAA, 2011a). Los beneficios previstos son considerables; se estima que un Tablet iPad, cuyo peso se sitúa alrededor de los 700 gramos, es capaz de sustituir a unos 16 kilos o más de papel en cabina. Recientemente, la aerolínea estadounidense American Airlines (AA) ha declarado que en su operativa puede ahorrar de forma estimativa 950.000 euros de combustible al año por la reducción de peso a bordo con el uso de este tipo de dispositivos (PI, 2011).

\subsubsection{Planes de interoperabilidad y programas actuales}

El ámbito tecnológico que aún describe tanto el Anexo 4 (AN/4) del Convenio -cuya última actualización data de 2009- como el denominado Manual de Cartas Aeronáuticas (8697-AN/889/2) para la puesta en práctica las normas y métodos recomendados del anexo anterior (ICAO, 1992), se encuentra a día de hoy plenamente superado por los planes de trabajo que pretenden conseguir una interoperabilidad de datos aeronáuticos a nivel mundial; en concreto, es de destacar el plan en vigor denominado genéricamente Transición de los Servicios de Información Aeronáutica o Aeronautical Information Services (AIS) a la Gestión de la Información Aeronáutica o Aeronautical information Management (AIM) (ICAO, 2009b). Auspiciado por la OACl, su objetivo es que toda la información aeronáutica, incluida la que contienen actualmente las distintas Publicaciones de Información Aeronáutica o Aeronautical Information Publication (AIP) se almacene en forma de conjunto de datos normalizados e interoperables que podrá consultarse desde diversas aplicaciones de usuario (Bossman, 2011; EUROCONTROL, 2006b).

El progresivo acercamiento a nuevas estandarizaciones acordes con el venidero contexto de servicios y aplicaciones del futuro escenario AIM es, por tanto, urgente. Esta necesidad está siendo recogida por numerosos grupos de interés desde diversos enfoques, tales como la aplicación del concepto de Infraestructuras de Datos Espaciales (IDE) para la producción de cartas aeronáuticas digitales propuesta por el Comité de Cartas Aeronáuticas del Instituto Panamericano de Geografía e Historia (IPGH) (IPGH, 2009), y de forma singular el empleo del estándar de Descriptores de Capas de Estilo (SLD) para los símbolos OACl del Grupo de Trabajo en el Dominio de la Aviación del Open Geospatial Consortium (OGC) (Bossman, 2011). También la propia OACl está ultimando una serie de nuevos requisitos técnicos (SARPS) y textos de orientación relacionados con la presentación electrónica de cartas, cuya publicación está estimada para el año 2013 (ICAO, 2008a).

Una vez completada la transición AIM en noviembre de 2016 (ICAO, 2009b), los productos de información aeronáutica tradicionales -ediciones cerradas de series cartográficas en formato papel y digital actualizadas en ciclos de 28 días- darán paso a aplicaciones de usuario que tendrán capacidad de acceder a diversas fuentes de 
datos, para así transformarlos y coordinarlos con otros libremente en orden a presentarlos al usuario final mediante el correspondiente proceso cartográfico tal y como éste lo requiera, indistintamente del formato portador (ICAO, 2009b).

Al respecto, los programas regionales que definen, desarrollan e implementan de modo efectivo los servicios y aplicaciones conformes con las directrices del plan de transición de la $\mathrm{OACl}$, como el europeo Single European Sky ATM Research (SESAR) (SESAR, 2010, 2011) o el estadounidense Next Generation Air Transportation System (NextGEN) (FAA, 2012b), se centran casi en exclusiva en el modelado conceptual de los elementos de datos de información aeronáutica, en la estandarización de formatos de intercambio y en el sustrato tecnológico de los servicios integrados que, de forma concatenada, lograrán una gestión eficiente de la información aeronáutica. Esta focalización de esfuerzos ha dejado al margen, aparentemente, la indagación de estrategias y métodos relacionados con el concepto de la codificación gráfica de Información Geográfica Aeronáutica (IGA) y su idoneidad respecto a las capacidades y limitaciones humanas previsibles. Todo ello en un futuro entorno de acceso libre y ubicuo a datos temáticos interoperables a través de la red.

Del contexto planteado se deriva una cuestión general que, entre otras, pretende ser examinada a través de esta propuesta de tesis doctoral: ¿puede diseñarse un modelo de cartas aeronáuticas que, aprovechando las capacidades tecnológicas del nuevo paradigma de la Gestión de la Información Aeronáutica (AIM), mejoren su comunicabilidad?

\subsubsection{Líneas de investigación en el campo de la visualización de la IGA}

Hasta ahora, los problemas de investigación en el área de la visualización y comprensión de datos aeronáuticos se han orientado hacia diversas temáticas:

- Desarrollo de dispositivos y displays gráficos para la navegación (Clay, 1993; Nadler, Yost, y Kendra, 2007).

- Dispositivos Head-Up Displays (Albert, 2010; Crawford y Neal, 2006), Sistemas de Visión Mejorada (EVS) (Bailey, Kramer, y Prinzel, 2006; Nojima y Kajimoto, 2008) y Sistemas de Visión Sintética (SVS) y combinada (EVS+SVS) (Domino, 2007; Theunissen et al., 2005; Ververs, He, Suddreth, y Odgers, 2011).

- Conciencia situacional para la navegación (Bolstad, Costello, y Endsley, 2006; Casner, 2006), retención del conocimiento aeronáutico (Casner, Heraldez, y Jones, 2006), actitudes y comportamiento frente a sistemas avanzados en cabina (Casner, 2008; Mitchell, Kristovics, y Bishop, 2010).

- Adaptabilidad y factores humanos en la representación (Catelani, Ciani, Signorini, y Barile, 2010; Chandra, Yeh, Riley, y Mangold, 2003; Gabree y Yeh, 2010; Landry y Jacko, 2006). 
En el ámbito concreto de las cartas de navegación, y paralelamente al desarrollo de dispositivos Head-Up Displays, EVS y SVS, durante los últimos 15 años se ha puesto especial atención en la investigación del diseño de las series de Cartas de Aproximación Instrumental (IAC), ya que en aviación comercial, la mayoría de accidentes con resultado de víctimas mortales se producen en las fases de aproximación y aterrizaje -37\% frente al 16\% en fases de despegue y subida inicial en el periodo de 2002 a 2011 - (Boeing, 2012). Al respecto, la Federación Americana de Aviación (FAA) lanzó a mediados de los años 90 un programa de adecuación de cartas IAC en el que se evaluó a) la información requerida a codificar (Hansman y Mykityshyn, 1995), b) las consecuencias de la aplicación del diseño gráfico habitual de esta tipología de cartas sobre la velocidad de lectura y la precisión de las búsquedas (Osborne, Huntley, Turner, y Donovan, 1995), así como c) se evaluaron prototipos alternativos (Blomberg, Bishop, y Hamilton, 1995). También se han estudiado las implicaciones del diseño en la formación de pilotos (Molesworth y Wiggins, 2003). En todos los trabajos el problema más evidente es el derivado de la densidad de información a la que se enfrentan tanto diseñadores como usuarios. Recientemente, en (Chandra, 2012) se estudian los efectos de la simplificación de las cartas IAC al aplicar los nuevos procedimientos de Desempeño de Navegación de Área (RNAV-RNP).

También se ha estudiado profusamente la simbología de las cartas aeronáuticas desde el punto de vista de elementos individuales (Chandra, 2009; Yeh y Chandra, 2008). Los símbolos que se utilizan en la representación de IGA varían a veces de forma muy significativa (Chandra y Kendra, 2008; Chandra y Yeh, 2007; Yeh y Chandra, 2005, 2008). Así, cuando se utilizan diferentes símbolos para representar un único objeto o elemento de la realidad, existe un evidente riesgo de confusión (Chandra, Yeh, y Donovan, 2007). El problema se agrava cuando algunos de los símbolos que están actualmente en uso no son bien reconocidos por los pilotos (Yeh y Chandra, 2005). También existe el problema contrario, es decir, cuando dos editores utilizan el mismo símbolo para representar diferentes fenómenos de la realidad. Esto puede provocar que los pilotos malinterpreten un símbolo si se basan en la representación de las cartas o visores de distintos fabricantes. Al respecto, destaca el trabajo normativo del comité de cartas aeronáuticas de SAE International (SAEG-10), que en el documento denominado Electronic Aeronautical Symbols (ARP 5289) propone diversas recomendaciones para símbolos de uso habitual en cartas aeronáuticas (SAE, 1997). De esta forma, cada especificación individual del símbolo recomendado es acompañada con la representación de los que son realmente utilizados tanto por los principales productores de cartas en papel y digital como por la industria aeronáutica.

Cabe considerar que existen pocas experiencias de la representación en tiempo real de información simbólica adicional sobre una carta aeronáutica. Aun así, destaca la aplicación AWE de Spirkovska y Lodha (2002), una de las primeras propuestas de adición de información meteorológica en tiempo real sobre una cartografía para vuelo visual. Mediante distintos artificios simbólicos, los autores tratan de codificar sobre una carta aeronáutica tradicional la información meteorológica relativa a las condiciones actuales de nubes, visibilidad y vientos en diferentes capas de altitud. El resultado es una cartografía dotada de diferentes símbolos multivariables dinámicos capaces de proporcionar una gran cantidad de datos meteorológicos relevantes para un vuelo (Spirkovska y Lodha, 2003), pero que adolece de una correcta integración con la información aeronáutica que debería complementar -ocultamiento, falta de unicidad y semántica simbológica, etc.-. 
En todas las investigaciones reseñadas han sido de aplicación múltiples principios de Factores Humanos (HF). Éstos, definidos como un conjunto determinado por habilidades, limitaciones y otras características humanas relevantes para el diseño de objetos y sistemas (FAA, 2003b; ICAO, 2008b), representan un dominio de importancia capital: el elemento humano es la parte más flexible, adaptable y valiosa del sistema aeronáutico, pero también es la más vulnerable a las influencias que pueden afectar negativamente a su comportamiento. Así, la búsqueda y asimilación de información para la toma de decisiones vitales a través del medio cartográfico presenta un evidente potencial de error debido a que las cartas pueden ser confusas, engañosas o excesivamente recargadas de elementos (Osborne et al., 1995). En el ámbito de la aviación, no parece que existan unas directrices específicas acerca de la correcta observancia de los factores humanos en la representación cartográfica de fenómenos geoespaciales. Si bien el Convenio sobre Aviación Civil Internacional de OACl estipula que el denominado Manual de instrucción sobre factores humanos (Doc. 9683) debe ser aplicado al diseño de cartas aeronáuticas (ICAO, 2008b), sus preceptos son enunciados desde un punto de vista ergonómico -diseño de equipos y pantallas de visualización-, obviando en gran medida los aspectos cognitivos y de expresión gráfica que los diseñadores deben aplicar para lograr una comunicación cartográfica adecuada.

En resumen, en esta revisión de antecedentes y estado actual del tema de la visualización de datos aeronáuticos se concluye que:

- La irrupción de nuevos soportes tecnológicos ha permitido crear entornos muy apropiados para la presentación electrónica de cartas aeronáuticas en el puesto de pilotaje.

- La cartografía aeronáutica, desde el punto de vista exclusivo del producto final, está superada; la transición de los Servicios de Información Aeronáutica (AIS) a la Gestión de la Información Aeronáutica (AIM) asegurará la provisión de datos aeronáuticos individuales y otros normalizados e interoperables que podrá consultarse desde diversas aplicaciones de usuario.

- Los programas regionales que, de conformidad con las directrices del futuro contexto de interoperabilidad de datos promovido por la OACl, definen, desarrollan e implementan de modo efectivo los servicios y aplicaciones, aparentemente obvian la indagación de metodologías relacionadas con una satisfactoria comunicabilidad de la Información Geo-Aeronáutica (IGA).

- Con respecto a la investigación relacionada con la expresión gráfica de la cartografía aeronáutica, se han contemplado trabajos acerca de a) la creación de dispositivos digitales de visualización a bordo (EFB), b) la adecuación de las series de Cartas de Aproximación Instrumental (IAC) tradicionales y de procedimientos RNAV, y c) la valoración de la convergencia de las diversas especificaciones de simbología que atienden a diversos editores, fabricantes y formatos de visualización.

- A día de hoy, las recomendaciones de OACI para la edición de cartas aeronáuticas no poseen unas directrices específicas acerca de la correcta observancia de los factores humanos en la representación cartográfica de fenómenos geoespaciales. A excepción de la especificación general para los símbolos 
aeronáuticos definida en el Anexo 4 (ICAO, 2009a), tampoco se provee a las oficinas AIS de consideraciones de tipo semiológico ni de eficiencia de la comunicación gráfica, lo que desde nuestro punto de vista implica un alto grado de incertidumbre a la hora de un adecuado diseño de documentos cartográficos.

Bajo este orden de cosas, presumimos que las innovaciones metodológicas que puedan ser alcanzadas en lo referente a la expresión gráfica de los modelos cartográficos para la navegación aérea tendrán plena actualidad y recorrido en el contexto conceptual, tecnológico y científico descrito.

\subsubsection{Consideraciones semiológicas del problema}

Apoyándose, entre otras, en las teorías derivadas de la Gestalt y la Bauhaus (Jackson, 2008; King, Wertheimer, Keller, y Crochetiere, 1994; Mennan, 2009), a partir de los años 60 del siglo pasado se crearon diversos modelos teóricos que trataban de explicar los elementos significativos de la realidad visual. Entre todas ellas destaca la semiología gráfica aplicada a las variables visuales planteada por Jacques Bertin, reconocida ampliamente en la actualidad (Bertin, 1967, 1977). De forma muy resumida, podemos indicar que el planteamiento de Bertin se basa en que los elementos conceptuales que utiliza el sistema gráfico de comunicación son exclusivamente el punto, la línea y el plano. Estos elementos primarios pueden verse perceptualmente modificados por algunas características que los diferencian -forma, dimensión, valor, trama-textura-grano, orientación, color y ubicación-, y que el autor denominó variables visuales retinianas. Bertin hace de esta variación el canal de difusión del mensaje que es transmitido en cualquier artefacto cartográfico. Para que el diseño resultante tenga el mayor número de concomitancias con el fenómeno original, la formulación concreta de variables visuales debe atender adecuadamente tanto a la dimensionalidad espacial del fenómeno representado -puntual, lineal, superficial, volumétrico, espacio-temporal-como a las escalas de medida con que se hayan clasificado los datos disponibles -nominal, ordinal, de intervalo, de razón-. Además de las consideraciones anteriores con respecto a las variables visuales, algunos autores también llaman la atención sobre la importancia de la adecuada discretización-elección de intervalos- de las variables a representar (Charre, 1995; Cheylan y Basciani-Funestre, 1989).

Por otro lado, para conseguir una adecuada especificación de símbolos son también de aplicación las tres dimensiones del estudio del signo propuestas por Morris: dimensión sintáctica -relaciones formales de los signos entre sí-, semántica -relaciones de significado entre signo y referente-y pragmática -relaciones significantes del signo con el intérprete- (Morris, 1968; Poisson, 2002). Adicionalmente, (P. D. Wood (1993); P. D. Wood y Fels (1992)) advierten que el diseño gráfico llega a ser satisfactorio cuando se obtiene una imagen con un alto grado de legibilidad.

Hasta el momento todos los preceptos anteriormente reseñados -variables visuales, discretización, dimensionalidad y legibilidad- han sido de consideración con mayor o menor acierto en el diseño cartográfico aplicado a la información aeronáutica. A través del estudio propio realizado se ha podido concluir que, en líneas generales, 
tanto la observancia de la dimensionalidad de los signos como, sobre todo, la aplicación concreta de las variables visuales se ha realizado de manera muy limitada, considerando los símbolos aisladamente en determinados conjuntos temáticos -topografía, hidrografía, obstáculos aeródromos, ayudas a la navegación, etc.-; éstos a su vez están agrupados usualmente en determinadas capas de información o significación: capa de relieve, capa de construcciones humanas, capa de procedimientos aeronáuticos, capa de meteorología, etc. (Moya y Bernabé, 2011). Esta aplicación individual y parcial de las variables visuales provoca que, cuando se considera la totalidad de las capas y de los grupos de símbolos en una carta aeronáutica compleja, el resultado sea en muchas ocasiones caótico y descoordinado, degradando las propiedades comunicativas de la lectura global o individualizada de la información representada.

Este hecho observado hace que nos planteemos la necesidad de proponer estrategias o reglas que, basadas en el estudio de la interferencia entre conjuntos de símbolos agrupados en distintos ámbitos o niveles de significado o realidad, se materialicen en una carga visual adecuada y ponderada cuando se visualicen varias capas de información, que facilite y mejore la percepción e interpretación visual de cartas aeronáuticas complejas.

\subsubsection{División del problema}

En consecuencia, este trabajo plantea dividir el problema general en dos partes, coincidente la primera de ellas con la consideración de las cuestiones básicas de fenómeno y representación, y la segunda con su percepción y visualización. En la primera parte, se propone estudiar la relación existente entre el diseño de sistemas de significación -usuales en la producción de cartografía para vuelo- y el conjunto de fenómenos aeronáuticos que deben ser representados según el mandato OACl. Las evaluaciones a determinar sobre la producción cartográfica de diferentes AIS mundiales representativos deberán estar encaminadas a la generación de una serie de prototipos gráficos, en forma de modelos cartográficos estereotipados. A su vez, el motivo conductor de los diferentes análisis estará en consonancia con aspectos puramente semióticos -fenómenos significantes, sistemas de significación, etc.- y con procesos asociados -producción e interpretación-.

Este conjunto de indagaciones aspira a ser dirigido a la generación de una serie de prototipados en forma de modelos gráficos estereotipados, creados exprofeso para esta evaluación, a partir de la producción cartográfica de diferentes AIS mundiales representativos. La metodología que logre generarlos estará en consonancia con aspectos puramente semióticos -fenómenos significantes, sistemas de significación, etc.- y con procesos asociados-producción e interpretación-.

Partiendo de las conclusiones de la evaluación propuesta, la segunda parte del problema corresponderá a la aportación de criterios de diseño cartográfico que, en forma de formulación combinatoria de variables visuales, puedan complementar a las normas y métodos OACl recomendados en vigor. Para ello se estudiará, desde un 
punto de vista de la percepción visual, las interferencias semiológicas provocadas usualmente entre los conjuntos habituales de símbolos aeronáuticos, agrupados a su vez en distintos niveles de significado o realidad. Metodológicamente, los modelos estereotipados serán las herramientas sobre las cuales realizar la deducción de relaciones.

\subsection{OBJETIVOS DE LA TESIS Y CUESTIONES DE INVESTIGACIÓN}

\subsubsection{Hipótesis}

Se plantea como HIPÓTESIS PRIMARIA que

"existe una interferencia en la percepción provocada por la suma de diferentes capas de información propias del contexto aeronáutico que puede limitarse con un ajuste transversal de las variables visuales aplicadas a la formulación gráfica de cada nivel de significado, mejorando así las propiedades narrativas que porta el mensaje gráfico original; estas mejoras pueden sistematizarse en forma de directrices de observancia de factores humanos y de especificaciones simbológicas"

\subsubsection{Objetivo general}

En consecuencia, se propone como OBJETIVO GENERAL de esta tesis doctoral

"diseñar un prototipo que mejore la comunicabilidad de las cartas aeronáuticas complejas en términos de comprensión y legibilidad, a partir del estudio relacional de la influencia resultante de la combinación perceptual de las variables visuales aplicadas a los niveles de representación estereotipo en este tipo de instrumentos gráficos"

Este objetivo general puede ser dividido en dos tareas sucesivas: a) evaluar la eficiencia comunicacional que posee la expresión gráfica habitual de la cartografía aeronáutica, y b) determinar la influencia perceptual que, para los pilotos, tiene la interacción visual de distintas agrupaciones de símbolos aeronáuticos estereotipados, atendiendo a la formulación característica de sus variables visuales. 


\subsubsection{Cuestiones de investigación}

Enunciado ya el objetivo general, se formulan las siguientes Cuestiones de Investigación (Cl):

Cl_01. ¿Qué particularidades acontecen durante el uso práctico de la cartografía aeronáutica por parte de los pilotos civiles?

Cl_02. ¿Hay conformidad entre las cartografías de los AIS y las normas y métodos recomendados por $\mathrm{OACl}$ y otros organismos normativos?

Cl_03. ¿Existe homogeneidad entre los estilos gráficos característicos de las ediciones de los AIS mundiales?

Cl_04. ¿Puede analizarse de forma objetiva la eficiencia comunicacional de una carta aeronáutica tipo?

Cl_05. ¿Cómo se modifica la efectividad del mensaje cartográfico al combinarse distintas formulaciones de variables visuales, a su vez alojadas en los distintos niveles de significación aeronáuticos?

Cl_06. ¿Puede ofrecerse una especificación de aplicación combinatoria de variables visuales para una carta aeronáutica?

\subsubsection{Objetivos específicos}

Como consecuencia del enunciado de las Cuestiones de investigación (Cl) se formulan los siguientes Objetivos Específicos (OE):

OE_01. Caracterizar la utilización práctica de la Información Geográfica Aeronáutica (IGA) por parte de las tripulaciones de aeronaves civiles.

OE_02. Concretar un conjunto limitado de cartas aeronáuticas estereotipadas sobre las que poder aplicar el tercer objetivo específico.

OE_03. Diseñar y aplicar una metodología para el análisis de la eficiencia comunicacional de las cartas aeronáuticas. 
OE_04. Determinar la influencia perceptual provocada por la combinación de Variables Visuales (W) aplicadas a distintas agrupaciones de símbolos aeronáuticos estereotipados.

OE_05. Diseñar y evaluar un prototipo de mejora aplicando una combinación adecuada de variables visuales.

\subsection{METODOLOGÍA}

A continuación se presenta la metodología propuesta para concretar los objetivos anteriormente planteados.

Para alcanzar el Objetivo Específico 1 -caracterización la utilización práctica de la información geo-aeronáutica-, se realizarán las siguientes tareas:

MT_OE_01.1. Revisar la literatura existente y aportar un estado general de la cuestión con respecto a la Información Geográfica Aeronáutica (IGA): expresión gráfica habitual, soportes físicos y tecnológicos, interoperabilidad, etc.

MT_OE_01. 2. Proponer un instrumento de evaluación adecuado para caracterizar el uso práctico de la IGA. Establecer formalmente el propósito, los aspectos a evaluar, la escala, el método de recogida de datos, etc.

MT_OE_01.3. Validary aplicar el instrumento propuesto a un universo poblacional concreto y controlado.

MT_OE_01.4. Analizar y discutir los resultados obtenidos, tratando de evidenciar y caracterizar adecuadamente posibles problemas -necesidades, comprensión del lenguaje cartográfico, etc.-

Para alcanzar el Objetivo Específico 2 -precisar un conjunto de cartas aeronáuticas estereotipadas-, se seguirá el siguiente proceso:

MT_OE_02.1. Revisary sintetizar las estandarizaciones y recomendaciones cartográficas internacionales que son de aplicación a la cuestión. 
MT_OE_02.2. Identificar justificadamente un conjunto homogéneo y característico de ediciones de cartas aeronáuticas de distintas regiones y continentes.

MT_OE_02.3. Establecer un listado de parámetros de comparación entre modelos de cartografía aeronáutica, y aplicarlos de forma práctica sobre el conjunto de ediciones características. Analizar y discutir los resultados obtenidos.

MT_OE_02.4. Aplicar el resultado anterior a la creación de un conjunto de modelos cartográficos de simbología estereotipada.

El objetivo específico 3 -análisis de la eficiencia comunicacional de las cartas aeronáuticas- se alcanzará con la siguiente metodología:

MT_OE_03.1. A partir de una revisión bibliográfica específica, identificar las implicaciones de factores humanos clave en cuanto a comunicación cartográfica se refiere.

MT_OE_03.2. Estudiar las metodologías existentes para el análisis de la eficiencia comunicacional cartográfica.

MT_OE_03.3. Definir una localización espacial prototípica para poder establecer un marco de evaluación homogéneo.

MT_OE_03.4. Aplicando el marco anterior, proponer una metodología de análisis que permita cuantificar la eficiencia de unas ediciones frente a otras y también con respecto a los modelos estereotipados generados en el Objetivo Específico 2.

Para alcanzar el Objetivo Específico 4 -análisis de la influencia perceptual provocada por la combinación de variables visuales-, se seguirá el siguiente proceso:

MT_OE_04.1. A partir de los resultados del Objetivo Específico 2, determinar los fenómenos y niveles de representación habituales y las agrupaciones típicas de símbolos aeronáuticos. 
MT_OE_04.2. Aplicar los códigos de representación simbólica estereotipados al marco de evaluación definido en el tercer objetivo específico, establecer una formulación de variables visuales a los fenómenos agrupados por medio de capas o niveles de significación.

MT_OE_04.3. Diseñar y emplear ensayos de percepción visual con un universo poblacional concreto y controlado, tratando de cuantificar diferencias entre distintas combinaciones transversales de variables visuales, en términos de modificación de la percepción visual y comprensión del mensaje cartográfico.

Finalmente, para alcanzar el Objetivo Específico 5 -diseño y evaluación un prototipo de mejora-, se seguirá el siguiente proceso:

MT_OE_05.1. A través de los resultados del Objetivo Específico 4, proponer una especificación combinatoria de variables visuales adecuada y aplicarla a un prototipo de evaluación.

MT_OE_05.2. Aplicando la metodología de análisis de eficiencia desarrollada en el Objetivo Específico 3, cuantificar la mejora comunicación obtenida mediante la especificación propuesta con respecto al modelo de partida.

\subsection{RESULTADOS PREVISTOS}

Los resultados previstos de la investigación son:

- La caracterización del uso que los pilotos hacen de los diferentes soportes físicos y tecnológicos de información geográfica identificados, en orden a descubrir tanto necesidades de provisión no resueltas como conductas básicas de utilización asociadas.

- La definición, en forma de principios de diseño, de una metodología de optimización de la visualización de la información aeronáutica basada en la adecuación a diferentes tipos de estímulos y condicionantes perceptivos.

- La demostración de que, en el escenario concreto de uso de las cartas aeronáuticas, se puede ampliar su eficiencia comunicativa por medio de una especificación de adecuación combinatoria de variables visuales que complemente a las especificaciones simbólicas clásicas. 


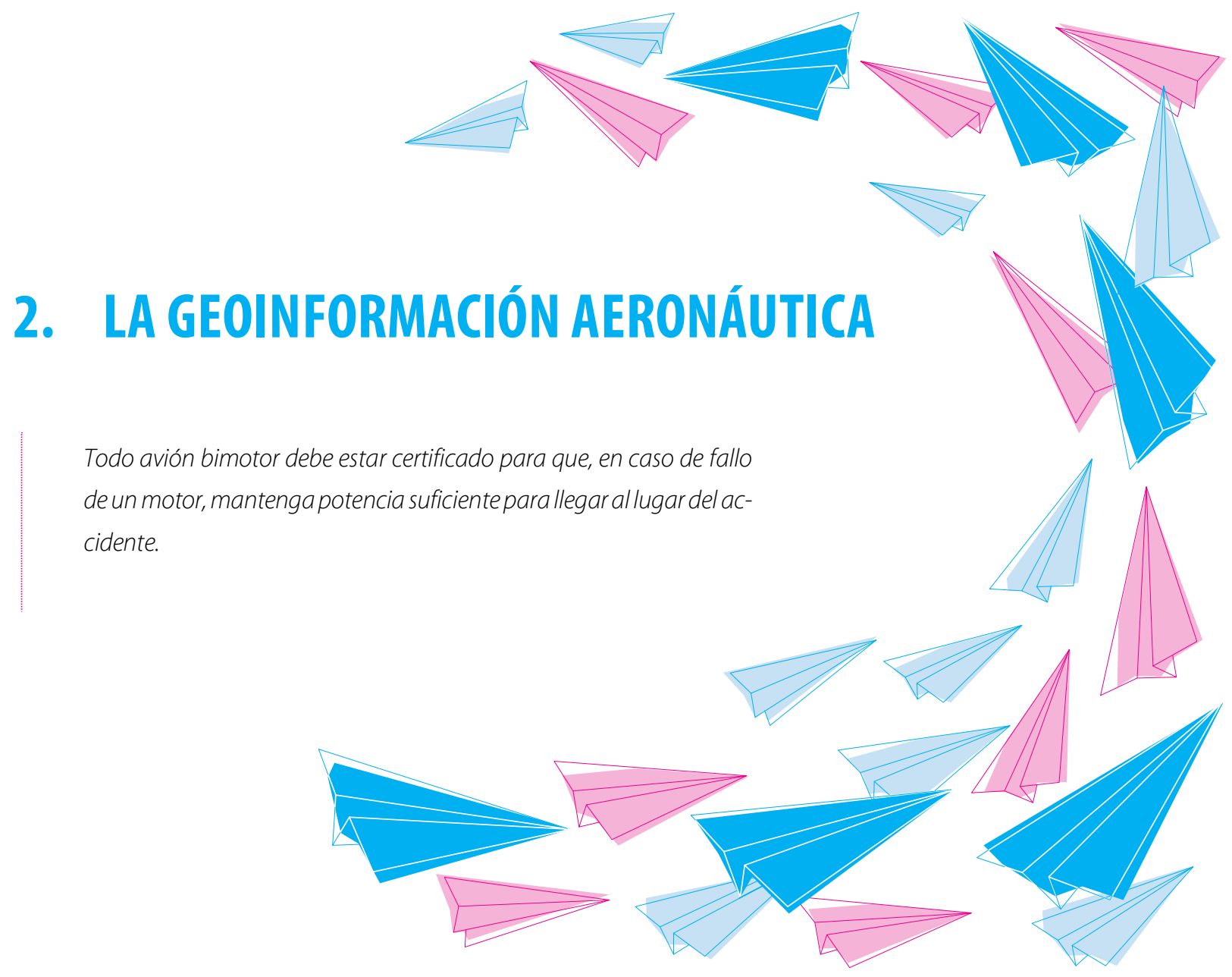

Aunque en nuestro ánimo esté que el discurso del trabajo de investigación evolucione de forma clara y contundente hacia la ideación, análisis y discusión de distintas claves de entendimiento centradas en la expresión gráfica, debemos considerar que, como toda cartografía temática dirigida a expertos en determinadas áreas de conocimiento, este trabajo se dirige hacia un grupo de usuarios, el de los pilotos de aviación y expertos cercanos, que usan la cartografía aeronáutica, muy poco conocida por otros grupos de lectores de cartografía. Este hecho implica que para el diseño de la misma y su evaluación se exija un buen conocimiento de cuestiones aeronáuticas. La información que portan las cartas de navegación, codificada de forma gráfica, describe de una forma sintética la ubicación espacio-temporal de diferentes fenómenos, pero también transmite determinados procedimientos de vuelo a priori complejos de entender para el neófito en la materia.

El que suscribe esta tesis se ha acercado al mundo de la cartografía aeronáutica con una formación que se encuentra en la orilla de la comunicación cartográfica, por lo que ha necesitado invertir, como paso previo al desarrollo de esta investigación una extraordinaria cantidad de tiempo y esfuerzo en completar esta base académica y profesional con un conocimiento aeronáutico, con el fin último de lograr que ambas perspectivas se puedan maridarse adecuadamente. 
Esta dualidad de conocimiento que describimos puede ser materializada a través de la metáfora del problema de la construcción de un puente, en la que se parte de un conocimiento básico de las características geotécnicas de la orilla en la que nos situamos -la orilla de la expresión gráfica y la orilla del conocimiento aeronáutico respectivamente-, mientras que se desconoce casi por completo las particularidades de la opuesta.

Construir los correspondientes apoyos de pilas y estribos sobre la orilla de la que tenemos conocimiento y volar sucesivamente ménsulas hasta alcanzar la opuesta es, además de inseguro, una mala estrategia. Además de la dificultad de completar el puente sin haber erigido los cimientos de apoyo en la orilla opuesta, las características inestables no conocidas del terreno de la misma dan pie a una constante incertidumbre acerca de la estabilidad de la construcción -nuestro discurso-. Al mismo tiempo, van a imposibilitar decidirse a priori con éxito sobre el tipo de puente -de arco, colgante, atirantado- más adecuado para nuestros propósitos -nuestro objetivo-

Fuertemente influenciados por este contexto de conocimientos de partida, nos inclinamos a alejarnos en cierta medida de la práctica habitual de concentrar en este segundo capítulo -el primero tras la introducción- el estado del arte de la cuestión temática central: la comunicación cartográfica. Como alternativa desarrollaremos, en primer lugar, una revisión del estado de la cuestión relacionado con la información aeronáutica; interesados en que el conocimiento de la cartografía aeronáutica se incorpore al mundo de los cartógrafos, aprovecharemos para introducir algunos conceptos básicos de navegación en orden a facilitar el entendimiento de la posterior disertación doctoral por parte de cualquier neófito en la materia aérea. A su vez, reservaremos el siguiente de los capítulos -el tercero- para ofrecer el estado de la cuestión de temas semiológicos y de representación gráfica, incorporando también determinados conceptos formales y normativos de las cartas aeronáuticas que nos serán necesarios a posteriori. Finalmente, coordinaremos esta dualidad de forma adecuada para que confluya en un único hilo argumental a partir del cuarto capítulo.

Aspiramos a que la revisión dual del estado de la cuestión a desarrollar durante los dos capítulos sea permeable y usable, en el sentido de servir de estímulo para comenzar a generar inmediatamente aportación propia de conocimiento. Por ejemplo, el entorno físico y operacional en el que se desarrolla la cuestión comunicadora nos resulta esencial, ya que, como demostraremos, los estímulos y rendimientos perceptuales del usuario pueden estar en buena medida condicionados por éste. La caracterización de ese entorno de uso práctico surgirá precisamente a partir del entendimiento previo de los conceptos aeronáuticos básicos.

En definitiva, la revisión del estado del arte tiene una filosofía dual, se extenderá a lo largo de dos próximos capítulos y será acompañada tanto por determinadas bases teóricas como por aportaciones propias que tratan de preparar lo que será el núcleo de la investigación, respetando en todo momento la metodología declarada.

Este segundo capítulo -La geoinformación aeronáutica- se estructura de la siguiente manera: La sección 2.1 110 años en el cielo- da cuenta de la evolución de la cartografía aeronáutica a través de la historia, cotejando esta con el desarrollo de las capacidades de las aeronaves, la evolución de las técnicas de navegación aérea y la progresiva tecnificación de los sistemas de información de componente visual. En la sección 2.2 -La navegación aérea- se describen los procedimientos básicos de navegación que se encuentran recogidos de forma 
gráfica en la cartografía aeronáutica. En la sección 2.3 -Estructura del espacio aéreo- se detalla la sectorización que las entidades regulatorias han aplicado al espacio aéreo internacional. En la sección 2.4 -Fases y procedimientos- se describe los procedimientos que deben llevarse a cabo en cada una de las fases en las que se divide un vuelo instrumental. En la sección 2.5 -Información geo-aeronáutica- se justifica la necesidad de dicha información, y se da cuenta del estado de la cuestión de la provisión, publicación e interoperabilidad de datos aeronáuticos.

En la sección 2.6 -Caracterización del uso práctico de la información- se exhibe una de las principales aportaciones de conocimiento propio de esta tesis doctoral, que no es otra que la caracterización del uso de la información geo-aeronáutica, desde el punto de vista de los usuarios. Así, se describen someramente los condicionantes externos de la comunicación de información aeronáutica en vuelo y se aporta, a través de un estudio propio, una visión general de la utilización práctica de la Información Geográfica Aeronáutica (IGA) por parte de las tripulaciones de aeronaves civiles españolas. El propósito final del estudio trata de revelar tanto necesidades de provisión como una serie de conductas generales o pautas de uso en el colectivo de pilotos.

Finalmente, en la sección 2.7 -Sumario- se realizará un sumario de las cuestiones tratadas a lo largo de las secciones de este capítulo.

\subsection{AÑOS EN EL CIELO}

\subsubsection{El gran salto}

Probablemente a los hermanos Orville y Wilbur Wright, aquel histórico 17 de Diciembre de $1903^{1}$ en Carolina del Norte -Estados Unidos-, lo que menos les preocupaba era cómo evolucionar por el aire con su frágil proto-

${ }^{1}$ Con asiduidad los historiadores dan por sentado que la primera de las secuencias documentadas de vuelo controlado de la historia realizada con un aeroplano fue la realizada por los hermanos Wright en 1903, discutiéndose si acaso a cuál de los hermanos le correspondería concretamente tal honor. Aprovechando la celebración del primer centenario del acontecimiento, C. F. Gray (2002) diserta sobre la cuestión y propone la siguiente definición para considerar, caracterizar o describir el primer vuelo: "La primera ocasión en la que una máquina motorizada, más pesada que el aire y controlada por el ser humano se levanta del suelo por medio del movimiento del aire sobre una superficie de elevación o de las superficies, manteniéndose en vuelo una distancia superior a 300 pies bajo la dirección intencionada del aviador a bordo a través del uso activo de los mecanismos de control aplicados durante el vuelo, y vuelve a tierra sin daño alguno para el aviador."

Según lo anterior, sería Wilbur y no Orville el que debería recibir tal honor, aunque el propio autor asegura al redactar sus conclusiones que ve poco probable que esta idea cale en el imaginario popular, a la vista de que la figura de Orville Wright es la que queda representada en forma de maniquí junto a la aeronave original que está 
tipo de madera sin perderse más allá de los despejados altozanos conocidos como las Colinas del Diablo Asesino. Bastante les suponía lograr levantar semejante ingenio tanto tiempo como fuera posible para que ese primer vuelo de apenas 12 segundos, en el que Orville consiguió desplazarse 37 metros a la lánguida velocidad de $11 \mathrm{~km} / \mathrm{h}$ (Padfield y Lawrence, 2003), pasara a los anales de la historia como el primer vuelo controlado con una aeronave más pesada que el aire (C. F. Gray, 2002).

Si bien durante esta temprana etapa el alcance de los vuelos realizados por los Wright en diversas sesiones ${ }^{2}$ apenas lograban alcanzar unos centenares de metros, paso a paso comenzaron a dominar la técnica del vuelo recto y nivelado, dejando de ser tan habituales los violentos aterrizajes, desperfectos en la aeronave e incluso daños corporales. Esto les llevó en meses posteriores a centrarse en la experimentación del control efectivo de la dirección de vuelo. Como resultado, apenas nueve meses después del primer vuelo consiguieron trazar en el aire el primer recorrido circular completo (Lee, 2003; Winchester, 2004a). Todos estos avances eran concienzudamente descritos en un diario, como si de un cuaderno de bitácora se tratase. En cada sesión de pruebas se anotaba en este la fecha, las condiciones atmosféricas, velocidad y dirección del viento, la distancia alcanzada, etc. Cuando los Wright experimentaban con la dirección del vuelo, dibujaban un croquis del recorrido efectuado; usualmente en el bosquejo realizado quedaba dimensionado métricamente el campo de vuelo, y además se representaban tanto los obstáculos circundantes como la dirección y velocidad del viento de la sesión, junto con el recorrido realizado por el avión [Figura 2-1].

expuesta colgada bajo la cubierta del National Mall de Washington, sede del National Air and Space Museum de Estados Unidos.

${ }^{2}$ Aunque habitualmente se hace referencia a los hermanos Wright, existe cierta controversia con respecto a quien tuvo el honor de realizar el primer vuelo controlado con una aeronave de mayor densidad que el aire. El bávaro Gustave Whitehead y el estadounidense Lyman Gilmore afirmaron que lograron alzar el vuelo en avión con éxito en 1901 y 1902 respectivamente, aunque en ninguno de los casos documentaron estos supuestos hechos (C. F. Gray, 2004).

En el caso concreto de Whitehead se conservaron los planos de los modelos presuntamente utilizados, disfrutando su relato de una cierta verosimilitud a partir de la biografía del aviador escrita por Randolph (1937). Lo cierto es que en 1985 un grupo de aficionados estadounidenses construyó una réplica del modelo denominado "Número 21" a partir de los planos conservados, realizando con él 20 vuelos en el año 1986. En uno de estos vuelos se logró un vuelo con un alcance de 100 metros (Godfrey, 2000), mientras que con otra réplica construida en Alemania se consiguió volar en 1998 una distancia de 500 metros (Braun, 1998). 


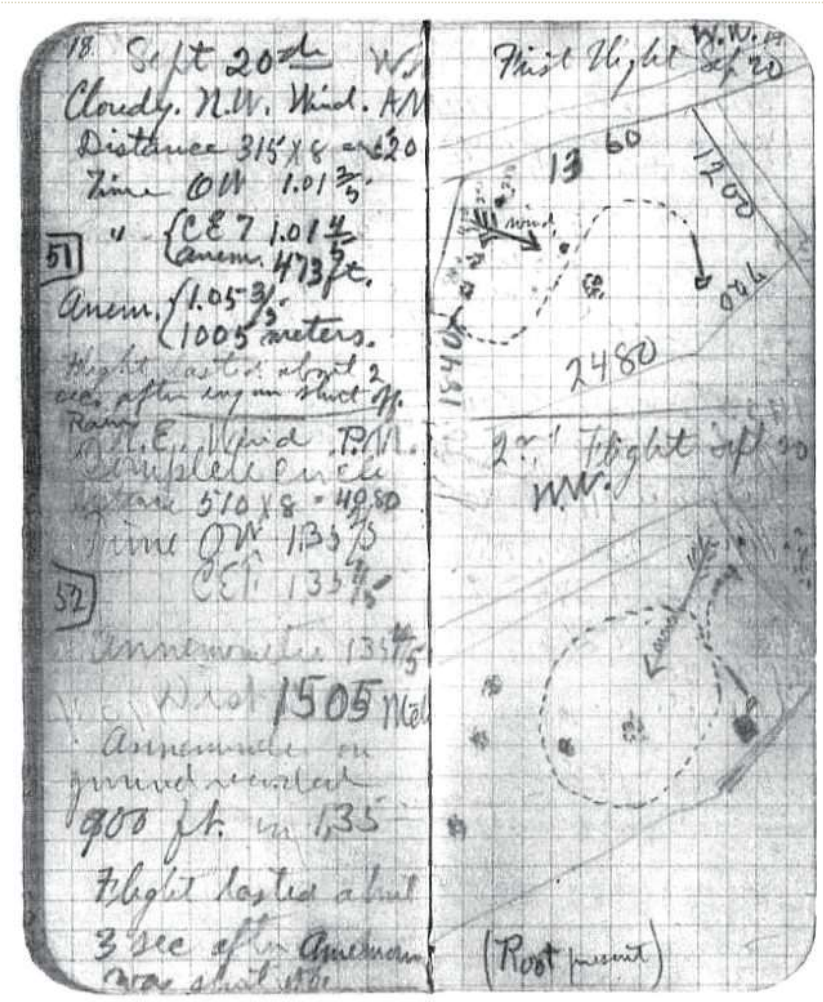

Figura 2-1: Página del logbook o diario de vuelo en la que se documenta el primer circuito de vuelo circular realizado por los hermanos Wright el 20 de septiembre de 1904 (Winchester, 2004a)

La consecución de grandes trayectorias tan sólo era una cuestión de tiempo. Resultó tan vertiginosa la evolución de las capacidades de los primitivos modelos de aeroplano que tan sólo 6 años después del vuelo de los hermanos Wright el francés Louis Blériot logró en uno de sus pequeños aviones artesanales cruzar por primera vez en la historia los casi 40 kilómetros que separaban Francia e Inglaterra sobre el Canal de la Mancha (Elliott, 2000; Wittreich, 2009). Aleccionado por el premio de 1.000 libras ofrecido por el diario Daily Mail a quien consiguiese semejante gesta, y tras los fallidos intentos del anglofrancés Hubert Latham y del ruso Charles de Lambert -discípulo a su vez de Wilbur Wright- (Walsh, 2007), la mañana del 25 de julio de 1909 Blériot despegó de las costas francesas rumbo a Inglaterra (Elliott, 2000). Una vez hubo conseguido llegar a la costa inglesa, y tras un violento aterrizaje, Bléirot relató a los corresponsales del diario allí desplazados la circunstancia no prevista que a punto estuvo de costarle la vida. Según reportó posteriormente mediante telegrama al diario The Washington Post, tras alzar el vuelo desde la costa francesa con el motor revolucionado a su máxima capacidad, redujo su velocidad hasta un promedio aproximado de $64 \mathrm{~km} / \mathrm{h}$ y se posicionó a unos 75 metros de altitud sobre el nivel del mar, dirigiéndose así de forma estabilizada hacia su objetivo en una mañana clara y despejada. "Comienzo mi vuelo estable y seguro hacia la costa de Inglaterra. No tengo temores, no hay sensaciones, pas du tout" (Wittreich, 2009). 
Hasta ese momento toda la preocupación de Bléirot se centraba en gestionar con rapidez cualquier falla mecánica que aconteciera o que la falta de potencia suficiente le impidiese llegar a la costa inglesa. Pero repentinamente las condiciones de visibilidad empeoraron drásticamente, quedando el avión envuelto en una densa neblina y provocando que el aviador perdiera de vista tanto los puntos de referencia costeros como al destructor de escolta Escopette, buque de la armada francesa destinado precisamente a observar su recorrido durante el intento (Harper, 1947). Las palabras de Bléirot al Daily Mail una vez llegó a tierras inglesas nos acercan a la situación límite a la que debió enfrentarse por la repentina pérdida de orientación: "Durante más de 10 minutos estuve completamente solo, aislado, perdido en medio de la inmensidad del mar; no vi nada en el horizonte, ni siquiera un simple barco" (N. Clark, 2009).

La puesta en común de la descripción de los primeros vuelos de los Wright y de la hazaña de Bléirot, acontecida pocos años después, puede ofrecer una muestra de la extraordinaria rapidez con la que evolucionó la aviación a motor desde su nacimiento: de los primeros y torpes vuelos de apenas unos centenares de metros sobre un escenario controlado ${ }^{3}$ se pasó en tan sólo 6 años a una travesía de 37 minutos de duración sobre las movidas aguas del Océano Atlántico. Pero en realidad nuestra intención al plantear este cotejo es la de poner de manifiesto el cambio de circunstancias que aconteció en la evolución de la aviación a partir de gestas como la de Blériot y las de otros muchos aviadores -John W. Alcock4, Sacadura Cabraly Ramón Franco ${ }^{5}$, Charles Lindbergh ${ }^{6}$, Mariano Barberán ${ }^{7}$ etc.--

${ }^{3}$ Otra de las controversias estriba en la utilización o no de medios auxiliares para despegarse del suelo. El primer vuelo aeronáutico propulsado a motor en Europa no tuvo lugar hasta el otoño de 1906, siendo este protagonizado por el brasileño Santos Dumont (C. F. Gray, 2002). Mientras que los Wright utilizaron durante sus primeros vuelos patines sobre una plataforma deslizante (lo que incluso hacía necesario el uso de una catapulta de lanzamiento en la ausencia de viento en contra), el avión de Dumont poseía un tren de aterrizaje con ruedas.Así, los partidarios de la reclamación de Santos-Dumont como pionero de la aviación se escudan en que para certificar cualquier hito de la aviación, la Fédération Aéronautique Internationale (FAl), organización fundada en Francia a principios del siglo, declaró entre sus reglas destinadas a validar cualquier registro que un avión debe ser capaz de despegar por sus propios medios (Barros, 2006; Hoffman, 2003).

${ }^{4}$ En 1919 el británico John William Alcock, junto con Arthur Whitten Brown, realizó la primera travesía trasatlántica con escalas en un avión.

${ }^{5}$ En 1922 los portugueses Sacadura Cabral y Gago Coutinho realizaron la primera travesía aérea del Atlántico Sur entre Lisboa y Rio de Janeiro. En 1926, Ramón Franco y Julio Ruiz de Alda cruzaron el Atlántico Sur a bordo del hidroavión Plus Ultra, realizaron desde Palos de la Frontera una ruta similar, siendo Buenos Aires la ciudad de destino.

${ }^{6}$ En 1927 Charles Lindbergh cruzó en solitario y sin escalas el océano Atlántico tras 33 horas y 32 minutos de vuelo.

${ }^{7}$ En 1933 Mariano Barberán, Joaquín Collar Serra y Modesto Madariaga, a bordo del Breguet XIX Super Bidon "Cuatro Vientos", realizaron la travesía sin escalas entre Sevilla (España) y Camagüey (Cuba). 
En un breve espacio de tiempo el diseño de las superficies de vuelo y la eficacia de los controles evolucionó a formas más eficaces, a la par que los motores utilizados eran cada vez más potentes y fiables. En definitiva, comenzaron a ser técnicamente viables travesías mucho más largas y, como consecuencia, se hizo necesario desarrollar técnicas de navegación que permitieran a aquellos pioneros volar hacia donde deseasen y poder tomar tierra firme de una sola pieza sin jugarse la vida en cada oportunidad por posibles problemas de desorientación sobre el territorio (Moya y Bernabé, 2011).

Por todo lo anterior, y desde un punto de vista meramente simbólico, datemos temporalmente el origen de la necesidad de desarrollar técnicas específicas de navegación aérea a partir del vuelo de Blériot sobre el Canal de La Mancha en 1909. Nuestra intención a continuación es la de exponer de modo retrospectivo la evolución acaecida por la información aeronáutica, que materializada a través de multitud de aparejos de navegación, desde entonces acompaña a los aviadores en sus desplazamientos por el aire.

\subsubsection{La especialización}

La mayor parte de los vuelos del primer cuarto del siglo XX no suponían travesías excesivamente largas, de manera que una buena dosis de experiencia en la lectura del terreno, la brújula y la inestimable ayuda de las guías de carreteras (Calvo, 2000) era, en principio, suficiente para que las tripulaciones se orientasen sin mayor complicación. Tales guías representan, junto con las de los ferrocarriles, las primeras cartas de navegación de las que hoy en día tenemos referencias (McGaugh, 2004; Pérez, 2003).

Como ayuda complementaria a la navegación, y con el objetivo de orientar a posibles pilotos extraviados, en esta época se comienza a rotular sobre las cubiertas de los hangares situados en los campos de vuelo el nombre de la población a la que pertenecen. La especial estrechez de las cabinas de pilotaje -por ello el término en inglés para referirse a ellas, cockpit, significa literalmente "foso de peleas de gallos"- (Simpson y Weiner, 1989), no invitaba a desplegar en toda su dimensión aquellas grandes guías de carreteras; si a ello le sumamos que los primeros aeroplanos no disponían de cabina capotada, el manejo de la aeronave y la lectura al unísono de las guías suponía un problema a los tripulantes.

Surgió entonces la necesidad de disponer de una cartografía más acorde a estas circunstancias que, en realidad, no diferían gran cosa de los comentados mapas de carreteras, excepto por el formato. Estas nuevas cartas ${ }^{8}$, pensadas para su utilización en la angostura de las pequeñas cabinas de la época, presentaban un formato alargado, plegado en forma de acordeón para facilitar su uso, y que representaba una franja de terreno de un

${ }^{8}$ Formalmente, un mapa se define como la representación geográfica de la Tierra o parte de ella en una superficie plana (RAE, 2001), pero esta afirmación tiene un matiz: si dicha representación cubre una gran extensión se debe utilizar la denominación de mapa, mientras que para las extensiones más limitadas la designación apropiada es la de plano. No obstante, nuestro idioma nos hace aceptar la denominación de carta cuando nos referimos particularmente a los mapas destinados a la navegación (Moya y Bernabé, 2011; Pérez, 2003). Así, es habitual referirse a las cartas náuticas y a las cartas de navegación aérea, respectivamente. 
ancho que cubriese preventivamente las posibles y comprensibles desviaciones de vuelo [Figura 2-2]. Generalmente las cartas no se orientaban necesariamente al Norte, sino que lo hacían en función de la dirección del trayecto para el que tenían que servir de ayuda, teniendo así como eje la ruta deseada (Connor, 2011).

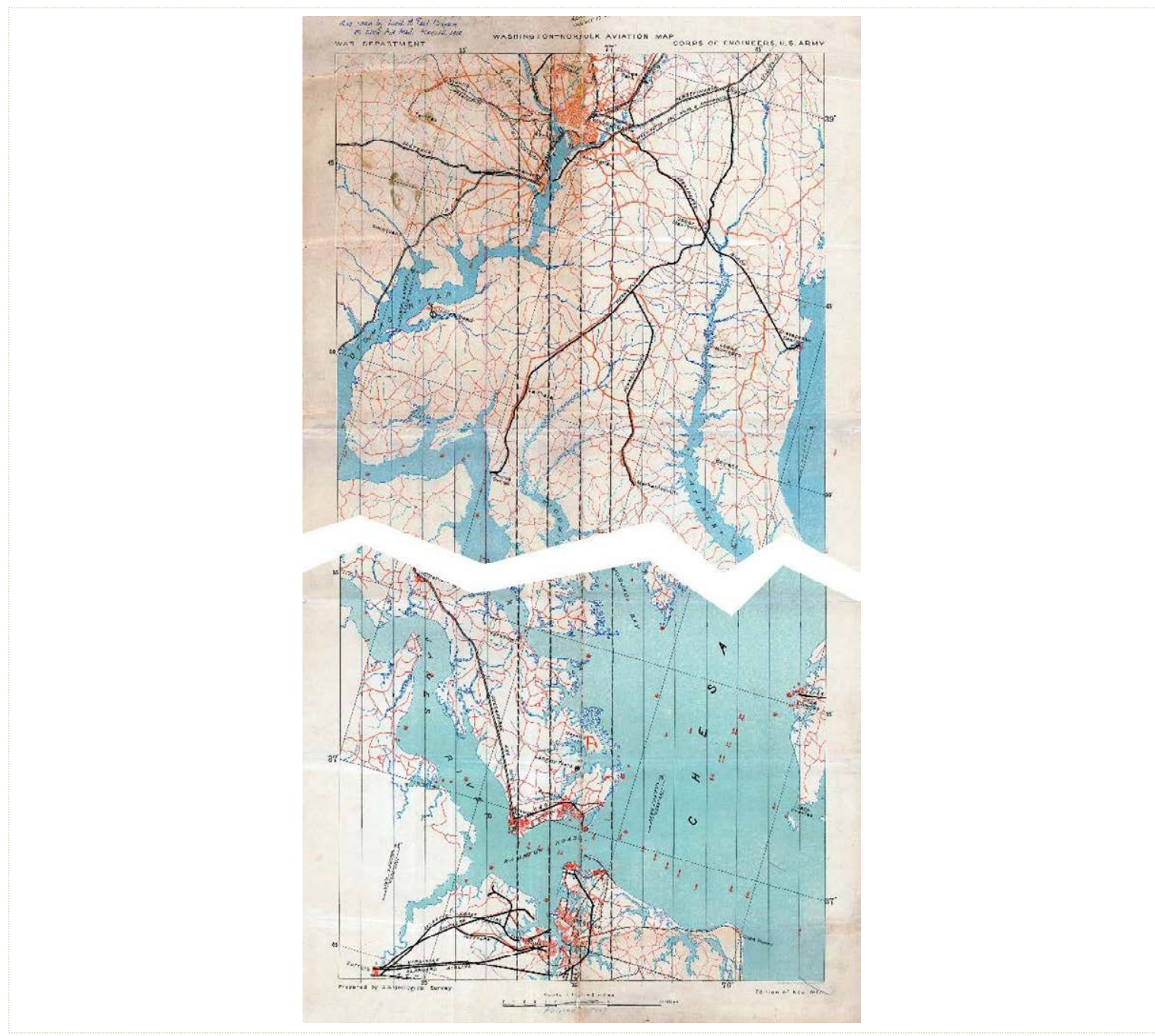

Figura 2-2: Carta de navegación de 1918 para el trayecto Washington-Norfolk (EE.UU.); además de ciudades, vías de comunicación, bases y depósitos, se indican los lugares de aterrizaje clasificados en buenos, malos e indiferentes. Proporción real: 1×3,1 (National Air and Space Museum, Washington, D.C.)

Pero incluso con el concurso de la mejor y más detallada información cartográfica, los vuelos estaban ciertamente limitados por la visibilidad atmosférica (McGaugh, 2004). Por ello no se puede hablar de una cartografía aeronáutica verdaderamente especializada hasta la década de los años treinta, con la instauración de las primeras ayudas radioeléctricas a la navegación en tierra (Moya y Bernabé, 2011). Un precedente de estas fueron los denominados aerofaros, cuyas luces de curso permitieron en 1924 los vuelos nocturnos para transporte 
regular de correo aéreo en Estados Unidos, aunque limitados a noches limpias de nubes bajas (Sáez y Portillo, 2003). Aerofaros y emisoras de radio comenzaron por tanto a quedar simbolizados en la cartografía [Figura 2-3].

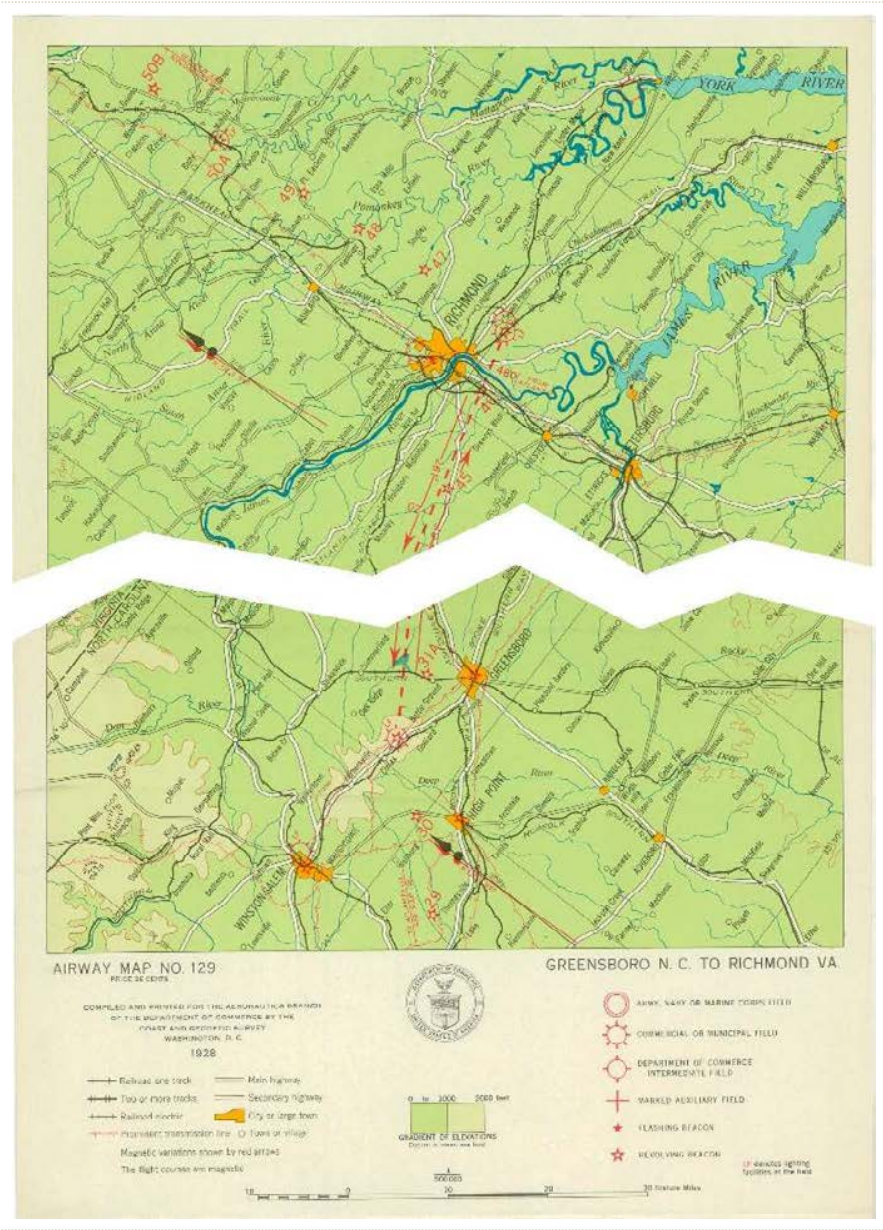

Figura 2-3: Carta de 1928 destinada a la ruta aérea entre Greensboro y Richmond (EE.UU.) balizada a través de aerofaros. Proporción real: 1×3. (National Air and Space Museum, Washington, D.C.)

Además de cartas a gran escala, cuya profusión de detalles para la navegación visual estaba especialmente destinada a aviones de baja velocidad, se fueron elaborando otras cartas de menor escala para aviones de velocidad y alcance superiores, en las que perdía importancia la representación de los accidentes geográficos para su posterior cotejo visual a favor de la localización de las radioayudas que se iban instaurando progresivamente. Así fue como en 1934 el capitán Elrey Borge Jeppesen ${ }^{9}$ presentó en Salt Lake City (Estados Unidos) las

${ }^{9}$ Los primeros pilotos comenzaron a hacer notas personales para ayudarles a navegar y a aterrizar en los aeródromos, cada vez más distantes entre sí. De hecho, la venta de estas notas a otros pilotos fue el comienzo de lo que se convertiría en la empresa de información aeronáutica del Elrey Jeppesen (McGaugh, 2004). 
primeras cartas de vuelo instrumental (R. Jeppesen, 2008), inspiradas en una filosofía particular: la orientación sobre el mapa ya no estaba absolutamente basada en puntos identificables sobre el terreno, sino que era relativa con respecto a las radioayudas [Figura 2-4], teniendo sobre estas referencia de orientación y distancia, gracias a la instrumentación de la propia aeronave.
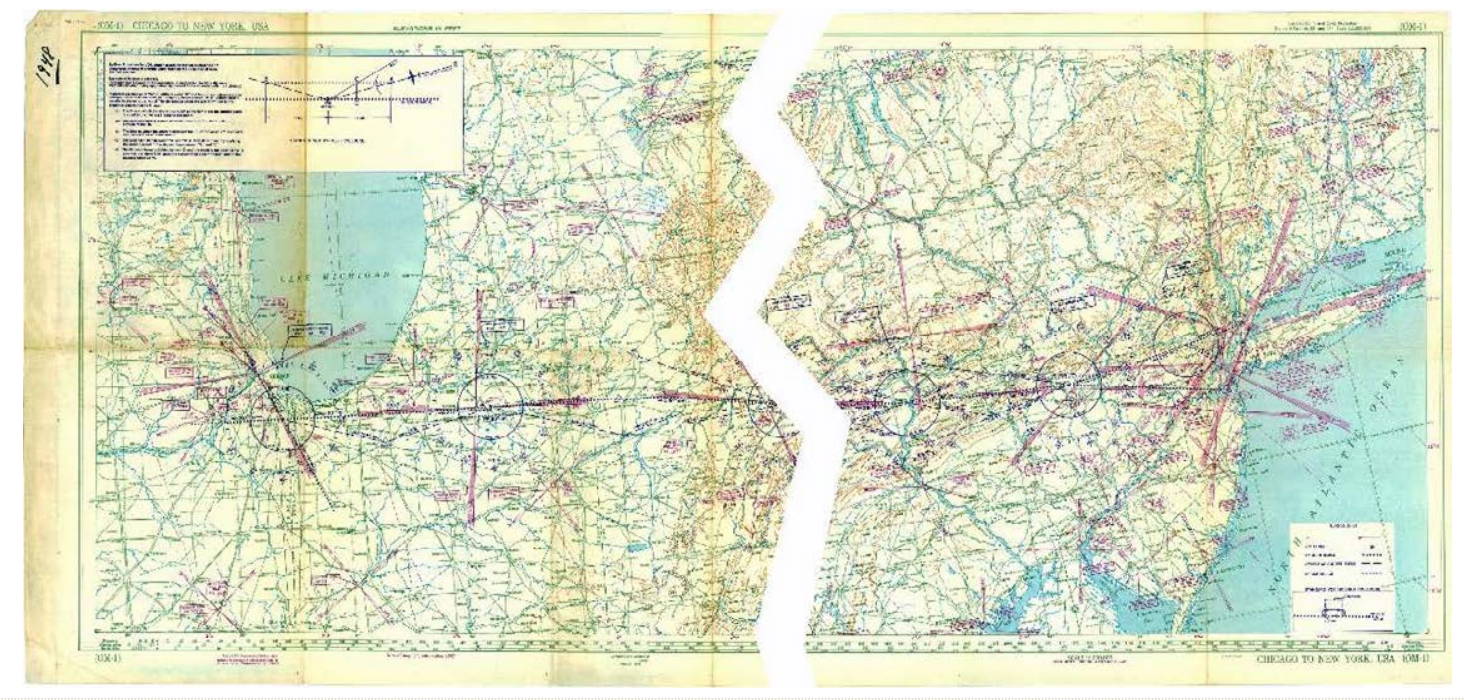

Figura 2-4: Prototipo de carta instrumental de 1948 para el trayecto Chicago-Nueva York (EE.UU.) en la que por primera vez se simbolizan los procedimientos de radionavegación VOR. Proporción real: 3x1 (National Air and Space Museum, Washington, D.C.)

La tecnología radioeléctrica aplicada a partir de los años 30 supuso un gran impulso a la industria aeronáutica. En estos años se crean distintas empresas de transporte civil a uno y otro lado del Océano Atlántico, algunas de las cuales operaban rutas internacionales dentro y fuera de cada respectivo continente. En Europa era ya constante la instauración de nuevos servicios aéreos de correo y pasajeros hacia las colonias africanas y de Oriente Medio (McGaugh, 2004; Pérez, 2003). Ante el aumento exponencial de la actividad aérea, en 1941 se desarrollaron las primeras cartas instrumentales especializadas en la aproximación y aterrizaje. Además de ser específicas para cada aeropuerto, estas cartas estaban especialmente ideadas para asistir a los pilotos en las maniobras de aterrizaje en condiciones de baja visibilidad (McGaugh, 2004).

\subsubsection{La batalla}

Durante la Segunda Guerra Mundial, y debido al crucial papel de la aviación en todos los frentes de la contienda, la demanda de cartografía aeronáutica se incrementó drásticamente. En 1943, la producción pasó de alrededor de medio millón por año a los 11 millones de cartas (McGaugh, 2004), siendo las fuerzas aéreas y 
navales de los distintos ejércitos las encargadas de crear sus propias cartas adaptadas a sus necesidades particulares en la disputa bélica. Una gran parte de ellas abarcaban zonas muy extensas -escalas de 1:5.000.000 o similares-, lo que ilustra hasta qué punto había avanzado la navegación a larga distancia. Los vuelos que superasen los 3.000 kilómetros de distancia eran ciertamente escasos antes de la contienda mundial, pero al llegar al tramo final de la guerra se convirtieron en algo muy habitual, sobre todo en el frente del Océano Pacífico (Connor, 2011).

Los avances en la navegación celeste y en los sistemas electrónicos de ayuda a la navegación de larga distancia como el LORAN hicieron de los vuelos de muy larga distancia sobre el mar algo rutinario; en este punto impresiona comparar la evolución de cualquier carta de navegación aérea oceánica editada a finales de la Segunda Guerra Mundial con la que confeccionó de forma artesanal Mariano Barberán tan solo diez años antes para realizar la histórica travesía del Cuatro Vientos entre Sevilla y la localidad cubana de Camagüey ${ }^{10}$ [Figura 2-5].

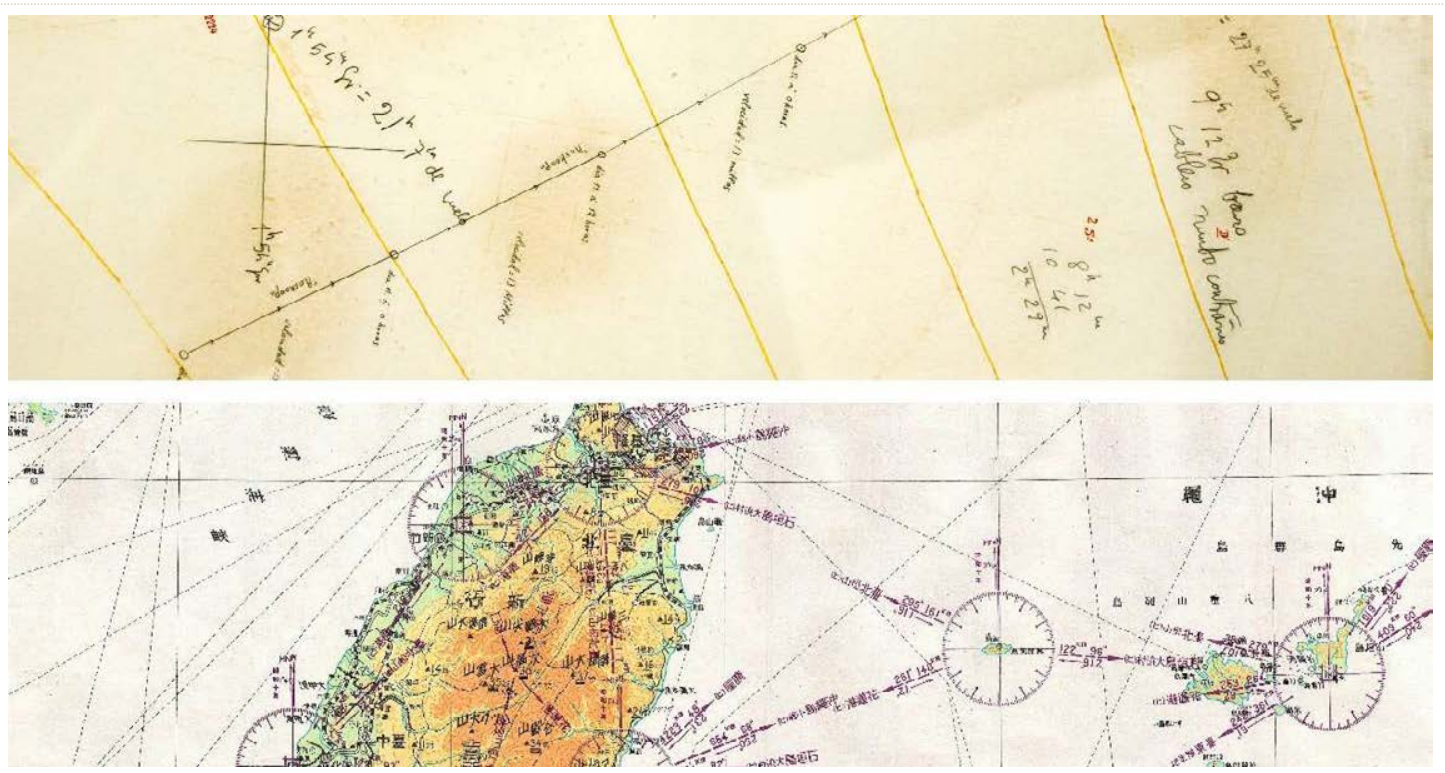

Figura 2-5: Comparativa parcial entre la carta de navegación de 1933 utilizada por la tripulación del Cuatro Vientos para realizar la travesía atlántica (Museo de Aeronáutica y Astronáutica de Madrid) y una carta aeronáutica japonesa de 1943, centrada en la isla de Taiwán -antigua Formosa- (Geographiclamacicus Antique Maps).

${ }^{10}$ Construida sobre papel fuerte, la ruta aparece dividida en tramos y segmentos con las correspondientes anotaciones horarias, gasolina consumida, régimen del motor y velocidad del avión, así como líneas de posición y las curvas de igual declinación magnética para corregir el rumbo (B. A. González, 2007). La carta, que posee una anchura de casi $50 \mathrm{~cm}$ y más de tres metros de longitud, se depositó en la embajada española en La Habana, mientras que el Cuatro Vientos prosiguió viaje rumbo a Ciudad de México. Durante este segundo trayecto, la aeronave desapareció misteriosamente (Domingo y Fernández-Coppel, 2003; Gismera V., 2008). 


\subsubsection{La estandarización}

La navegación aérea fue uno de los temas tratados en la Conferencia de Paz de Paris de 1919. En ella la secretaría del estado francés para la aviación lideró la idea de crear una Comisión especial Aeronáutica, siguiendo la línea marcada por el Comité de Aviación Inter-Aliado creado dos años antes (McGaugh, 2004; Wensveen y Wells, 2007). La Comisión Aeronáutica definió finalmente un primer convenio relativo a la regulación de la navegación aérea internacional, ratificado en primera instancia por 27 estados a finales de 1919 (OACl, 2012). A partir de entonces, de forma individual o coordinada, numerosas organizaciones comenzaron a redactar borradores de normas y estándares para la aviación relativos a mapas, cartas e información aeronáutica en general (McGaugh, 2004).

No fue hasta acabada la última contienda mundial cuando la comunidad internacional abordó, esta vez de forma efectiva y definitiva, la necesaria estandarización de los métodos de provisión de información que diesen soporte a la actividad aeronáutica civil. Fruto de esta necesidad es la Organización de Aviación Civil Internacional (ICAO-OACI), la agencia especializada de las Naciones Unidas creada en 1947 para proveer de seguridad, eficiencia y una ordenada evolución al transporte aéreo internacional (Krasnicka, 2010). A partir del Convenio sobre Aviación Civil Internacional firmado en 1944 por 52 estados (ICAO, 1944) comenzaron a establecerse las obligaciones para los Estados en materia de generar, mantener y difundir determinados tipos de cartas aeronáuticas, normalizando para ello su cobertura, formato, identificación dentro de una determinada serie y contenidos, incluyendo también la simbología normalizada y el color. Además de la $\mathrm{OACl}$, en el periodo de la postguerra se establecieron y maduraron definitivamente muchas de las agencias y asociaciones que, relacionadas con la aviación, podemos ver hoy en día: La Asociación Internacional de Transporte Aéreo (IATA) ${ }^{11}$, la Organización Europea para la Seguridad de la Navegación Aérea (EUROCONTROL) ${ }^{12}$, la Administración Federal de Aviación estadounidense (FAA) ${ }^{13}$, etc.

11 En 1919 seis líneas aéreas fundaron en Holanda el germen de la moderna Asociación para el Transporte Aéreo Internacional (IATA), formalmente fundada en 1945 en La Habana (Cuba) (IATA, 2012).

${ }^{12}$ La European Organisation for the Safety of Air Navigation (EUROCONTROL) fue fundada en Bruselas en 1960 por Alemania, Bélgica, Francia, Luxemburgo, Países Bajos y Reino Unido, en el intento de desarrollar un sistema seguro, eficaz y coordinado del tráfico aéreo europeo. Actualmente integra 39 estados miembros (EUROCONTROL, 2010).

${ }^{13}$ La Ley de Comercio Aéreo de 1926 y la sección de aeronáutica del Departamento de Comercio erigida a partir de esta ley marcaron el inicio de la regulación aeronáutica en los Estados Unidos. En 1938, la Ley de Aeronáutica Civil transfirió las responsabilidades federales del citado departamento a un nuevo organismo independiente, la Autoridad de Aeronáutica Civil. En 1940 Franklin D. Roosevelt separó sus responsabilidades en dos distintas agencias, la Administración de Aeronáutica Civil (CAA) y la Junta de Aeronáutica Civil (CAB), pero en 1958 sus funciones fueron nuevamente reunidas en la Agencia Federal de Aviación, que en 1967 recibe el definitivo nombre de Administración Federal de Aviación (FAA) (FAA, 2012a). 


\subsubsection{La presurización}

Además de los esfuerzos de coordinación en materia de legislación, los años 50 y 60 del siglo pasado supusieron la llegada de los reactores a la aviación comercial. Aunque los comienzos fueron dubitativos debido a los accidentes por fatiga estructural del modelo pionero -el británico De Havilland Comet- (Withun, 1976), con la introducción de los evolucionados Boeing 707, Douglas DC-8 y Convair 880, las aerolíneas comenzaron a operar hacia 1960 con una seguridad inusitada hasta entonces, llenando sus flamantes aviones presurizados de confiados pasajeros en rutas intercontinentales. Las cartas instrumentales de aquella época ya no diferían en demasía de las actuales, salvo en la escasa densidad de elementos mostrados, lo que es una muestra inequívoca del incremento de las operaciones aéreas desde entonces (Moya y Bernabé, 2011).

En la década de los años sesenta la industria aeronáutica civil se lanzó a la carrera por la automatización de los sistemas de pilotaje. Un interesante precursor de los actuales mapas digitales de navegación apareció a bordo del Hawker Siddeley HS-121 Trident $^{14}$. El modelo de corto y medio alcance por excelencia de la BEA -antigua British Airways- poseía, entre otras avanzadas características para la época, una pantalla en el panel central de instrumentos en la que se representaba un mapa móvil [Figura 2-6] en forma analógica (International, 1965b; Winchester, 2004b). Este sistema electromecánico incluía una aguja que indicaba la posición lateral del avión con respecto a la dirección de la ruta planeada, la cual estaba representada sobre un rollo de papel. La posición se obtenía de un sistema de navegación Doppler, que proporcionaba velocidad respecto a tierra y deriva; estos datos, combinados con el de rumbo, permitían a unos pequeños motores eléctricos mover acompasadamente la aguja en dirección lateral y el rollo de papel en el sentido de la marcha del avión. De esta manera se ofrecía en todo momento al piloto la posición real del avión con respecto a la ruta representada.

${ }^{14}$ El primer vuelo de pruebas del HS-121 Trident aconteció en 1962, aunque ya en 1960 se hizo pública la intención de equipar este modelo con el mapa pictórico móvil que caracteriza físicamente la parte central de su tablero de mandos (International, 1960). 


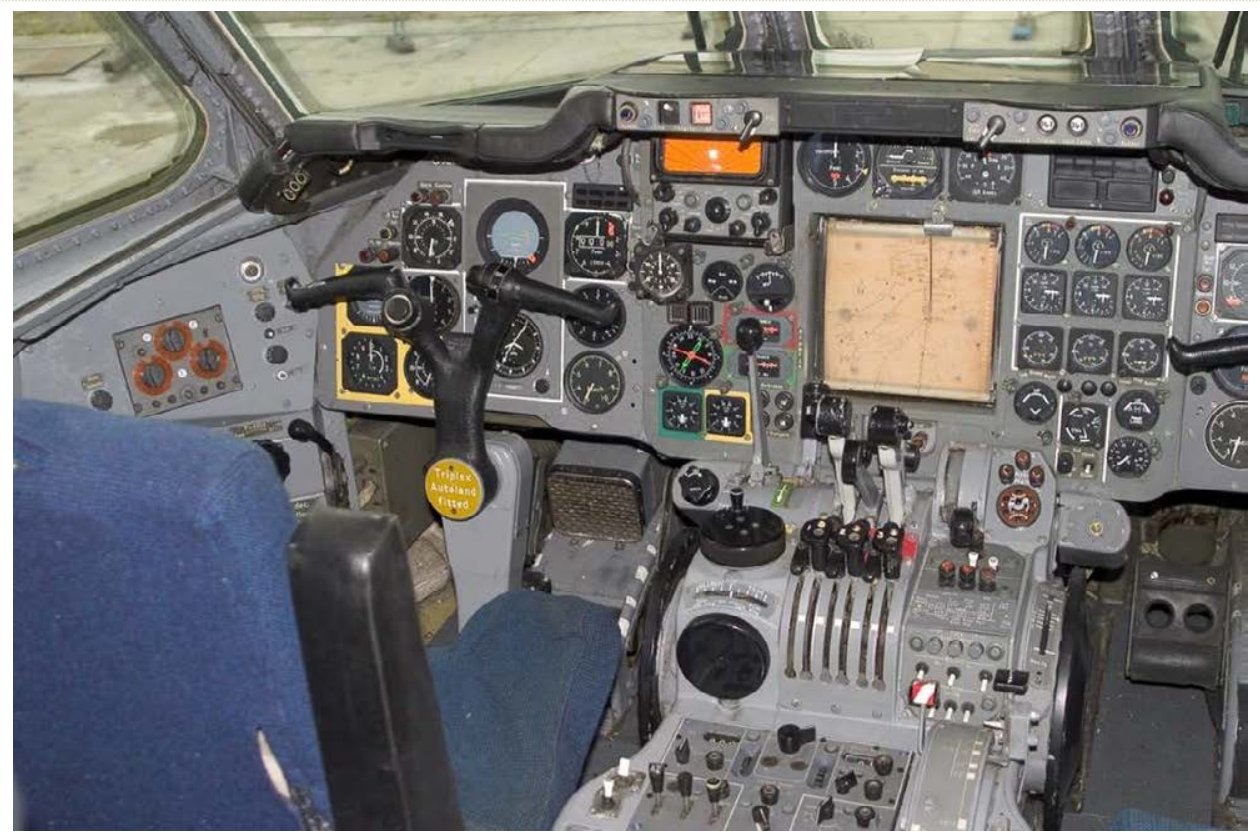

Figura 2-6: Mapa móvil de navegación en formato papel, integrado en la instrumentación de un HS-121 Trident (Steve Petch, Airliners.net).

A mediados de la década de los años 60 los equipos de diseño del modelo supersónico europeo Concorde ${ }^{15}$ y su equivalente estadounidense Boeing 2707 -este último finalmente cancelado antes de entrar en producciónrecomendaron instalar pantallas con mapas de navegación móviles en todos sus modelos de producción [Figura 2-7]. Los ingenieros estimaban de forma entusiasta que su uso reduciría la carga de trabajo en áreas terminales, reducirían los posibles errores de seguimiento del vuelo supersónico, facilitaría la ejecución de desvíos no programados y un desplazamiento más seguro por zonas subsónicas. Sin embargo, las líneas aéreas interesadas en el Concorde no reclamaron finalmente como equipamiento de a bordo el mapa de navegación automático propuesto, porque deseaban que los pilotos tuviesen una transición menos abrupta con respecto a la instrumentación habitual de los aviones de la época (Hagglund, 1987; Murlin, 1965; Owen, 2001).

${ }^{15}$ El Ferranti AMD, cuyas sigas significan Pantalla de Mapa Automático o Automatic Map Display, fue el equipamiento testeado para el primer prototipo del Concorde ensamblado a finales de los años 60 (International, 1965a, 1969). Evolucionaba el modelo de rollo de papel a bordo del HS-121 Trident al utilizar como soporte de las cartas de navegación negativos fotográficos intercambiables, cuya función era la de retroproyectar los gráficos de la filmina gracias a una fuente luminosa. Este modelo analógico supone el precedente histórico de los actuales displays de navegación cuyos gráficos son procesados mediante sistemas informáticos. 


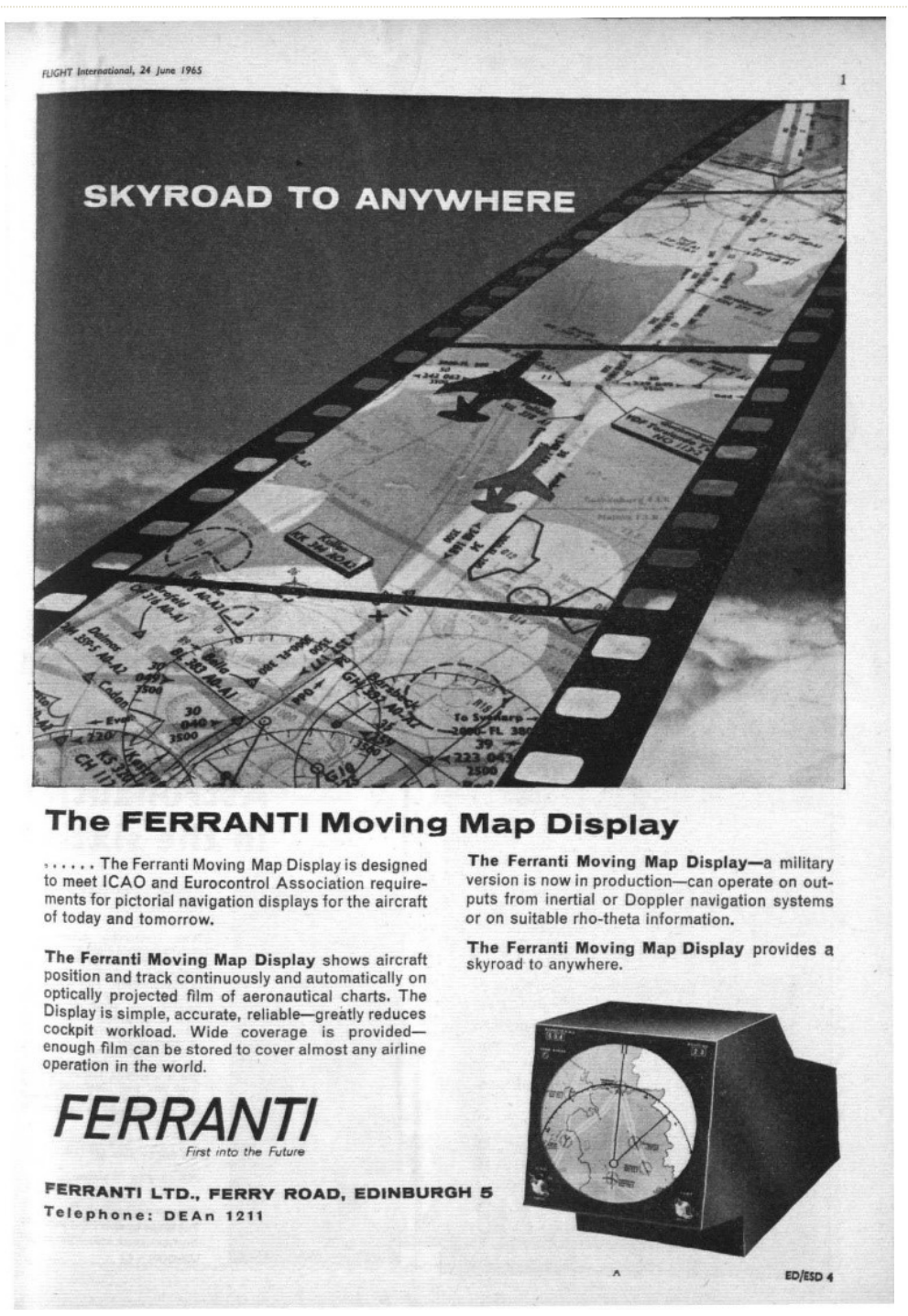

Figura 2-7: Publicidad del Ferranti Moving Map Display en revistas de la época. Alrededor de 1965 hacían acto de presencia los primeros anuncios comerciales de pantallas de mapas móviles en las revistas especializadas de la industria aeronáutica, las cuales recogían los primeros requerimientos de ICAO y EUROCONTROL acerca de las pantallas gráficas de navegación (International, 1965a).

\subsubsection{Los trazos luminosos}

No es hasta principios de la década de los años 80 cuando la tecnología de representación electrónica de gráficos en pantallas de vídeo de Tubo de Rayos Catódicos (CRT) es lo suficientemente madura (International, 
1981a, 1981b) como para dar el salto de los prototipos de aviación militar a la comercial. Así, diferentes compañías especializadas en aviónica ${ }^{16}$ propusieron a los fabricantes de aeronaves el desarrollo de diversas metodologías de Sistemas de Instrumentación Electrónica de Vuelo (EFIS) para sus futuros modelos ${ }^{17}$; todas ellos estaban basadas en un generador electrónico de símbolos cuyo control por software posibilitaba la representación dinámica de gráficos en unas pequeñas pantallas de vídeo CRT. Sobre éstas se emulaban electrónicamente diversos instrumentos de navegación analógicos o bien se presentaba distinta información posicional atendiendo en todo momento a las diferentes fases de vuelo instrumental.

La tecnología de las pantallas evolucionó con rapidez, haciendo posible una tasa de refresco de imagen aceptable para la comodidad visual de los pilotos, efectos tridimensionales básicos, sensores de luminosidad ambiental, y la aplicación de colores básicos en los gráficos que hacían posible la representación cromática del horizonte artificial, la agrupación de símbolos bajo diferentes categorías, y la representación hipsométrica de la orografía y meteorología circundante en la pantalla de navegación (International, 1981a).

Los sistemas EFIS propuestos ${ }^{18}$ comprendían inicialmente un Indicador Director de Actitud (ADI) y un Indicador de Dirección Horizontal (HSI) [Figura 2-8]. La intención era sustituir varios de los tradicionales instrumentos electromecánicos de navegación -horizonte artificial, velocímetro, altímetro, etc.- por una representación en vídeo más sofisticada y con mucha mayor información, coordinando la lectura de todos ellos en una única pantalla de vídeo denominada Pantalla Primaria de Vuelo o Primary Flight Display (PFD). Por otra parte, otra pantalla denominada Navigation Display (ND) sustituía el Indicador de Dirección Horizontal (HSI) tradicional por un mapa móvil electrónico donde quedaba representada la ruta planificada en función de la situación real de la aeronave, las radioayudas circundantes y la información del radar meteorológico, todo ello bajo diferentes modos de representación -compás magnético, arco frontal, etc.-. Para los pilotos, siempre temerosos con la posibilidad de perderse fuera de la ruta planeada, poseer en el puesto de pilotaje esta pantalla de navegación les suponía incrementar enormemente su grado de conciencia situacional y, en consecuencia, la seguridad del vuelo (Sweetman, 1982).

${ }^{16}$ Thomson-CSF y Rockwell-Collins fueron las empresas que trabajaron con Airbus y Boeing respectivamente para dotar de los primeros sistemas EFIS a sus modelos de nueva generación (International, 1980).

${ }^{17}$ Los primeros modelos comerciales que introdujeron pantallas de vídeo como parte de su instrumentación electrónica de navegación fueron el Boeing B767 (1981), el Boeing B757 (1982) y el Airbus A310 (1982) (International, 1982; Sweetman, 1982).

${ }^{18}$ En 1980 ya eran públicos los prototipos finales de pantallas PFD y de Display de Navegación (International, 1980). La disposición de elementos del PDF y los modos de visualización del mapa móvil eran muy similares, pero existían ciertas diferencias en la simbología adoptada para la representación gráfica y textual de las escalas de velocidad, altitud, radioayudas, etc. El grafismo de los sistemas EFIS que adoptaron ambas compañías se ha ido replicando a lo largo del tiempo en sus modelos sin apenas cambios durante las últimas tres décadas. 

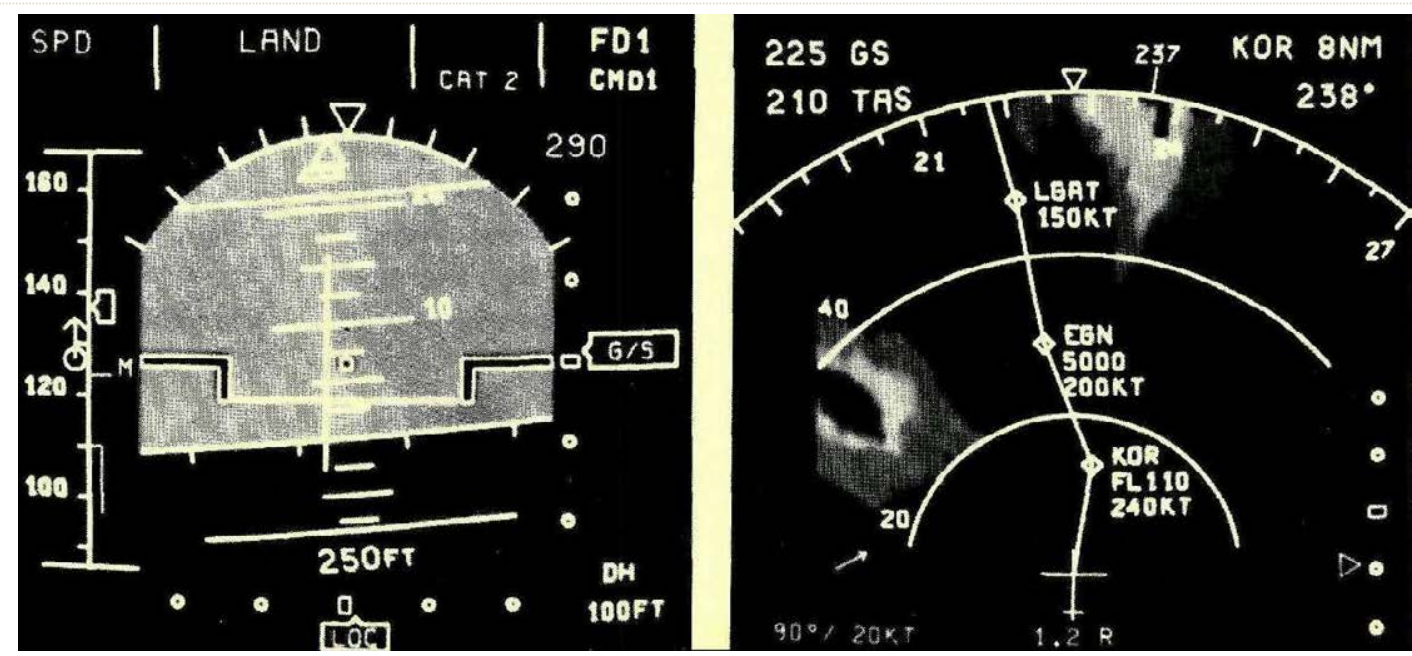

Figura 2-8: Prototipo de PFD y ND de Thomson-CSF propuesto para equipar al Airbus A310 (International, 1980).

\subsubsection{El papel pixelado}

Durante los últimos treinta años la apertura del sistema de posicionamiento global GPS para uso civil ${ }^{19}$ y la aparición de nuevos soportes tecnológicos, han permitido crear entornos apropiados para la presentación electrónica de cartas aeronáuticas en el puesto de pilotaje. En cuanto a los soportes gráficos, se abandona progresivamente la tecnología de pantallas de Tubo de Rayos Catódicos (CRT) a favor de las pantallas planas de tecnología de Transistor de Película Fina o Thin-Film Transistor (TFT) (Catelani et al., 2010). Con una luminosidad, definición y fiabilidad cada vez mayores, se están integrando con rapidez en la instrumentación de las grandes aeronaves comerciales, destacando como excelentes medios para la consulta de cartografía digital, coexistiendo plenamente con el uso de cartas tradicionales en papel de diferentes proveedores.

${ }^{19}$ En agosto de 1983, la tripulación de un Boeing 742 de Korean Air, en ruta desde Alaska hasta Seúl (vuelo KAL 007), cometió un grave error de navegación al fijar un rumbo equivocado. Este error llevó a la aeronave a internarse en dos ocasiones en territorio soviético restringido, a 550 kilómetros más al norte de la ruta prevista. En un momento dado, sobre la isla Moneron - mar de Japón-, dos cazas soviéticos Sujoi Su-15 abatieron al aparato coreano causando la muerte de las 249 personas a bordo entre pasajeros y tripulación. Cinco años antes otro avión de Korean Air (vuelo KAL 902) fue obligado a realizar un aterrizaje de emergencia sobre la Península de Kola tras desviarse de su ruta y ser alcanzado por el disparo de un caza interceptor soviético, falleciendo dos pasajeros por la descompresión explosiva provocada por el impacto del misil (Gollin y Allardyce, 1994).

Tras el grave suceso del vuelo KAL 007, el presidente norteamericano Ronald Reagan anunció en septiembre de 1983 que, una vez estuviese plenamente completado, el novedoso Sistema de Posicionamiento Global militar por satélite (GPS) estaría liberado y disponible para uso civil, en un intento de evitar errores similares de navegación en un futuro (Pace, 1995; Schroeer, 2000). 
Paralelamente a la mejora de las pantallas, a bordo es cada vez más habitual el uso a bordo de dispositivos para la gestión de información y de cartografía electrónica. Denominados genéricamente Maletines de Vuelo Electrónico o Electronic Flight Bag (EFB) (FAA, 2003a), estos dispositivos han sido ideados como plataforma de propósito general para reducir y sustituir completamente ${ }^{20}$, en determinados casos, el uso de papel en cabina manuales de operación de aeronaves, manual de la tripulación de vuelo operativo, cartas de navegación, etc.-. Su versatilidad hace que, además de poseer varias funciones aeronáuticas de utilidad que se sirven de la misma, como la generación de un plan de vuelo, cálculo de rumbos, velocidades, tiempos estimados, combustible y parámetros de despegue (Norris, 2001), sea posible la instalación de programas de navegación que permiten el seguimiento visual del vuelo sobre la cartografía, logrando el desplazamiento automático del mapa acorde con la posición real de la aeronave, de modo análogo a como sucede en los displays de navegación instrumental (ND).

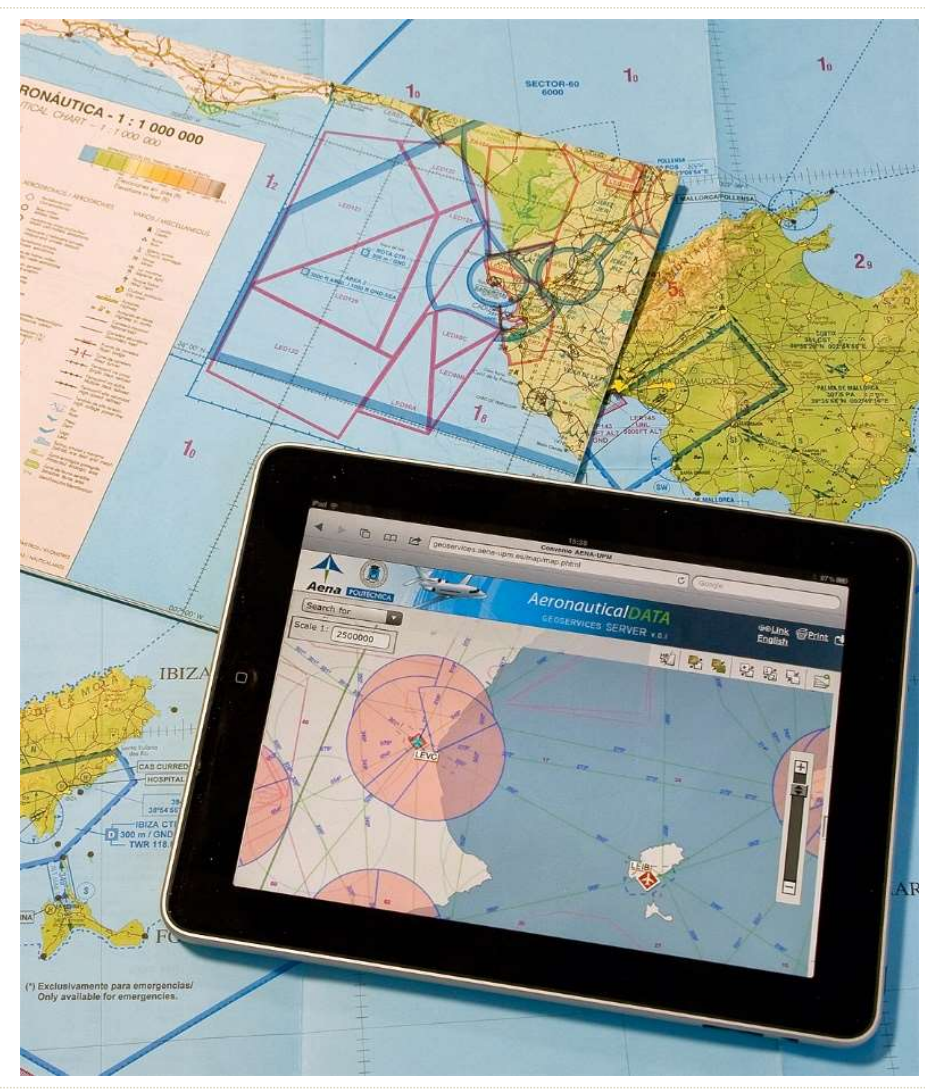

Figura 2-9: Cotejo de una hoja actual de la carta aeronáutica-OACI 1:500.000 publicada por Aena y su equivalente digital desplegado en un prototipo visor interoperable de cartografía aeronáutica on-line sobre un dispositivo electrónico portable iPad (Moya y Bernabé, 2011).

${ }^{20}$ Se estima que un iPad, cuyo peso se sitúa alrededor de los 700 gramos, es capaz de sustituir a unos 16 kilos 0 más de papel en cabina (PI, 2011). 
Otra evidente cualidad de muchos de los dispositivos electrónicos presentes hoy en día en la cabina de pilotaje es su portabilidad, de tal manera que permiten trabajar con ellos indistintamente dentro o fuera del avión, y además pueden ser utilizados en el día a día fuera del ámbito estrictamente aeronáutico como agenda, ordenador personal, etc. Es el caso de las pequeñas aeronaves con instrumentación más sencilla, en las que ya es común el uso de reducidos y asequibles dispositivos portátiles de tipo táctil -agendas electrónicas personales, tabletas, etc.- [Figura 2-9], extendiendo así el uso de las cartas aeronáuticas digitales a la aviación de negocios²1, deportiva y de ultraligeros, comenzando también a certificarse para el uso en la operativa de vuelos comerciales en distintas fases de vuelo (PI, 2011).

\subsubsection{Más allá de la propia realidad}

El término Realidad Aumentada (RA) hace referencia, dentro del campo de la investigación de metodologías informáticas, a la posibilidad de combinar el mundo real con datos generados por medio de un sistema informático (Azuma, 1997; Azuma et al., 2001). En otras palabras, es una técnica que presenta objetos que existen únicamente en un ordenador -objetos virtuales-como si estuviesen en el mundo real, de modo que cuando el punto de observación del usuario se mueve con respecto a la escena real, los objetos gráficos virtuales parecen conservar su posición, como ocurre con los objetos reales (You, Neuman, y Azuma, 1999). Los objetos virtuales pueden consistir en cualquier tipo de imagen elaborada por ordenador que se genere en el dispositivo de visualización y se presente como parte de la realidad aumentada: textos, figuras planas y tridimensionales, etc. (Dubois y Nigay, 2000). Este dispositivo en el ámbito aeronáutico se denomina Pantalla de Visualización Frontal o Head-Up Display (HUD) (R. B. Wood y Howells, 2001), y en su forma de construcción más sencilla consiste en una pieza angular de vidrio transparente que, colocada frente al piloto, funciona como divisor de haz que redirige hacia el piloto las imágenes virtuales generadas a través de un proyector; de este modo se permite al usuario visualizar el campo de visión exterior a la aeronave y la imagen virtual proyectada al mismo tiempo, con la vista enfocada constantemente al infinito (Nojima y Kajimoto, 2008).

En el ámbito concreto de la aviación, la tecnología de información visual aumentativa comenzó a desarrollarse de forma práctica a finales de los años 50 del siglo pasado. La idea era lograr que los pilotos de aviones militares dispusieran de las marcas gráficas del horizonte artificial de la Pantalla Primaria de Vuelo o Primary Flight Display (PFD) sobre la escena real sin tener que bajar constantemente la cabeza para revisar los instrumentos. En algunas de las primeras pruebas realizadas (Lambert, 1964) se concluyó que el tiempo medio para adquirir los estímulos visuales requeridos era mucho menor que cuando se divide la exploración entre la escena externa y el panel de instrumentos. En forma de ventaja inferida también se afirmó que durante la aproximación, el piloto puede obtener una pre-lectura de las dimensiones de la pista y de su posición con respecto a ésta antes incluso de tenerla visualmente disponible.

${ }^{21}$ En 2011 la FAA autorizó a la compañía Executive Jet Management (EJM) a reemplazar las cartas de aproximación en formato papel por la aplicación Jeppesen's Mobile TC de cartografía digital sobre una tabla iPad de Apple (FAA, 2011a). 
El tránsito del ámbito militar al civil no resultó ser inmediato, al existir diferentes problemas tecnológicos y de instalación a bordo, unos costes de desarrollo muy elevados y cierta confusión en las certificaciones que serían necesarias. Wolfe y Sleight (1968). Se constataba que, además del temor a que la falta de experiencia de las tripulaciones supusiera un evidente factor de accidente, la industria tardó en tener claro cuál era el rol que podía llegar a adquirir los sistemas HUD en la aviación civil.

Sólo en fechas relativamente recientes ${ }^{22}$ las firmas comerciales han decidido proporcionar en sus modelos más vendidos este tipo de sistemas, al menos como equipamiento opcional. Para Albert (2010) el uso práctico parece confirmar que el uso de los sistemas HUD es una manera cómoda de estabilizar el avión durante la fase de aproximación y aterrizaje (Albert, 2010); sin embargo Ercoline (2000) y Crawford y Neal (2006) advierten que aun teniendo muchas características excelentes y ampliamente documentadas en la literatura científica, este artilugio no es intuitivo, requiriendo práctica y formación continua de las tripulaciones en su uso.

En la [Figura 2-10] se observa una aproximación en corta final ${ }^{23}$ a través de un HUD en condiciones atmosféricas ideales. Cuando se atraviesan nubes bajas, las marcas fiduciales visualizadas a través del dispositivo ayudan al piloto a mantener la trayectoria del avión estabilizada sobre la senda de descenso, aun sin contacto visual con la pista. Precisamente la evolución tecnológica de este sistema visual de información y ayuda al aterrizaje ${ }^{24}$ se concentra en tratar de modificar la vista natural exterior para garantizar la visión de la pista y del terreno circundante en todo momento, independientemente de la cobertura de nubes. Para ello el concepto de HeadUp Display pasa a ser el de Head-Down Display o de Cabeza Baja, ya que la visión del exterior se realiza a través de pantallas de vídeo en las que, de igual modo, también se replica la representación del horizonte artificial (Liu y Wen, 2004; L. J. Prinzel et al., 2004). La señal de vídeo exterior puede también estar basada en distintos sensores -radares reflectivos, cámaras térmicas, etc.- ideados para penetrar en los fenómenos meteorológicos, tales como la oscuridad, niebla, neblina, Iluvia y nieve (L. J. Prinzel y Kramer, 2009).

${ }^{22}$ En 1998 Boeing anuncia que la nueva generación de su modelo de medio alcance B737 Next-generation puede equiparse con un sistema Head-up Display (Angers, 2009), posibilidad que comparte el Boeing B787 lanzado comercialmente en el año 2011 (S. Clark y Trampus, 2011). En el caso de Airbus, es desde el año 2002 cuando extiende la posibilidad de equipar con este dispositivo de visualización a su gama de modelos. A partir de 2007, se comienza a certificar en la familia A318/19/20 y A380 una nueva generación de HUD denominada MPP -MultiProgramme Project- HUD. En el ámbito civil, este sistema es el primero en estar basado exclusivamente en tecnología digital, lo que le proporciona una mayor luminosidad, nitidez, y una reducción en su peso, volumen y consumo energético (Albert, 2010).

${ }^{23}$ El término aeronáutico "corta final" se emplea para concretar la situación de una aeronave en la última parte del tramo final, cuando se encuentra próxima a aterrizar.

${ }^{24}$ Según un análisis de la Flight Safety Foundation, aproximadamente el 75\% de los accidentes ocurridos en la aproximación 0 en el aterrizaje se han producido en aeropuertos cuyos sistemas de ayuda al aterrizaje instrumental no han sido utilizados o bien no están disponibles (Theunissen et al., 2005), por lo que los sistemas HUD y derivados pueden aportar una mayor seguridad en el aterrizaje en aeropuertos con una orografía complicada o bien que no dispongan de tecnologías de ayuda al aterrizaje automático tipo ILS. 


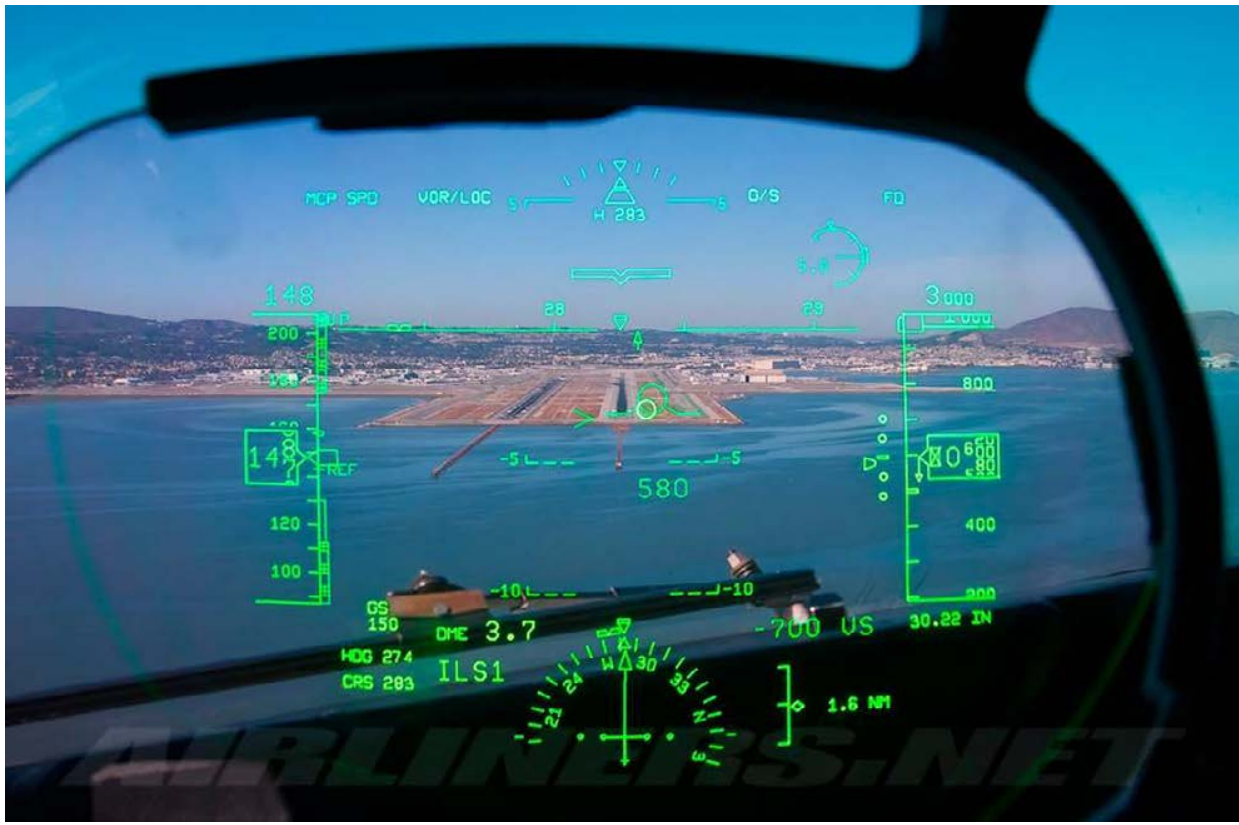

Figura 2-10: Visualización del Primary Flight Display (PFD) de un Boeing B737-800 en aproximación al Aeropuerto Internacional de San Francisco a través de un dispositivo Head-up Display (HUD) (Brett B. Despain, Airliners.net).

Su uso aumenta la visión normal haciendo visible algunas de las características del territorio aun en condiciones de baja visibilidad -visión aumentativa-, siendo conocidos estos sistemas como Sistemas de Visión Mejorada (EVS) (Theunissen et al., 2005). La imagen real derivada de los sensores asociados, cuyas características hacen posible su penetración más allá de cualquier condición de luz y cobertura meteorológica adversa, usualmente puede ser también procesada en tiempo real por medio de diferentes algoritmos, en orden a detectar digitalmente el borde de la pista u objetos que puedan suponer un obstáculo en las inmediaciones de la senda de descenso (L.J. Prinzel, Kramer, Arthur, Bailey, y R., 2005).

Una variación de este concepto se encuentra en los Sistemas de Visión Sintética (SVS), en los cuales se sustituye directamente la visión exterior -sea aumentativa o no- por una representación virtual del territorio [Figura 2-11]. En (FAA, 2005) se define la Visión Sintética (SV) como una imagen generada por ordenador de la escena orográfica exterior vista desde la perspectiva de la cabina de mando, la cual es derivada a partir de la actitud de la aeronave, datos de alta precisión de los sistemas de navegación y una base de datos del terreno, obstáculos y características humanas relevantes, siendo el SVS una manera electrónica de visualizar un modelo detallado de la realidad circundante en el puesto de pilotaje ${ }^{25}$. La visión sintética es una tecnología que potencialmente

${ }^{25}$ El sistema de visión sintética se compone de cuatro elementos: una visión mejorada e intuitiva, la detección y advertencia visual de riesgos, monitorización integral y alerta, y navegación con guiado de precisión (L. J. Prinzel y Kramer, 2009). 
puede eliminar las condiciones de baja visibilidad ${ }^{26}$ como factor causal de accidentes de aeronaves civiles, con la posibilidad añadida de poder replicar sus beneficios en las operaciones de vuelo habituales, independientemente de las condiciones de visibilidad exterior (Bailey et al., 2006).

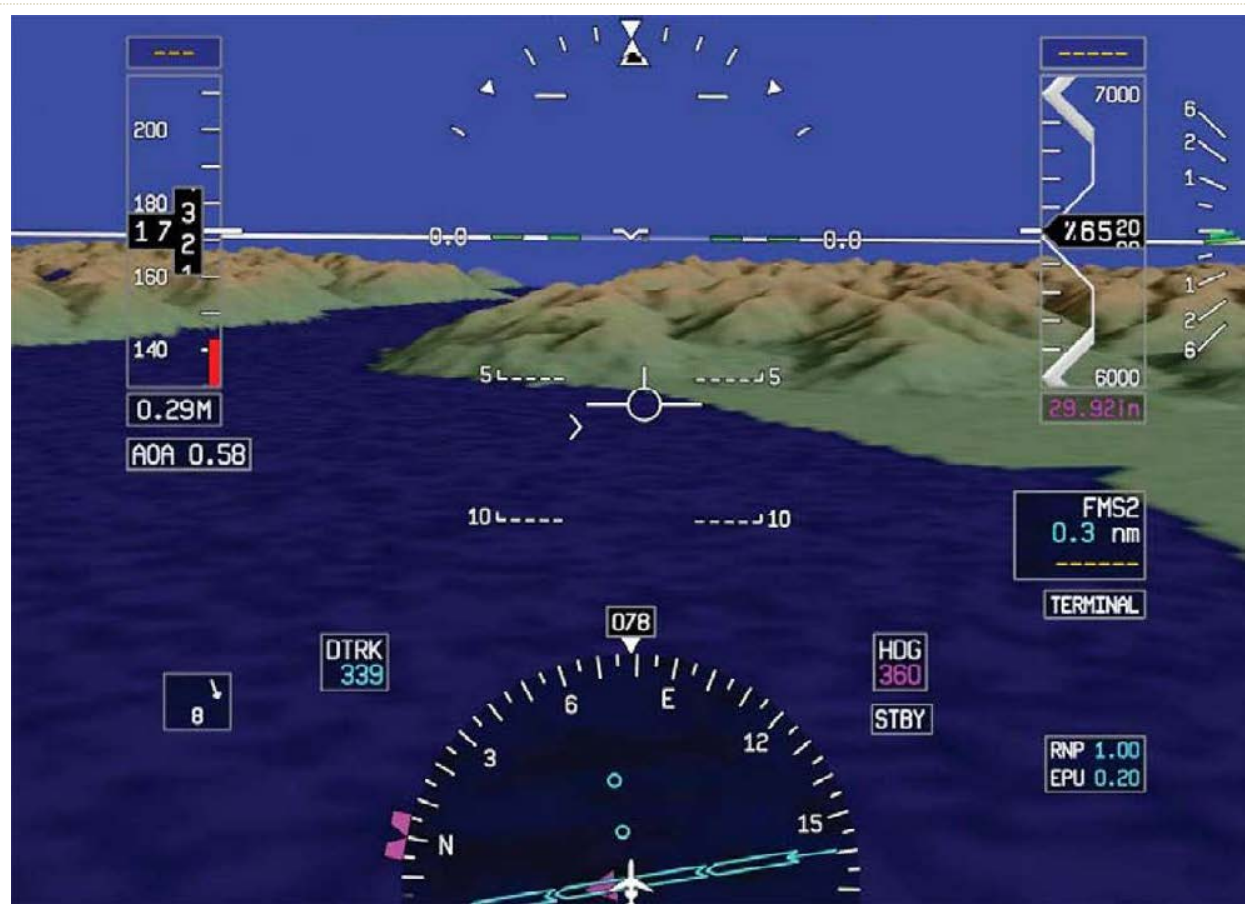

Figura 2-11: Sistema de Visión Sintética asociada a la pantalla de vuelo primario (SV-PFD dispuesto a bordo de una aeronave Gulfstream (Ververs et al., 2011).

Con la aportación de una representación tridimensional virtual, los pilotos deben ser capaces de determinar su posición con relación a puntos de referencia esenciales, tales como la pista de aterrizaje, el terreno y los obstáculos circundantes -torres de comunicaciones y de alta tensión-. Por analogía con los equipos multifuncionales y mapas móviles comunes, también es posible la representación de otras características posicionales, tales como pequeños lagos, ríos, carreteras, vías de tren, etc. Sin embargo su representación no debe impedir en ningún caso la visibilidad de la información primaria (FAA, 2005).

Este sistema aumentativo no pretende sustituir a las cartas de aproximación tradicionales; cuando se decide incorporar la visión de la tridimensionalidad del terreno, ésta debe correlacionarse en lo posible con la información aportada por las correspondientes cartas de aproximación (FAA, 2005). La tendencia actual considera a los sistemas EVS y SVS complementarios entre sí (L.J. Prinzel et al., 2005; Theunissen et al., 2005; Theunissen, Roefs, Rademaker, y Etherington, 2004), estando en continua evaluación tanto las estrategias de integración en las distintas pantallas propuestas por diferentes autores como la propia mejora del rendimiento, el aumento

${ }^{26}$ Las Condiciones Meteorológicas Instrumentales (IMC), los vuelos de baja visibilidad y el vuelo nocturno son las tres áreas de operación en las que se producen la mayoría de accidentes fatales en la aviación general (FAA, 2005). 
de la conciencia situacional y la disminución de la carga de trabajo en cabina conseguida a través de su uso (Bailey et al., 2006; L. J. Prinzel y Kramer, 2009).

\subsection{LA NAVEGACIÓN AÉREA}

El Diccionario de la Real Academia Española presenta como primera definición del término navegar -del latín navigare- la de "viajar en un buque o en otra embarcación, generalmente por mar" (RAE, 2001). Históricamente los artífices de estos viajes eran los navegantes (Hofmann-Wellenhof, Legat, y Wieser, 2003); a lo largo del siglo XX la voz asociada a los navegantes "nauta" - del latín nauta, y esta a su vez del griego vaútnc, nautes- ha entrado a formar parte de derivados y compuestos -como astronauta, internauta, etc.- precisamente por extensión del concepto original de navegación. Usualmente el término navegación es utilizado en el lenguaje cuando el desplazamiento se realiza por un medio adverso, no conocido o hasta cierto punto peligroso. Coloquialmente no "navegamos" por carretera pero sí por desiertos, océanos y cielos. La razón última de esta distinción, más allá de razones etimológicas, está en la necesidad de disponer de referencias visuales o de claves de ubicación para lograr trasladarse de una forma segura y sin extraviarse.

Dejada atrás la época de los grandes descubrimientos, la navegación ya no se supedita al mar en exclusiva, entendiéndose como el proceso de desplazarse en un vehículo de un punto a otro a través de un medio cualquiera, además de las técnicas necesarias para conseguirlo (Sáez, 2012). Cuando el vehículo considerado es una aeronave en vuelo, se habla entonces de navegación aérea (Calvo, 2000). Las velocidades relativamente altas con las cuales se desplazan las aeronaves, la limitación de combustible, y el riesgo constante de colisión con los obstáculos del terreno o con otros usuarios del espacio aéreo hacen que la navegación aérea presente perfiles críticos singulares (Sáez, 2012). Además, el medio por el que se desplaza una aeronave -la atmósferaes extremadamente cambiante y dinámico (B. González, 2009; J. Martín, Grimalt, y Mauri, 1996), lo cual resulta una importante dificultad añadida. En consecuencia, una definición completa de navegación aérea sería la de "el arte de conocer en todo momento la posición de la aeronave y la trayectoria más adecuada y segura para su transporte, en presencia de otras aeronaves" (Pérez, 2003).

Respecto a métodos de navegación aérea, se realiza una clara distinción entre métodos autónomos y asistidos, dependiendo respectivamente de si el piloto necesita o no de instalaciones exteriores a la aeronave para poder guiarse (Calvo, 2000). Esta división es clave para distintos aspectos del actual sistema de navegación, incluidos los que atañen a la propia cartografía aeronáutica: los elementos que se disponen en ella, la forma de simbolizarlos, y otras características específicas como la escala, la proyección, etc. diferirán enormemente, dependiendo de si la serie cartográfica está dedicada a una u otra forma de navegación (Moya y Bernabé, 2011). 


\subsubsection{La determinación de la posición de una aeronave}

El concepto fundamental para la navegación es el posicionamiento (Calvo, 2000; Hofmann-Wellenhof et al., 2003). Conocida su posición inicial, la determinación constante de la situación física de un avión vendrá determinada por su velocidad y dirección de desplazamiento (Adsuar, 2001, 2007). Según Pérez (2003), los sistemas o marcos de referencia -espaciales y temporales- necesarios para determinar inequívocamente la posición de una aeronave en vuelo son:

- Un sistema espacial de referencia global que fije la posición y velocidad del avión sobre la superficie terrestre ${ }^{27}$, definido por la red geográfica de meridianos y paralelos.

- Un sistema espacial de referencia local que posibilite conocer la actitud de la aeronave ${ }^{28}$, definido por el triedro formado por el eje de cabeceo, eje de alabeo y eje de guiñada [Figura 2-12].

- Un sistema temporal de referencia global -al ser la velocidad una función del tiempo- definido por el Tiempo Universal Coordinado (UTC), que es el tiempo del huso o zona horaria de referencia, respecto a la cual se calculan todas las restantes zonas horarias del mundo.

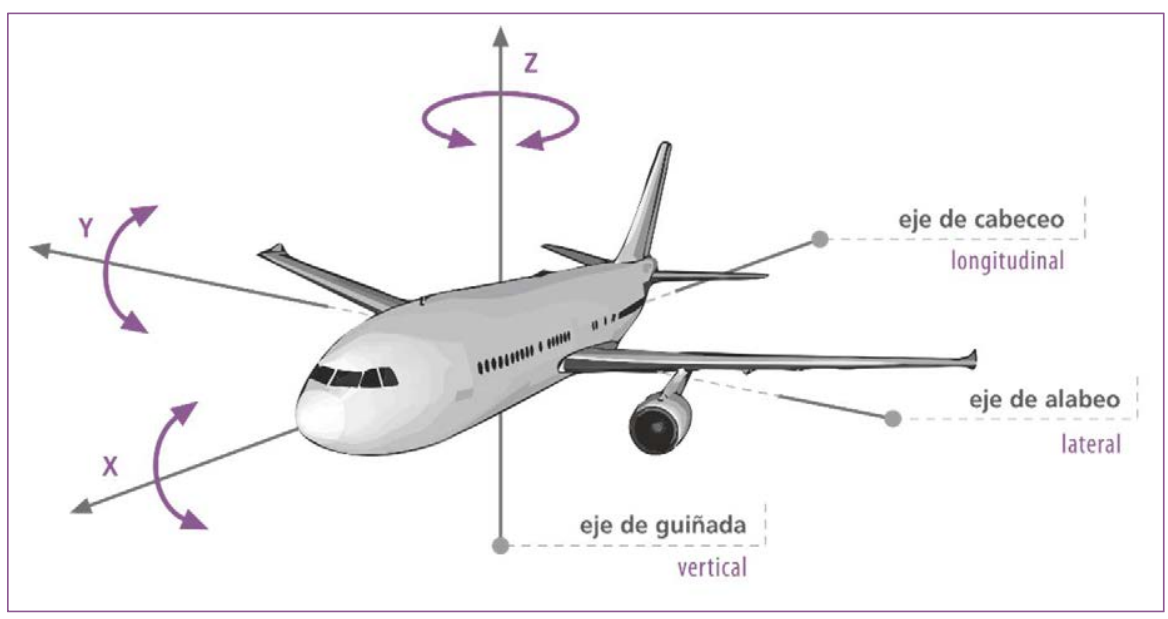

Figura 2-12: Ejes implicados en la determinación de la actitud de una aeronave (Moya y Bernabé, 2011).

${ }^{27}$ Hasta una altura atmosférica determinada, a efectos prácticos se considera que la aeronave se desplaza sobre la superficie terrestre. En consecuencia el sistema de referencia consistirá en ejes ligados a la Tierra. En el caso de una nave espacial, el sistema de referencia se apoyará en estrellas "fijas" del Universo (Corbasí, 1998).

${ }^{28}$ La actitud de un avión se refiere a la orientación del mismo en el espacio -el cabeceo del morro, la inclinación de las alas, etc.- (Sáez y Portillo, 2003; Salazar, 2008). 


\subsubsection{Los métodos de navegación autónomos}

La navegación visual se basa en la estimación de la posición por la simple observación de referencias físicas en el terreno -montañas, costas, ríos, carreteras, etc.--, siendo estas conocidas o localizadas en una carta o un mapa (Adsuar, 2001). Navegar en condiciones de vuelo visual requiere de unas condiciones climatológicas y ambientales adecuadas, que permitan en lo posible el contacto visual con el terreno. La pérdida de referencias visuales del terreno, sin contar con otro sistema de navegación alternativo, pondría al piloto en una situación de alto riesgo.

Alternativamente a la utilización de referencias visuales en el terreno, es posible hacer uso de cuerpos celestes como el Sol, la Luna y las estrellas. A la determinación de la posición por observación de la situación relativa de estos elementos se le denomina navegación astronómica (Mederos, 2008). Históricamente utilizada en la navegación marítima (Sellés, 2000), en el caso de la navegación aérea actual se encuentra prácticamente en desuso (Arán y Aragoneses, 1983).

Añadiendo a la navegación visual algunos instrumentos sencillos -anemómetro y reloj ${ }^{29}$-, se accede a una técnica más elaborada, denominada navegación a estima. Esta consiste en la estimación de la posición en un instante dado teniendo en cuenta el rumbo -dirección magnética- tomado, la velocidad media mantenida y el tiempo transcurrido desde el paso por la última posición conocida (Adsuar, 2001; Calvo, 2000).

En condiciones de viento en cara o en cola, la componente del rumbo -dirección a la que señala físicamente el morro del avión- y la derrota -proyección sobre la superficie terrestre del desplazamiento descrito por el avión en el aire- coinciden. Sin embargo, lo habitual es que la dirección del viento sea lateral. En esa situación la trayectoria real de la aeronave varía respecto de la prevista, de tal forma que en vez del rumbo -dirección a la que señala el morro del avión-, lo que realmente se sigue es una dirección determinada por un ángulo denominado de deriva ${ }^{30}$, formado por el rumbo y la derrota [Figura 2-13]. Dicha deriva se calcula a partir del rumbo magnético y la velocidad indicada por el anemómetro de la aeronave, junto con la dirección e intensidad del viento ${ }^{31}$. En estas condiciones de viento lateral, el avión mantendrá su eje longitudinal en rumbo magnético $\beta$, pero seguirá una trayectoria distinta, definida por el vector velocidad sobre el suelo -derrota- que es resultante del vector velocidad y del vector viento.

${ }^{29}$ El anemómetro aeronáutico o tubo Pitot se sirve de la presión atmosférica y de la presión de impacto de aire para estimar la velocidad de la aeronave (Harris, 2003). A su vez, el uso del reloj permite al piloto cronometrar distintos tiempos de paso.

${ }^{30}$ El ángulo de deriva será tanto mayor cuanto más perpendicularmente incida el viento sobre la aeronave, y tanto menor cuanto mayor sea la velocidad del avión.

${ }^{31}$ El principal problema consiste precisamente en cómo determinar adecuadamente la intensidad y dirección del viento para corregir la velocidad medida por el anemómetro y obtener así la ruta real (Adsuar, 2007). 


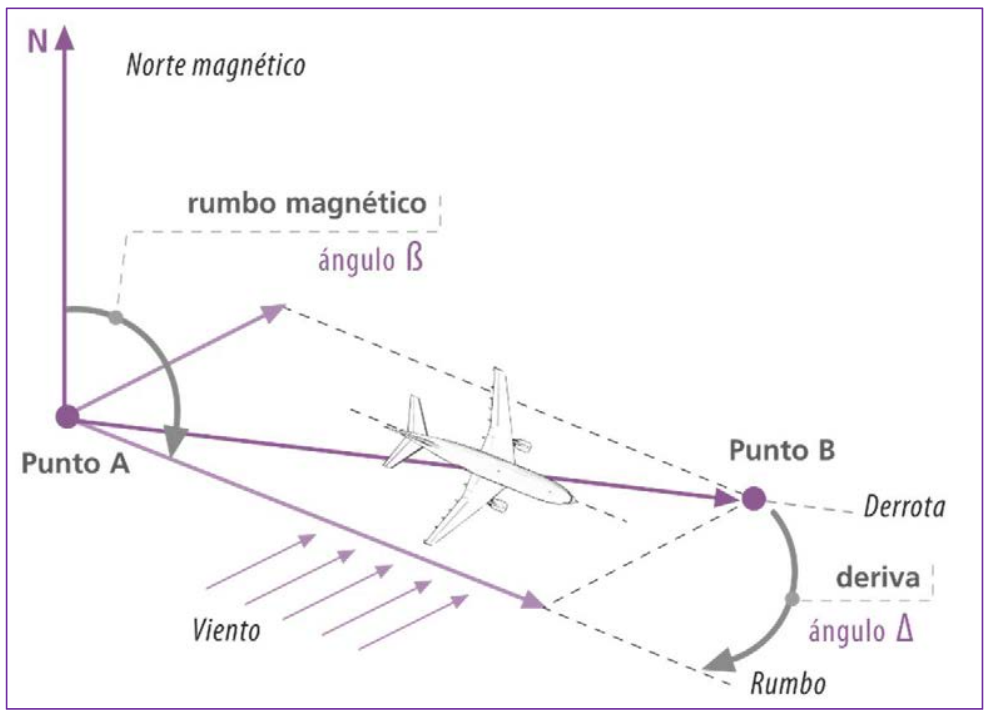

Figura 2-13: Componentes del ángulo de deriva en una navegación con viento cruzado (figura propia a partir de Pérez (2003)).

Como la acción del viento lateral puede suponer un desvío significativo ${ }^{32}$, es necesario comprobar periódicamente -cuando la cobertura de las nubes así lo permita- la posición real a través de la identificación visual de elementos geográficos en el terreno, cotejando estos con su representación en la cartografía (Adsuar, 2001).

El más reciente de los métodos de navegación autónomos -las primeras experiencias datan de mediados del siglo XX- es la navegación inercial (Britting, 1971; Madigan y Canniff, 1969). Se basa en la medición de las aceleraciones que sufre la aeronave, mediante unos sensores dispuestos sobre una plataforma giroestabilizada -estabilizada giroscópicamente- en la dirección de los tres ejes del avión (Lawrence, 1998). Conocidas las coordenadas del punto inicial del vuelo, si la aceleración detectada en cada uno de los ejes se integra matemáticamente a lo largo del tiempo, se obtiene la velocidad de la aeronave respecto al suelo según cada uno de los ejes. De forma análoga, integrando las componentes del vector velocidad según los ejes con respecto al tiempo, se obtendrá la distancia recorrida según esas direcciones (Biezad, 1999; Rogers, 2003). Sumando a las coordenadas iniciales el incremento de posición calculado, se obtiene una nueva posición, y así sucesivamente (Peña, 2000).

${ }^{32}$ Como se muestra en la [Figura 2-13], para ir al punto B con viento lateral, se debe volar con un rumbo magnético $\beta$ tal que compense la componente del viento. 


\subsubsection{Los métodos de navegación asistidos}

Cuando el piloto se apoya en instalaciones exteriores a la aeronave para guiar el avión, se hablará de navegación asistida. Estas infraestructuras reciben el nombre de ayudas a la navegación, las cuales pasan a ser sucintamente descritas a continuación.

\section{a) Ayudas radiales}

Para guiar horizontalmente una aeronave a través de su instrumentación se utiliza un tipo de ayudas denominadas radiales. Primigeniamente se utilizaba a bordo un equipo denominado radiogoniómetro, a través del cual era posible detectar y plasmar sobre una cartografía básica la dirección de la que proceden señales de radio. Éstas podían ser emitidas desde estaciones específicas para la navegación aérea -denominadas NDB o Radiofaros No Direccionales ${ }^{33}$ - o bien desde emisoras de radiodifusión normales. En los sistemas más antiguos (RDF) el piloto giraba manualmente la antena del equipo ${ }^{34}$, hasta que el indicador de señal marcaba cero; siguiendo esta marcación se llegaba al foco emisor en tierra (Pérez, 2003).

Añadiendo un servomecanismo y un comparador, se consiguió una búsqueda e indicación angular automática. Este equipo se denomina Buscador Automático de Dirección o ADF, el cual de una forma automática indica la dirección a la estación NDB sobre un radiocompás por medio de una aguja (Corbasí, 1998). Al poseer cada estación NDB una frecuencia asignada y un código de letras para su identificación en la cartografía, es posible seleccionar en el propio equipo a bordo la frecuencia de la estación NDB en cuestión para obtener inmediatamente su dirección ${ }^{35}$.

A posteriori se implantaron los Radiofaros Omnidireccionales VHF -más conocidos como VOR-. Utilizados por las aeronaves para seguir en vuelo una ruta preestablecida, en la actualidad forman parte del sistema más extendido en el mundo para la navegación en rutas de corto y medio alcance (Sáez y Portillo, 2003). La antena de la estación VOR emite una señal de radiofrecuencia VHF en todas direcciones, que es recibida por el equipo VOR de cualquier aeronave que se encuentre dentro del rango de alcance -máximo unos 240 km- y tenga sintonizada la frecuencia de dicha estación.

${ }^{33}$ Se dice que el NDB no es direccional porque, por método de emisión, solo indica la dirección en la que se encuentra la estación, pero no da idea de la desviación que la aeronave sufre sobre una determinada ruta.

${ }^{34}$ La manipulación de la antena abstraía al piloto de otros aspectos del vuelo, y por otro lado el indicador marca cero en una posición y en la opuesta -en consecuencia se corre cierto riesgo de equivocarse $180^{\circ}$ si no se tiene una idea clara de la posición de la estación en tierra- (Pérez, 2003).

${ }^{35}$ Desde el año 2005, el Plan Europeo de Radionavegación (ERPN) prevé la retirada paulatina de los radiofaros no direccionales NDB (Calvo, 2000). 
La estación ofrece información referida a los 360 radiales $^{36}$ en los que se divide su emisión, los cuales están referidos al Norte magnético. De forma análoga a las estaciones NDB, un VOR viene determinado por un nombre, un código identificativo de tres letras y una frecuencia concreta; el piloto selecciona en su equipo la frecuencia de la estación VOR de su interés y recibe la marcación de la estación sobre un radiocompás -empleado para conocer el radial en el que se encuentra la fuente emisora de la señal- (Arán y Aragoneses, 1983; Corbasí, 1998).

Igualmente, al ser un emisor direccional, ofrece información de la desviación que sufre la aeronave respecto del radial de referencia que haya seleccionado el piloto, así como de la posición relativa de la estación. Esta es la gran ventaja del VOR frente al antiguo ADF/NDB, ya que al intentar seguir este último con viento lateral [Figura 2-14], al no darnos más que la marcación a la estación sin información alguna de la desviación -ayuda no direccional-, nos hace volar siguiendo una curva en lugar de una línea recta, que es la que seguiríamos en teoría al volar encima del radial seleccionado (Pérez, 2003).

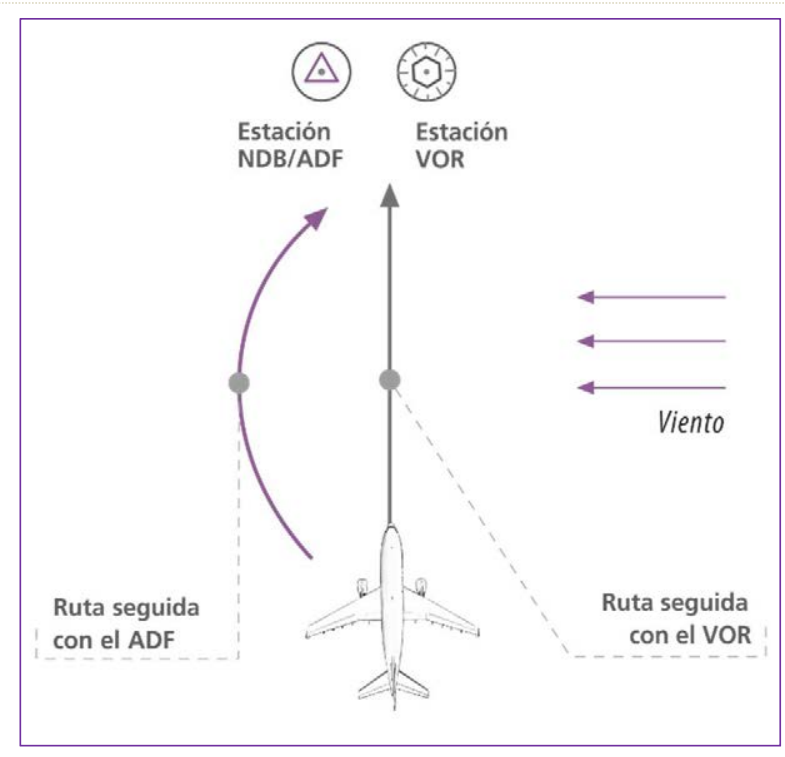

Figura 2-14: Distintas trayectorias con viento lateral, al utilizar un equipo NDB/ADF o una radioayuda VOR, respectivamente (figura propia a partir de Pérez (2003)).

Usualmente a cada estación VOR se le asocia un equipo DME o Equipo de Medida de Distancia -cuando esto ocurre la estación se denomina VOR/DME-, por lo que el piloto recibe la información del radial sobre el que se encuentra -referido al VOR-y la distancia al mismo, consiguiendo una identificación muy precisa de su posición.

${ }^{36}$ Los VOR emiten parte de su señal de forma variable, cambiando su fase según la dirección en la que sea emitida, lo que a efectos prácticos permite dividir el espacio en 360 sectores alrededor de la antena. Podemos así visualizar una antena VOR como el punto desde el cual parten 360 líneas de dirección -denominadas radiales- que nos van a permitir medir nuestra posición con respecto a dicho punto como un azimut o ángulo respecto al Norte magnético. 
La información acerca de la distancia es presentada en millas náuticas ${ }^{37}$. En la mayoría de las aeronaves suele visualizarse en el mismo instrumento que da información de la posición del avión respecto a la estación VOR, denominado HSI o Indicador de Situación Horizontal (Harris, 2003).

Las radioayudas VOR, junto con el sistema DME, constituyen los vértices de las líneas poligonales que determinan las aerovías o pasillos de navegación a gran altura que aparecen en las cartas de navegación aérea. El conjunto de aerovías constituye una densa red de rutas aéreas de tal forma que sus tramos pueden ser recorridos de una estación VOR a otra [Figura 2-15].

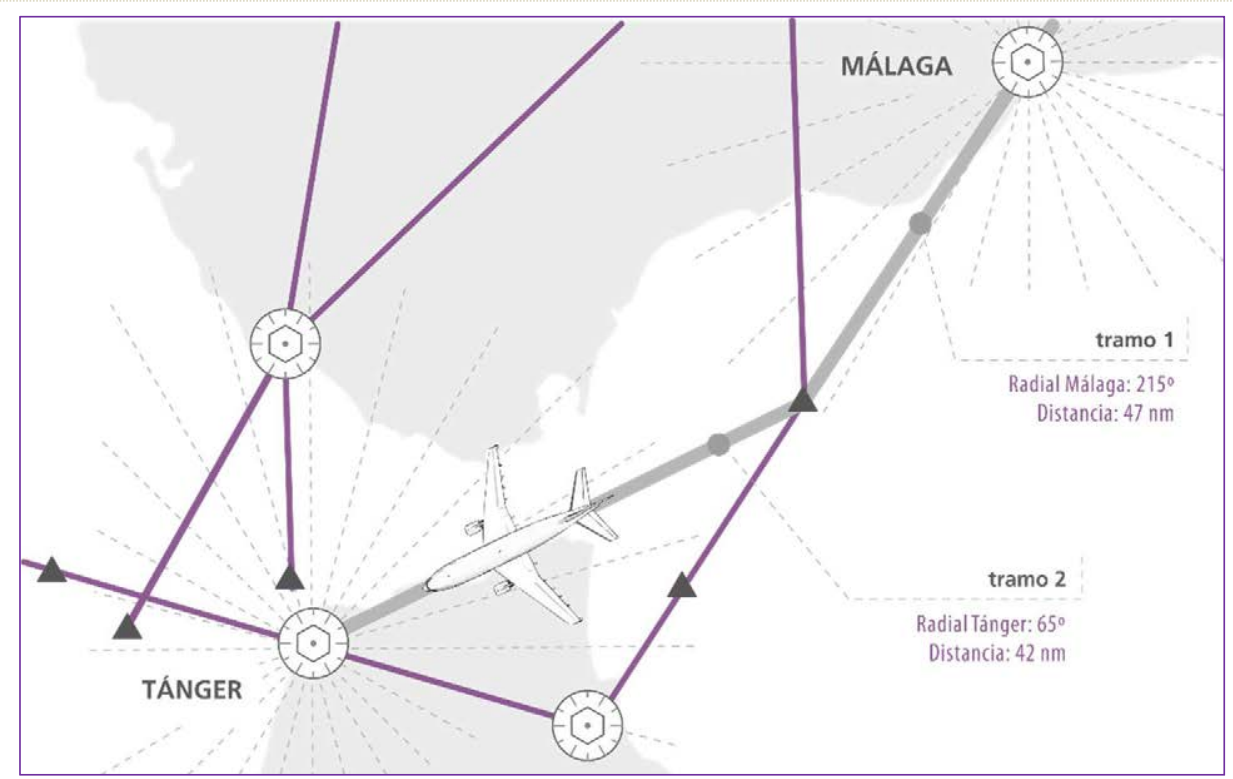

Figura 2-15: Ejemplo de navegación radial asistida con estaciones VOR/DME (Moya y Bernabé, 2011).

Además de servir para definir los tramos de las aerovías, existen también estaciones VOR que emiten con menor potencia, y que sirven de ayuda a la navegación en las trayectorias de despegue y aterrizaje en las proximidades de los aeropuertos, denominándose en este caso VORT o VORTerminal. A su vez, los aviones militares utilizan, junto con el DME, una ayuda similar a la del VOR. Se denomina Navegación Aérea Táctica o TACAN y su parte DME de medición de distancias puede ser utilizada por las aeronaves civiles. En ocasiones, la estación VOR y la TACAN son instaladas en combinación en el mismo punto, denominándose entonces VORTAC (Calvo, 2000; Corbasí, 1998; Pérez, 2003).

${ }^{37}$ Es importante tener en cuenta que la distancia medida por el DME es la distancia real en línea recta entre el avión y la estación, y que por tanto para una posición de latitud y longitud fijada, ésta variará dependiendo de la altitud a la que se encuentre la aeronave. 
b) Ayudas a larga distancia

Si bien las ayudas ADF y VOR/DME llevan ya establecidas durante décadas como base para la navegación aérea de corta y media distancia, a lo largo de la historia también han existido diferentes intentos de crear un sistema de navegación de larga distancia, por ejemplo entre continentes separados por grandes océanos en los que es imposible establecer radioayudas convencionales, y que lograse su implantación mundial de forma generalizada. Son el grupo de sistemas de ayuda a la navegación de larga distancia denominados hiperbólicos como el sistema DECCA, el LORAN y el OMEGA-, los cuales están basados en la medida de la diferencia en el tiempo de llegada al avión de las ondas electromagnéticas procedentes de tres o más transmisores (Calvo, 2000; Corbasí, 1998; Peña, 2000).

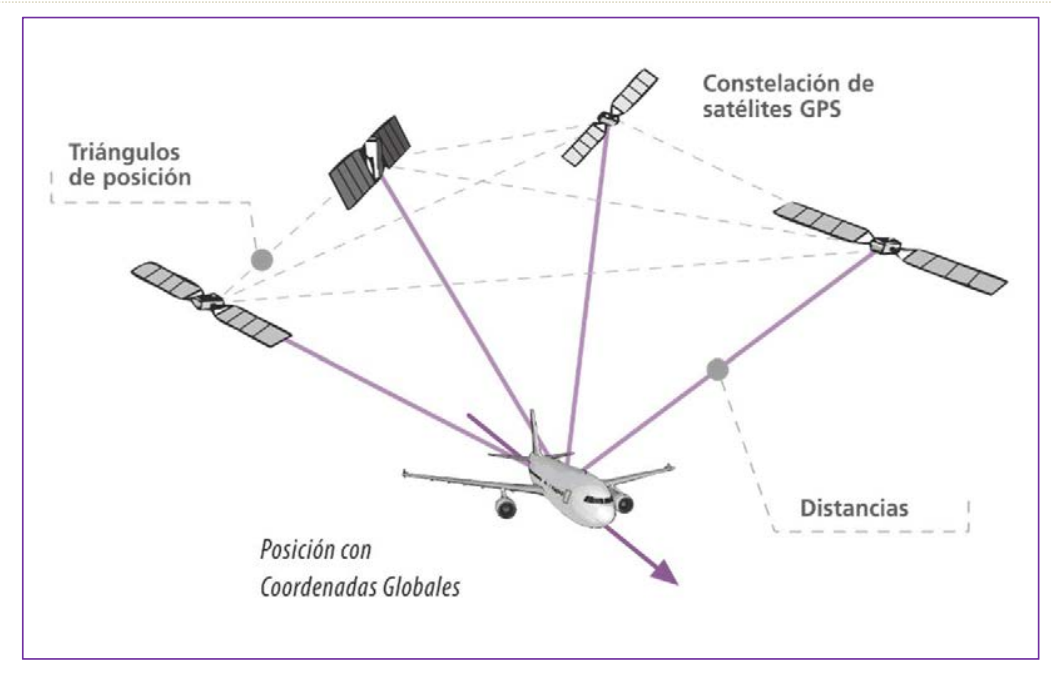

Figura 2-16: Esquema de triangulación de la red de satélites GPS para el posicionamiento tridimensional de una aeronave (Moya y Bernabé, 2011).

A mediados de los años ochenta, las ayudas a la navegación a larga distancia sufrieron un salto cualitativo cuando se permitió a la aviación civil el uso - hasta entonces restringido al ámbito militar- del Sistema de Posicionamiento Global GPS-NAVSTAR ${ }^{38}$ (Pace, 1995; Schroeer, 2000). De iniciativa estadounidense ${ }^{39}$, está basado

${ }^{38}$ La constelación de satélites GPS, compuesta por 24 satélites en órbita sobre el globo, posee trayectorias sincronizadas para envolver toda la superficie terrestre desde una órbita geoestacionaria situada a 20.200 kilómetros de altitud, garantizando así que desde cualquier punto de la Tierra se pueda observar simultáneamente cuatro de ellos (Núñez-García, Valbuena, y Velasco, 1992).

39 Junto al sistema GPS, se encuentra operativo un sistema análogo de posicionamiento por satélite de iniciativa rusa denominado GLONASS (Corbasí, 1998; Núñez-García et al., 1992). A su vez, la Unión Europea ultima su propio sistema de navegación global denominado Galileo (De Mateo, 2004; Hansen y Wouters, 2012). 
en la medida de distancias desde la aeronave a una base de tres o más satélites de una red de satélites artificiales [Figura 2-16]. El receptor GPS utilizado localiza automáticamente como mínimo tres satélites de la red ${ }^{40}$, de los que recibe unas señales que portan cierta información acerca de la posición y reloj interno de cada uno de ellos. A partir de estos datos, el aparato sincroniza el propio reloj del GPS y calcula el retardo de las señales; o lo que es lo mismo, la distancia a cada satélite del que se reciba señal. Las distancias calculadas se pueden considerar radios de esferas ficticias con centro en los propios satélites, cuya posición también es conocida; por tanto la posición de la aeronave se determina por intersección de tantas esferas como satélites (De Mateo, 2004; Dixon y Harris, 2004).

Conocidas las distancias, se puede determinar fácilmente la propia posición relativa respecto a los satélites, y conociendo además las coordenadas o posición de cada uno de ellos por la señal que emiten, se obtiene la posición absoluta o coordenadas reales de la aeronave. En la aviación comercial los aviones suelen ir equipados con uno o dos sistemas GPS, combinados con sistemas inerciales para la determinación ponderada de la posición (Arán y Aragoneses, 1983; Harris, 2003).

\section{c) Ayudas al aterrizaje}

Además de las ayudas radioeléctricas descritas ideadas para la navegación de aeronaves a medias y largas distancias, también se han establecido distintos sistemas y ayudas que aseguren en lo posible la seguridad de los aterrizajes, ya que no siempre es posible disponer de unas condiciones óptimas de visibilidad.

Un sistema especial empleado para el guiado de aeronaves en las áreas terminales de los aeropuertos es el sistema RADAR, cuyo acrónimo significa Detección y Medición de Distancias por Radio (Lownsborough y Calcutt, 1993). En la navegación por RADAR un controlador aéreo en tierra sigue la trayectoria de las aeronaves que transitan por el espacio aéreo de su responsabilidad a través de una pantalla ${ }^{41}$, lo que le permite comunicarse de forma oral mediante radiocomunicación con cualquiera de ellas y proporcionar a las tripulaciones en vuelo información acerca de su posición con respecto al terreno o a los aviones circundantes o instrucciones para su guiado seguro al aeropuerto de destino (Sáez, 2012).

Diseñado originalmente para misiones de vigilancia aérea y naval (Corbasí, 1998), su funcionamiento se basa en la emisión de un impulso de radio, que se refleja en la superficie del objetivo-aeronave- y es recibido en el receptor en tierra, en el que físicamente también se encuentra el emisor. La señal de vuelta es procesada, de manera que mide la distancia al móvil calculando el tiempo que tarda la señal -cuya velocidad es constante-

${ }^{40}$ Es necesaria la recepción de al menos cuatro satélites para tener redundancia y, en consecuencia, la posibilidad de detectar errores en el posicionamiento. A mayor número de satélites recepcionados, mayor precisión en la medida (Núñez-García et al., 1992).

${ }^{41}$ La Pantalla de Datos Radar (PDR) presenta datos radar dinámicos, mapas estáticos y datos de vuelo. Forma parte de la Unidad de Control de Sector (UCS), consola que agrupa distintos periféricos que permite a los controladores realizar las funciones de Control de Tráfico Aéreo ATS (Calvo, 2000). 
desde el momento de su emisión hasta el de su recepción ${ }^{42}$. La posición del blanco queda definida por la distancia medida y por la localización relativa del móvil con relación a la posición de la antena en el momento de la emisión de la señal (Tooley y Wyatt, 2007).

Con todo, el sistema de control más usual para guiar con precisión las aeronaves durante la aproximación a la pista de aterrizaje es el denominado Sistema de Aterrizaje Instrumental o ILS ${ }^{43}$. Esta ayuda deja al piloto con seguridad a una distancia y altura del punto de contacto tales que, dependiendo de las condiciones meteorológicas, le permitan el contacto visual con la pista justo antes del aterrizaje. Consta de dos subsistemas independientes: uno sirve para proporcionar guía lateral y el otro vertical -en altitud- (Corbasí, 1998; Kershner, 2002; Tooley y Wyatt, 2007). Para el guiado en el plano horizontal, el ILS dispone de un emisor en tierra llamado localizador, que está situado en un lateral de la pista en el extremo contrario de la misma. A su vez, para el guiado en el plano vertical, dispone de una estación en tierra situada al lado de la pista, en su extremo más próximo, para ofrecer información en cabina de la desviación del avión respecto de la senda ideal de planeo. Como se representa en [Figura 2-17], las señales del ILS son presentadas e interpretadas en cabina a modo de desviación de la ruta adecuada (Kershner, 2002), mientras que en numerosos casos el sistema es complementado con un equipo DME, con lo que además del guiado de trayectoria horizontal y vertical se dispone de información de distancia a la pista en millas náuticas (Pérez, 2003).

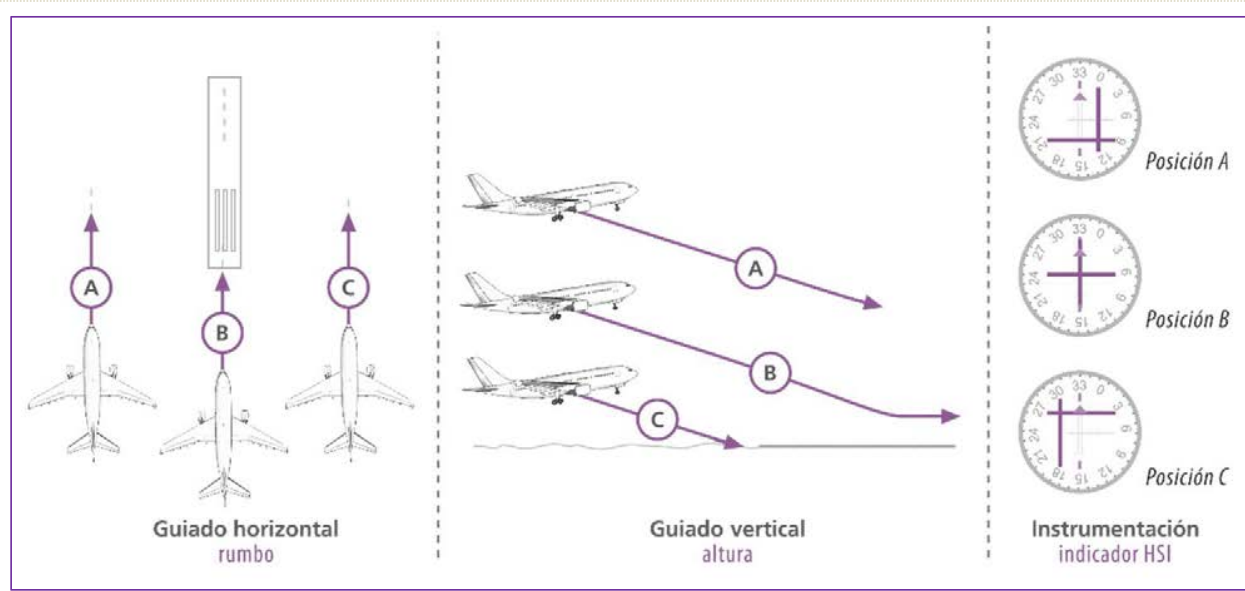

Figura 2-17: Indicaciones de desviación al establecerse en una senda de planeo del sistema ILS (Moya y Bernabé, 2011).

${ }^{42}$ En los radares de impulso, el método para medir la distancia se basa en el cálculo de tiempo transcurrido desde que el radar emite un impulso hasta que recibe su eco teniendo en cuenta simplemente la velocidad de las ondas, mientras que en los radares de onda continua la distancia se calcula midiendo el desfase entre la señal emitida y la recibida, gracias a la modulación en frecuencia de la primera (Peña, 2000).

${ }^{43}$ Se estima que existen más de 1500 pistas con ILS (40 de ellas en España) y 200.000 receptores embarcados en aeronaves (Peña, 2000). 
Los sistemas ILS se encuentran categorizados en consonancia con unos mínimos operacionales. En consecuencia, se establecen tres categorías de actuación ILS ${ }^{44}$-CATI III III ${ }^{45}$-, siendo esta última la más exigente (Sáez, Pérez, y Gómez, 2002). Para mayor seguridad operacional, las categorías necesarias para condiciones extremas en cuanto a falta de visibilidad requieren de una certificación adicional tanto del avión como de la tripulación (Calvo, 2000).

Además de las ayudas radioeléctricas, en el comienzo de las pistas de aterrizaje se suelen disponer de luces que indican el comienzo la pista de aterrizaje y sirven de ayuda visual a los pilotos. Un ejemplo es el denominado Indicador de Trayectoria de Aproximación de Precisión (PAPI). Consiste en una barra que, alineada en forma perpendicular al eje de la pista de aterrizaje, porta un total de cuatro elementos de lámparas múltiples o sencillas por pares- diseñada de tal forma que las luces se ven o blancas o rojas, dependiendo del ángulo desde el cual son vistas las luces. De este modo se advierte visualmente al piloto de la posición en la que se encuentra la aeronave con respecto a la trayectoria de aproximación ideal [Figura 2-18]. Así, cuando la aeronave está aterrizando en el ángulo de aproximación apropiado -trayectoria correcta-, el primer par de luces las más alejadas de la pista- se ven blancas y las del segundo conjunto, rojas. Cuando ambos conjuntos se ven blancos, el sistema PAPI indica que se está volando demasiado alto, y alternativamente demasiado bajo cuando ambos conjuntos se observan rojos ${ }^{46}$ (Cudós, 2004; García, 2000).

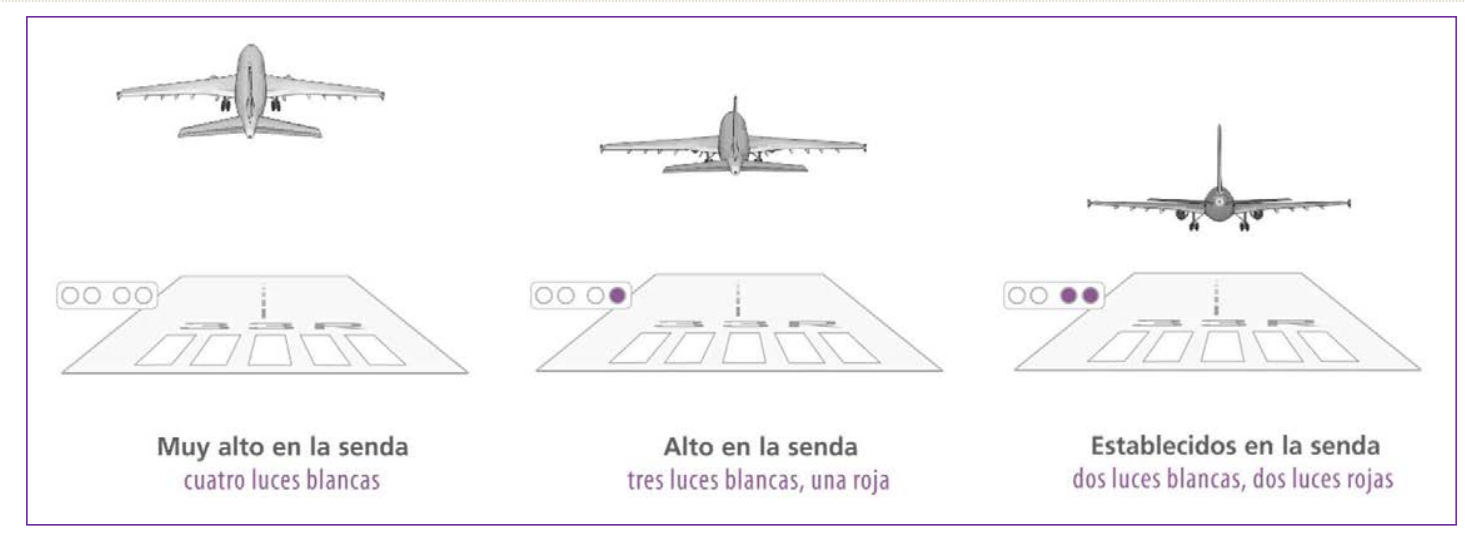

Figura 2-18: Distintas respuestas de un indicador luminoso PAPI a pie de pista (Moya y Bernabé, 2011).

${ }^{44}$ La OACI dispone la clasificación de los sistemas ILS atendiendo a los parámetros: la altura del punto de decisión (DH) y la distancia de visibilidad de la pista (RVR) (Peña, 2000).

${ }^{45}$ A su vez, la categoría CAT III se subdivide en IIIA, IIIB y IIIC, permitiendo esta última el aterrizaje con visibilidad cero (Peña, 2000).

${ }^{46}$ También es posible la combinación de una luz de un color y tres de otro, indicando así estados de posición intermedios. 


\subsubsection{Las reglas de vuelo}

Según dicta el Reglamento de Circulación Aérea ${ }^{47}$, las aeronaves tanto en vuelo como en el área de movimientos en tierra de los aeródromos se deberán ajustar, además de a las reglas generales, a cualesquiera de las dos tipologías de reglas de vuelo existente -visuales e instrumentales, respectivamente.-

\section{a) Reglas de Vuelo Visual}

Bajo Reglas de Vuelo Visual o VFR el piloto deberá tener las condiciones suficientes para que pueda navegar y mantener una separación de seguridad con cualquier obstáculo con la única ayuda de la observación visual, aunque le está permitido utilizar los instrumentos de vuelo a bordo como ayuda suplementaria (Sáez et al., 2002). Además de mantenerse dentro de unos límites determinados de altitud sobre el terreno, solo podrán volar bajo vuelo visual si existen una serie de Condiciones Meteorológicas Visuales o VMC. Estos requerimientos garantizan que el vuelo puede realizarse sin acudir a otra técnica distinta a la de la observación directa del terreno. Por este motivo en España, bajo reglas VFR, generalmente no está permitido volar de noche o atravesar capas de nubes (España, 2002; Sáez et al., 2002; Sáez y Portillo, 2003).

\section{b) Reglas de Vuelo Instrumental}

Bajo Reglas de Vuelo Instrumental o IFR el piloto tendrá la capacidad de conducir su aeronave en Condiciones Meteorológicas Instrumentales o IMC, es decir, en aquellas condiciones de visibilidad reducida o incluso nula que no permiten el vuelo visual (ICAO, 2005a). En estas condiciones, el piloto controla su avión atendiendo a la lectura de los instrumentos de vuelo, y confía en las cartas aeronáuticas y los servicios de control de vuelo en tierra para ver y evitar colisiones con otros aviones u obstáculos ${ }^{48}$. Para ello se aplican unos criterios de separación entre aeronaves y unos complejos procedimientos reglados (ICAO, 2006b, 2006c). De los primeros es en parte responsable el controlador aéreo, mientras que los segundos, por su propia naturaleza, están recogidos con claridad y detalle en las cartas de navegación aeronáutica.

\subsection{ESTRUCTURA DEL ESPACIO AÉREO}

Con el objetivo de garantizar la seguridad de cualquier aeronave en tránsito, desde mediados del siglo XX las autoridades de aviación civil -encabezadas a nivel mundial por la OACl- han sistematizado progresivamente el

${ }^{47}$ El Reglamento de Circulación Aérea es un documento normativo aplicable a las aeronaves españolas cualquiera que sea el espacio aéreo en el que se encuentren, siempre que no se oponga a las normas dictadas por el Estado que tenga jurisdicción sobre él. También es aplicable a aeronaves extranjeras en circulación general, que se encuentren en espacio aéreo o territorio de soberanía española (España, 2002).

${ }^{48}$ La práctica habitual es que los aviones comerciales de pasajeros operen bajo las reglas de vuelo instrumental, incluso cuando las condiciones meteorológicas permitan el vuelo visual (Cuerno, 2008). 
uso del denominado espacio aéreo, definido de forma genérica como la porción de la atmósfera terrestre, tanto sobre tierra como sobre agua, regulada por un país en particular (Calvo, 2000). El espacio aéreo no tiene límites tangibles, pero presenta determinados límites inmateriales, del mismo modo en que otras actividades humanas disponen sobre el territorio diversos tipos de fronteras administrativas. Estos límites definen una serie de sectores, clasificados por la OACl en espacios aéreos controlados, no controlados, espacios aéreos de uso especial, y otros (ICAO, 2005b). La tipología concreta del espacio aéreo se define dependiendo de diferentes factores, tales como el movimiento de aeronaves, el propósito de las operaciones que se desarrollan, y el nivel de seguridad requerido.

\subsubsection{El control del cielo}

En las primeras décadas de la historia de la aviación las tripulaciones disfrutaban de cierta libertad para evolucionar en el espacio aéreo, ya que el alcance del control en tierra era tecnológicamente limitado [Figura 2-19]. A medida que la actividad comercial se desarrollaba surgió la necesidad de poner orden en los cielos; la cada vez mayor densidad del tráfico aéreo y el acontecer de diversos accidentes mediáticos como el ocurrido en 1956 sobre el Gran Cañón del Colorado ${ }^{49}$, impulsaron definitivamente la decisión de confinar los vuelos comerciales en espacios aéreos acotados y perfectamente definidos para aumentar la seguridad y eficiencia del control del tráfico aéreo.

Como consecuencia el navegante aéreo ha perdido en la actualidad el aura de pionero explorador para convertirse en un usuario más de un complejo sistema normalizado de navegación aérea, a su vez compuesto de distintos servicios, elementos y dominios. Participar en este sistema implica que debe respetarse todo aquello que se disponga en el denominado Reglamento del Aire ${ }^{50}$. Como contrapartida se le brinda al piloto -como usuario del sistema- diferentes servicios de información aeronáutica que le son necesarios para garantizar una navegación eficiente dentro del espacio aéreo. Existen tres grandes servicios: Servicios de Tránsito Aéreo

${ }^{49}$ En la década de los años 50 del siglo pasado los pilotos que cruzaban Estados Unidos de costa a costa en días despejados tenían el hábito de desviarse sobre el Cañón del Colorado para ofrecer al distinguido pasaje el espectáculo de su observación desde el aire. La zona no tenía ningún control de radar ni de radio cercano, por lo que este recorrido alejado de la ruta original se realizaba volando según reglas de vuelo visuales y tomando como referencia puntos de tierra reconocibles (ICAO, 1956). En esta tesitura, en junio de 1956 un DC7 de la United y un Lockheed L-1049 Super Constellation de la TWA chocaron en pleno vuelo sobre el cañón causando 128 víctimas mortales (ABC, 1956; Aviation, 2012).

${ }^{50}$ No es posible realizar un trayecto sin anunciar previamente nuestro plan de vuelo a las autoridades competentes, es decir, sin asumir la tutela por parte de un sistema de control en tierra (España, 2002; ICA0, 2005b, 2007). Podemos señalar entonces que el espacio aéreo mundial -la porción de la atmósfera en la que los aviones tienen capacidad mecánica para volar- está estrictamente controlado y regulado. 
$(\text { ATS })^{51}$, de Gestión de Afluencia de Tráfico Aéreo (ATFM) ${ }^{52}$ y de Gestión del Espacio Aéreo (ASM) $)^{53}$, agrupados en un concepto más amplio denominado Gestión del Tránsito Aéreo (ATM) (De Mata y Morales, 2001; Sáez et al., 2002; Sáez y Portillo, 2003). Además existen otros tres servicios directamente asociados a la navegación aérea: Servicio Meteorológico (MET), Servicio de Búsqueda y Salvamento (SAR), y el Servicio de Información Aeronáutica (AIS) (Calvo, 2000). Este último servicio es el que recopila, verifica y difunde la información aeronáutica necesaria para la navegación segura a través de diferentes medios, entre ellos las propias cartas aeronáuticas; profundizaremos en este servicio más adelante.

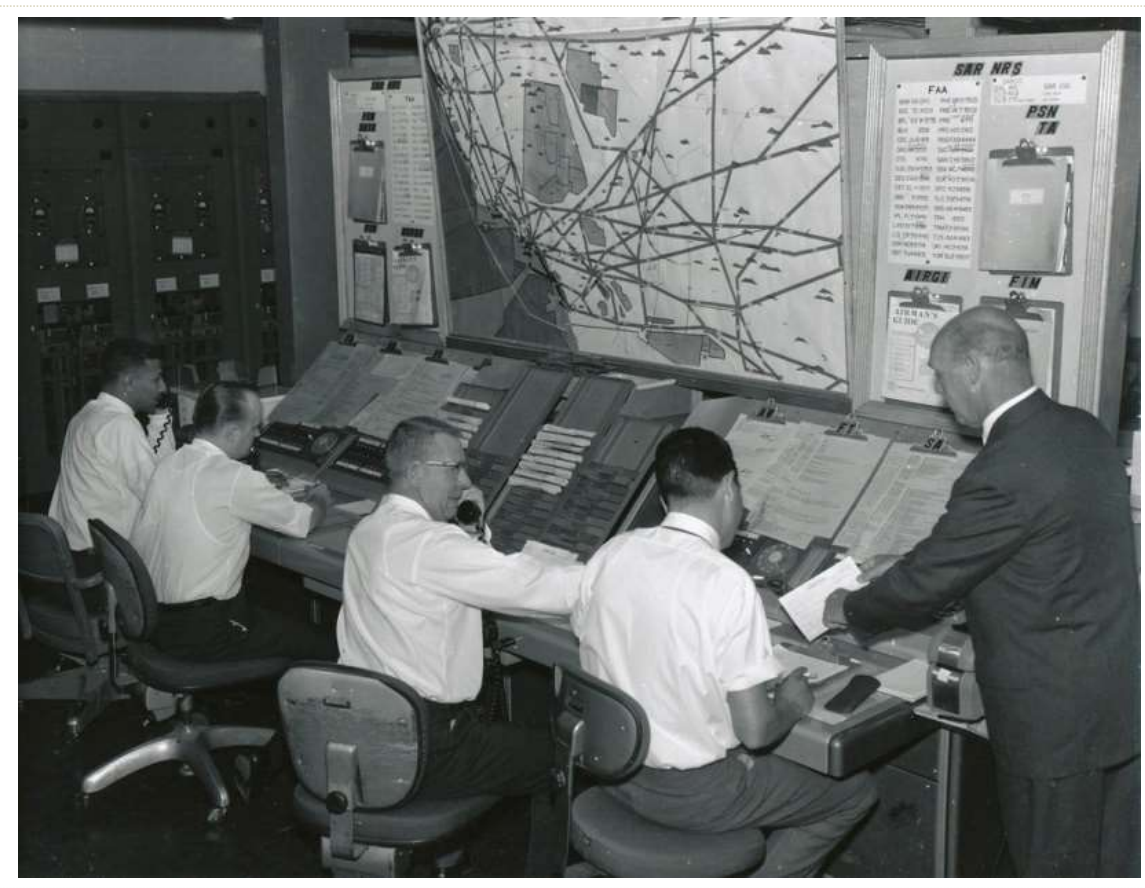

Figura 2-19: Centro de Control de tráfico de Los Ángeles en 1956. La cobertura radar ATC en EE.UU era extremadamente limitada. Por ello los aviones comerciales informaban de su posición aproximada a los controladores y estos a su vez realizaban estimaciones del tiempo de llegada a la siguiente posición (LostFlights Archive Photo).

${ }^{51}$ ATS es una expresión genérica que se aplica, según el caso, a los servicios de información de vuelo, alerta, asesoramiento y control de tránsito aéreo -servicios de control de área, aproximación o aeródromo-(ICA0, 2005b).

${ }^{52}$ Servicio establecido con el objetivo de contribuir a una circulación segura y ordenada del tránsito aéreo asegurando que el volumen de tránsito es compatible con las capacidades declaradas por la autoridad ATS competente (Sáez et al., 2002).

${ }^{53}$ Gestión orientada a optimizar la estructura del espacio aéreo para acomodar la demanda previsible de tráfico. 


\subsubsection{Las regiones de información de vuelo}

Para su control, la mayoría de los países establecen en su correspondiente espacio aéreo nacional un Espacio Aéreo Superior y un Espacio Aéreo Inferior. El límite puede variar de un país a otro; concretamente en España el límite entre estos dos espacios se establece en FL 245 54 , es decir, Nivel de Vuelo 24.500 pies, lo que equivale aproximadamente a 7.500 metros sobre el nivel del mar (España, 2002).

Además, el espacio aéreo de cada Estado se divide en Regiones de Información de Vuelo, denominadas FIR [Figura 2-20]. En estas zonas, los Estados proporcionan a las aeronaves en tránsito servicios de información de vuelo y alerta ${ }^{55}$. A su vez, se pueden dividir en dos partes, coincidiendo con el límite del Espacio Aéreo Superior e Inferior: FIR Superior o Región Superior de Información de Vuelo -también denominada UIR- por encima de FL 245 y FIR Inferior o Región Inferior de Información de Vuelo -genéricamente denominada FIR- por debajo de FL 245 (Aena, 2013a; Calvo, 2000; Sáez et al., 2002).

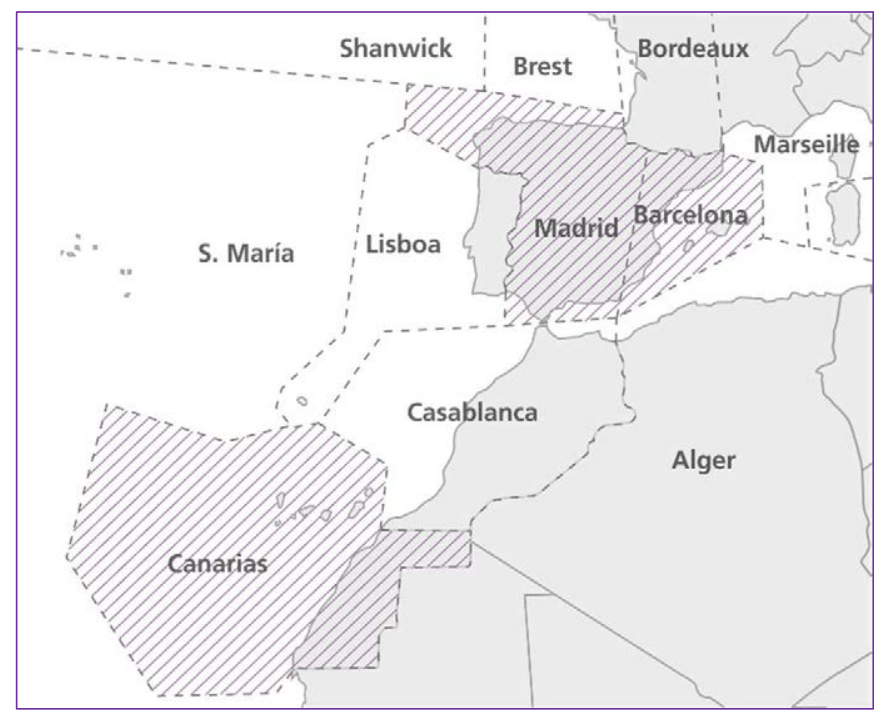

Figura 2-20: Las tres Regiones de Información de Vuelo -denominadas Madrid, Barcelona y Canarias- de responsabilidad española (figura propia a partir de (Aena, 2013a)).

${ }^{54}$ En España, el espacio aéreo por encima de los 24.500 pies se denomina Espacio Aéreo Clase A, y estando su uso restringido a vuelos exclusivamente instrumentales (España, 2002).

${ }^{55}$ Los límites laterales de las FIR nacionales se pueden extender a espacios aéreos internacionales mediante diferentes acuerdos. Por ejemplo, la responsabilidad del control del espacio aéreo situado sobre el Sahara Occidental corresponde al Centro de Control de Canarias (C. Ruiz, 2010). 


\subsubsection{Los espacios aéreos controlados}

Dentro del espacio aéreo de una FIR se definen hasta cinco tipos de espacios aéreos controlados ${ }^{56}$ en los cuales se presta servicio de tránsito aéreo a todos los vuelos VFR e IFR que se encuentren dentro de él (Calvo, 2000; Sáez et al., 2002). Todos ellos pasan a ser descritos sucintamente a continuación [Figura 2-21].

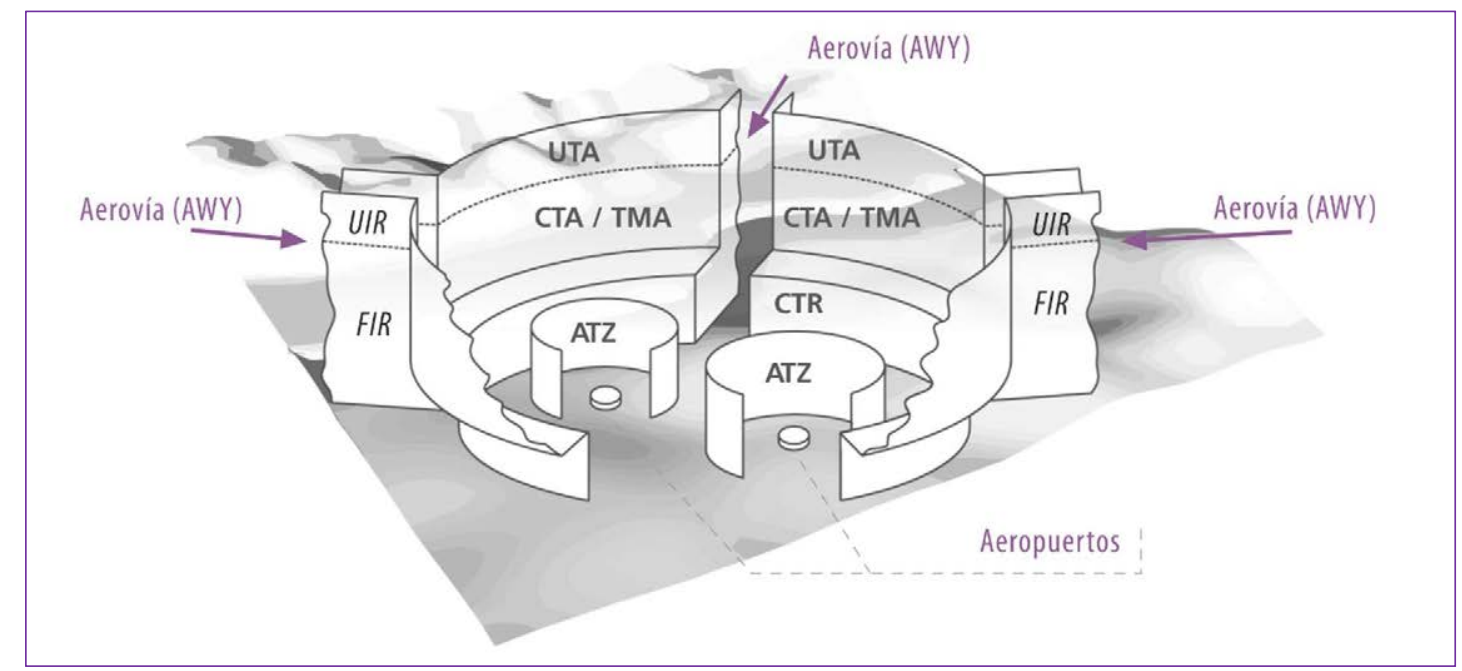

Figura 2-21: Esquema de las estructuras normalizadas del Espacio Aéreo Controlado (figura propia a partir de Calvo (2000) y Sáez et al. (2002)).

a) Las Aerovías o Airways (AWY) son espacios aéreos controlados en forma de corredores que se intersectan entre sí, y que como si de una red de autopistas aéreas se tratase, canalizan el tránsito aéreo entre diferentes puntos del espacio aére ${ }^{57}$. Generalmente, y dependiendo de cada espacio aéreo, las aerovías son designadas para distintos sentidos de vuelo de una zona a otra (Aena, 2013a).

b) Sobre los aeropuertos principales en cuyas proximidades confluyen varias aerovías normalmente se establece un espacio aéreo controlado denominado Área de Control Terminal o Terminal Manouverin Area (TMA), cuyo objeto es controlar el tránsito aéreo IFR que entra y sale de ellos.

${ }^{56}$ El espacio aéreo declarado como controlado requiere estar vigilado por la dependencia responsable, por lo que, independientemente de que sean vuelos VFR e IFR, las tripulaciones están obligadas a seguir las instrucciones del ATC (Sáez et al., 2002).

${ }^{57}$ Actualmente es más apropiada la denominación de "ruta ATS" (Sáez et al., 2002). 
c) Para los aeropuertos en los que sus dimensiones y tráfico no justifican implantar un TMA, se establece sobre ellos una zona controlada denominada Área de Control o Controlled Traffic Area (CTA), que si se localiza en el Espacio Aéreo Superior se denomina Área de Control Superior (UTA).

d) Las Zonas de Control o Controlled Traffic Region (CTR) son también espacios aéreos controlados asociados a aeródromos ${ }^{58}$ que tienen por objeto proteger las entradas y salidas de los vuelos IFR.

e) Finalmente, para que la torre de control pueda controlar el tránsito aéreo -el movimiento de las aeronaves de las proximidades de dicho aeródromo- se establecen las denominadas Zonas de Tránsito de Aeródromo o Aerodrome Transit Zone (ATZ), de manera que también se proteja el tránsito VFR. Cuando existe tráfico IFR y se ha establecido una CTR, normalmente esta engloba a la zona de tránsito ATZ.

En orden a facilitar el tránsito simultáneo de vuelos VFR e IFR por determinadas áreas, la OACI ha clasificado el espacio aéreo en siete clases diferentes, identificadas con una letra de la A a la G. La clase A representa el nivel más alto de control, mientras que las clases Fy G son espacio aéreo no controlado (Aena, 2013a; España, 2002).

Para conseguir que todos los vuelos existentes en un sector del territorio sean atendidos desde una única posición de control, los Servicios de Tránsito Aéreo, las Regiones de Información de Vuelo y los Espacios Aéreos Controlados se gestionan normalmente en sectores. Esta sectorización puede ser flexible en el tiempo, en función del volumen de tráfico previsto, según los días del año e incluso de las horas del día (Calvo, 2000).

\subsubsection{Las reservas del espacio aéreo}

Con independencia de las reglas de vuelo seguidas, son de especial atención las denominadas reservas del espacio aéreo, volúmenes del espacio aéreo -controlados o no- que se designan de uso especial al presentar o poder presentar en un momento dado restricciones para su uso general. Las restricciones son debidas a diferentes situaciones o a actividades desarrolladas en ellas y que pueden entrañar algún riesgo para el tránsito de las aeronaves (Sáez et al., 2002). La existencia de cadenas montañosas, zonas de paso de aves migratorias, maniobras de aeronaves militares, lanzamiento de paracaídas, etc. son algunas de estas situaciones.

\begin{tabular}{|c|c|c|}
\hline Grado & Identificador & Definición \\
\hline Zona Peligrosa & Letra (D) + número & $\begin{array}{l}\text { Espacio aéreo sobre sistemas montañosos en el cual } \\
\text { pueden desplegarse en determinados momentos activi- } \\
\text { dades peligrosas para el vuelo. El piloto decide si corre el } \\
\text { riesgo de volar o no en él. }\end{array}$ \\
\hline
\end{tabular}

${ }^{58}$ Cuando existen varios aeródromos muy próximos entre sí se suele definir una sola CTR que los incluya. 


\begin{tabular}{|lcl|}
\hline Zona Restringida $\quad$ Letra $(\mathrm{R})+$ número & $\begin{array}{l}\text { Espacio aéreo en el cual está restringido el vuelo de las } \\
\text { aeronaves. Por las actividades que en estas zonas se } \\
\text { desarrolla no se permite al piloto decidir si es posible o } \\
\text { no la penetración en ellas. }\end{array}$ \\
\hline Zona Prohibida $\quad$ Letra $(\mathrm{P})+$ número & $\begin{array}{l}\text { Espacio aéreo dentro del cual está totalmente prohibido } \\
\text { el vuelo, salvo expresa autorización del control en tierra. }\end{array}$ \\
\end{tabular}

Tabla 2-1: Tipos de reservas del espacio aéreo (Aena, 2013a)

Las restricciones tienen diferente grado [Tabla 2-1] y además pueden ser temporales o permanentes. Las primeras se activan durante periodos limitados de tiempo, por lo que los servicios de tránsito aéreo se encargan de coordinar la planificación de la circulación aérea durante el tiempo que dure la limitación. Por el contrario las restricciones permanentes, por su propia definición, aparecen siempre convenientemente reseñadas en las cartas aeronáuticas ${ }^{59}$ (Aena, 2013a).

\subsection{FASES Y PROCEDIMIENTOS}

Los vuelos realizados bajo Reglas de Vuelo Instrumental (IFR) deben evolucionar bajo una serie de procedimientos normalizados (España, 2002; ICAO, 2005a). Las indicaciones de estos procedimientos -junto a la información de las ayudas a la navegación y la sectorización delespacio aéreo- aparecen convenientemente reflejadas en la cartografía aeronáutica.

El vuelo de una aeronave desde que parte de su origen hasta que llega al destino puede ser dividido en fases. De igual modo, y con el fin de asegurar la operación segura y eficaz de la aeronave, las cartas aeronáuticas se

${ }^{59}$ Las reservas del espacio aéreo se identifican con dos letras - LE para península y Baleares, GE para Ceuta y Melilla, GC para Canarias- seguidas por el tipo de zona - $P$ prohibida, $R$ restringida y $D$ peligrosa- más un código alfanumérico de hasta tres cifras (Aena, 2013a). También deben identificarse los límites superior e inferior de la porción vertical afectada. 
especializan atendiendo a esta división. Como regla general, un vuelo instrumental puede dividirse operativamente en las siguientes fases ${ }^{60}$ : subida -salida-, crucero -en ruta-, descenso -llegada-y aproximación ${ }^{61}$ (Calvo, 2000). A todo ello hay que sumar la fase de rodaje desde el estacionamiento inicial hasta la cabecera de la pista y, una vez aterrizado, la fase de rodaje desde la salida de la pista hasta el estacionamiento final [Figura 2-22].

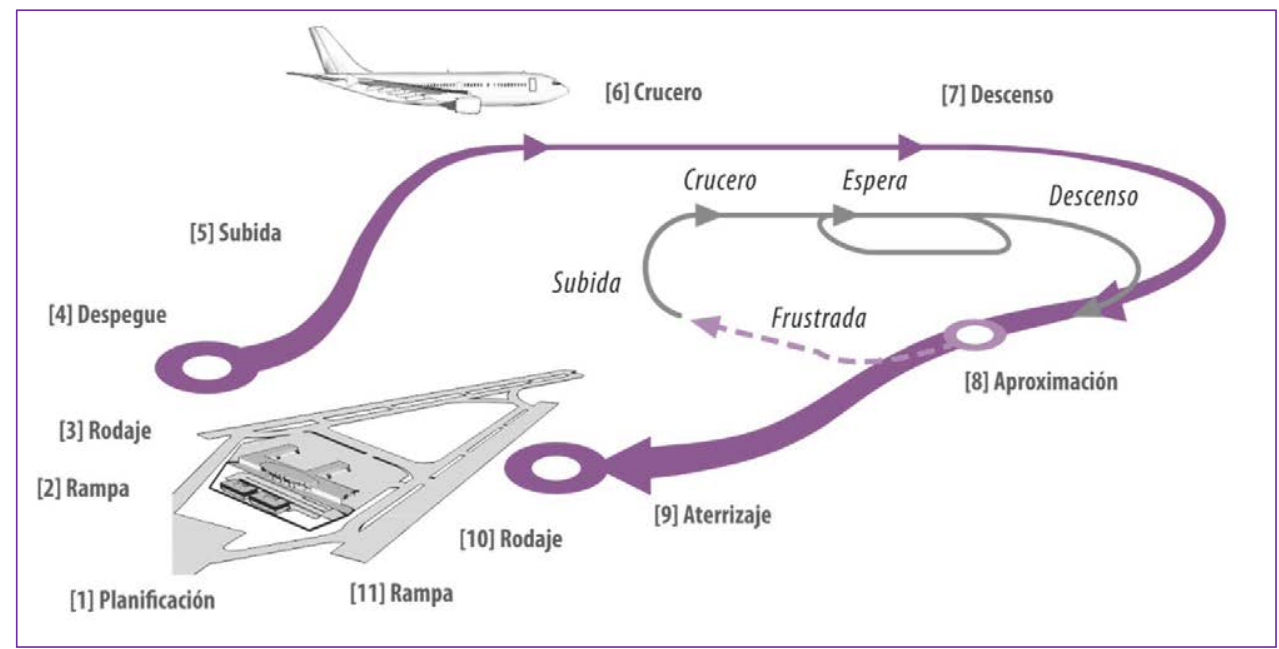

Figura 2-22: Esquema de las fases de vuelo bajo reglas IFR instrumentales (ICA0, 2005b; Moya y Bernabé, 2011).

\subsubsection{La fase de subida (ascenso)}

El objetivo de esta fase es incorporar a la aeronave a la red de rutas de crucero-aerovías- de la manera más segura y eficaz posible, respetando siempre las restricciones impuestas para reducir el impacto ambiental que supone el ruido sobre las poblaciones y entornos naturales. Como regla general las rutas de salida instrumentales presentan por una parte uno o varios tramos de subida, que proporcionan a la aeronave la separación adecuada respecto al terreno y la acercan a la estructura de rutas de crucero, y por la otra varios tramos de

${ }^{60}$ Sáez et al. (2002) identifican una fase previa de despegue, caracterizada por el guiado para rodar por la pista y el ascenso hasta completar el segundo segmento en el despegue, situado al menos a 400 pies de la pista. En ICAO (2005b) se hace referencia al concepto gate-to-gate, según el cual las operaciones de tráfico aéreo son tales que la planificación y las fases operativas sucesivas se gestionan y se pueden lograr de una forma sencilla y coherente; bajo esta perspectiva operacional las fases de vuelo para la gestión de la prestación de servicios ATM consisten en planificación, rampa, salida de superficie, salida, dispersión, crucero, recolección, aproximación, llegada de superficie y rampa, respectivamente.

${ }^{61}$ Cuando un piloto se ve obligado a abortar el aterrizaje, efectúa una maniobra publicada, adecuada para el aeropuerto y pista en uso. La maniobra -denominada go-around- acaba en un circuito de espera donde se mantendrá hasta que el ATC le pueda incorporar de nuevo a la secuencia de aproximación y aterrizaje (Calvo, 2000; Sáez et al., 2002). 
aceleración; en estos últimos el piloto va cambiando progresivamente la velocidad y la configuración aerodinámica de la aeronave, hasta alcanzar la velocidad y altitud óptimas para la fase de crucero (Calvo, 2000).

\subsubsection{La fase de crucero (en ruta)}

Alcanzada la velocidad y altitud de crucero, la aeronave se desplazará hacia su destino a través de la red de aerovías. Denominadas también rutas ATS, todas las rutas de crucero son siempre instrumentales. Las rutas de crucero convencionales quedan definidas por tramos rectos que unen puntos existentes a lo largo de la ruta. Estos últimos pueden ser puntos significativos -generalmente balizados en tierra a través de una radioayuda-, y puntos de notificación, en los cuales el piloto proporciona información sobre su situación a las dependencias de los Servicios de Tránsito Aéreo (ATS) ${ }^{62}$. A su vez pueden ser puntos de notificación obligatoria o bien a petición de la dependencia ATS (Calvo, 2000).

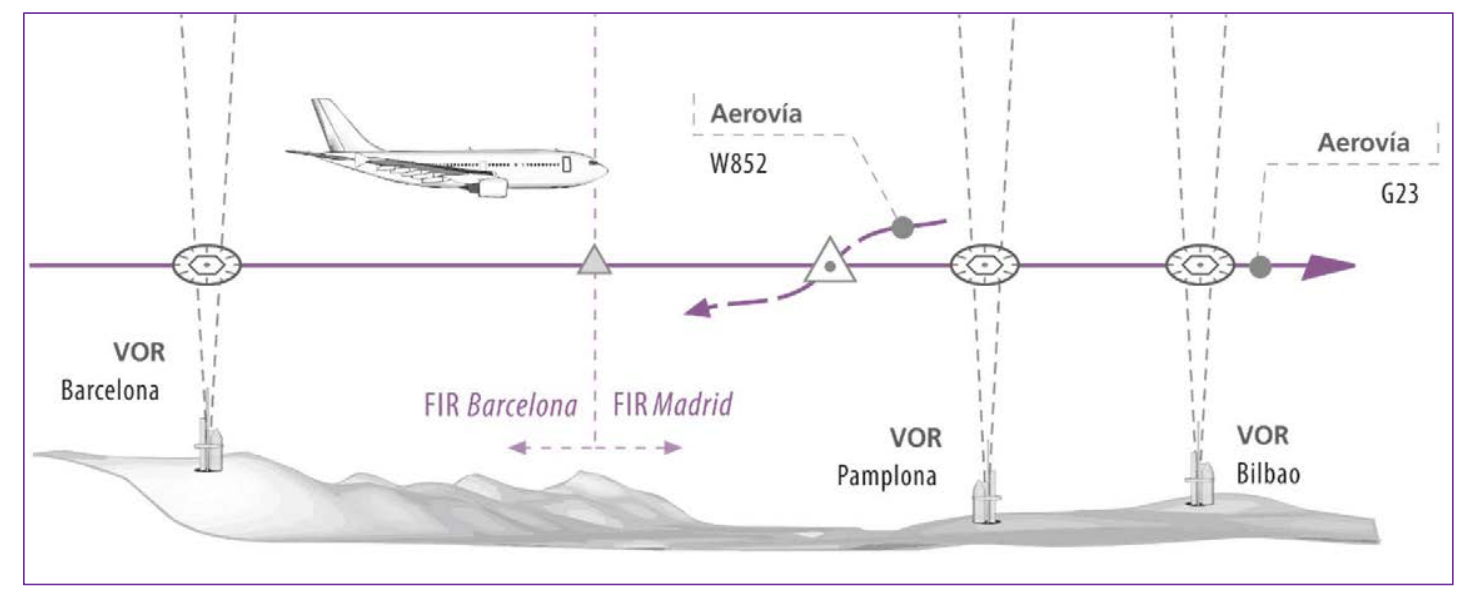

Figura 2-23: Puntos significativos y de notificación en una ruta de crucero o ATS (Moya y Bernabé, 2011).

Los tramos que unen los puntos significativos descritos anteriormente tienen dos propiedades básicas: su dirección -rumbo magnético correspondiente a los dos posibles sentidos-y su longitud-distancia en millas náuticas entre los puntos que los definen-. Además, deberá ser respetada una determinada separación vertical ${ }^{63}$ entre las

62 Tanto los puntos significativos como los de notificación, además de marcar los tramos de rutas ATS, pueden señalar gran variedad de circunstancias: entrada y salida de las FIR/UIR o de espacios aéreos controlados, transferencias entre diferentes áreas de control, intersección con otras rutas ATS, cambios de nivel de vuelo, etc. [Figura 2-23]

${ }^{63}$ Históricamente la separación vertical estándar era de 1.000 pies entre la superficie y nivel de vuelo FL 290; 2.000 pies entre los niveles de vuelo FL 290 y FL 410, y 4.000 pies por encima de este último (ICAO, 2007). Hoy en día la mayoría de países han adoptado la Reducción de Separación Mínima Vertical o RVSM, que reduce la separación 
aeronaves que circulen en uno $u$ otro sentido del tramo. Todas las aerovías poseen un identificador único formado por una letra del alfabeto seguida por un número del 1 a 999; además cuando la ruta discurre por una región superior de vuelo, se le antepone la letra U de upper, o superior (Aena, 2013a).

El sistema de aerovías definidas por radioayudas conforma una red de rutas convencionales en las que existe poca flexibilidad y eficiencia. Con motivo de una reducción de tiempos de vuelo o de congestión de tráfico aéreo, ocasionalmente los centros de control pueden autorizar al piloto a salirse de las aerovías y volar directamente a algún punto de la ruta (ICAO, 2007). Para superar esta rigidez se están implantando progresivamente las rutas RNAV (aRea NAVigation) en las cuales los puntos que definen cada tramo pueden estar basados en radioayudas o crearse ficticiamente. Estos últimos, denominados waypoints, son calculados por la aeronave según la información que esta posea sobre su posición, en base a las propias radioayudas, sistemas autónomos o sistemas de posicionamiento por satélite (ICAO, 2006c; Sáez, 2012; Sáez et al., 2002).

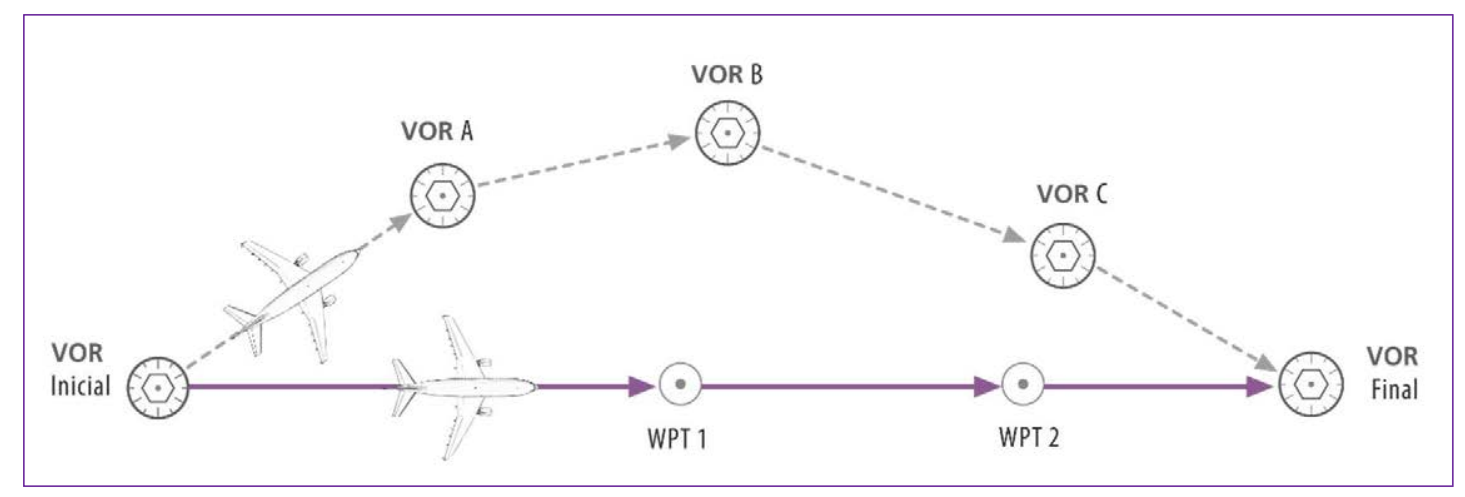

Figura 2-24: Diferencia entre una ruta convencional y una ruta RNAV (Moya y Bernabé, 2011).

La aeronave, a través de su Sistema Gestor de Vuelo o Flight Management System (FMS), interpreta los waypoints como si fuesen puntos convencionales tipo radioayudas ${ }^{64}$; además de proporcionar exactitud a la navegación, permiten la independencia respecto a las instalaciones de tierra. Así es posible crear rutas más cortas que las convencionales publicadas en las cartas aeronáuticas y de menor impacto ambiental gracias al ahorro de combustible y reducción del ruido al flexibilizar los procedimientos de salida y llegada en zonas pobladas [Figura 2-24].

a la mitad de estos valores y consigue duplicar el número de tráficos que pueden volar una ruta al mismo tiempo (Calvo, 2000; ICAO, 2002).

${ }^{64}$ No todas las aeronaves están capacitadas para utilizar rutas RNAV (ICAO, 2007). El equipo básico de a bordo necesario utiliza varios sistemas de navegación -la unidad FMS, equipos de radionavegación, equipos inerciales INS, sistemas GPS-, que se complementan unos a otros en la ejecución de la función de navegación RNAV. 


\subsubsection{La fase de descenso (llegada)}

Las rutas de llegada consisten en una serie de maniobras predefinidas y generalmente apoyadas en radioayudas, que van a permitir a la aeronave transitar con seguridad desde un punto significativo de la fase de crucero a otro punto significativo donde puede comenzar el descenso final al aeródromo correspondiente -fase de aproximación-. A lo largo de esta trayectoria se establece un Margen Mínimo de Franqueamiento de Obstáculos o Minimum Obstacle Clearance (MOC), determinando así las zonas en las que es necesario considerar los obstáculos del terreno (ICAO, 2006c).

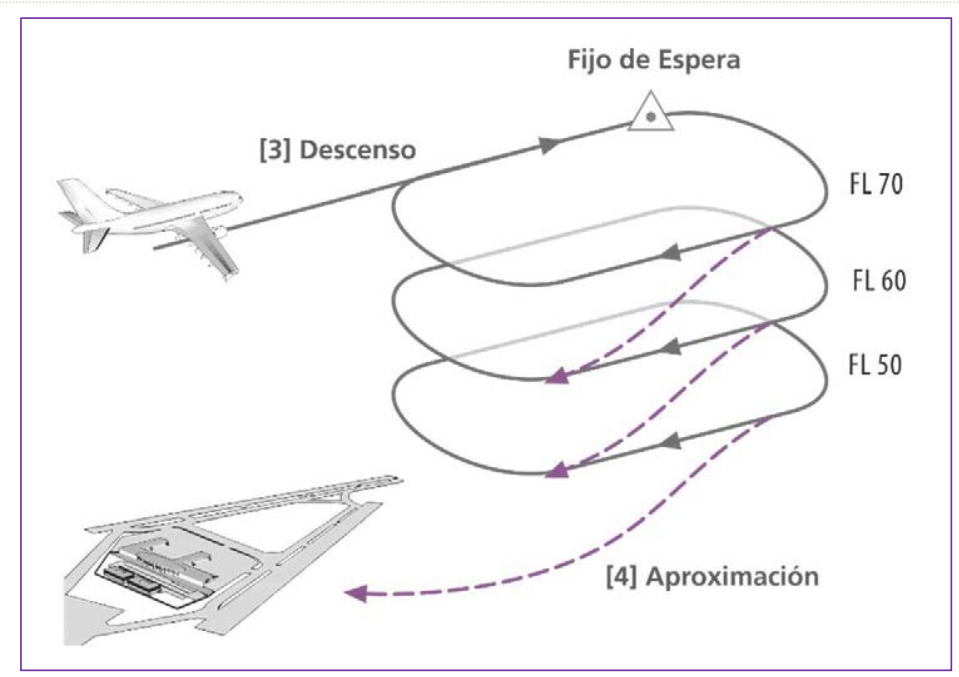

Figura 2-25: Procedimiento de espera por congestión de tráfico (Moya y Bernabé, 2011).

Cuando se produce congestión de llegadas sobre los aeródromos, el control en tierra regula el tráfico de tal manera que los aviones comiencen la aproximación ordenadamente y con una adecuada separación entre ellos, activando si es necesaria la formación de esperas en forma de pila. Estas constan de varios circuitos en forma de hipódromo con separaciones verticales reglamentarias de 1.000 pies [Figura 2-25]. Generalmente los virajes del circuito son en el sentido de las agujas del reloj-aunque el sentido de viraje viene especificado en cada caso en la correspondiente carta-. Así, las aeronaves acceden a la pila por su parte superior y descienden de nivel a medida que el inmediato inferior quede libre (Calvo, 2000). 


\subsubsection{Las fases de aproximación y aterrizaje}

Finalmente, en la fase de aproximación se efectúan varias maniobras normalizadas que van a permitir a la aeronave evolucionar con seguridad desde un punto de aproximación inicial hasta la pista del aeropuerto. Una aproximación por instrumentos cuenta con tres diferentes tramos o segmentos: El primero que el piloto debe abordar en el procedimiento es el Segmento Inicial ${ }^{65}$, tramo comprendido entre un punto Fijo de Aproximación Inicial (IAF) y un punto Fijo Intermedio (IF); seguidamente afronta un segmento intermedio, comprendido entre el punto Fijo Intermedio (IF) y el punto Fijo de Aproximación Final (FAF), segmento en el cual se configura la aeronave, estabilizándola para el aterrizaje [Figura 2-26] (ICAO, 2006c). Posteriormente, en el segmento final el piloto se sitúa a pocos metros sobre el nivel del suelo, decide si el aterrizaje es factible dependiendo de las condiciones de visibilidad y, si lo es ${ }^{66}$, lo lleva a cabo (ICAO, 2006b).

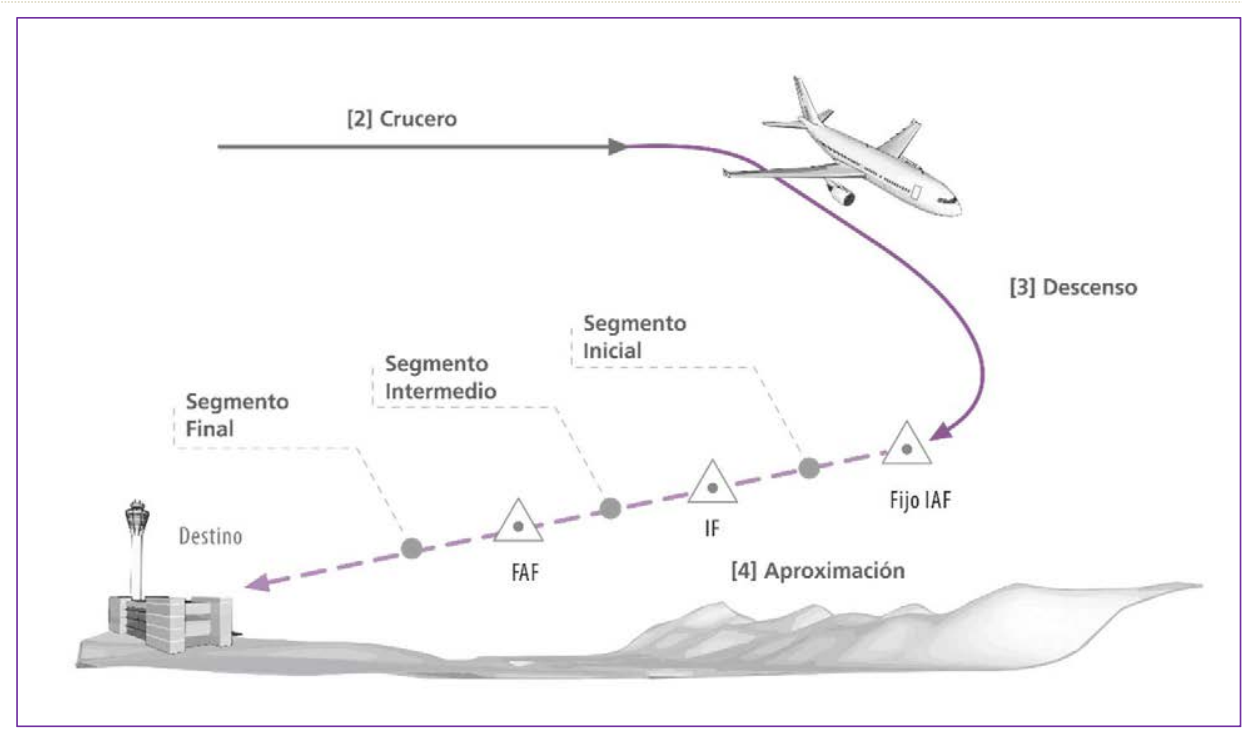

Figura 2-26: Segmentos y puntos fijos de la fase de aproximación (figura propia a partir de (ICA0, 2006b)).

El segmento final puede realizarse por aproximación directa, cuando la alineación del segmento final y el eje de pista coinciden o son casi coincidentes, y por aproximación indirecta o en circuito, cuando el tramo instrumental de la aproximación final está separado del eje de pista más de $30^{\circ}$ (ICAO, 2006b). En este último caso se suele finalizar la aproximación rodeando al aeródromo mediante la ejecución de un circuito, manteniendo

${ }^{65}$ En algunos casos puede que no parezca el segmento inicial por estar ubicado el punto fijo intermedio en la propia estructura de las rutas de crucero/descenso.

${ }^{66}$ En una aproximación de precisión o con guía vertical, se establece una Altitud de decisión (DA), a la cual debe iniciarse una maniobra de aproximación frustrada si no se ha establecido la referencia visual requerida para continuar la aproximación (ICA0, 2006b). 
siempre la referencia visual a las pistas (Calvo, 2000; ICAO, 2006c). Cuando no se dan las circunstancias necesarias para conseguir un aterrizaje seguro -debido a una aproximación deficiente, falta de alineamiento, escasa visibilidad, otra aeronave en vuelo o en pista que interfiere en el aterrizaje, etc.- el piloto debe frustrar la aproximación y llevar el avión hasta una posición en la cual pueda iniciar nuevamente una fase de descenso y aproximación, respetando en el recorrido diferentes criterios de franqueamiento de obstáculos.

La trayectoria inicial de la frustrada será recta siempre que sea posible [Figura 2-27]. En la mayoría de las ocasiones en las que se aborta el aterrizaje se obliga a la aeronave a incorporarse a un circuito de espera, antes de iniciar un nuevo intento de aproximación y aterrizaje (Calvo, 2000). Será el control en tierra el que indique al piloto el momento en el que las circunstancias del tráfico permitan realizar este nuevo intento (España, 2002).

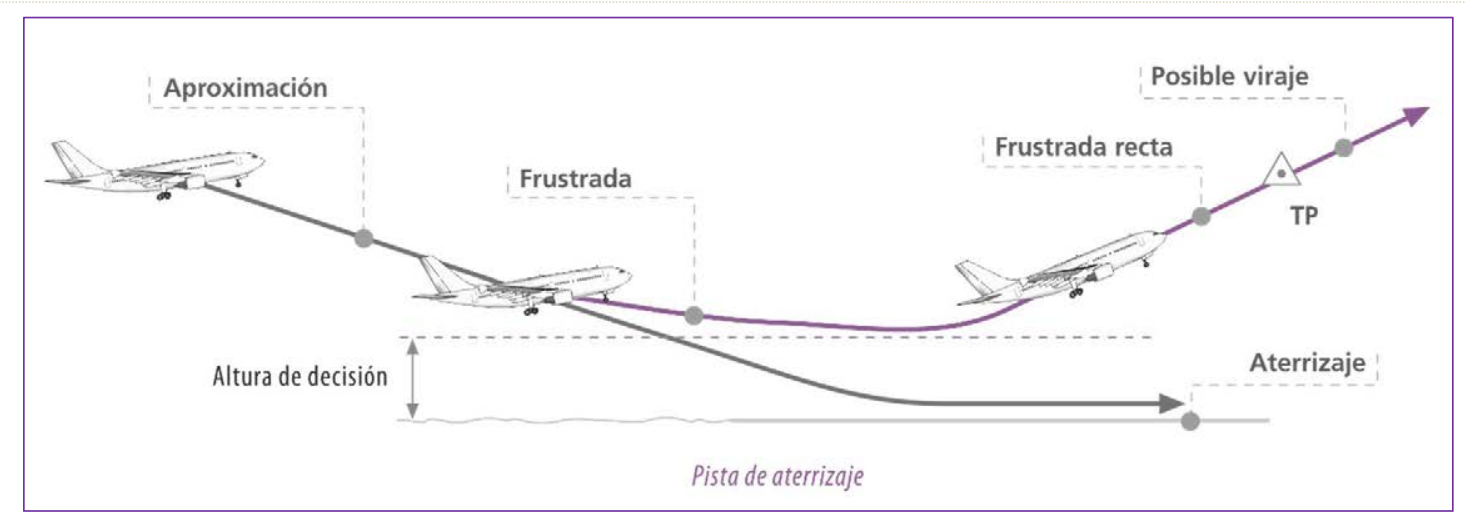

Figura 2-27: Maniobra de aproximación frustrada (Moya y Bernabé, 2011).

\subsection{INFORMACIÓN GEO-AERONÁUTICA}

Los datos aeronáuticos son la representación de hechos, conceptos o instrucciones aeronáuticos de manera formalizada que permita que se comuniquen, interpreten o procesen. El resultado sintetizado de la agrupación, análisis y formateo de datos aeronáuticos indispensables para la navegación aérea es lo que ha de considerarse Información Aeronáutica (ICAO, 2004). Finalmente son los Servicios de Información Aeronáutica (AIS) los encargados de asegurar que esta información se distribuye en todo momento a las tripulaciones a través de los medios que se consideren convenientes.

En esta tesis doctoral es de interés particular la información que denominaremos geo-aeronáutica, es decir, aquella información que tienen como variable esencial de su definición la localización espacial. Su adecuada caracterización se muestra compleja, debido a sus particularidades y al carácter intrínseco que, como variable de localización, tiene en cualquier dato de tipo aeronáutico. 


\subsubsection{La necesidad}

El ejercicio de la navegación aérea implica la necesidad de un flujo de información constante y seguro, que permita al piloto -responsable último de cualquier vuelo- tomar decisiones adecuadas en dos aspectos críticos: seguridad y orientación.

a) Asegurar la seguridad de tripulantes, pasajeros y la propia aeronave

El piloto debe adquirir una percepción constante y detallada del relieve alrededor de su posición. Este conocimiento es útil para proveerse de orientación pero, sobre todo, le permitirá evaluar y minimizar cualquier riesgo de colisión con el terreno circundante. Así, y dependiendo del tipo de vuelo, aeronave, y fase operativa, existirá un límite particular de altitud por debajo del cual existe un mayor riesgo de colisión con el terreno o con obstáculos próximos a su trayectoria -cuanto más cercana al terreno se encuentre, más detallada y precisa deberá ser esta información- (Sáez y Portillo, 2003). Otros factores a considerar en cuanto a la seguridad de las operaciones son el conocimiento de la posición del tráfico aéreo circundante y la provisión de información meteorológica; su rápido análisis permite evitar, en lo posible, riesgos innecesarios para la navegación.

b) Desplazarse de modo efectivo por un recorrido previamente planificado

La información trasladada al piloto debe permitirle conducir su aeronave de un lugar a otro determinando su posición en cualquier instante, existan o no condiciones climatológicas y ambientales que permitan el contacto visual con el terreno. Esto obliga, en el caso de una navegación de tipo instrumental, a la observancia estricta tanto de las trayectorias normalizadas como de las indicaciones que se provean desde el control de tráfico en tierra (España, 2002).

\subsubsection{El ambiente}

En vuelo, la percepción y comprensión de los modelos de información por parte del ser humano no es un hecho aislado como tal; está condicionado tanto por determinadas circunstancias operacionales -de las que ya hemos dado cuenta- como por un entorno físico concreto, el cual puede ser tratado a su vez desde el punto de los factores humanos. Por ello la cabina de vuelo, definida como ambiente central donde se desarrolla esta actividad, posee una especial importancia.

Situado en la parte delantera de cualquier avión, este habitáculo interior es en el que la tripulación técnica de vuelo controla la aeronave. Es el Sancta Sanctórum ${ }^{67}$ de todo piloto: el frontal envuelto por la cabina de vuelo contiene los paneles donde se disponen los controles y la instrumentación le que permite hacer volar, dirigir y aterrizar el aparato. En los aviones militares a este espacio se le denomina carlinga, mientras que en lengua

${ }^{67}$ En el antiguo Egipto, el Sancta Sanctórum era el lugar más sagrado y recóndito de los templos allí construidos, donde solo los sacerdotes y el faraón tenían acceso (Ares, 2003). 
inglesa se utiliza el término cockpit. La inmensa mayoría de los aviones modernos poseen una cabina de vuelo cerrada, exceptuando algunos modelos de aeronaves ligeras y ultraligeros (Ascacíbar, 2003). En el caso de los aviones comerciales este espacio, además de presurizado, está físicamente separado de la cabina de pasajeros.

La cabina de vuelo es, forzosamente, un espacio estrecho e incómodo en el que tripulación, instrumentación y mandos de control quedan confinados. Éste es el medio -no precisamente ideal- en el que se realiza la provisión, lectura y comprensión de la información necesaria para conducir la aeronave por el espacio aéreo ${ }^{68}$. El diseño y función de controles e instrumentación deben de adecuarse a un espacio físico limitado, sin perjudicar a su vez la conciencia situacional del piloto debido a una excesiva sobrecarga de información. Este empeño, surgido con fuerza a mediados del siglo XX $X^{69}$ en base a la aplicación del concepto de los factores humanos (FAA, 2003b), ha causado en las aeronaves actuales una cierta normalización de la disposición de controles de las cabinas de mando [Figura 2-28]. La ubicación habitual de los elementos básicos se resume a continuación:

- Panel principal (A): Instrumentos generales; horizonte artificial, displays de navegación, pantallas de información, etc.

- Pedestal -entre asientos- (B): Sistemas de comunicaciones, columna de gases, control de superficies auxiliares, etc.

- Panel superior-overhead- (C): Sistemas de controles eléctricos, hidráulicos y de presurización.

- Panel de visera -glareshield- (D): Controles automáticos de vuelo.

${ }^{68}$ Históricamente el despliegue de los mapas en cabina ha sido siempre una tarea problemática, ya que estos habitáculos no dan lugar a mucho más espacio del imprescindible. La decisión de Airbus a finales de los años ochenta de sustituir en sus nuevos modelos el tradicional mando de control situado entre las piernas del piloto en forma de volante -o cuernos- por un mando de palanca -sidestick- ubicado en un lateral (Airbus, 1998), tuvo como consecuencia colateral la posibilidad de ubicar una bandeja plegable frente al piloto, dispositivo que ofrece un espacio físico adicional muy adecuado para la consulta de manuales de vuelo, fichas y cartas de navegación.

${ }^{69}$ Alfonso Chapanis es considerado como uno de los autores pioneros en la investigación de factores humanos en el puesto de pilotaje (Lavietes, 2002), llegando a demostrar que a través de un diseño alternativo de los mandos de instrumentación podía reducirse reducía la alta tasa de accidentes número accidentes del bombardero Boeing B-17 en el aterrizaje. En cuanto a la mejora de la interacción visual con la instrumentación, el uso de direcciones naturales y la optimización de las escalas de graduación y de las formas de flechas de flujo fueron algunos de sus postulados más reconocidos (Chapanis, 1953). 


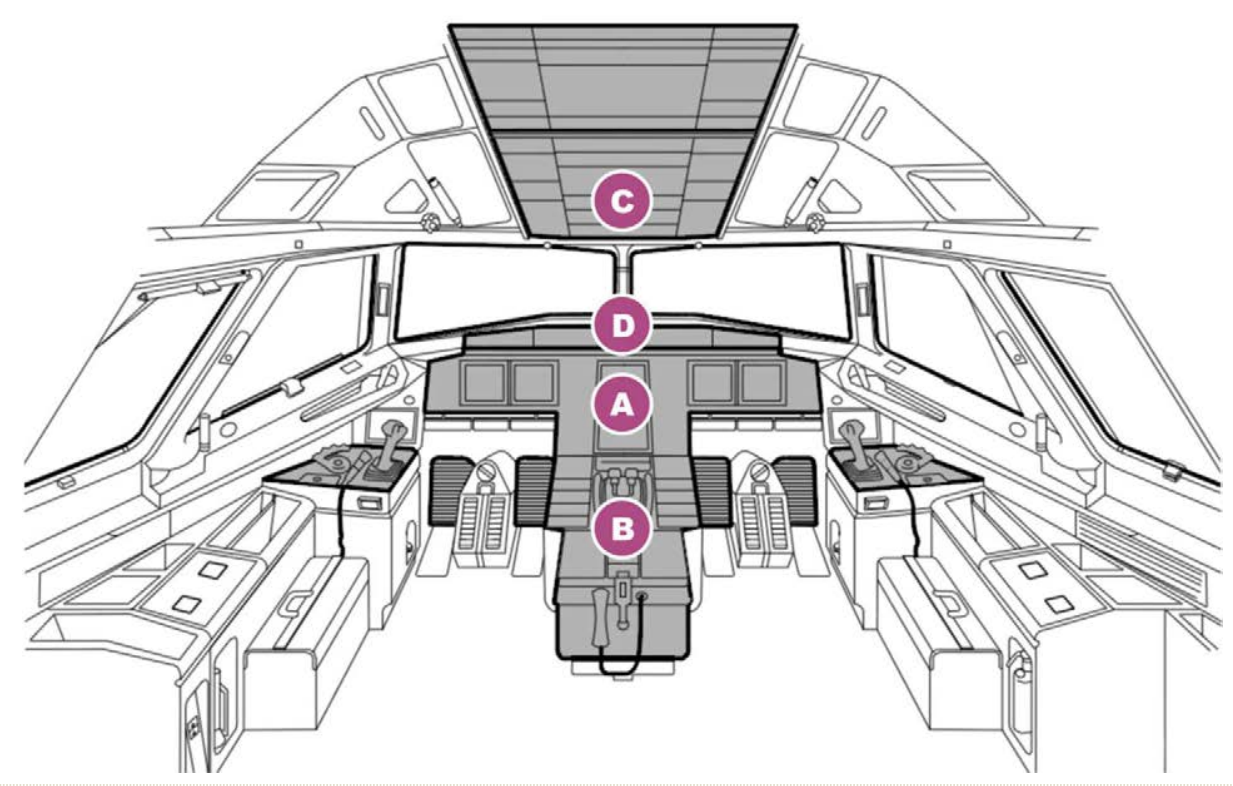

Figura 2-28: Esquema general de paneles de control e indicación de la serie A319/320/321. (Airbus, 1998)

Los paneles de instrumentación de las aeronaves proveen de cierta información geo-espacial al piloto, aunque su función principal es la de mantener informado al piloto sobre el resultado de la actuación sobre los mandos de control. Así, ciertos instrumentos presentan al piloto lecturas constantes de la posición y actitud de la aeronave con respecto al espacio que le rodea en términos de rumbo, altura sobre el terreno, velocidad, inclinación, etc. Los modelos más avanzados, incluso, poseen un sistema de prevención anticipada de colisiones con el terreno (EGPWS) (R. B. Wood y Howells, 2001) que automatiza el análisis de instrumentación y cartografía necesario para evitar este tipo de riesgos.

Algunos de los instrumentos que facilitan determinada información espacial al piloto (FAA, 2008) son el horizonte artificial, el altímetro, el indicador de rumbo, el indicador de velocidad aerodinámica, el indicador de velocidad respecto a suelo y el indicador de velocidad vertical. La tendencia actual de la industria es agrupar todos los elementos de información en pantallas electrónicas, sindicando las acciones de los controles de instrumentación en sencillas teclas multifunción asociadas a estas pantallas (Kershner, 2002). A las cabinas de vuelo que poseen este tipo de paneles de control se les denomina "de tipo glass-cockpit", por el predominio de los displays digitales (Kershner, 2002; Sorin, 2003). En el caso de las pequeñas aeronaves ligeras, cuya instrumentación es muy sencilla y nada profusa en la utilización de pantallas electrónicas, los pilotos pueden complementar la misma con pequeños dispositivos portátiles con capacidad de recepción GPS, permitiéndoles así disponer de datos de posicionamiento (Moya y Bernabé, 2011); es un caso especial en el que el piloto sube al avión su propia instrumentación. 


\subsubsection{La provisión}

Dejando a un lado los paneles de instrumentación, las tripulaciones en vuelo disponen, fundamentalmente, de dos fuentes primarias de información: los Servicios de Tránsito Aéreo (ATS) y la Cartografía Aeronáutica. Además de acelerar y mantener ordenadamente el movimiento del tránsito aéreo, los servicios ATS -expresión aplicada, según el caso, a los servicios de información de vuelo, alerta y control de tránsito aéreo- tienen como misión proveer al piloto de información crítica para la realización segura y eficaz de los vuelos (ICAO, 2005b). En concreto:

a) Impiden situaciones potencialmente peligrosas al usuario, gracias a la transmisión normalizada de instrucciones que eviten colisiones con obstáculos del terreno u otras aeronaves.

b) Facilitan información útil para la realización segura y eficaz de los vuelos, tal como la situación meteorológica prevista, el estado de la infraestructura, la congestión de tráfico en áreas terminales, etc.

El flujo de información que se establece entre los servicios de información ATS y las aeronaves es bidireccional: el comandante de una aeronave provista de equipo de radiocomunicaciones debe transmitir informes de posición, intenciones y cualquier modificación ulterior al servicio ATS correspondiente. Este último puede así particularizar adecuadamente la información a suministrar.

La comunicación Tierra/Aire (T/A) o viceversa se basa en los denominados Sistemas de Comunicaciones de Voz (SCV) (ICAO, 2001; Tooley y Wyatt, 2007), aunque también existe un sistema de enlace digital de datos $(A C A R S)^{70}$ que mantiene en comunicación constante a las compañías aéreas con sus vuelos a través de mensajes cortos de texto (Carlsson, 2002; Ontiveros, 2009). Tras analizar las características de los sistemas SCV a través de diferentes fuentes -fundamente informes finales de accidentes e incidentes en las que se identificaran como una de las causas problemas relacionados con los SCV en distinto grado-y cotejar las conclusiones propias con las opiniones de distintos pilotos de aerolíneas, evidenciamos que el soporte tecnológico habitual de la provisión de información ATC -comunicaciones de voz vía radiofrecuencia- impide asegurar en cualquier posición y circunstancia:

70 Diseñado en 1978 por ARINC para reemplazar las comunicaciones VHF (Carlsson, 2002), el sistema ACARS acrónimo de Aircraft Adressing and Reporting System- es un sistema de enlace digital vía radio o satélite capaz de enviar mensajes de texto relativamente simples que mantiene en comunicación constante a las compañías aéreas con sus vuelos, de igual modo que se envían mensajes automáticos a la compañía a la que pertenece el avión cuando se produce algún tipo de fallo, lo que queda registrado y facilita las labores de mantenimiento. 
1. La continuidad del servicio. La falta de cobertura en zonas oceánicas, deshabitadas o lejos de los centros de control impiden que las tripulaciones puedan hacer acopio de información vía ATC en cualquier momento ${ }^{71}$.

2. La integridad de la información. El sistema de provisión debe de ser tal que entregue la información al destinatario sin variar nada de lo enviado por el remitente. Las interferencias y ruido al que están sujetas las comunicaciones por radio, y las limitaciones propias de las comunicaciones orales, condicionan enormemente la integridad de la información ${ }^{72}$.

3. La provisión de forma inmediata de la información requerida. La limitación y congestión de frecuencias de radio en las zonas aeroportuarias provocan demoras en el establecimiento de comunicaciones.

4. La edición y perdurabilidad del mensaje. La sucesión de información es efímera, no se aloja en contenedor físico alguno a través del cual pueda consultarse a posteriori -salvo grabación-. Tampoco es un mensaje sobre el que se tenga capacidad física de manipular la información en ella dispuesta, como sí ocurre con los formatos gráficos. En definitiva, es totalmente dependiente de la capacidad de memoria del ser humano $^{73}$.

Aun siendo reconocida como una fuente primaria de información, en el caso de esta investigación no consideramos adecuada la toma en consideración de las comunicaciones vía radio de los servicios ATS por las razones anteriormente señaladas, es decir, no permiten garantizar en todo momento la continuidad, integridad, inmediatez y perdurabilidad de la información. En consecuencia, y a efectos de la investigación, acotaremos el alcance de la cuestión e identificaremos a partir de este momento a las cartas aeronáuticas como única fuente a considerar para la provisión de información aeronáutica en vuelo.

${ }^{71}$ El accidente del vuelo AF447 de Air France de 2009 sobre el Océano Atlántico (France, 2012) volvió a poner de manifiesto que a día de hoy todavía existen graves dificultades de comunicación en áreas a partir de unas 150 millas de distancia de la costa, en las que se producen tanto zonas negras de cobertura radar como grandes problemas en los Sistemas de Comunicación por Voz por culpa de las interferencias en los enlaces de Muy Alta Frecuencia (VHF).

${ }^{72}$ En el accidente aéreo del aeropuerto tinerfeño de Los Rodeos de 1977 -impacto entre dos Boeing B747 con el resultado de 583 fallecidos-, el "standby for take-off... I will call you" de la torre de control, coincidió con el "we are still taking down the runway" del avión estadounidense de PANAM, lo que hizo que la transmisión no llegara con toda la claridad que hubiera sido de desear. El silbido que interfirió la comunicación duró cerca de tres segundos (España, 1977).

${ }^{73}$ Cuando en el accidente de Los Rodeos el Copiloto del KLM repite la autorización de ATC, finaliza con "we are now at take-off", por lo que el controlador, a quien no se ha solicitado permiso para despegar -y por consiguiente no haberlo autorizado-, no entiende que el avión holandés están despegando (España, 1977). 


\subsubsection{La publicación}

Según (Aena, 2013d), su División de Información Aeronáutica, actuando en nombre de las autoridades de Aviación Civil del Estado, es la entidad encargada de prestar el Servicio de Información Aeronáutica (AIS) ${ }^{74}$, siendo responsable de recibir o crear, cotejar o ensamblar, editar, formatear, publicar, almacenar y distribuir la información y los datos aeronáuticos necesarios para garantizar la seguridad, regularidad y eficiencia de la navegación aérea en España ${ }^{75}$. En consecuencia es la responsable de la producción de la cartografía aeronáutica necesaria utilizada por la aviación civil, tanto nacional como internacional, en territorio español y en aquellas zonas donde el Estado tenga la responsabilidad de suministrar servicios de tránsito aéreo (España, 2002).

Esta producción cartográfica se edita como parte integrante de la Publicación de Información Aeronáutica o Aeronautical Information Publication (AIP), manual expedido por cualquier Estado, o con su autorización, que contiene la información aeronáutica de carácter permanente y cambios temporales de larga duración, indispensable para la navegación ${ }^{76}$ en el espacio aéreo de su responsabilidad (ICAO, 2004). La publicación AIP, disponible para su consulta en el portal Web de Aena ${ }^{77}$, se encuentra dividida en tres partes ${ }^{78}$ [Tabla 2-2]. A su

${ }^{74}$ Este servicio es el encargado de suministrar la información aeronáutica necesaria para que las operaciones aéreas se desarrollen con seguridad, regularidad y eficiencia (ICAO, 2004). Toda esa información se publica y distribuye desde los servicios centrales de Navegación Aérea de forma global como paquete de documentación integrada de información aeronáutica (Aena, 2013e), compuesto por la Publicación de Información Aeronáutica (AIP), suplementos y enmiendas, Circulares de Información Aeronáutica (AIC) y NOTAM.

${ }^{75}$ Todo Estado contratante del convenio OACI deberá suministrará servicios de información aeronáutica o bien llegar a un acuerdo con uno o varios Estados contratantes para el suministro conjunto de los servicios o como alternativa delegar la autoridad de suministrar los servicios a una entidad extragubernamental, siempre que se satisfagan adecuadamente las normas y métodos recomendados en (ICAO, 2004)

${ }^{76}$ Siempre que sea factible, la AIP ha de presentarse en forma que facilite su utilización en vuelo (ICA0, 2004).

${ }^{77}$ En (Aena, 2013b) se especifica que la información contenida en la web de AIS es un fiel reflejo de la difundida en papel, que se encuentra disponible en los aeródromos gestionados por Aena en todo el país. Sin embargo, según la propia Aena (2013c),únicamente el texto impreso, publicado en el AIP, tiene la consideración de oficial y auténtico, ya que Internet no está reconocido por $\mathrm{OACl}$ como una red segura para el suministro de información aeronáutica.

${ }^{78}$ Según dicta ICAO (2004), las publicaciones AIP deberán dividirse en tres partes, con secciones y subsecciones, cuya referencia uniforme permita hacer electrónicamente el almacenamiento y extracción ordinaria de datos. 
vez, toda la información suministrada en la AIP se mantiene actualizada mediante enmiendas regulares ${ }^{79}$, enmiendas AIRAC ${ }^{80}$, suplementos ${ }^{81}$, NOTAM ${ }^{82}$ y circulares $^{83}$.

\begin{tabular}{|ll|}
\hline Partes AIP & Contenido \\
\hline Generalidades (GEN) & $\begin{array}{l}\text { Consta de cinco secciones que contienen información de carácter ad- } \\
\text { ministrativo y explicativo. }\end{array}$ \\
\hline En Ruta (ENR) & $\begin{array}{l}\text { Consta de siete secciones que contienen información relativa al espa- } \\
\text { cio aéreo y su utilización: procedimientos y normas ATS, descripción } \\
\text { del espacio aéreo, etc. }\end{array}$ \\
\hline Aeródromos (AD) & $\begin{array}{l}\text { Consta de cuatro secciones que contienen información relativa a los } \\
\text { aeródromos/helipuertos del territorio español y su utilización: datos } \\
\text { geográficos y administrativos, características físicas, cartografía aso- } \\
\text { ciada, etc. }\end{array}$ \\
\hline
\end{tabular}

Tabla 2-2: Partes en las que se divide una publicación AIP (Aena, 2013b).

${ }^{79}$ Publicadas de forma mensual, las Enmiendas Regulares ó amendment (AMDT) contienen pequeños cambios y correcciones editoriales, así como información de carácter permanente que ha sido previamente distribuida en NOTAM o suplementos (Aena, 2013b).

${ }^{80}$ La información predecible de carácter permanente y de importancia para la navegación aérea y/o las operaciones aeroportuarias se incorporan a la AIP a intervalos de 28 días mediante Enmiendas AIRAC ó Aeronautical Information Regulation And Control (AIRAC AMDT) (Aena, 2013b). Estas enmiendas pueden visualizarse con antelación a su fecha de efectividad, lo que permite realizar una planificación previa de su contenido.

${ }^{81}$ Los Suplementos complementan o varían la información contenida en el AIP y contienen información de carácter temporal que requiere textos extensos y/o gráficos explicativos (Aena, 2013b). Existen Suplementos Regulares (REGULAR SUP) y Suplementos AIRAC (AIRAC SUP).

${ }^{82}$ Los NOTAM o Notice TO Air Men son avisos distribuidos por medios de telecomunicaciones que contiene información relativa al establecimiento, condición o modificación de cualquier instalación aeronáutica, servicio, procedimiento o peligro, cuyo conocimiento oportuno es esencial para el personal encargado de las operaciones de vuelo (ICAO, 2004).

${ }^{83}$ Las Circulares de Información Aeronáutica (AIC) se reservan para publicar información que no requiera la iniciación de un NOTAM ni la inclusión en la AIP: cambios en la legislación o reglamentos, implantación de nuevas instalaciones, cambios en procedimientos de publicación, etc. (Aena, 2013b; ICA0, 2004) 
Al ser el Estado español miembro de la Organización Internacional de Aviación Civil (OACl), la cartografía publicada por el AIS-España debe ajustarse a las exigencias mínimas requeridas por la misma, excepto en aquellos casos que se indique lo contrario. Como consecuencia, la AlP dispone de seis tipos diferentes de cartas aeronáuticas que la $\mathrm{OACl}$ considera de publicación obligatoria [Tabla 2-3], cinco tipos de cartas de publicación condicional| ${ }^{84}$ [Tabla 2-4] y seis tipos de cartas que son de publicación opcional| ${ }^{85}$ [Tabla 2-5] (ICAO, 1992; Salazar, 2008). En orden a asegurar la necesaria de uniformidad en el ámbito internacional, en ICAO (2009a) figuran distintas disposiciones normativas específicas para cada uno de los 17 tipos de cartas.

\begin{tabular}{|ll|}
\hline Cartas obligatorias & Descripción \\
\hline $\begin{array}{l}\text { Plano de obstáculos de aeró- } \\
\text { dromo - OACl tipo A }\end{array}$ & $\begin{array}{l}\text { Para aquellos aeródromos en los que existen obstáculos } \\
\text { destacados en el área de la trayectoria de despegue. }\end{array}$ \\
\hline $\begin{array}{l}\text { Carta topográfica para aprox. de } \\
\text { precisión - OACl }\end{array}$ & $\begin{array}{l}\text { Para todos los aeródromos que tienen disponible aproxi- } \\
\text { mación de precisión de categorías II y III. }\end{array}$ \\
\hline $\begin{array}{l}\text { Carta de navegación en ruta - } \\
\text { OACl }\end{array}$ & $\begin{array}{l}\text { Para todas las zonas donde se hayan establecido regio- } \\
\text { nes de información de vuelo (FIR). }\end{array}$ \\
\hline $\begin{array}{l}\text { Carta de aproximación por instru- } \\
\text { mentos - OACl }\end{array}$ & $\begin{array}{l}\text { Para aquellos aeródromos donde se hayan establecido } \\
\text { procedimientos de aproximación instrumentales. }\end{array}$ \\
\hline $\begin{array}{l}\text { Plano de aeródromo/helipuerto- } \\
\text { OACl }\end{array}$ & $\begin{array}{l}\text { Necesario para todos aquellos aeródromos/helipuertos } \\
\text { regularmente utilizados por la aviación civil. }\end{array}$ \\
\hline $\begin{array}{l}\text { Carta aeronáutica mundial - OACl, } \\
\text { Publicada de acuerdo a lo indicado en el propio anexo 4. }\end{array}$ \\
\hline
\end{tabular}

Tabla 2-3: Cartas de publicación obligatoria disponibles en la AIP-España (Aena, 2013a)

\footnotetext{
${ }^{84}$ Han de presentarse determinadas circunstancias para su publicación en la AIP.

${ }^{85}$ En este caso la OACl delega a las autoridades de cada país la decisión sobre su publicación si consideran que estas cartas contribuirán a la seguridad, regularidad y eficiencia de las operaciones aéreas.
} 


\begin{tabular}{|ll|}
\hline Cartas condicionales & Descripción \\
\hline $\begin{array}{l}\text { Plano de obstáculos de aeró- } \\
\text { dromo - OACl tipo B }\end{array}$ & $\begin{array}{l}\text { Necesario sólo si en el AIP no se publican los datos sobre } \\
\text { obstáculos que requieren los explotadores para generar } \\
\text { sus procedimientos. }\end{array}$ \\
\hline Carta de área - OACI & $\begin{array}{l}\text { Requerida si las rutas o los requisitos de notificación de } \\
\text { posición son complicados y no pueden indicarse ade- } \\
\text { cuadamente en la carta habitual para ello (Carta de nave- } \\
\text { gación en ruta - OACI). }\end{array}$ \\
\hline $\begin{array}{l}\text { Carta de salida normalizada - } \\
\text { vuelo por instrumentos (SID) - } \\
\text { OACl }\end{array}$ & $\begin{array}{l}\text { Denominadas cartas SID, se publican cuando existe una } \\
\text { salida normalizada de este tipo y no se pueda indicar con } \\
\text { la claridad suficiente en la Carta de área - OACl. }\end{array}$ \\
\hline $\begin{array}{l}\text { Carta de llegada normalizada - } \\
\text { vuelo por instrumentos (STAR) - } \\
\text { OACl }\end{array}$ & $\begin{array}{l}\text { Denominadas cartas STAR, se publican cuando existe } \\
\text { una llegada normalizada y no se pueda indicar con la cla- } \\
\text { ridad suficiente en la Carta de área - OACl. }\end{array}$ \\
\hline Carta de aproximación visual - \\
OACl
\end{tabular}

Tabla 2-4: Cartas de publicación condicional disponibles en la AIP-España (Aena, 2013a)

\begin{tabular}{ll}
\hline Cartas opcionales & Descripción \\
\hline $\begin{array}{l}\text { Plano de obstáculos de aeró- } \\
\text { dromo-OACl, Tipo C }\end{array}$ & $\begin{array}{l}\text { Se publica como ayuda para determinar las alturas críti- } \\
\text { cas en algún procedimiento. }\end{array}$ \\
\hline $\begin{array}{l}\text { Plano de aeródromo para movi- } \\
\text { mientos en tierra - OACl }\end{array}$ & $\begin{array}{l}\text { Se publica sólo cuando en el Plano de aeródromo / heli- } \\
\text { puerto - OACI no pueden indicarse con suficiente clari- } \\
\text { dad datos necesarios para el movimiento de aeronaves } \\
\text { en las calles de rodaje. }\end{array}$
\end{tabular}




\begin{tabular}{|ll|}
\hline $\begin{array}{l}\text { Plano de estacionamiento y atra- } \\
\text { que - OACl }\end{array}$ & $\begin{array}{l}\text { Se publica cuando, por la complejidad del terminal aé- } \\
\text { reo, no puede señalarse en el plano de aeródromo / heli- } \\
\text { puerto - OACl ni en el Plano de aeródromo para movi- } \\
\text { mientos en tierra - OACl suficiente información con res- } \\
\text { pecto al estacionamiento de las aeronaves. }\end{array}$ \\
\hline $\begin{array}{l}\text { Carta aeronáutica - OACl } \\
\text { 1:500.000 }\end{array}$ & $\begin{array}{l}\text { Cuando los requisitos para la navegación visual indiquen } \\
\text { que puede sustituir o complementar a la Carta aeronáu- } \\
\text { tica mundial - OACl, 1:1.000.000. }\end{array}$ \\
\hline - OACl, escala pequeña & $\begin{array}{l}\text { Cuando los requisitos para la navegación visual indiquen } \\
\text { que puede sustituir o complementar a la Carta aeronáu- } \\
\text { tica mundial - OACl, 1:1.000.000. }\end{array}$ \\
\hline Carta de posición - OACI & $\begin{array}{l}\text { Son cartas útiles para mantener un registro continuo de } \\
\text { la posición de una aeronave en vuelo sobre zonas oceá- } \\
\text { nicas o escasamente pobladas. }\end{array}$ \\
\hline
\end{tabular}

Tabla 2-5: Cartas de publicación opcional disponibles en la AIP-España (Aena, 2013a)

Adicionalmente a las anteriores, el AIS español (Aena, 2013a) publica otro tipo de cartas que intentan completar ciertas necesidades de información, entre otras la carta para guía vectorial y carta de cobertura (RADAR), las cartas de circulación VFR para los TMA de Madrid, Palma y Barcelona, la carta de rutas migratorias de aves, etc.

Otro criterio de clasificación para la tipología de cartas normalizadas OACl es el de su utilización principal, de tal manera que en (ICAO, 1992) los 17 tipos normalizados se encuentran distribuidos en 4 diferentes grupos [Tabla 2-6].

\begin{tabular}{|ll|}
\hline Grupos de cartas OACI & Tipos incluidos \\
\hline Grupo 1: Cartas destinadas exclu- & 1. Plano de obstáculos de aeródromo - Tipo A \\
sivamente a la planificación & $\begin{array}{l}\text { 2. Plano de obstáculos de aeródromo - Tipo B } \\
\text { 3. Plano de obstáculos de aeródromo - Tipo C } \\
\text { 4. Carta topográfica para aprox. de precisión }\end{array}$ \\
\hline Grupo 2: Cartas destinadas a las & 5. Carta de navegación en ruta \\
fases comprendidas entre el des- & 6. Carta de área \\
pegue y el aterrizaje & 7. Carta de salida normalizada - vuelo por instrumentos - \\
& (SID) \\
& 8. Carta de llegada normalizada - vuelo por instrumentos \\
\hline
\end{tabular}




\begin{tabular}{|ll|}
\hline & - (STAR) \\
& $\begin{array}{l}\text { 9. Carta de aproximación por instrumentos } \\
\text { 10. Carta de aproximación visual }\end{array}$ \\
& \\
\hline Grupo 3: Cartas destinadas a los & 11. Plano de aeródromo/helipuerto \\
movimientos de las aeronaves en & 12. Plano de aeródromo para movimientos en tierra \\
la superficie del aeródromo & 13. Plano de estacionamiento y atraque \\
\hline Grupo 4: Cartas destinadas a la & 14. Carta aeronáutica mundial - OACl, 1:1.000.000 \\
navegación aérea visual, planifi- & 15. Carta aeronáutica - OACI 1:500.000 \\
cación y determinación de la po- & 16. Carta de navegación aeronáutica - OACl, escala pe- \\
sición & queña \\
& 17. Carta de posición \\
\hline
\end{tabular}

Tabla 2-6: Grupos de cartas 0ACl según su utilización principal (ICA0, 1992)

Como aportación, se clasifica razonadamente las tipologías de planos y cartas aeronáuticas OACl recogidas en el AIP español según su uso en las distintas fases de vuelo detalladas en 2.4 -Fases y procedimientos-, aprovechando además para resumir los usos característicos de cada tipo que se encuentran referidas en (ICAO, 2012a). Para facilitar el cotejo con los grupos de la [Tabla 2-6], se indica entre paréntesis la numeración de tipos reseñada en (ICAO, 1992).

\section{a) Fase de rodaje}

El plano de aeródromo/helipuerto (11) [Figura 2-29] que es necesario en esta fase proporciona una ilustración del aeródromo o helipuerto que permite al piloto reconocer su configuración general y las características más importantes para seguir con acierto las instrucciones para el rodaje. Indica las áreas de movimiento del aeródromo o helipuerto, los emplazamientos de los indicadores visuales, las ayudas de guía para el rodaje, la iluminación del aeródromo o helipuerto, los hangares, edificios terminales y puestos de estacionamiento de aeronave. También incorpora los puntos de referencia necesarios para verificar los sistemas de navegación de la aeronave y presenta diferente información operacional, como puede ser la resistencia del pavimento y las frecuencias de las instalaciones de radiocomunicaciones.

En los grandes aeropuertos, donde no es posible representar toda la información en un único documento, se proporciona información complementaria en el plano de aeródromo para movimientos en tierra (12) y en el plano de estacionamiento y atraque (13). 


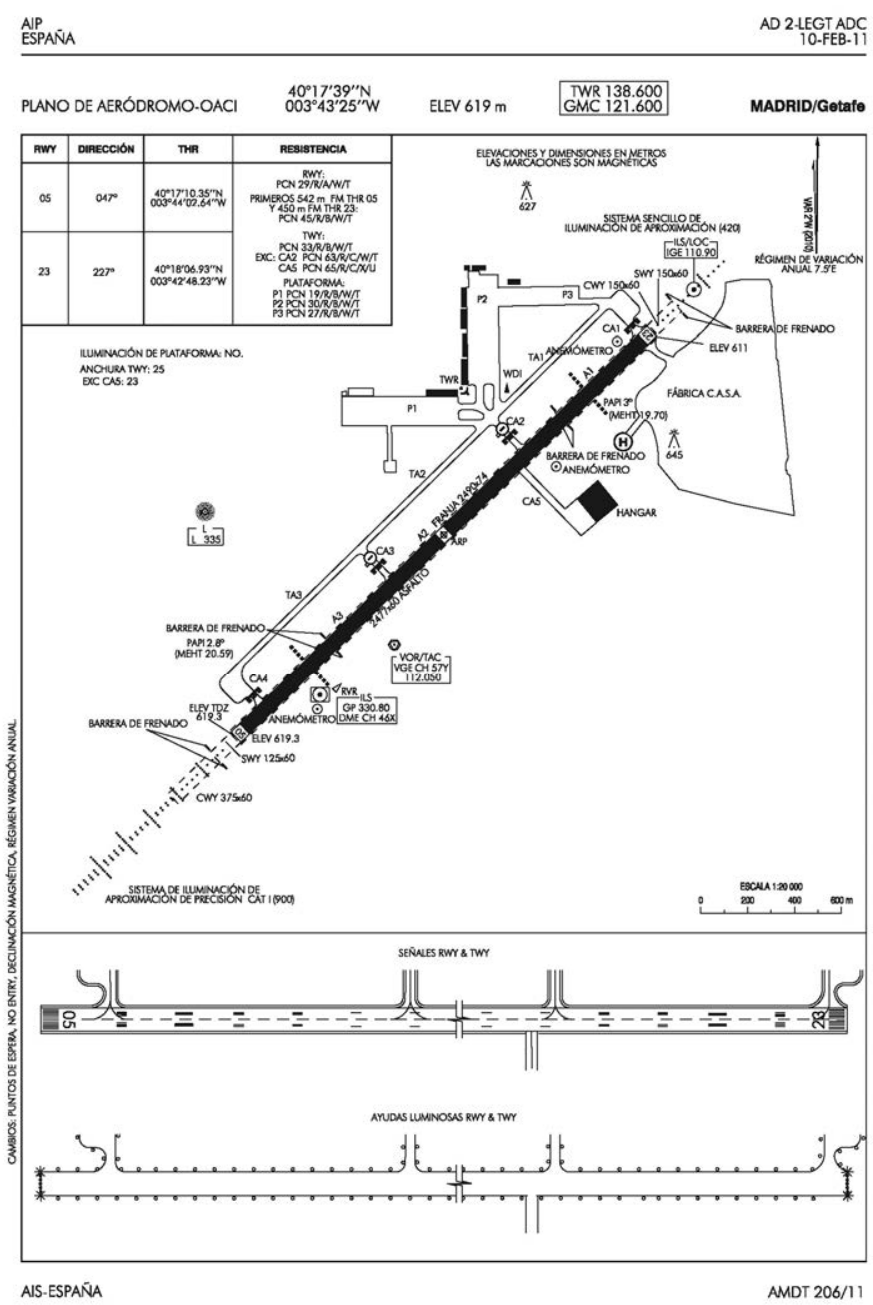

Figura 2-29: Plano de aeródromo - OACI. ADC - LEGT. (Aena 2013a)

b) Fases de salida (ascenso) y llegada (descenso)

Normalmente los requisitos de las rutas de los servicios de tránsito aéreo son diferentes para las salidas y las llegadas. Esto suele conllevar que no puedan representarse con suficiente claridad en la carta del área circundante al aeródromo, por lo que se dedican documentos separados. Así, la carta de salida normalizada de vuelo por instrumentos - SID (7) [Figura 2-30] facilita información sobre las rutas a seguir desde la fase de despegue hasta la fase en ruta, para aquellos aeródromos en los que se hayan establecido unas rutas normalizadas. Su equivalente para la fase de descenso es la Carta de llegada normalizada de vuelo por instrumentos - STAR (8). De manera complementaria, la carta de área (6) proporciona datos sobre los procedimientos a seguir por las aeronaves que operen en las áreas terminales (TMA) u otras áreas de estructura compleja del espacio aéreo. 


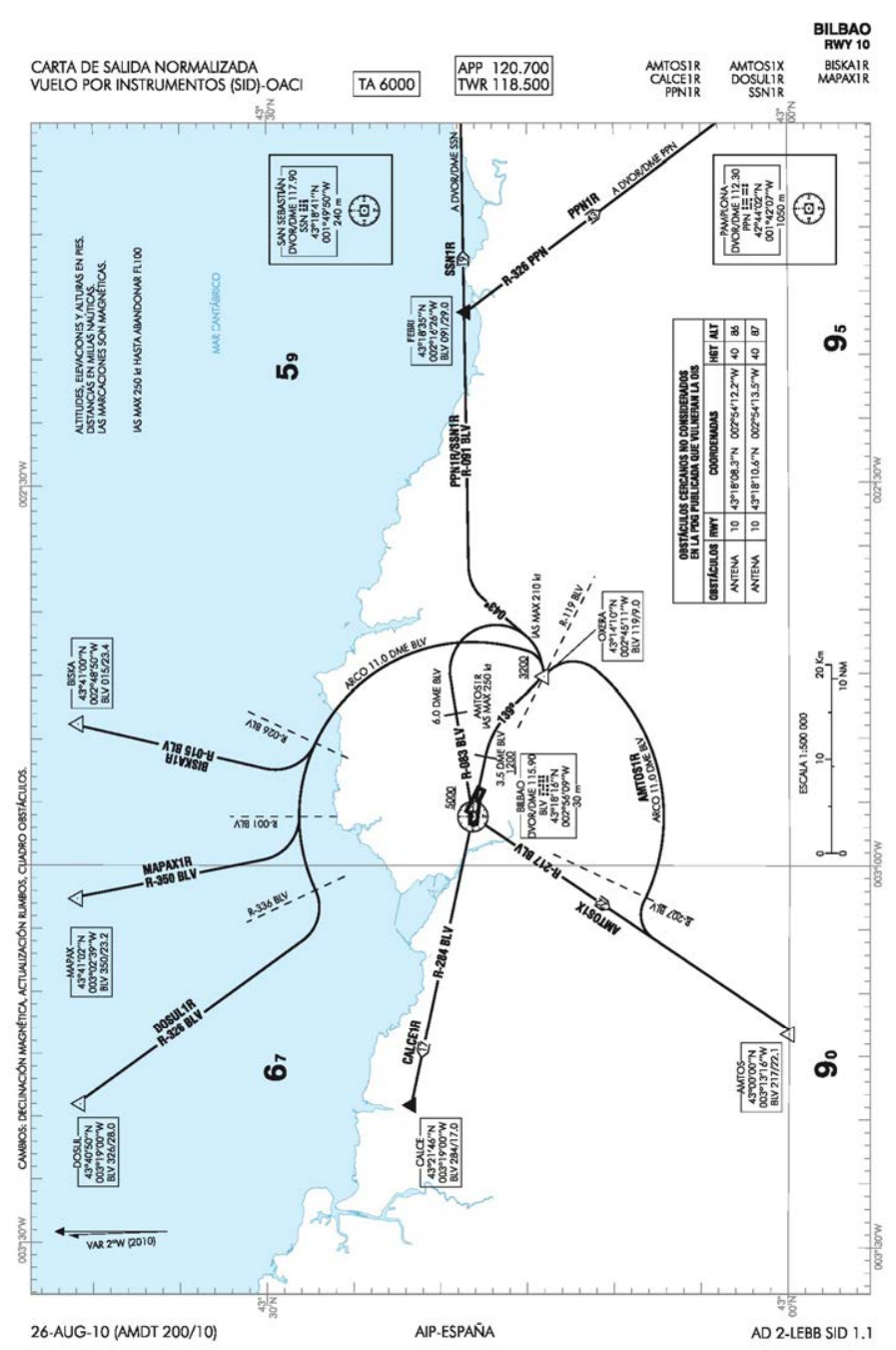

Figura 2-30: Carta de salida normalizada por instrumentos (SID) - OACI. SID 1 / RWY 10 - LEBB. (Aena, 2013a)

Finalmente, la información sobre la altura de los obstáculos en torno a los aeropuertos tiene tal importancia para la seguridad de las operaciones que es recogida en un plano independiente. Así, en los planos de obstáculos de aeródromo de tipo A (1) [Figura 2-31], B (2) y C (3) se proporciona información detallada sobre los obstáculos. En ellos se incluyen los obstáculos en el área de la trayectoria de despegue, distancias declaradas en ambos sentidos, el área de la trayectoria de despegue, vistas en planta y perfil de la pista, zonas libres de obstáculos, etc. Su finalidad consiste en proporcionar a las tripulaciones los datos necesarios para que puedan efectuar los complejos cálculos de masa de despegue, distancia y potencia necesaria, entre ellos los necesarios para hacer frente a casos de emergencia, por ejemplo, un fallo de motor en pleno despegue. 


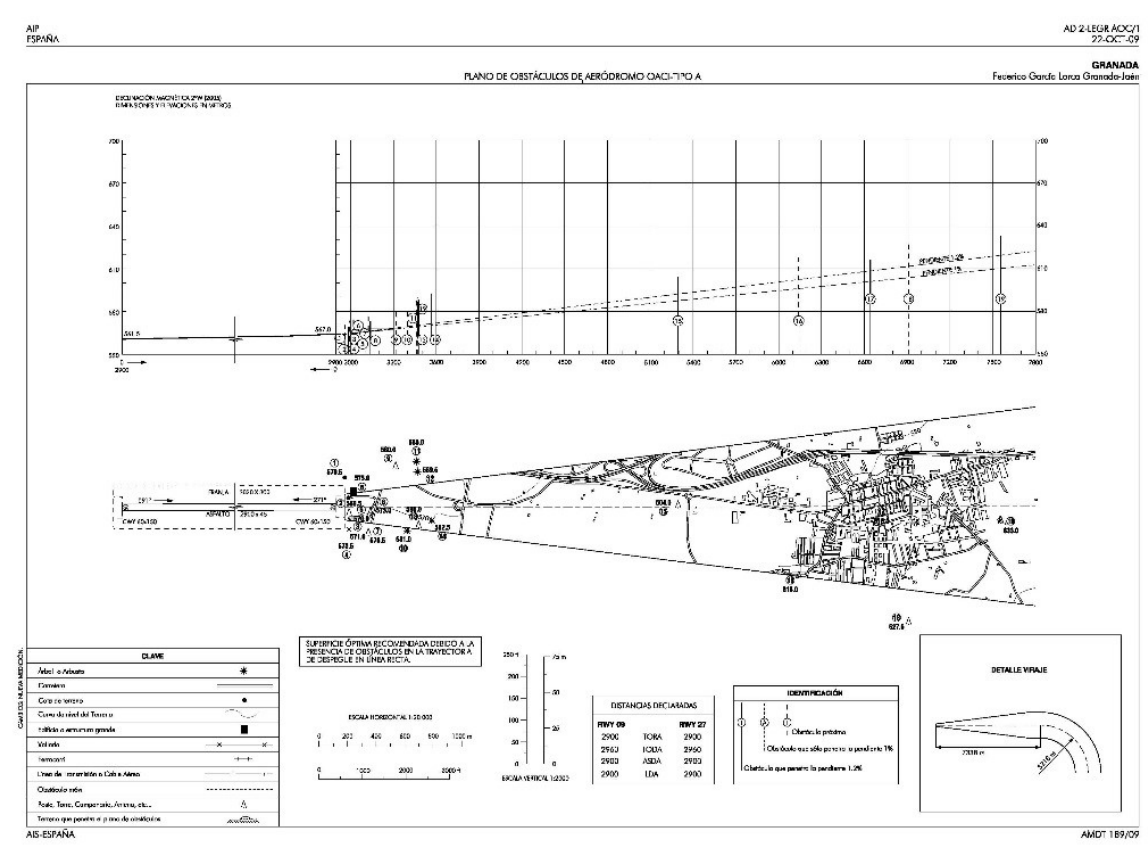

Figura 2-31: Plano de obstáculos de aeródromo (tipo A) - OACI. AOC/1 - LEGR. (Aena, 2013a)

\section{c) Fase de crucero (en ruta)}

La carta de navegación en ruta (5) [Figura 2-32] es la cartografía destinada precisamente a representar la red de aerovías, radioayudas para la navegación y el resto de elementos del sistema de servicios de tránsito aéreo indispensables para la navegación en ruta. Cuando los vuelos atraviesan extensas zonas oceánicas poco pobladas, la carta de navegación aeronáutica de escala pequeña (16) y la carta de posición (17) proporcionan un medio de mantener en vuelo un registro continuo de la posición de la aeronave; estos dos tipos suelen producir como complemento de las anteriores cartas de navegación en ruta que son más densas y complejas en información.

En el caso de los vuelos visuales VFR, la carta visual de navegación de la Península Ibérica a escala 1:1.000.000 (14), o cualquiera de las diez cartas que componen la serie a escala 1:500.000 (15) expresan datos sobre la topografía del terreno, localización de aeródromos, radio ayudas, zonas prohibidas, restringidas y peligrosas, obstáculos, límites de FIR, etc. siendo ideal para la planificación de las rutas en las operaciones VFR. Con mayor detalle, la carta de circulación VFR (13) reflejan los procedimientos de entrada, salida y tránsito particulares para las operaciones VFR dentro de zonas donde la estructura del espacio aéreo es conflictiva y compleja. 


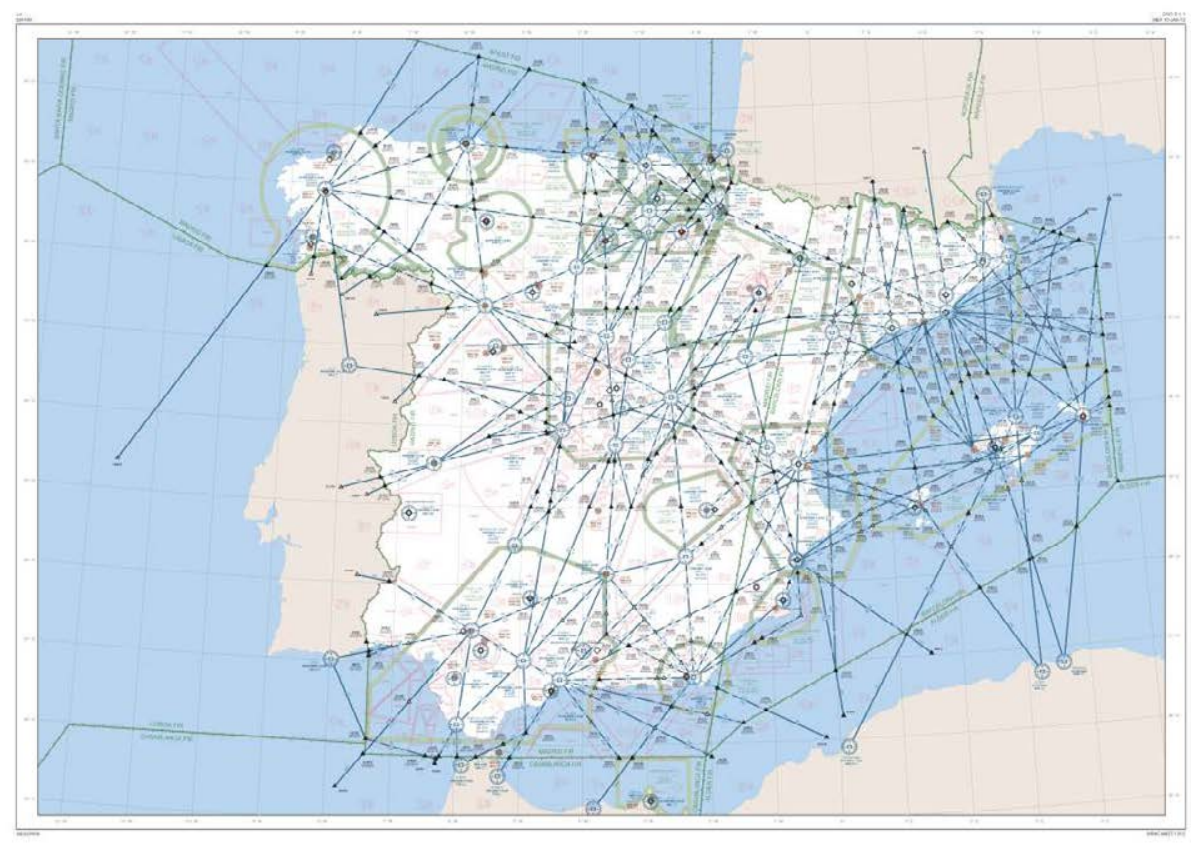

Figura 2-32: Cartas de Radionavegación - Espacio Aéreo Inferior -Península- ENR 6.1.1. (Aena, 2013a)

\section{d) Fase de aproximación}

La carta de aproximación por instrumentos (9) [Figura 2-33] proporciona al piloto una representación gráfica de los procedimientos de aproximación por instrumentos y de los procedimientos de aproximación frustrada que la tripulación habrá de observar cuando deba abortar una operación de aterrizaje. Este tipo de carta contiene una vista en planta y otra de perfil de la aproximación, con detalles completos de las radioayudas para la navegación y la información topográfica y del aeródromo necesaria. En el caso de las aproximaciones de precisión de categorías II y III, se dispone de la carta topográfica para aproximaciones de precisión (4), la cual permite evaluar el efecto del terreno sobre la determinación de la altura de decisión ${ }^{86}$.

${ }^{86}$ Al contrario que los altímetros barométricos clásicos, los Radioaltímetros (RA) utilizados en la última fase del aterrizaje miden la Altura sobre el Nivel del Suelo (AGL) a partir de la emisión de una señal radioeléctrica hacia el terreno - en forma de pulsos o en forma de onda continua modulada en frecuencia-, por lo que las construcciones humanas y determinadas configuraciones orográficas pueden falsear la medida, comprometiendo la correcta determinación de la Altura de Decisión (DH). 


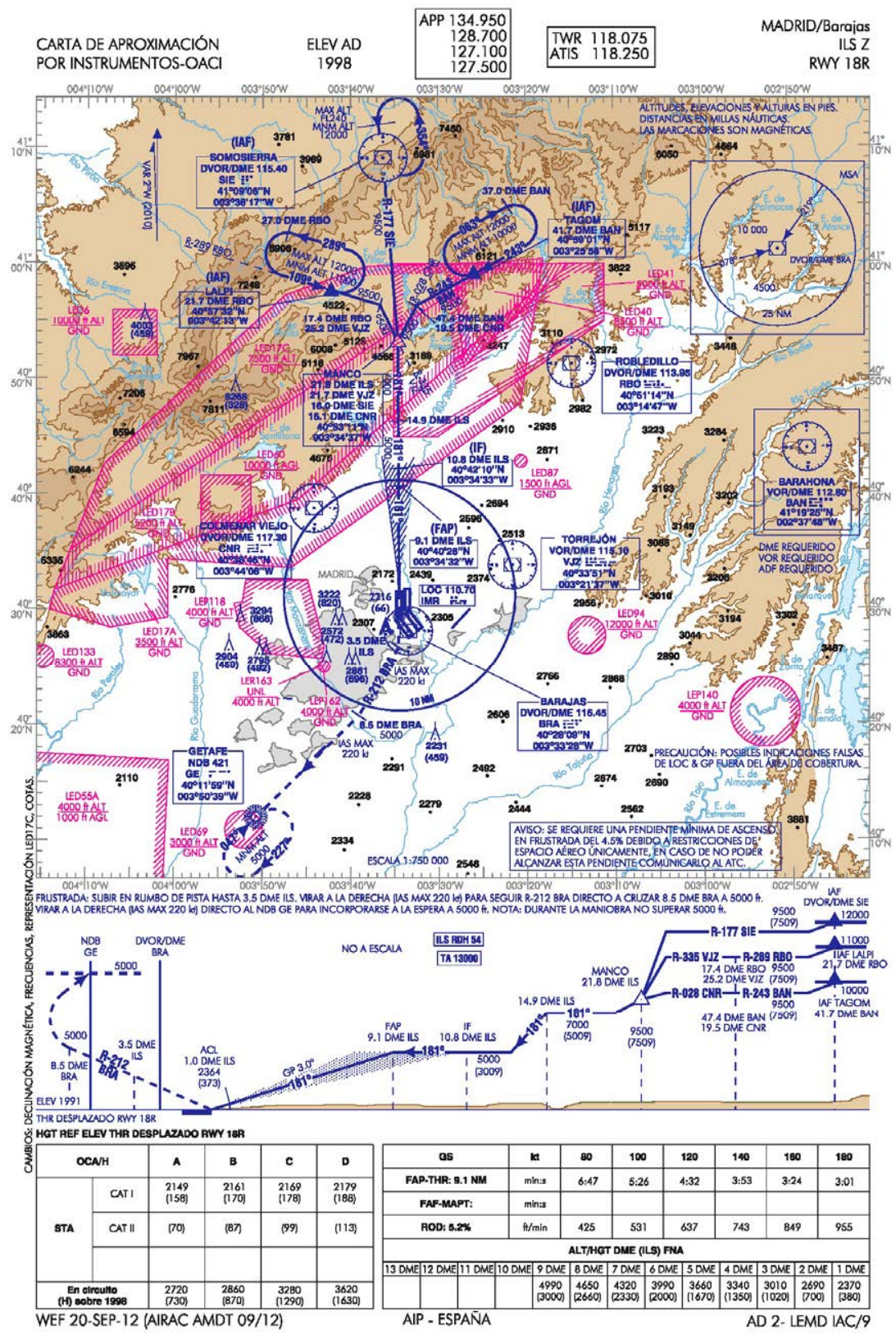

Figura 2-33: Carta de aproximación por instrumentos - OACI. IAC/9 ILS Z RWY 18R - LEMD. (Aena, 2013a)

Cuando en un vuelo VFR se efectúa una aproximación visual, el piloto puede acudir a la carta de aproximación visual (10) [Figura 2-34], la cual ilustra la disposición general de aeródromo y las características del área circundante que pueden reconocerse fácilmente desde el aire.Además de proporcionar orientación, estas cartas están destinadas a destacar posibles peligros tales como obstáculos, elevaciones del terreno y zonas peligrosas del espacio aéreo. 


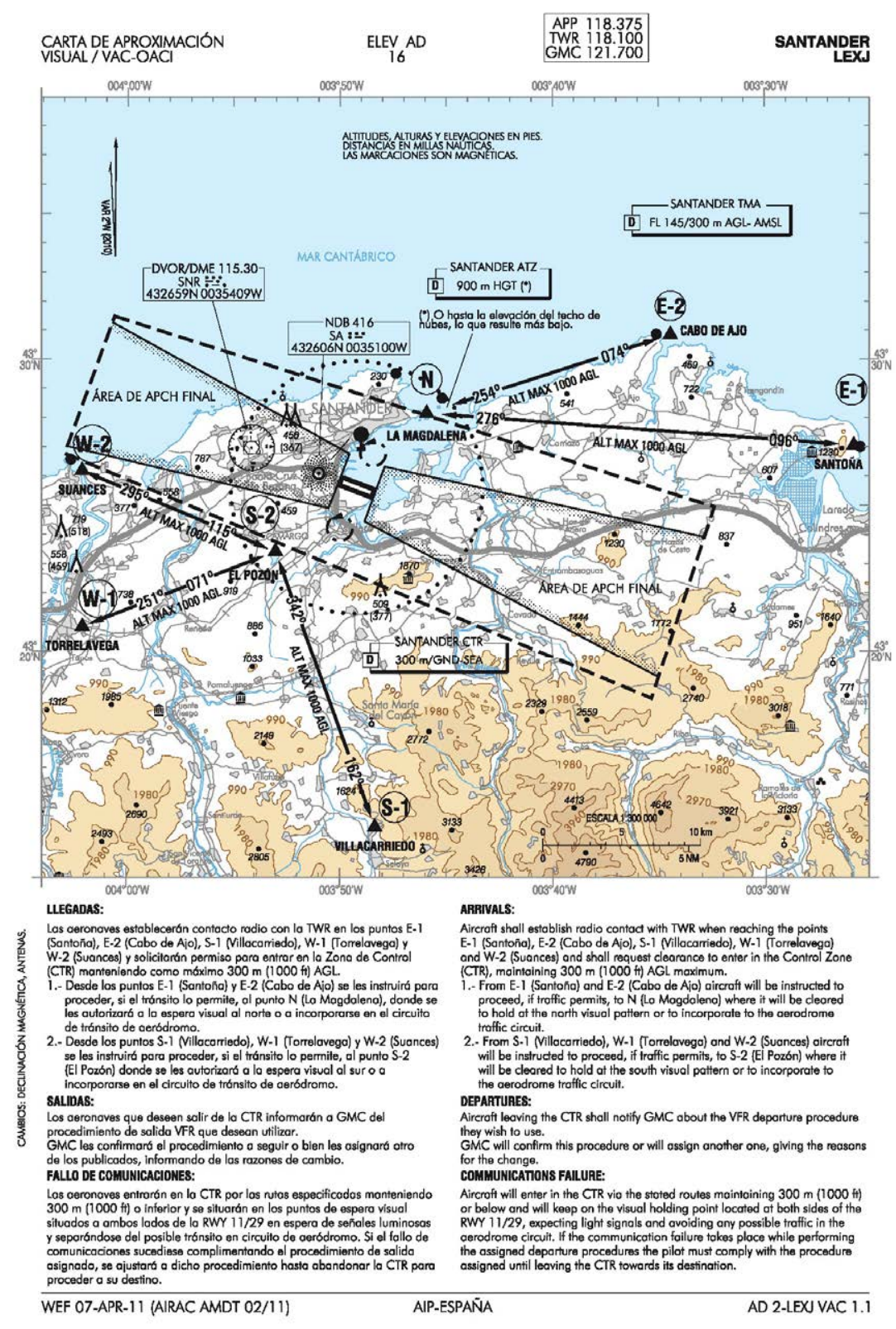

Figura 2-34: Carta de aproximación visual - OACI. VAC/1 - LEXJ. (Aena, 2013a)

\subsubsection{Los formatos}

Como se ha reseñado, el flujo constante de Información geográfica a bordo de una aeronave gira en torno a determinados elementos; a efectos de esta investigación se consideran aquellos contenedores que posibilitan la perdurabilidad del mensaje gráfico que responde a la codificación de la información, y que además sean 
físicamente visibles y tangibles por el usuario: un mapa en papel, una brújula, una pantalla de la instrumentación, etc. A priori, el uso de tales elementos puede ser complementario entre sí, lo que implica que se establece un proceso de comunicación entre el piloto y los diferentes sistemas, dispositivos y objetos alojados en el cockpit; este proceso nos será de particular interés.

Tras el correspondiente examen de la información generada a lo largo de este capítulo, identificamos tres elementos contenedores o formatos de información cartográfica que cumplen con las características anteriormente mencionadas: capacidad para ser manipulado físicamente y perdurabilidad del mensaje portado.

\section{a) Cartas tradicionales en papel}

El papel es el soporte tradicional de la cartografía aeronáutica desde su aparición, aproximadamente en los años veinte del siglo pasado -ver 2.1.110 años en el cielo-. Como formato las cartas en papel cumplen perfectamente las necesidades de medio manejable, condensado y coordinado. Sus dimensiones físicas van desde las grandes cartas plegadas para vuelos visuales y escalas menores, hasta un amplio conjunto de fichas de tamaño más reducido -correspondientes a diferentes procedimientos, rutas, aeródromos, etc.-

La responsabilidad de su confección corresponde por mandato de $\mathrm{OACl}$ a las diferentes entidades gubernamentales que designe cada estado contratante del Convenio sobre Aviación Civil Internacional -ver 2.5.4. La publicación-. También existen distintas empresas privadas editoras de cartas aeronáuticas en papel cuyos productos deben estar, obligatoriamente, validados por las autoridades reguladoras correspondientes.

En el caso específico de los vuelos visuales, cierta cartografía no especializada en el ámbito aeronáutico -por ejemplo, los mapas puramente geográficos y de carreteras- también puede ser destinada al apoyo a la orientación en vuelo, aunque su uso no se encuentra actualmente regulado.

\section{b) Cartas digitales}

El ámbito de la visualización electrónica de información geográfica tiene su origen en la introducción en cabina de las pantallas de Tubos de Rayos Catódicos (CRT) -ver 2.1.6. Los trazos luminosos-. Sin embargo, no es hasta la llegada de la generación de pantallas de tipo Thin-Film Transistor (TFT) cuando se extiende con fuerza el uso del formato digital para la visualización de cartografía aeronáutica. A este hecho contribuyó tanto la mejora de las propiedades de luminosidad, definición, ligereza y eficiencia energética como la polivalencia de los dispositivos portátiles que, actualmente, hacen uso de las pantallas TFT como elemento de salida visual: GPS de mano, agendas y teléfonos inteligentes, ordenadores portátiles, tabletas digitales tipo iPad, etc.-. Todos ellos presentan características muy variables y en constante evolución.

La funcionalidad de la presentación de cartas aeronáuticas electrónicas plenamente desarrollada puede llegar a abarcar mucho más que aquella de las cartas impresas (ICAO, 2009a). Además de la posibilidad de visualizar la carta en su totalidad de forma análoga a una carta en formato papel tradicional, usualmente es posible gestionar la información de interés a través de la activación y desactivación de capas, la modificación dinámica de la escala, la variación de la zona de la carta visualizada, etc. 
Este tipo de capacidades, sumadas a la disponibilidad y el intercambio de información aeronáutica electrónica que posibilitan actualmente las Tecnologías de la Información y las Comunicaciones (TIC), ha creado un entorno muy apropiado para la preparación rápida de cartas electrónicas que pueden presentarse en el puesto de pilotaje -ver 2.1.7. El papel pixelado-. La mayor o menor vinculación con la aviónica de la aeronave implica un rango de capacidades de integración que van desde la simple visualización precisa y permanente de la posición de la aeronave en los dispositivos portátiles independientes que dispongan de un receptor GPS hasta la modificación de la presentación de los objetos gráficos según las especificaciones necesarias para la fase de vuelo u otras condiciones operacionales, propia de los Electronic Flight Bag (EFB) más avanzados.

Como en el caso de las cartas aeronáuticas en soporte papel tradicional, la OACl también recoge una serie de reglamentaciones que intentan que el uso de las cartas electrónicas no esté reñido con la seguridad del vuelo. Las recomendaciones que la OACl dispone (ICAO, 2009a) son prácticamente comunes a lo que se puede esperar de cualquier sistema de visualización electrónico de mapas al uso, sin embargo aportan características particulares sobre el soporte físico -el tamaño apropiado, su capacidad, su visibilidad- que atienden a las circunstancias especiales a las que debe de enfrentarse en su uso en cabina: variación de la luminosidad interior, distancia relativa a la pantalla, usabilidad en condiciones de atención a distintas tareas de navegación, etc.

\section{c) Displays de navegación}

Como se avanzó en 2.1.6 -Los trazos luminosos-, los Displays de Navegación (ND) forman parte de los sistemas electrónicos de instrumentos de vuelo de las aeronaves modernas, los cuales sustituyen progresivamente a los instrumentos tradicionales -relojes analógicos-. El conjunto coordinado de estos sistemas instrumentales se denomina genéricamente Electronic Flight Instrument System (EFIS) (FAA, 2008).

El EFIS es un generador de símbolos gráficos basado en una unidad central de proceso; esta adquiere la información de multitud de parámetros de la aeronave a través de diferentes sensores, procesándola y proporcionando la señal de vídeo adecuada en forma gráfica a dos pantallas electrónicas principales. La primera es la Pantalla Primaria de Vuelo (PFD), la cual muestra en formato gráfico toda la información crítica para el vuelo rumbo, velocidad, altitud, etc.-, integrando en una única pantalla la información de varios instrumentos analógicos tradicionales -horizonte artificial, anemómetro, altímetro, etc.- La segunda es la Pantalla de Navegación (ND); el piloto, a través de esta última, puede ver representada la posición real de la aeronave con respecto a la ruta definida en el Sistema de Control de Vuelo (FMS).

Mientras que la información posicional es adquirida a través de la coordinación de Sensores Inerciales (INS) y de Posicionamiento Global por Satélite (GPS), la presentación de datos aeronáuticos -aerovías, radioayudas, circuitos de espera, etc.- se sirve de una base de datos integrada como parte del sistema de información. Dependiendo del fabricante, también puede visualizar la posición real de las aeronaves circundantes que son interrogadas por el Sistema de Alerta de Tráfico y Evasión de Colisión o TCAS (Airbus, 1998). 


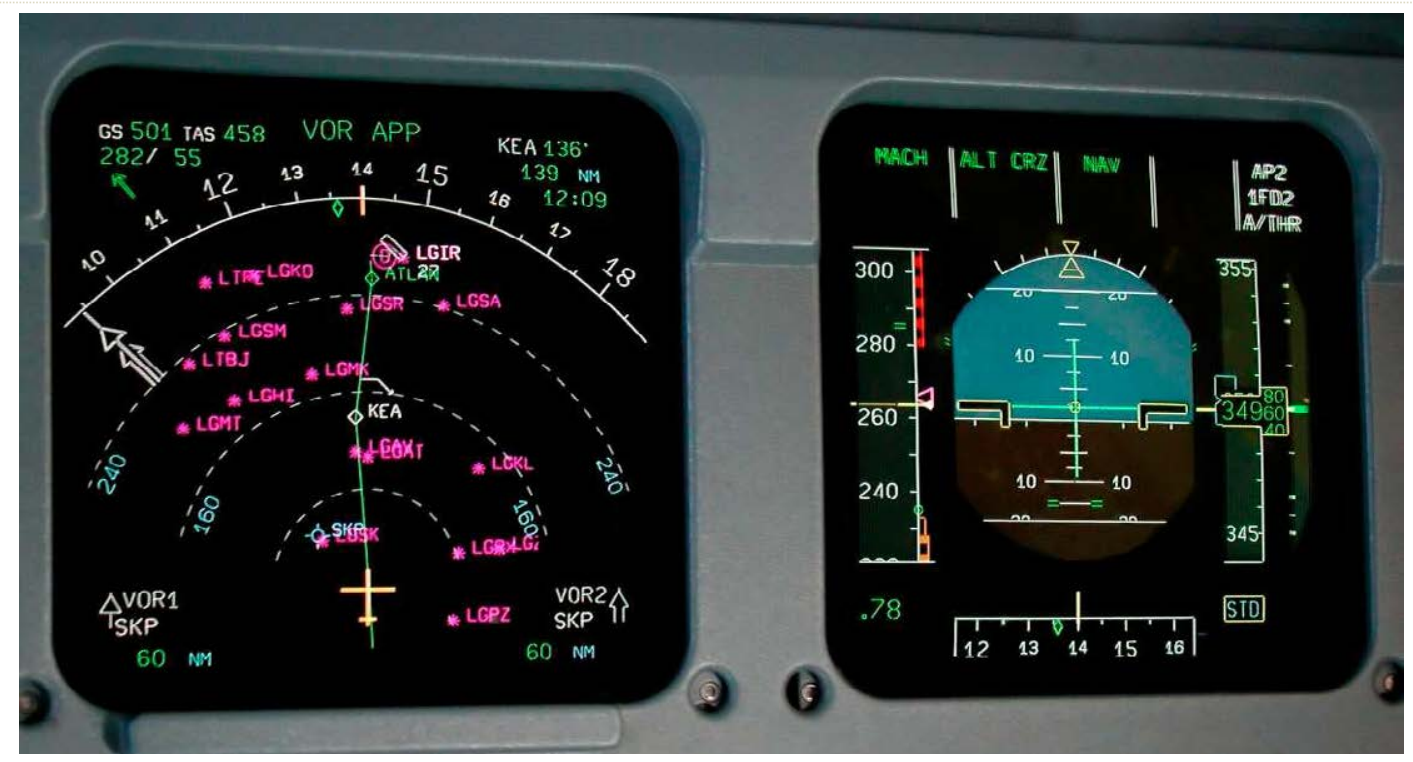

Figura 2-35: Pantalla Primaria de Vuelo (PFD) -derecha- y Display de Navegación (ND) -izquierda-. El modo y alcance visualizados son ARC y 320 millas náuticas respectivamente. (Florian Sindermann, Airliners.net).

Un panel de control asociado permite controlar distintos modos de operación, alcance -escala-y brillo de las pantallas ND [Figura 2-35]. En general, los modos disponibles en este tipo de dispositivos son los siguientes (Airbus, 1998):

- Rose ILS: muestra las desviaciones del sistema de aterrizaje automático ILS.

- Rose VOR: muestra las indicaciones de desviación y del radial de la radioayuda de tipo VOR seleccionada.

- Rose NAV: posición horizontal del avión respecto al plan de vuelo.

- $\quad$ ARC: presenta la desviación del plan de vuelo en un diagrama de 90 grados con respecto al sentido de vuelo.

- PLAN: mapa orientado al norte verdadero. Está centrado en uno de los puntos del plan de vuelo seleccionado para ello.

Frente a un mapa en papel tradicional o digital, en los que la ruta trazada debe ser seguida por medio del pilotaje manual o por medio de automatismos de rumbo, la total integración de las Pantalla de Navegación con el control automático de vuelo permite seguir automáticamente y de forma precisa la ruta presentada en el mapa, lo que se simplifica enormemente las tareas de navegación. 


\subsubsection{La interoperabilidad}

La información aeronáutica especializada posee aproximadamente un siglo de vida, fijando cronológicamente su nacimiento a partir de la época en la que los primeros pilotos realizaban y compartían anotaciones y croquis personales de navegación. De este periodo, correspondería la existencia de la información aeronáutica digital a las cuatro últimas décadas, ya que es a principios de los años 70 cuando comienzan a comercializarse los primeros datos aeronáuticos digitales (C. Jeppesen, 2012b) que alimentan a los Sistemas Electrónicos de Gestión y Guía de Vuelo o Flight Management Computer Guidance Systems (FMCGS), presentes en cualquier aeronave comercial moderna (Biezad, 1999; Tooley y Wyatt, 2007).

Desde entonces, la evolución de los datos aeronáuticos en un entorno digital ha estado ligeramente retrasada respecto a la experimentada en el ámbito global de la Información Geográfica (IG) cuyo desarrollo efectivo comenzó en la década de los años 80, periodo en el que irrumpen con fuerza y en paralelo los conceptos de los sistemas informáticos especializados en la gestión avanzada de datos geoespaciales y las bases de datos. El uso de los Sistemas de Información Geográfica (SIG) permitió a los productores mejorar la gestión e integración de gran cantidad de datos de diferentes fuentes, evitar las operaciones cartográficas, así como personalizar y automatizar sus procesos ${ }^{87}$.

En el caso del usuario final, el uso de las Tecnologías de la Información Geográfica (TIG) posibilita una alternativa al formato tradicional de cartas de papel. Jeppesen, el mayor productor de datos aeronáuticos, comercializa desde 1996 JeppView, un sistema de información en CD-ROM basado en una librería de cartas aeronáuticas mundiales (C. Jeppesen, 2012a). La aplicación ha evolucionado hacia un sistema multifuncional de planificación de vuelos, visualizador cartográfico y mapa móvil -módulo flitedeck-, cuya base de datos se actualiza a través de nuevos CD-ROM enviados periódicamente, o a través de actualizaciones en línea.

Pese al evidente beneficio de la aplicación de los Sistemas de Información Geográfica (SIG) en la gestión, provisión y uso de datos aeronáuticos, el panorama general evidencia la existencia de soluciones no interoperables que imposibilitan establecer servicios y bases de datos distribuidos (EUROCONTROL, 2006b). Por ello, la tradicional provisión de información centrada en el producto, ya sea carta en papel impreso o carta digital, está siendo sustituida por una solución que exige que toda la información aeronáutica se almacene de forma normalizada, distribuida y unívoca como datos individuales estandarizados, a los que se puedan acceder con cualquier tipo de aplicación. A este concepto de aplicación global, aún en desarrollo, se le denomina Gestión de Información Aeronáutica o Aeronautical Information Management (AIM) (ICAO, 2009b), siendo uno de sus objetivos fundamentales transitar hacia una información aeronáutica digital e interoperable a la que cualquier usuario del espacio aéreo pueda acceder en cualquier momento o fase del vuelo a través de medios portables

${ }^{87}$ Como ejemplo, la National Geospatial Intelligence Agency (NGA) utiliza el sistema de producción de mapas denominado PLTS -Production Line Tool Sets- junto con la aplicación Maplex Label, para administrar el diseño de sus series de cartas (McGaugh, 2004).Este sistema es capaz de producir cartas de cualquier escala, orientación y proyección, e incorporar elementos inteligentes que se actualizan automáticamente basándose en el contenido de una geodatabase asociada. 
(computadoras portátiles, agendas electrónicas, cuadernos digitales, etc.), manteniendo en todo caso los requisitos de calidad que caracterizan a la cartografía en papel.

Para alcanzar este objetivo, la información aeronáutica debe proporcionarse e intercambiarse en un formato electrónico basado en modelos de datos normalizados. En la actualidad ya existen o están en fase de diseño (EUROCONTROL, 2006a) estándares que definen distintos modelos de datos de intercambio para la información aeronáutica, como el Aeronautical Information Exchange Model (AIXM) ${ }^{88}$, Airport Mapping Exchange Model $(\mathrm{AMXM})^{89}$, Weather Information Exchange Model (WXXM) $)^{90}$, Airport Operations Information Exchange Model (AOXM), Terrain Information Exchange Model (TIXM) y el Environmental Information Exchange Model (ENXM) (ICAO, 2009b). Según los estándares han ido evolucionando, las distintas aplicaciones relacionadas con las TIG han ido añadiendo complementos y soportes a los mismos. De esta manera, a día de hoy diferentes programas de Sistemas Información Geográfica (SIG) ya incluyen conexiones, modelos de datos basados en AIXM, o desarrollos compatibles con importaciones o exportaciones. Prueba de ello es el desarrollo por parte de la FAA del denominado Sistema de Información Geográfica de Aeropuertos (AGIS), SIG especializado en la provisión, gestión y mantenimiento de datos aeronáuticos aeroportuarios a través de estándares interoperables y abiertos. Su visión es la de integrar distintas aplicaciones aeronáuticas para la gestión y visualización de la superficie aeroportuaria, todo ello de una forma estandarizada y segura (FAA, 2009, 2011 b, 2013).

El uso de las redes globales -internet- para la distribución ubicua de datos aeronáuticos amplía las posibilidades de estos sistemas, principalmente para obtener datos vigentes de un modo inmediato en entornos $\operatorname{críticos}^{91}$. Por ejemplo, Baučić, Medak, y Roguljić (2011) han desarrollado un GIS en línea para el Aeropuerto de Split Croacia- en el que, entre otros beneficios, puede proporcionar información inmediata sobre el camino más corto para los vehículos de emergencia en caso de incidente o accidente, y todo ello de conformidad con las normas internacionales de la OACl.

${ }^{88}$ El Modelo de Intercambio de Información Aeronáutica o Aeronautical Information Exchange Model (AIXM) está diseñado para permitir la gestión y distribución de los servicios de información aeronáutica (AIS) de datos en formato digital (EUROCONTROL, 2013a).

${ }^{89}$ Desarrollado por EUROCONTROL, el Modelo de Intercambio de Mapas Aeroportuarios o Airport Mapping Exchange Model (AMXM) da lugar, a través de una implementación de esquemas XML, al Esquema de Intercambio de Mapas Aeroportuarios o Airport Information Exchange Schema (AMXS) (EUROCONTROL, 2012a).

${ }^{90}$ El Modelo y Esquema de Intercambio de Información Meteorológica o Weather Information Exchange ModelSchema (WXXM-WXXS) están diseñados para permitir el intercambio armonizado de información meteorológica, de forma que cubran todas las necesidades de la industria del transporte aéreo (EUROCONTROL, 2013b).

${ }^{91}$ Una de las primeras iniciativas al respecto fue la aplicación Aviation Weather Data Visualization Environment (AWE) (Spirkovska y Lodha, 2002), sistema de visualización que permitía superponer sobre las cartas digitales datos meteorológicos actuales recogidos a través de sensores a bordo de distintas aeronaves. 
El empleo de la filosofía de interoperabilidad de datos permite además la generación de múltiples aplicaciones que, independientemente de sus constructores, pueden relacionarse aumentativamente con otras de terceros a través del cumplimiento de los estándares geográficos propuestos por el Open Geospatial Consortium $(\mathrm{OGC})^{92}$. Referencia obligada es la aplicación de escritorio SkyView2 ${ }^{93}$, proyecto de EUROCONTROL destinado a la gestión de datos aeronáuticos en plataformas SIG (EUROCONTROL, 2012b), si bien distintas compañías de ámbito exclusivamente privado como Luciad y Frequentis ${ }^{94}$ también ofrecen distintas utilidades modulares que aplican simultáneamente algunos de los conceptos y estándares definidos por ISO y OGC (Siabato, Moya y Bernabé, 2016).

En la medida en la que vayan siendo superadas determinadas barreras de telecomunicación de datos digitales entre las aeronaves y los sistemas en tierra (Martínez, 2010; Muros, 2010), la evolución lógica del concepto de interoperabilidad de la información aeronáutica será la extensión e incorporación de este tipo de sistemas a la propia cabina de las aeronaves, cuyo uso en vuelo supone varias ventajas como son: la reducción del papel, la generación de vistas personalizadas bajo criterios concretos de posicionamiento geográfico y operacional ${ }^{95}, y$ la posibilidad de integrar las aplicaciones directamente en las pantallas de los sistemas de navegación.

\subsection{CARACTERIZACIÓN DEL USO PRÁCTICO DE LA INFORMACIÓN}

En los inicios de la investigación se ha pretendido indagar en las cuestiones esenciales acerca del alcance de la Información Geográfica (IG) en el ámbito aeronáutico, tratando así de establecer las vinculaciones básicas entre la navegación aérea -definida como el conocimiento de posición y trayectoria más adecuada de una aeronave en todo momento- y su dependencia con la información territorial. Esta última es transmitida a los usuarios a través de la codificación cartográfica.

${ }^{92}$ El Open Geospatial Consortium (OGC), consorcio cuya misión es la definición de estándares abiertos e interoperables dentro de los Sistemas de Información Geográfica y de la World Wide Web, posee un grupo de trabajo en el dominio de la aviación denominado Aviation DWG (OGC, 2012).

${ }^{93}$ SkyView2 admite, entre otros, el Esquema de Intercambio de Mapas Aeroportuarios (AMXS) y los Servicios de Mapas en Web (WMS) y los Servicios de Fenómenos en Web (WFS) de OGC, respectivamente.

94 SmartAIM suite, de Frequentis (Frequentis, 2012), ofrece, entre otras características, el manejo de bases de datos AIXM para la generación de cartas aeronáuticas, la generación de paquetes integrados de Publicaciones de Información Aeronáutica (AIP), gestión de planes de vuelo, información meteorológica y NOTAM digitales.

95 Lido RouteManual, de Lufthansa Systems (Lufthansa, 2012), aporta mejoras en la visualización de cartas y manuales bajo criterios de usabilidad, ya que cuida especialmente que la información representada sea únicamente la relevante para un usuario particular en unas condiciones específicas de vuelo, facilitando así su lectura. 
Para tal fin se ha manejado una extensa documentación, parte de la cual ha sido ya referenciada a lo largo de las cinco secciones anteriores: normativas y convenios de regulación internacional, libros aeronáuticos, publicaciones y manuales de vuelo, etc. También se han formulado distintos sondeos informales y entrevistas personales acerca de este particular tanto con responsables del Servicio de Información Aeronáutico español (AISAENA), como con un reducido grupo de comandantes de líneas aéreas comerciales y pilotos privados.

Como conclusión preliminar se puede establecer que la utilización de la IGA en cada caso concreto puede estar sistematizada atendiendo a aspectos variables y dispersos. Entre otros:

- La tipología constructiva de la aeronave implicada.

- Las características de sus equipos de a bordo -aviónica-

- La tipología concreta del vuelo considerado -visual, instrumental-.

- La fase concreta de vuelo en la que se desarrolla la navegación -ascenso, ruta, llegada, aproximación, etc.-

- El control y densidad del tráfico aéreo y los diversos condicionantes externos -climatológicos, orográficos, etc.-

También se ha logrado constatar una continua evolución de los procedimientos de vuelo, debido a la aplicación incesante de nuevos adelantos tecnológicos y la inusitada facilidad de acceso a dispositivos digitales personales de los últimos años.

En otro orden de cosas, al desplegar las diferentes técnicas de navegación, el flujo práctico de provisión de Información Geográfica que se desarrolla en el interior de una aeronave es un criterio que no tiene por qué ser inflexible o estar reglamentado en su totalidad. Se infiere, a partir del estudio previo, que cada piloto o tripulante tiene cierto margen de preferencias al utilizar los diversos elementos de suministración de IG en vuelo en cada circunstancia y situación particular: los contenedores de información se pueden complementar entre sí. Este hecho es particularmente interesante de indagar, pero su estudio debe ser basado en mediciones que, se espera, presenten una carga de subjetividad importante. En definitiva, a partir de este punto se requiere pasar de una investigación meramente documental a otra de recolección ordenada de datos -en base a encuestas u otros instrumentos análogos-, con objeto de sistematizar la comparación de múltiples aspectos de la información acopiada.

A través de la recolección ordenada de datos se pretende indagar de forma más específica en las circunstancias reales y cuantificables que tiene la propia información geográfica en vuelo, más allá de las cuestiones meramente teóricas y operacionales. El fin último es descubrir de forma objetiva qué necesidades respecto a la información geográfica son comunes a la mayoría de las tripulaciones para, a continuación, analizar el grado de satisfacción de los aparejos cartográficos actuales que deben resolverlas. En el caso de que esta satisfacción sea menos que óptima, se abre la posibilidad de plantear soluciones que, aplicadas a los modelos cartográficos, 
ayuden a mejorar la provisión, visualización y manipulación de la información geográfica y, en última consecuencia, la propia seguridad de vuelo.

\subsubsection{Los aspectos de interés y el instrumento de evaluación}

Vistas las conclusiones preliminares, a continuación se enuncian qué aspectos de interés pretenden ser resueltos a través del estudio de caracterización realizado -entendiendo los aspectos como rasgos o matices que, sumados, van a lograr caracterizar a la cuestión general. Los aspectos resultan numerosos y relacionados entre sí; además muchos de ellos son de difícil definición al sustentarse en entidades subjetivas tales como actitudes, conductas, conocimientos y habilidades.

Los aspectos de interés, una vez redactados, se agrupan en cuatro grupos temáticos concatenados, teniendo como eje argumental la consideración de los distintos formatos de información:

Grupo 1: Relaciones generales

¿Cómo es el proceso de adquisición de la información geográfica aeronáutica en el colectivo de pilotos españoles?

¿Qué relación o relaciones pueden ser establecidas entre tipo de piloto, de aeronave, de vuelo e información acopiada?

Tabla 2-7: Aspectos relacionados con las relaciones generales

Grupo 2: Preferencias y especializaciones

¿Qué preferencias de uso tienen los distintos formatos de información geo-aeronáutica por parte de los pilotos españoles?

Si son combinados varias de ellos, ¿en qué proporción?

¿Qué ventajas o especializaciones tienen unas herramientas o formatos respecto de otras?

¿Se puede establecer una jerarquía de eficiencia entre las diferentes herramientas o formatos?

Tabla 2-8: Aspectos relacionados con las preferencias y especializaciones 


\section{Grupo 3: Adecuación de la representación e interpretación}

En cada uno de los formatos; ¿es adecuada su ergonomía de uso?

¿Es adecuado el volumen y síntesis de información que suministran?

¿Es adecuada la representación gráfica de los diversos fenómenos?

¿Hasta qué punto los problemas de interpretación pueden provocar incidencias relevantes para la seguridad en vuelo?

Tabla 2-9: Aspectos relacionados con la adecuación de la representación e interpretación

\section{Grupo 4: Condicionantes ambientales}

¿De qué forma afecta al uso de los formatos el espacio físico disponible en la cabina de mando?

¿Y por las condiciones ambientales exteriores?

¿Son habituales las anomalías técnicas de los formatos digitales?

Tabla 2-10: Aspectos relacionados con las condiciones ambientales

Fijado como fenómeno general a medir las particularidades de la utilización de la geo-información aeronáutica en vuelo, y expresado este a través de la suma de los cuatro grupos de aspectos indicados, se establece como instrumento de investigación la encuesta por muestreo ${ }^{96}$ de tipo individual en base a un cuestionario estandarizado para la recogida de información ${ }^{97}$-ver 9.1.1 Consideraciones adicionales acerca del instrumento de evaluación-

${ }^{96}$ Habitualmente a los estudios basados en cuestionarios son denominados encuestas, en especial cuando se ocupan de grupos de personas numerosos y dispersos. A su vez, son adjetivados como encuestas por muestreo cuando sólo se ocupan de una fracción representativa de una población total -universo- (J. Ruiz, Izquierdo, y Piñera, 1998).

${ }^{97}$ Como instrumento, la encuesta no es un método específico de ninguna disciplina de las ciencias sociales y se aplica en forma amplia a problemas de muchos campos. Para Mayntz, Holm, and Hübner (2004) esta capacidad de múltiple aplicación y su gran alcance hace de la encuesta una técnica de gran utilidad cuando se necesita descubrir modelos de conducta. 


\subsubsection{El propósito de la escala}

Se trata de establecer, por este orden, el contenido, la población a la que va dirigida, la forma de administración y el formato del cuestionario.

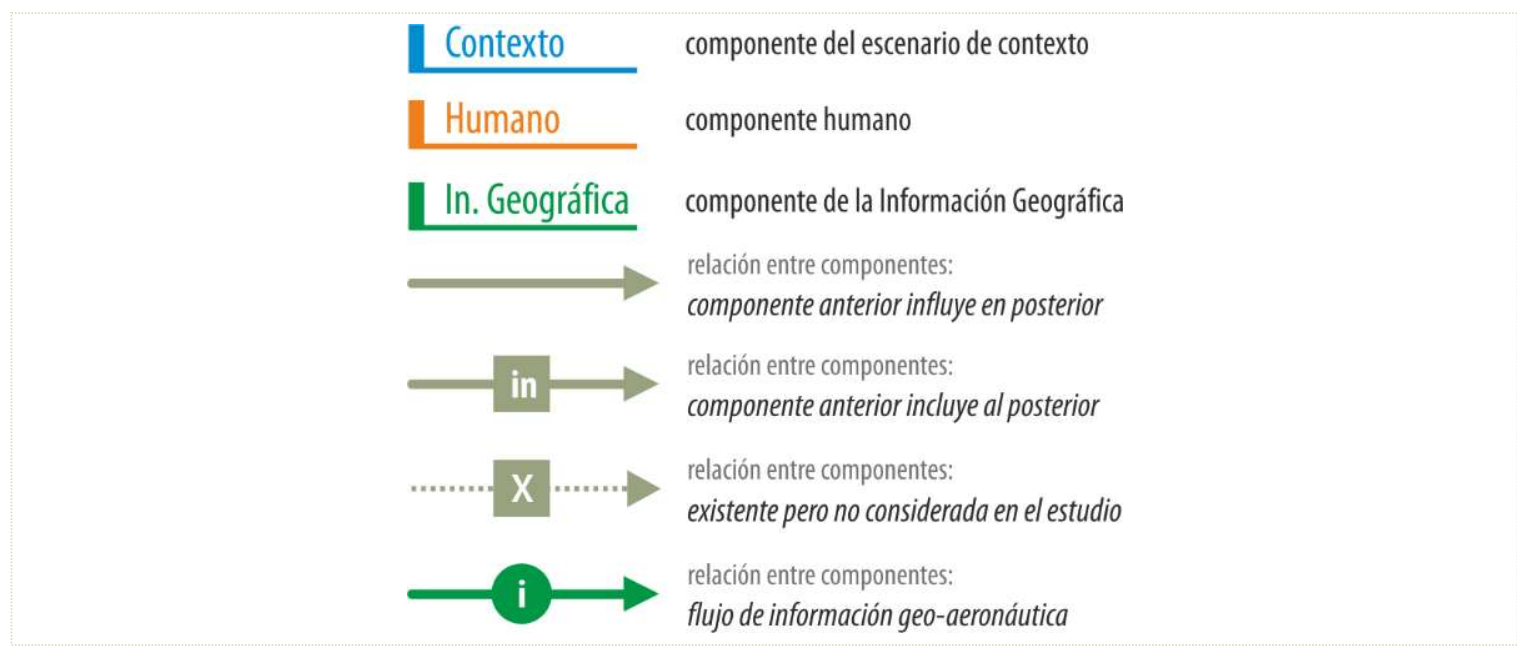

Figura 2-36: Leyenda de componentes y tipo de relaciones entre componentes considerados (figura propia).

Con respecto al contenido, se ha ideado un esquema relacional [Figura 2-36] y [Figura 2-37] que, en forma de componentes y factores -ver 9.1.2 Contenido del cuestionario-, sirve como estructura argumental que conduzca la creación del contenido final del cuestionario.

La temática y la definición concreta del estudio requieren de una muestra de población específica. En el caso que nos ocupa, el cuestionario se dirige al colectivo de pilotos españoles de aeronaves civiles; este abarca desde los pilotos privados de pequeños ultraligeros y monomotores, hasta las tripulaciones de los grandes modelos de aviación comercial -bimotores y cuatrimotores-. Al tratarse de un colectivo concreto y limitado, a la hora de redactar las preguntas del cuestionario se ha tenido en cuenta tanto el escenario de contexto en el que trabajan, como el nivel cultural y lenguaje habitual del conjunto.

En cuanto a las características elegidas para la muestra, se ha considerado un tamaño no inferior a 100 encuestados y la búsqueda, en lo posible, de un equilibrio entre vuelo instrumental y visual, además de una variedad de modelos de aeronave, y rutas. 


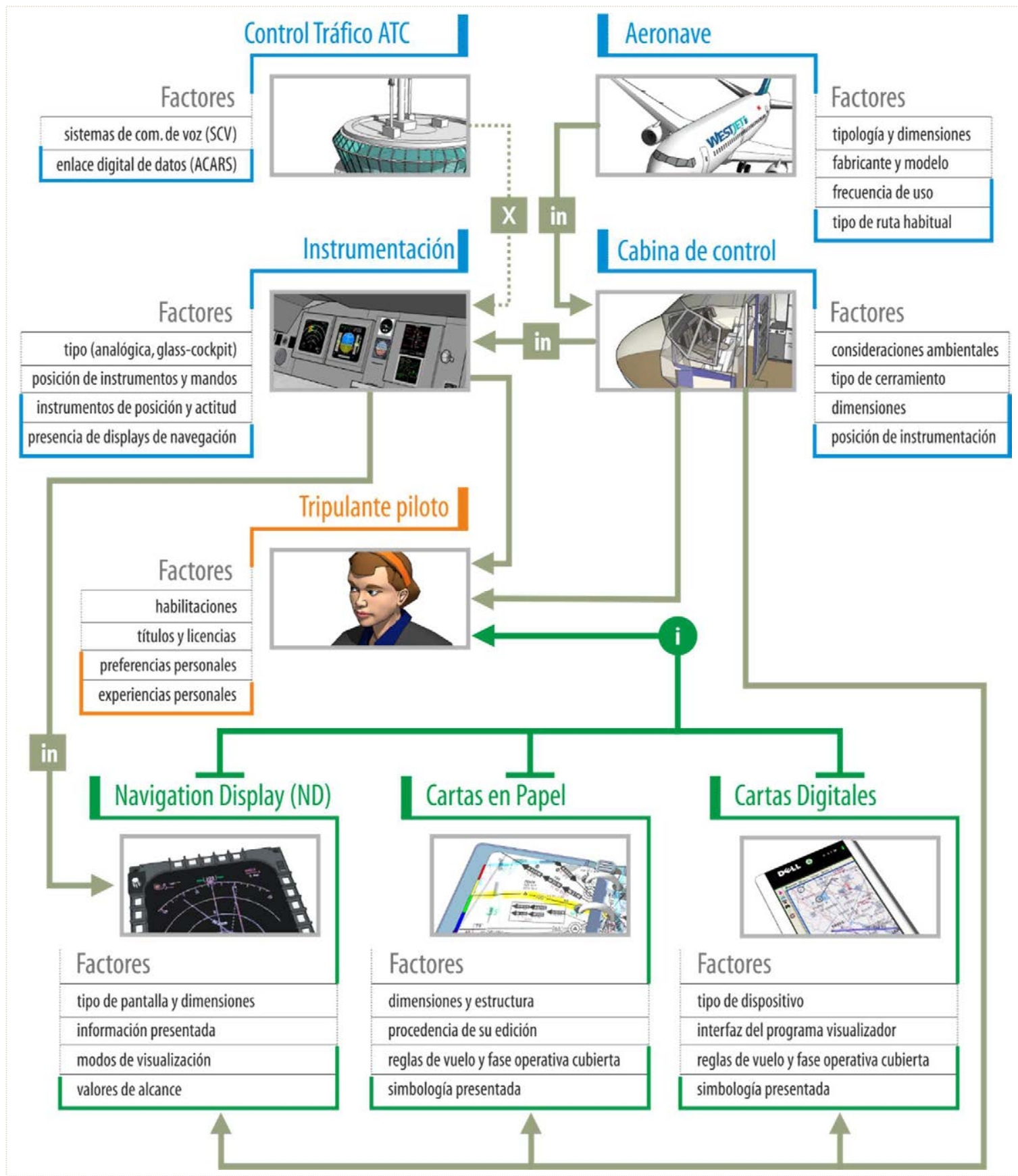

Figura 2-37: Esquema relacional de componentes y factores considerado en el estudio (figura propia). 


\subsubsection{La definición, redacción, ordenación y codificación de ítems}

Enlazando aspectos, componentes y factores, se redactan finalmente los ítems o preguntas [Figura 9-1], que son la unidad básica de información de un instrumento de evaluación. Normalmente constan de una pregunta y una respuesta cerrada a completar (M. C. Martín, 2004). En el estudio realizado se evalúan alrededor de 100 ítems ${ }^{98}$ o preguntas distintas, reducidos a 73 en la versión definitiva del cuestionario ${ }^{99}$.

La definición de cada uno de los ítems debe ser exhaustiva y mutuamente excluyente, y en su redacción se obliga a controlar los posibles sesgos que pudiesen experimentar los pilotos en su cumplimentación -error de tendencia central ${ }^{100}$, deseabilidad social ${ }^{101}$ y sesgo de aprendizaje y proximidad ${ }^{102}$. . La redacción efectiva ${ }^{103}$ del cuestionario -preguntas de comprensión dudosa, preguntas dobles, etc.- el orden de las preguntas y el formato de la codificación de respuestas -entre otros- también puede introducir sesgos en la recogida de la información (Choi y Pak, 2005).

Una vez redactado el borrador de preguntas, estas se agrupan y ordenan siguiendo un hilo argumental, que a su vez ha sido dividido en dos partes. En la primera parte se identifica el perfil básico del piloto, las aeronaves

${ }^{98}$ Como regla general, se considera que el número de ítems para evaluar un fenómeno -en nuestro caso el uso de la información geográfica a bordo- puede ir desde 10 a 90, de manera que puedan abarcar de forma proporcional cada una de las dimensiones definidas en el conjunto de aspectos a medir. En (M. C. Martín, 2004), se recomienda realizar el doble de ítems de los que se prevé van a necesitarse en la versión final.

${ }^{99}$ El cuestionario es un instrumento de investigación cuantitativa, utilizado para la recogida de información, diseñado para poder cuantificar y universalizar la información. Su finalidad es conseguir comparar múltiples aspectos de la información acopiada (J. Ruiz et al., 1998).

${ }^{100}$ Es la tendencia a elegir entre diferentes opciones de respuesta, la central o centrales (Choi, Granero, y Pak, 2010; Choi y Pak, 2005; M. C. Martín, 2004). Se ha intentado paliar reduciendo el número de gradaciones entre categorías verbales calibradas (Grover y Vriens, 2006), eliminando además la opción central en las escalas de Likert.

${ }^{101}$ Se tiende a responder en función de lo que se considera socialmente aceptable (Bradburn, Sudman, y Wansink, 2004; Grover y Vriens, 2006). Para contrarrestar este posible sesgo se redactan las preguntas que impliquen falta de pericia del encuestado de tal modo que se le exime de la culpa señalando posibles causas externas.

${ }^{102}$ Se tiende a contestar de forma similar a las respuestas anteriores (Choi y Pak, 2005). Para evitarlo, se trata en lo posible de alejar los ítems con cuestiones relativamente análogas entre sí.

${ }^{103}$ Se han seguido una serie de criterios para la correcta redacción de las preguntas, tales como utilizar preguntas breves y fáciles de comprender, no emplear palabras que induzcan una reacción estereotipada, no redactar preguntas en forma negativa, evitar el uso de la interrogación "por qué", no formular preguntas en las que una de las alternativas de respuesta sea tan deseable que difícilmente pueda rehusarse, evitar preguntas que obliguen a hacer cálculos o esfuerzos de memoria, etc. 
que habitualmente pilota y los formatos de IGA que manifiesta utilizar en cada una de ellas. En la segunda parte se inquiere al encuestado acerca de los diferentes aspectos a medir de cada uno de los formatos: requerimientos, usabilidad, frecuencia de uso, etc.

En esta segunda parte se ha estimado aplicar una táctica de personalización del flujo narrativo: así, dependerá de los formatos que el encuestado declare en la primera parte de la encuesta para que le sean mostrados uno, dos o hasta tres bloques de cuestiones más, uno por cada formato de información geográfica [Figura 2-38]. Al personalizar el cuestionario se pretende optimizar en lo posible el tiempo que el encuestado debe dedicar a completarlo, eliminando a priori ítems que son irrelevantes en el estudio para cada encuestado en particular. Además se proporciona un cierto valor de rapport ${ }^{104}$, -afinidad o empatía- necesario para conseguir que las respuestas de tipo abierto sean lo más enriquecedoras posibles para la investigación.

Para la codificación de la totalidad de las preguntas del formulario, se utilizan las escalas de asociación ${ }^{105}$ y de Likert ${ }^{106}$-ver 9.1.3 Codificación de respuestas a través de escalas-. Las escalas asociativas se destinan a las cuestiones más objetivas y protocolarias. A su vez, se acude a las escalas de Likert en las encuestas en las que se valoran comportamientos y motivaciones.

En vistas a recopilar de una manera directa valoraciones cualitativas de los encuestados, adicionalmente se ha introducido preguntas abiertas o de respuesta libre, en las que se inquiere por cuestiones totalmente cualitativas y que buscan recopilar aspectos de interés que no han sido recogidos en la programación de ítems del estudio.

104 Rapport es un término inglés utilizado en teoría de encuestas como sinónimo de comunicación, relación y conexión. Designa el clima general de comunicación positiva producido por la interacción, en el curso del contacto entre dos personas (Simpson y Weiner, 1989).

${ }^{105} \mathrm{~A}$ través de las escalas de asociación se trata de relacionar atributos de diversos conjuntos. Las escalas de asociación proporcionan, cuando se tabulan, tablas de frecuencia a asociación entre los atributos y los objetos (Abascal y Esteban, 2005).

106 Las escala de Likert o analógicas verbales (Edmondson, 2005; Likert, 1932), consisten en formular proposiciones relativas a una serie de atributos de un objeto y que el entrevistado exprese su grado de acuerdo o desacuerdo en una escala de varias categorías. Generalmente oscilan entre 3 y 7 categorías (M. C. Martín, 2004). 


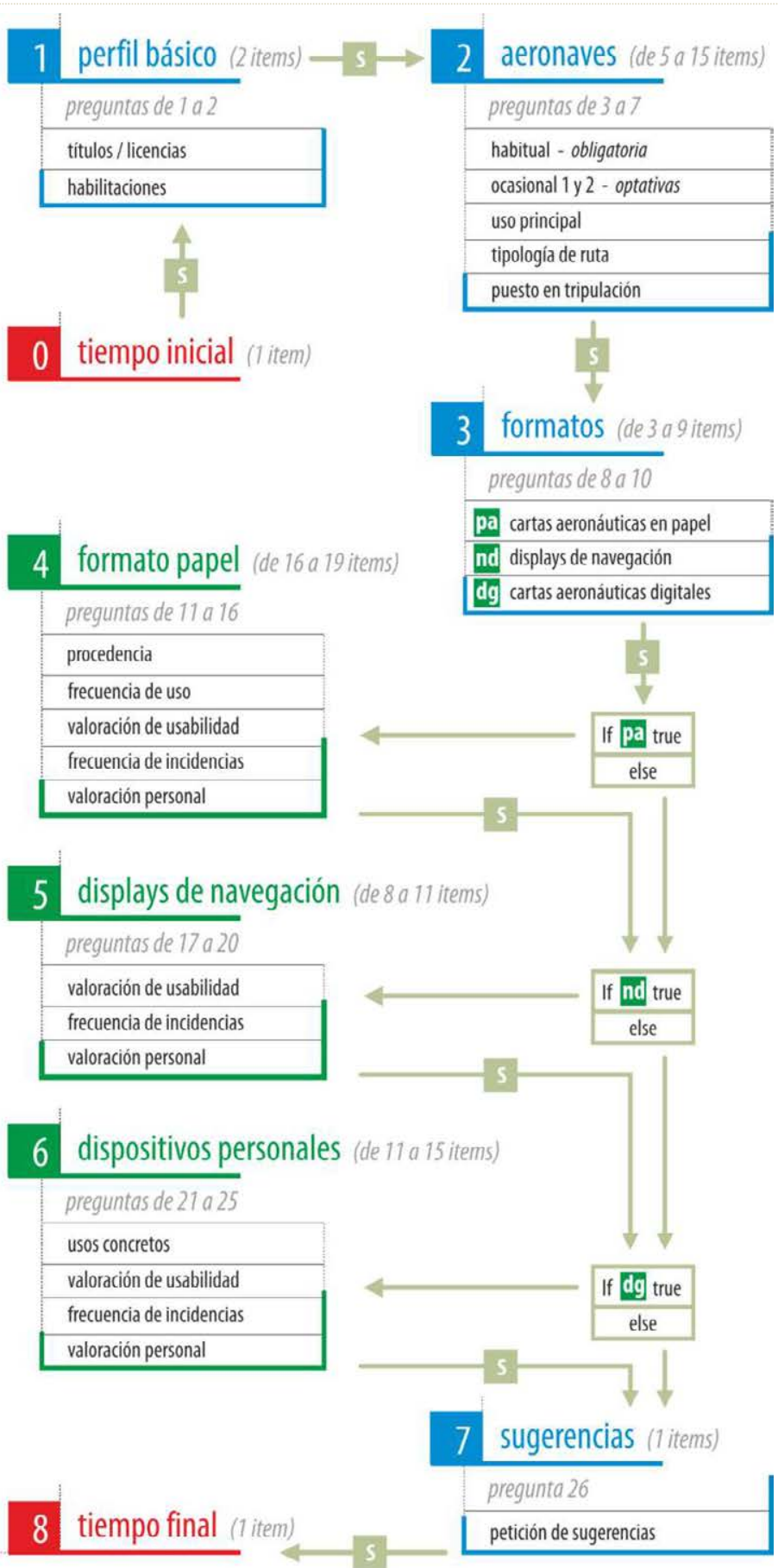

Figura 2-38: Esquema del flujo personalizado de preguntas. (pa) cartas papel, (nd) displays de navegación, (dg) cartas digitales, (s) registro en la base de datos (figura propia). 


\subsubsection{El formato y la programación del cuestionario}

Como formato de difusión se opta por la programación de una encuesta on-line con recogida de datos automatizada. Este procedimiento trata de solventar el conjunto de condicionantes descritos en el diseño de la muestra. Además de evitar los errores de transcripción de datos, adicionalmente permite la personalización del flujo de preguntas para cada uno de los encuestados, garantizando el anonimato y la confidencialidad de lo recogido. Las ventajas de esta elección y otras cuestiones de interés con respecto a la homogeneidad de la muestra son declaradas en 9.1.4-Formato del cuestionario-.

En orden a crear un conjunto de formularios informatizados, el borrador inicial de preguntas se traslada a formato HTML, atendiendo en todo momento a la ordenación de ítems y al flujo personalizado previsto en la planificación inicial. También se han tenido en consideración los principios heurísticos de Nielsen (1994) para asegurar un nivel adecuado de usabilidad en la aplicación final. Todo lo anterior implica la adición de varias características, como el establecimiento de un código de color en los encabezados y otro tipográfico en los bloques y conjuntos de preguntas, avisos textuales en cada ítem del tipo de respuesta posible, la imposibilidad de respuesta multivariable en las respuestas de tipo único, la revisión automatizada de la validez de las respuestas, indicación en todo momento del porcentaje de cuestiones completadas, etc. La declaración completa de características de usabilidad está disponible en 9.1.5 -Principios considerados en la creación de formularios-.

Completada ya una primera versión, se diseña un modelo de datos que conexione la información recogida a través de los formularios HTML a una base de datos estandarizada, siguiendo en todo momento el flujo narrativo acordado. Tanto el Diagrama de Entidad/Relación (ERD) creado para tal fin, como la estrategia llevada a cabo para la conexión entre la base de datos y los formularios, puede ser consultada en 9.1.6-Diagrama de entidad/relación y conexión de la base de datos-.

\subsubsection{La prueba piloto}

Para evaluar el artefacto metodológico previamente a su puesta en marcha, se ha realizado un pre-test cognitivo o prueba piloto tanto del cuestionario como del método informático que soporta la encuesta. En ella participaron 25 personas relacionadas con la IG y una selección reducida de pilotos pertenecientes al programa de capacitación del nuevo modelo Embraer E-195 de la compañía Air Europa. La prueba piloto ha permitido evaluar -ver 9.1.7 Principios considerados en la prueba piloto- la adecuada fluidez y longitud del cuestionario, la categorización, orden y complejidad de las preguntas, la comprensión de los términos empleados, la usabilidad de los formularios y la correcta recopilación de las respuestas en la base de datos. Un total de 16 personas aportaron indicaciones y sugerencias válidas. Como resultado de estas y del análisis propio de los registros del test en la base de datos, se ha modificado la redacción de varias de las preguntas, cambiando además la tipología de respuesta en alguna de ellas. También se han eliminado distintos errores de programación detectados, permitiendo así realizar una simulación completa de extracción de datos mediante consulta directa a las tablas de la base de datos. 
El listado final de cuestiones que se ha considerado como apto para su difusión consta de un total de 26 preguntas simples o compuestas, con la posibilidad de almacenar entre 51 y 73 distintos ítems para cada uno de los sujetos encuestados. El conjunto definitivo de formularios en formato HTML que, recogiendo todas las consideraciones anteriores, es publicado como medio de recogida de información puede ser consultado de forma íntegra en 9.1.8 -Formularios Web publicados para la recogida de información-.

\subsubsection{El plan de difusión y recogida de datos}

El cuestionario se dirige exclusivamente al colectivo de pilotos españoles de aeronaves civiles. Aun teniendo definido un universo poblacional concreto y limitado, obviamente no es posible llegar a todos y cada uno de los individuos que lo componen, por lo que se plantea extraer una muestra. Para su definición inicial se propone un tamaño no inferior a 100 encuestados y un equilibrio entre pilotos de vuelo visual y vuelo instrumental, buscando en el caso de pilotos de aeronaves comerciales la mayor variedad posible entre los modelos de avión implicados, compañías aéreas y rutas habituales.

Con vistas a posibilitar una muestra controlada, homogénea y lo más balanceada posible, se ha priorizado el contacto con diferentes instituciones y asociaciones. Principalmente han sido tres las agrupaciones profesionales que han prestado su colaboración al estudio: el Colegio Oficial de Pilotos de la Aviación Comercial (COPAC), la Asociación Española de Pilotos de Aeronaves Ligeras (AEPAL), y el Sindicato Español de Pilotos de Líneas Aéreas (SEPLA). En 9.1.9 -Particularidades del plan de difusión- pueden encontrarse más detalles al respecto.

El periodo de obtención de datos se prolonga durante 6 semanas, recogiéndose un total de 392 tentativas de participación. De las anteriores, 253 pertenecen a cuestionarios completados en su totalidad. El tiempo medio dedicado a cada encuesta completada es de 16 minutos y 54 segundos. A efectos estadísticos y de análisis cuantitativo sólo se han considerado como válidos para el estudio los cuestionarios cumplimentados en su totalidad y en los que, adicionalmente, se dedicase a esta tarea un tiempo mínimo de 5 minutos.

\subsubsection{La representatividad y fiabilidad del estudio}

Para despejar la incertidumbre sobre si la muestra recogida es o no verdaderamente representativa, se concibe una muestra aleatoria estratificada, consistente en subdividir a la población en subgrupos o estratos más homogéneos, de los que se toman muestras aleatorias simples de cada uno de ellos. Se han considerado dos estratos: pilotos comerciales y pilotos privados o de aeronaves ligeras. La clasificación de individuos dentro de ellos se ha realizado a posteriori a través de filtros en las preguntas clave. 
Asumiendo como hipótesis una cifra estimativa de 7.500 pilotos comerciales sindicados y/o colegiados, y alrededor de 2.500 pilotos privados, para que la encuesta sea representativa en las condiciones planteadas ${ }^{107}$ resulta ser suficiente con disponer de, al menos, 192 encuestados, de los cuales 48 deben pertenecer al estrato de pilotos privados VFR y 144 al estrato de pilotos comerciales VFR/IFR. En 9.1.10 -Estimación de la representatividad de la muestra- puede encontrarse información detallada al respecto.

Dado que se requiere el diseño de un instrumento de medida que permita comparar las particularidades de uso de la IG de diferentes individuos en un ámbito específico o la del mismo individuo en diferentes ámbitos, es obligado asegurar que -en lo posible- el instrumento de medida sea fiable. Así, para medir la fiabilidad de la escala se acude al cálculo del Alfa de Cronbach ${ }^{108}$ en cada uno de los formatos gráficos evaluados -cartas en papel, displays de navegación y cartas digitales-. Tanto el procedimiento seguido como el análisis de los valores de fiabilidad alcanzados se declaran en 9.1.11 -Evaluación de la fiabilidad de la metodología propuesta-.

\subsubsection{La explotación de datos}

La programación realizada no sólo se ha limitado a lograr la automatización de la tarea de recopilación de datos; con ella también se intenta facilitar la extracción de datos y su análisis en cualquier instante del periodo de recogida de información, permitiendo así un proceso de análisis continuo, dinámico y sin límites temporales. Para tal fin se establece una gramática de consultas de tipo Structured Query Language (SQL) a dos niveles: el primero tiene como objetivo la extracción directa de datos concretos -adición y cálculo de porcentajes con respecto a total de consultados o de subgrupos de interés-. El segundo, más complejo, se dirige a la comparación particular de relaciones que sean de interés una vez analizadas las consultas anteriores -datos derivados-.

${ }^{107}$ Hipótesis del tamaño de la población estadística cifrada en diez mil pilotos, balanceados en un 75\%-25\%. Elección en forma aleatoria simple, considerando que se ha trabajado con un $95 \%$ del nivel de confianza y un $5 \%$ de error y que de la muestra extraída un $15 \%$ no reúna las características de la población.

${ }^{108}$ Se han obtenido valores de 0,66 para las cartas en papel, 0,68 para los displays de navegación y 0,81 en el caso de las cartas digitales. Según el criterio general de George and Mallery (2003), un coeficiente alfa menor de 0,5 se considera inaceptable. A partir de este valor mínimo, por encima de 0,5 se considera pobre y por encima de 0,6 cuestionable, siendo aceptable por encima de 0,7 y bueno si se alcanza un valor mayor de 0,8 . Valores por encima de 0,9 se consideran excelentes. 
Usualmente, estas consultas pueden ser realizadas inspeccionando directamente las tablas y campos correspondientes al diagrama de Entidad/Relación de la base de datos asociada al sistema de formularios ${ }^{109}$. Adicionalmente pueden ser encapsuladas a través de una vista y almacenarlas en la base de datos ${ }^{110}$. El uso de vistas implica dos interesantes posibilidades:

- Es posible crear un repositorio de consultas de interés, ya que las vistas son reutilizables en todo momento. Pueden así aplicarse con un simple clic de ratón, y se tiene además la posibilidad de modificarlas y/o mejorarlas en todo momento.

- Las vistas pueden ser llamadas desde aplicaciones de escritorio que posibiliten gestionar de una manera más conveniente el análisis de la información.

Una ventaja adicional de este procedimiento radica en que se puede consultar dinámicamente y en cualquier momento los resultados de las consultas programadas, sin que por ello se impida la adición de nuevos datos y valoraciones por parte de los encuestados.

En 9.1.12 -Metodología de creación automatizada de consultas- se detalla con mayor profundidad la metodología de explotación de datos propuesta. También se muestran al gunas de las consultas SQL personalizadas que, gracias a la metodología de vistas aplicada, pueden ser planteadas para facilitar la extracción concatenada de cualquier tipo de listado o dato cualitativo de interés.

\subsubsection{El perfil general de las tripulaciones y sus aeronaves}

El perfil general de los pilotos participantes se ha clasificado en tres grupos: pilotos privados, pilotos de líneas aéreas y pilotos de ultraligeros. En el primer caso, se advierte una separación difusa entre ellos -muchos pilotos de líneas aéreas realizan fuera de su horario de trabajo vuelos de índole privada-, lo que dificulta en cierta medida el análisis. En el caso de los pilotos de ultraligero -y aun existiendo conexiones desde/hacia los otros dos gruposse observa una sectorización más clara y cerrada, lo que se traduce en un conjunto de tipologías más homogénea de aeronaves, rutas y desempeños.

Para descubrir el perfil general de los pilotos que han colaborado en la encuesta, se ha tomado como referencia el listado de títulos y licencias aeronáuticos civiles reguladas en (España, 2000). Bajo esta clasificación, un 48\% de los encuestados dispone de licencia de piloto de transporte de líneas aéreas, un 34\% de piloto privado y un $20 \%$ de piloto comercial, siendo un 16\% el resto de las titulaciones reguladas en la orden ministerial tomada

${ }^{109}$ Por ejemplo, a través de la línea de comandos de MySQL Query Browser o utilidad equivalente.

${ }^{110}$ En el caso concreto de la metodología aplicada, han sido programadas una serie de vistas reutilizables; a través de un interfaz Connector/ODBC (Open Database Connectivity), se posibilita a su vez la llamada a las mismas desde una hoja de cálculo Excel. 
como referencia ${ }^{111}$. Destaca en todo caso el 36\% alcanzado en el apartado de otras licencias, que en el estudio han sido asociadas a posteriori a licencias de piloto de ultraligero, ya que en principio esta licencia queda fuera de la clasificación de títulos y licencias considerada en la JAR-FCL ${ }^{112}$.

Una mayoría de pilotos que han participado en el estudio poseen una habilitación ${ }^{113}$ que les permite pilotar aviones multimotor, y además estando certificadas para ser tripuladas por más de un piloto. Aproximadamente, por cada 2 habilitaciones de clase para aviones de un solo piloto, se dan 3 para aviones de más de un piloto. En cuanto a las licencias de vuelo instrumental, por cada habilitación de vuelo instrumental para aviones monomotor, se han registrado 4 para vuelo multimotor ${ }^{114}$.

En el estudio han sido registradas un total de 422 aeronaves, las cuales han quedado clasificadas en diferentes modelos y tipos. Tanto la clasificación completa en modelos y tipologías como su frecuencia pueden consultarse en 9.1.13 -Tipología y cuantificación de las aeronaves del estudio-.

Además del modelo habitual, 4 de cada 10 pilotos han aportado un modelo de aeronave de uso ocasional ${ }^{115}$, mientras que 1 de cada 4 llega a declarar incluso dos modelos de uso ocasional. Los aeroplanos con motor y los ultraligeros de ala fija son las tipologías de aeronaves más usuales en los profesionales consultados. Su presencia varía de forma aproximadamente lineal en relación con el uso habitual o no de la aeronave. Así, mientras que si son consideradas exclusivamente aeronaves habituales el uso mayoritario se da con aeroplanos con motor, cuando el uso va siendo cada vez más esporádico el perfil de la aeronave cambia a ultraligero de ala fija, aumentando también el porcentaje de otros tipos.

${ }^{111}$ A través del Real Decreto 270/2000 de 25 de febrero de 2000, se determinan las condiciones para el ejercicio de las funciones del personal de vuelo de las aeronaves civiles (JAR-FCL).

${ }^{112} \mathrm{~A}$ la vista del elevado porcentaje de pilotos que poseen esta licencia, hubiese sido conveniente ampliar el listado de la JAR-FCL con esta licencia particular expedida por la Dirección General de Aviación Civil en la Orden de 24-41986 (BOE de 7/5/1986).

${ }^{113}$ Generalmente, las habilitaciones son anotaciones en cada una de las licencias que establece condiciones especiales, atribuciones o limitaciones a la misma. La normativa JAR-FCL distingue entre habilitaciones de clase, de tipo, de vuelo instrumental, etc. (España, 2000)

${ }^{114}$ Es conveniente distinguir entre los pilotos como tales -una única persona-y los títulos o licencias que posee el mismo -un piloto puede poseer varios títulos o licencias para distintas categorías o aeronaves-, de tal forma que han quedado registrados 243 pilotos 0 encuestados que han concluido todos los bloques de preguntas; concretamente el cómputo global arroja una cifra de 390 títulos o licencias, con una media de 1,6 por piloto 0 encuestado.

${ }^{115}$ Se obliga a todos los encuestados a declarar una aeronave de uso habitual, dando además la posibilidad de declarar una o dos aeronaves que el encuestado considere de uso ocasional. 
El análisis de usos de las aeronaves declaradas indica un significativo cambio de perfil al transitar desde las aeronaves habituales a las ocasionales [Figura 2-39]. Mientras en el primer caso el ámbito comercial y de transporte de pasajeros representa la mitad de los usos, en el uso de aeronaves ocasionales el entretenimiento y ocio -es decir, cuando el hecho del vuelo no supone una obligación laboral- abarca a 3 de cada 4 pilotos, siendo también mayor el uso para labores de adiestramiento y aprendizaje. En las aeronaves ocasionales el uso comercial es exiguo 0 , simplemente, desaparece ${ }^{116}$.

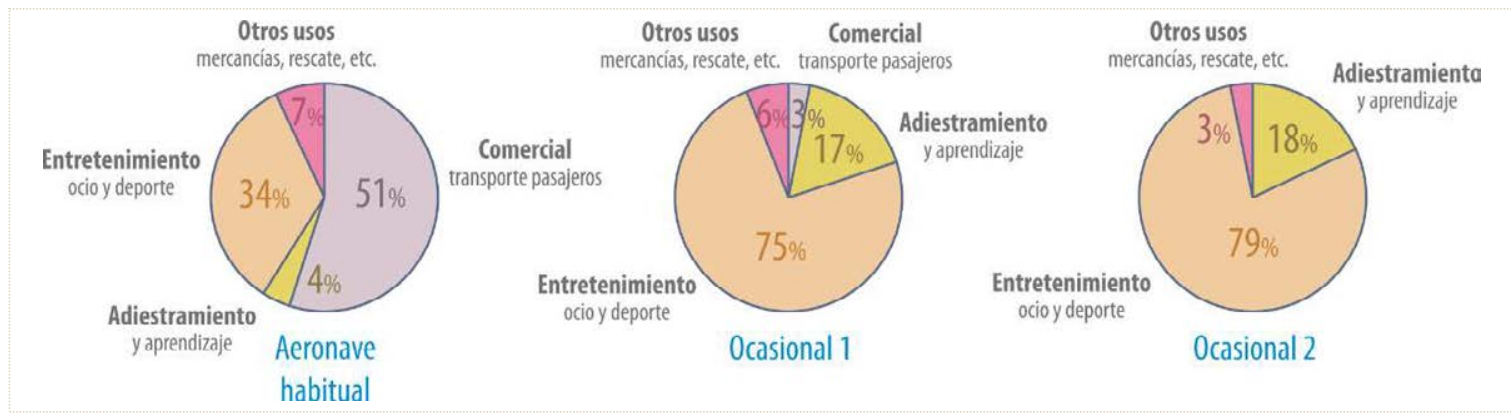

Figura 2-39: Usos principales a los que se destinan las aeronaves (figura propia).

En 9.1.14 -Tipología y cuantificación de rutas y desempeños a bordo- pueden consultarse porcentajes detallados acerca de la tipología de rutas habitual y los desempeños de los pilotos a bordo.

En resumen, para conseguir la definición de un perfil general de los participantes en el estudio, se ha investigado acerca de la tipología de las aeronaves, su uso y el desempeño a bordo. Las conclusiones parciales se sintetizan a continuación:

- La identificación de modelos concretos de aeronaves permite disponer, en líneas generales, de dos modelos concretos con similar aceptación por cada tipo o perfil característico de piloto, lo cual permitiría modelar de una forma acertada el entorno de trabajo compuesto por el espacio en cabina, mandos, aviónica e instrumentación, etc.

- El uso profesional-comercial, adiestramiento, etc.- es más evidente en las aeronaves habituales que en las ocasionales, donde por el contrario es mayoritario el uso para entretenimiento. También existe una clara atomización en las rutas navegadas: mayoritarias las grandes distancias para el caso de las

${ }^{116}$ Un contraste de este resultado con los datos recabados acerca de las preferencias personales indica que, en el caso de vuelos comerciales, las rutinas de provisión son más constantes y ceñidas a la regularidad de las operaciones. En el caso de los vuelos de ocio existe un evidente relajamiento y una mayor libertad operacional y de provisión de información geográfica. 
aeronaves habituales, estas se muestran meramente testimoniales en el caso de aeronaves ocasionales -evidentemente por el tipo y envergadura de aeronave implicada en cada caso-.

- En el caso de los desempeños en cabina, las grandes aeronaves comerciales permiten la participación de dos tripulantes en las tareas, lo que queda reseñado en el estudio. El porcentaje de comandantes y copilotos se reparte aproximadamente a partes iguales en cualquiera de los ámbitos de uso predefinidos. El cotejo de los resultados de usos principales y desempeños valida estos porcentajes.

Finalmente, y a la vista de las conclusiones anteriores, a efectos prácticos se han podido establecer los siguientes perfiles significativos de usuario:

a) Piloto privado, con licencia correspondiente y habilitación de clase para avión de un solo piloto. Está asociado a aeroplanos con motor característicos -de tipo Cessna C172 o Piper PA 28-, con desempeño de piloto único. Como uso principal está el de entretenimiento, ocio y deporte, aunque en uso ocasional también se destina secundariamente a adiestramiento y aprendizaje. La tipología de rutas es variada, aunque en su mayor parte del tipo local/regional bajo reglas VFR/IFR y rutas nacionales.

b) Piloto de líneas aéreas, con título/licencia en vigor de piloto de transporte de línea aérea, y añadiendo una licencia de piloto privado en su caso, con habilitación de tipo para avión certificado para más de un piloto y de vuelo instrumental para aviones multimotor. Está asociado a aviones comerciales bimotores, de aproximadamente 160 plazas tipo Airbus A320-211 o Boeing 737-800NG, evidentemente para uso comercial. El tipo de rutas que sirve son rutas nacionales o internacionales -dentro de un mismo continente-, en vuelo instrumental. Su desempeño como tripulación es la de comandante. Ocasionalmente, dispone de una aeronave ocasional para entretenimiento, ocio y deporte, volando en rutas locales/regionales bajo reglas VFR.

c) Piloto de ultraligero, con licencia específica, asociado con aeronave de ala fija tipo P92/96 Tecnam ala fija inferior- o Coyote Rans -ala fija superior-, las cuales son aeronaves de piloto único. Su uso habitual es la de entretenimiento -ocio y deporte-, volando en rutas locales/regionales bajo reglas VFR. Los componentes de este perfil de pilotos no suele volar otro tipo de aeronaves en uso ocasional.

\subsubsection{Utilización de los elementos de información geográfica en vuelo}

Al ser considerada la variable de uso más o menos intensivo de las aeronaves utilizadas [Figura 2-40], los resultados muestran con nitidez que cuanto menor es el índice de utilización de la aeronave, también menor es el uso de cartas en formato papel y, por el contrario, mayor el de cartas en formato digital. Además, mientras que el crecimiento del uso de cartas digitales es más suave -alrededor de 10 puntos porcentuales-, el decrecimiento porcentual en el uso del formato papel es más intenso -reduciéndose a la mitad en el caso de aviones más ocasionales-. Llama la atención el porcentaje significativo de usuarios que afirman no consultar en vuelo ningún tipo de carta aeronáutica en las aeronaves ocasionales -9\% y $18 \%$ respectivamente-. 


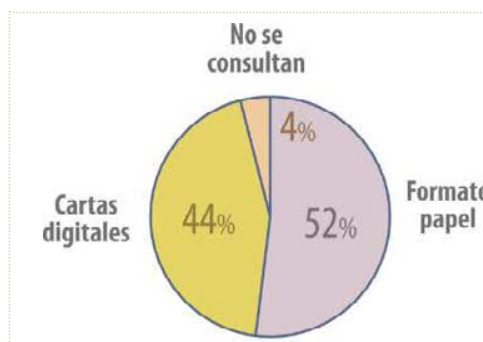

Aeronave

habitual

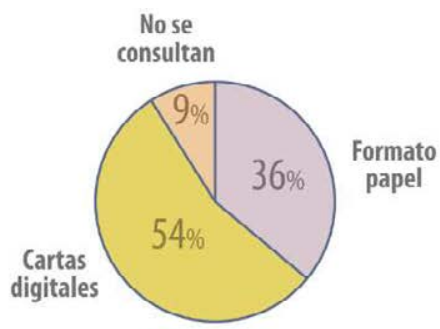

0casional 1

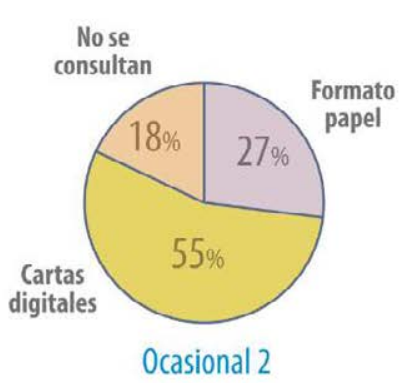

Figura 2-40: Formatos de cartas utilizados a bordo según la frecuencia de uso de la aeronave (figura propia).

A la vista del perfil de pilotos y aeronaves inferido en la sección anterior, se deduce que cuanto más ligera es la aeronave y su uso menos comercial, con mayor intensidad se utilizan las cartas digitales. En vuelos habituales, el uso de cartas en papel y digitales es bastante equilibrado, siendo el porcentaje de usuarios que no consultan ninguno de los dos formatos reducido. Contrariamente, el uso de cartas clásicas en papel decrece al decrecer también la intensidad del uso. En el caso extremo, 1 de cada 5 pilotos afirma que vuela sin consultar las cartas en papel-al menos en cabina-.

También puede ser interesante cotejar cómo se muestra el uso de los formatos de información dependiendo del perfil general del piloto. Para ello se ha realizado una estratificación de la población encuestada en pilotos de vuelo visual (VFR) y pilotos de vuelo instrumental (IFR) ${ }^{117}$.

117 Para estudiar los elementos de información geográfica en vuelo, se ha considerado clave clasificar a los encuestados en pilotos de vuelo visual y pilotos de vuelo instrumental. Así, en el posterior análisis de cada uno de los formatos propuestos se separan los porcentajes de ambos grupos definitorios, ya que a priori se estima que poseen distintas necesidades de provisión. Para conseguirlo de forma automática se ha recurrido al filtrado del apartado de 'usos' de las aeronaves, separando a los usuarios que sólo ejecutan vuelos bajo reglas VFR del resto. En consecuencia, en el estudio de aquí en adelante van a ser considerados dos grupos diferenciados:

a) Pilotos de vuelo visual VFR: Aquellos que exclusivamente vuelen bajo reglas VFR - Visual Flight Rules- y, aparentemente, no tengan experiencia en vuelo instrumental.

b) Pilotos de vuelo instrumental IFR: Aquellos que vuelen normalmente bajo vuelas IFR -Instrumental Flight Rulesmás aquellos que, aun volando habitualmente bajo reglas VFR, tengan también experiencia en vuelo instrumental. 


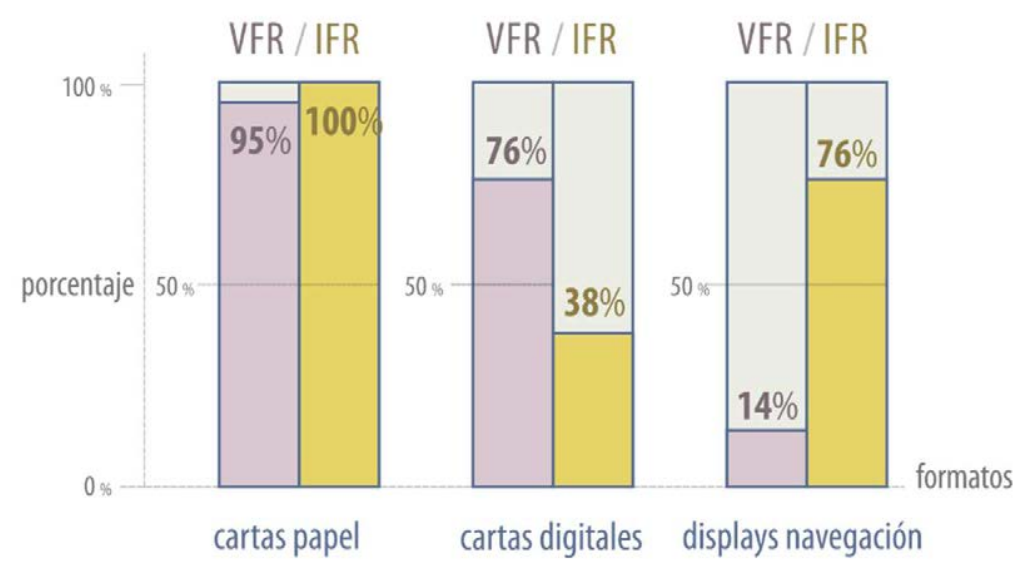

Figura 2-41: Formatos de cartas utilizados a bordo respecto al perfil general del piloto. Los porcentajes agregados totales son del $97 \%$ en cartas papel, $48 \%$ en cartas digitales y del $61 \%$ en el caso de los displays de navegación (figura propia).

A través de la gráfica presentada [Figura 2-41] se aprecia la llamativa diferencia existente en el uso de los distintos formatos, dependiendo de si se consideran pilotos visuales o instrumentales respectivamente. Mientras que en el caso de pilotos instrumentales el uso de displays de navegación nativos se dispara hasta 3 de cada 4, en el caso de vuelos VFR el uso se reduce a un exiguo 14\%. En cuanto a las cartas digitales, se invierten los términos, siendo consideradas por 3 de cada 4 en el caso de pilotos de vuelo visual, y bajando este porcentaje hasta el $40 \%$ en el caso de vuelo instrumental.

A la vista del anterior análisis, se deduce que el uso de displays de navegación en vuelo instrumental está bastante extendido, mientras que la falta de estos dispositivos en los aviones de vuelo visual es suplida con los dispositivos personales electrónicos de consulta de cartografía digital. En cualquiera de los dos casos, la utilización de cartas en papel es prácticamente unánime, aunque destaca el porcentaje del 5\% de pilotos visuales que, o bien por imposibilidad práctica de uso en cabinas no cerradas o bien por la confianza absoluta en los dispositivos digitales, declaran no utilizarlas en vuelo.

En el anexo 9.1.15 -Consideraciones adicionales acerca del uso de formatos a bordo- se presenta una completa información adicional al respecto.

En resumen, y según los resultados obtenidos, una caracterización básica de usos de los elementos de información geográfica puede ser sintetizada como sigue:

- Cuanto menor es el índice de utilización de la aeronave -es decir, cuanto más ligera es la aeronavey su uso menos comercial-, menor es el uso de cartas en formato papel, y por el contrario mayor el de cartas en formato digital. A su vez, existe una clara distinción entre las aeronaves comerciales -dotadas de displays de navegación- y las aeronaves ligeras o ultraligeras. En este último caso, la inexistencia de 
esta ayuda instrumental es suplida en un alto porcentaje por el uso de dispositivos electrónicos portátiles.

- A través de una reclasificación de pilotos VFR e IFR respectivamente, se descubre que mientras el uso de displays de navegación no sustituye el uso de cartas en papel, en el caso del uso de dispositivos personales sí lo hace, de forma que incluso un 5\% de los pilotos de vuelo visual afirma no utilizar nunca en vuelo cartas aeronáuticas en papel ${ }^{118}$. En el extremo contrario, el 100\% de los pilotos de vuelo instrumental utilizan habitualmente las cartas en papel en vuelo, aun teniendo una herramienta de conciencia situacional tan flexible como los displays de navegación.

\subsubsection{Evaluación de características semiológicas, de usabilidad y de eficiencia}

Como parte esencial de la tarea de caracterización del uso práctico de la información geográfica a bordo de las aeronaves, se ha tratado de evaluar la opinión que poseen los usuarios sobre diversas características clave referidas sobre todo al manejo e interpretación- de las cartas aeronáuticas. A través de esta valoración, se pretende examinar determinados problemas semiológicos y de usabilidad, midiendo el impacto que producen dichos problemas tanto en la correcta provisión de información como en la propia seguridad del vuelo.

El análisis se ha particularizado en cada uno de los formatos identificados en 2.5.5 -Los formatos-. En consecuencia, en los anexos 9.1.16 -Valoración semiológica y de usabilidad: cartas en papel-, 9.1.17 -Valoración semiológica y de usabilidad: displays de navegación-y 9.1.18 -Valoración semiológica y de usabilidad: cartas digitales- se presenta el desarrollo completo y pormenorizado del análisis realizado.

Los resultados mostrados en los anexos reseñados han sido sintetizados en forma de gráficos sectorizados, a los que además les ha sido aplicado un código de color ${ }^{119}$ que intenta facilitar de forma visual la identificación de posibles problemas y su incidencia en los diferentes apartados.

Para cada uno de los formatos de información geo-aeronáutica, las deducciones parciales que arroja el estudio pueden ser sintetizadas como sigue:

118 Puede presuponerse que una de las causas de esta situación es la estrechez de las cabinas de vuelo en las pequeñas aeronaves, sobre todo en los ultraligeros.

${ }^{119}$ Se ha tratado de sistematizar visualmente las adecuaciones y problemas, recogidos a través de escalas de Likert o escalas analógicas verbales, a través de un código semiológico basado en colores verdes -positivos-, amarillos menos positivo-, naranjas -menos negativo- y rojos -negativos-. 
- Con respecto a las cartas aeronáuticas en formato clásico o papel,

Algo más de 1 de cada 2 pilotos indica que tienen problemas derivados del espacio necesario para el manejo de cartas en papel en cabina. Sin embargo, existe una acentuada diferencia entre perfiles: mientras que un $77 \%$ de pilotos de vuelo visual tienen problemas al respecto -un $25 \%$ afirma que muchos-, en el caso del perfil instrumental el porcentaje se reduce a un $44 \%$-con un $8 \%$ que afirma tener muchos problemas-

Respecto a la posible existencia de problemas en la velocidad de búsqueda de información en la cartografía, existe prácticamente equivalencia entre el número de pilotos que mantiene que la adecuación del volumen y densidad gráfica de la información mostrada es correcta -un 56\%-y los que creen que es inadecuada -un 44\%-. Además, apenas existe diferencia en este resultado al considerar perfiles de piloto.

En cuanto a la adecuada representación cartográfica de límites de velocidad, altitud y sectorización, algo más de 2 de cada 5 pilotos indica que las representaciones no son adecuadas, si bien la valoración negativa extrema -nada adecuadas- apenas alcanza el 3\%. No se encuentran diferencias significativas al atender a perfiles de piloto.

Más de 2 de cada 5 pilotos indica que la representación de la orografía y los obstáculos del terreno no es adecuada. Los pilotos de vuelo visual tienen una valoración ligeramente más negativa al respecto. Por el contrario aquellos instrumentales que indican su disconformidad muestran que el impacto del problema es algo mayor.

Existe equivalencia entre el número de pilotos que mantiene que señalan bastantes o muchas dificultades para interpretar zonas de la carta con gran densidad de datos y simbología con respecto a los que no las tienen. Frente a perfiles, un $61 \%$ de los pilotos de vuelo visual tienen bastantes dificultades -un 8\% muchas-, frente a un 48\% de pilotos instrumentales -un 5\% muchas dificultades-.

También existe equivalencia total entre el número de pilotos que valora positivamente la eficacia que poseen las cartas VFR en formato papel para el objetivo de una correcta orientación en el espacio y los que no. No existen diferencias al atender a perfiles de piloto. En cualquier caso el rango de valoraciones extremas -totalmente o nada eficaces- fluctúa entre un 2\% y un $8 \%$ en ambas clases. 
Pese a haber aflorado porcentajes significativos de valoración negativa con respecto a todos los aspectos anteriores, menos de 1 de cada 10 pilotos de vuelo visual indican haber experimentado bastantes o muchas incidencia debidas a problemas de uso y/o lectura e interpretación cartográfica, las cuales pudiesen haber comprometido la seguridad en vuelo en algún momento dado. Este porcentaje todavía es menor en el caso de pilotos instrumentales que realizan vuelos VFR apoyándose en cartas en papel.

- Con respecto al formato de Displays de Navegación (ND),

Poco más de 1 de cada 5 pilotos considera que los displays de navegación poseen una incorrecta adecuación de la luminosidad y visibilidad de la pantalla con respecto a las posibles condiciones de luz ambiental en vuelo. No existe apenas diferencia al atender a perfiles, aunque en el caso de los pilotos visuales que indican su disconformidad, 1 de cada 2 afirman que la adecuación es totalmente inadecuada.

Para aproximadamente 9 de cada 10 pilotos, la adecuación del volumen y densidad de la información mostrada en los displays es bastante o totalmente conveniente. Por el contrario, apenas constan pilotos que valoren como nada apropiada tal adecuación. No existe apenas diferencia al considerar perfiles.

Un 94\% del total de los pilotos consultados interpreta como bastante o totalmente apropiada la adecuación de los modos de visualización del selector de la unidad de control del display para sus necesidades de navegación. Esta consideración tan positiva es ligeramente menor en el caso del perfil de pilotos de vuelo visual.

Un 93\% del total de los pilotos consultados valora como adecuados los valores de alcance del selector de escala del display de navegación. Para 1 de cada 4 pilotos la adecuación es total.

Algo más de 3 de cada 4 pilotos creen posible ejecutar rutas con seguridad guiándose exclusivamente -sin control automático- a través del display de navegación. El 11\% de pilotos de vuelo instrumental se muestra poco de acuerdo con esta afirmación, mientras que el nivel de desacuerdo en el perfil de pilotos instrumental alcanza el 23\%.

En cuanto al acomodamiento y claridad con la que este tipo de dispositivos ofrece la representación orográfica del terreno, casi 3 de cada 5 pilotos lo valora negativamente, resultando ligeramente más crítico con este aspecto el perfil instrumental, con un elevado 17\% de valoración totalmente negativa. 
En cuanto a la revisión de incidencias en vuelo que puedan haber comprometido la seguridad, algo más de 2 de cada 5 pilotos afirma que no ha sufrido incidencia alguna por cuestiones de dificultades de interpretación, frente a 1 de cada 4 en el caso de anomalías técnicas. Un exiguo 4\% del total declara que ha sufrido bastantes incidentes debido a dificultades de interpretación de la información gráfica -un 9\% por anomalías técnicas-. Al respecto, y si diferenciamos por perfiles generales, emerge un importante porcentaje de bastantes incidencias en el caso del perfil VFR: un $22 \%$.

- Con respecto a las cartas aeronáuticas en formato digital,

Prácticamente existe equivalencia entre el número de pilotos que mantiene una valoración positiva de la adecuación de la visibilidad de las cartas digitales para cualquier condición de luz ambiental en cabina, con respecto a los que no la tienen. El perfil de pilotos de vuelo visual es más crítico al respecto -57\%, con un 13\% devaloración totalmente negativa-.

3 de cada 4 pilotos creen que las cartas digitales son más eficientes que sus equivalentes en formato papel. Por perfiles, el 85\% de pilotos de vuelo visual sostiene esta afirmación, contra el 67\% de los pilotos instrumentales.

Casi 7 de cada 10 pilotos considera adecuada la ergonomía de los dispositivos portables de cartografía digital en orden a manejar el dispositivo sin dificultad y con seguridad para control de vuelo. El perfil instrumental es más crítico al respecto: un $27 \%$ de pilotos de vuelo visual tienen una valoración negativa contra el 38\% del perfil instrumental.

Poco más de 6 de cada 10 pilotos considera adecuada la usabilidad y funcionalidad de los interfaces de usuario de los programas que manejan la cartografía sobre estos dispositivos. El perfil de pilotos instrumentales es ligeramente más crítico al respecto.

Del conjunto de los consultados, existe una consideración prácticamente simétrica -48\% favorable, 52\% desfavorable- con respecto a la afirmación de que los programas soporte de cartas digitales con gran cantidad de opciones son más eficaces con respecto a los equivalentes más sencillos y con apenas posibilidad de interacción. Sin embargo, se observa una marcada diferenciación por perfiles: mientras que un $67 \%$ de los pilotos de vuelo visual cree más adecuados los programas con interfaces sencillos -un 10\% rechaza de pleno los programas con gran cantidad de opciones-, un 57\% de pilotos de vuelo instrumental opta por programas con mayor número de opciones y posibilidades de personalización. 
Algo más de 7 de cada 10 pilotos considera que la cartografía digital es una alternativa válida en vuelo para solventar -o al menos minimizar- las carencias detectadas de los mapas en papel y los displays de navegación. Un 38\% de los pilotos de vuelo visual están totalmente de acuerdo con esta afirmación, frente a un $21 \%$ en el caso del perfil instrumental.

En cuanto a la revisión de incidencias en vuelo que puedan haber comprometido la seguridad, un $8 \%, 19 \%, 15 \%$ y $16 \%$ del total de los pilotos han declarado haber sufrido incidencias a bordo en el uso de estos dispositivos debido a dificultades de interpretación, dificultades de manejo, anomalías técnicas y falta de cobertura GPS, respectivamente. El perfil de pilotos de vuelo instrumental tiene una afectación ligeramente mayor: un $4 \%$ de los pilotos de este perfil indican haber sufrido muchas incidencias debido a dificultades de manejo y anomalías técnicas, las cuales han comprometido su seguridad en vuelo.

En modo de pregunta abierta de tipo cualitativo, se ha inquirido a los pilotos acerca de las eficiencias e ineficiencias -según su criterio particular- que demuestran los distintos formatos cartográficos en su uso práctico en vuelo.

De igual forma, el análisis se ha particularizado en cada uno de los formatos identificados en 2.5.5 -Los formatos.En consecuencia, en los anexos 9.1.19-Eficiencias e ineficiencias del formato de cartas en papel-, 9.1.20-Eficiencias e ineficiencias del formato de displays de navegación-y 9.1.21 -Eficiencias e ineficiencias del formato de cartas digitales- se presenta el desarrollo completo y pormenorizado del análisis realizado.

Para cada uno de los formatos de información geo-aeronáutica, el estudio realizado puede ser sintetizado como sigue:

- Con respecto a las cartas aeronáuticas en formato clásico o papel, y según el criterio de los pilotos, las cualidades más destacables son -entre otras-:

Fiabilidad, seguridad e independencia: no dependen de ningún sistema eléctrico, por lo que no están expuestas a averías o fallos electrónicos ${ }^{120}$.

Las distintas ediciones de cartas en papel se muestran muy completas y poseen todos los datos necesarios para el desempeño con el que fueron concebidas.

${ }^{120}$ Según el criterio de los pilotos, las cartas en papel son alternativa de reserva en el caso de uso de cartografía digital. 
Posibilidad de extraer información de una forma rápida e intuitiva a través de su representación gráfica, la cual además permite una gran amplitud y perspectiva de visualización.

Sobre ellas se puede realizar cualquier tipo de anotación rápida -planificación preliminar, briefing de aproximaciones, etc.-

- Por el contrario, y según el criterio de los pilotos, los aspectos más negativos o susceptibles de mejora en el caso de las cartas aeronáuticas en formato clásico o papel son -entre otros-:

Archivo y almacenaje: el tiempo dedicado a encontrar la carta o ficha correcta, en las colecciones que deben de llevarse a bordo es, en muchas ocasiones, excesivo.

En algunas series concretas -SID, STAR, aproximación, etc.- existe una excesiva densidad de datos y simbología que dificulta enormemente su rápida lectura. En ocasiones no aparecen resaltados los datos verdaderamente importantes y básicos de navegación, los cuales se requiere que sean identificados con rapidez.

Las turbulencias y vibraciones, sobre todo en las pequeñas aeronaves y ultraligeros, hace en ocasiones impracticable la lectura de la carta. Se añade el problema de la falta de luz natural en determinados horarios.

Fácil deterioro y degradación. Son sensibles a la humedad y frágiles en las líneas de pliegues.

- Con respecto a los Displays de Navegación (ND), y según el criterio de los pilotos, las cualidades más destacables son -entre otras-:

Eficaces para dotar al piloto de conciencia situacional, respecto tanto al territorio como al plan de vuelo programado, a las ayudas a la navegación y a los puntos de paso de los procedimientos instrumentales.

Grafismo sencillo y claro, interpretable con un solo golpe de vista. Si bien no aporta la misma cantidad de información que las cartas en papel, la que presenta es verdaderamente importante y definitoria de los procedimientos de navegación.

Integración total con el control automático de vuelo, lo que se simplifica enormemente las tareas de navegación. 
Proporciona orden en cabina. Correcta ergonomía en su interfaz de usuario: modos de presentación, alcance o escala de visualización y filtrado de información.

- Por el contrario, y según el criterio de los pilotos, los aspectos más negativos o susceptibles de mejora de los Displays de Navegación (ND) son -entre otros-:

La luz solar directa provoca molestos reflejos que dificultan la lectura de la información, sobre todo en las antiguas pantallas CRT.

Problemas de visualización para grandes alcances, en los cuales la cantidad de símbolos y objetos gráficos que aparecen en pantalla puede ser tal que hace totalmente ilegible la información presentada.

Deficiente representación orográfica. Mínima resolución y limitado uso de la variable color para representar la altimetría del terreno.

Al trasladarse la responsabilidad de la interpretación de los datos geográficos y la propia navegación al control automático de vuelo del avión, se provoca una peligrosa actitud de complacencia y de dejadez de comprobaciones: el piloto tiende a convertirse en un mero observador pasivo.

- Con respecto a las cartas aeronáuticas en formato digital, y según el criterio de los pilotos, las cualidades más destacables son -entre otras-:

Integración y rango de datos diversos. Gestión de la información de interés a través de la activación y desactivación de capas, variación manual de la zona de la carta visualizada, modificando dinámica de la escala, etc.

Portabilidad: permiten trabajar con ellos indistintamente dentro o fuera del avión.

Seguridad: añadiendo un receptor de señal GPS, es posible lograr el desplazamiento automático del mapa acorde con la posición real de la aeronave, de modo análogo a como sucede en los displays de navegación instrumental.

Los programas soporte, además de permitir el seguimiento visual del vuelo sobre la carta, pueden disponer de varias funciones aeronáuticas de utilidad: generación de un plan de vuelo, cálculo de rumbos, velocidades, tiempos estimados, combustible, etc. 
- Por el contrario, y según el criterio de los pilotos, los aspectos más negativos o susceptibles de mejora en el caso de las cartas aeronáuticas en formato digital son -entre otros-:

En los dispositivos portátiles se acrecientan los problemas de reflejos solares que a veces presentan los displays instrumentales de navegación: el tamaño, la luminosidad y el contraste de sus pantallas no están pensados en exclusividad para un uso aeronáutico.

El manejo de los menús y opciones de los programas de navegación es, en muchas ocasiones, engorroso y poco intuitivo, con lo que pueden distraer peligrosamente al piloto de sus labores de manejo de la aeronave.

Cierta falta de fiabilidad y predisposición a fallos y cuelgues, mucho mayor que en el caso de los displays de navegación.

Dependencia de la alimentación eléctrica. No es fácil disponer de una conexión eléctrica adecuada a bordo, por lo que la capacidad y autonomía de la batería es una cuestión crítica.

\subsubsection{Resolución de aspectos de interés}

En 2.6.1 -Los aspectos de interés y el instrumento de evaluación- fueron enunciados los aspectos de interés que daban pie al estudio de caracterización realizado. Estos aspectos deben ser entendidos como rasgos o matices que, sumados, van a lograr caracterizar a la cuestión general. Tras completar dicho análisis, a continuación se pasa a resolver sucintamente cada una de las cuestiones planteadas.

Bloquel: En cuanto a los aspectos relativos a las relaciones generales.

1. ¿Cómo es el proceso de adquisición de la información geográfica aeronáutica en el colectivo de pilotos españoles?

Los datos recabados no permiten hacer una composición del orden en el que los usuarios se proveen de información. Aun así, analizados los comentarios de tipo cualitativo, se desprende que los usuarios de cartografía en papel requieren de una composición genérica y situacional antes de proceder a la extracción de datos concretos y de detalle. Idéntico es el proceso mental en el caso de la cartografía digital, aunque menos marcado, ya que se dota al usuario de la posibilidad de composición y filtrado previo de la información. 
2. ¿Qué relación o relaciones pueden ser establecidas entre tipo de piloto, de aeronave, de vuelo e información acopiada?

A la vista de los resultados obtenidos, estas relaciones pueden ser sintetizadas en al menos tres perfiles significativos, que en el estudio se han denominado piloto privado, piloto de líneas aéreas y piloto de ultraligero. La descripción de perfiles se desarrolla en 2.6.9 -El perfil general de las tripulaciones y sus aeronaves-, engranando tipos de piloto, de aeronave y de desempeños a bordo.

Bloque ll : En cuanto a los aspectos relacionados con las preferencias y especializaciones.

3. ¿Qué preferencias de uso tienen los distintos formatos de información geo-aeronáutica por parte de los pilotos españoles?

Excepción hecha de las instrucciones vocales del ATC, como medios de provisión de información geográfica aeronáutica son utilizadas las cartas aeronáuticas en papel, las cartas electrónicas portadas -visualizadas en libretas electrónicas, ordenadores portátiles, PDA's y smartphones-y los dispositivos integrados de navegación instrumental.

Las cartas en papel pueden agruparse en cartas de gran formato, y pequeñas fichas que forman parte de una colección relacionadas con uno o varios aeropuertos y/o zonas de control de tráfico en áreas aeroportuarias. En el caso de las herramientas para la gestión de cartografía digital, existen numerosos tipos de dispositivos electrónicos, en constante evolución y con características muy variables, tanto ergonómicas como de capacidades y particularidades de los programas de gestión.

Las preferencias de uso están claramente influenciadas por los perfiles de usuarios descubiertos en el estudio, las capacidades intrínsecas de cada formato -analógico vs. digital-, así como por las tendencias personales de cada usuario -más difíciles de medir-. En un cómputo estrictamente global, la práctica totalidad de los pilotos utilizan cartas en papel -salvo un 5\% en el caso de los pilotos visuales-; 5 de cada 10 cartas digitales -casi 8 de cada 10 visuales y 4 de cada 10 instrumentales- y finalmente 6 de cada 10 pilotos utilizan los displays de navegación -casi 8 de cada 10 pilotos instrumentales, algo más de 1 de cada 10 si nos referimos a los pilotos que vuelan habitualmente en reglas visuales-. 
4. Si son combinados varias de ellos, ¿en qué proporción?

Es posible deducir combinaciones habituales entre medios, pero cuando estos se combinan entre sí es aventurado extraer un porcentaje de uso entre ellos.

5. ¿Qué ventajas o especializaciones tienen unas herramientas o formatos respecto de otras?

De forma muy simplificada se puede establecer que las cartas en papel proveen de seguridad e independencia a los pilotos, ya que no dependen de sistemas electrónicos. Los displays de navegación dotan al tripulante de conciencia situacional, estando además coordinados con los sistemas de navegación automática de los aviones que lo portan. Finalmente, los dispositivos personales de consulta de cartas digitales son capaces de integrar y relacionar datos de distintas fuentes $y$ temáticas, con lo que se dota al piloto de la capacidad de personalizar la información, añadiendo incluso datos de otras fuentes.

6. ¿Puede ser establecida una jerarquía de eficiencia entre las diferentes herramientas o formatos?

No es posible establecer un ranking como tal, ya que cada uno de los formatos está condicionado por sus facetas positivas y negativas. Según el estudio, la tendencia general es no confiar en un único medio, sino hacer uso de al menos dos, combinándolos o al menos disponiendo siempre en vuelo de uno de ellos como respaldo.

Bloque III : En cuanto a los aspectos relacionados con la representación e interpretación.

7. En cada uno de los formatos; ¿es adecuada su ergonomía de uso?

Las cartas en papel presentan claras limitaciones ergonómicas, como son el tamaño -límites de la percepción visual con respecto a la densidad de la información y el tamaño de texto y símbolos- y la falta de suficiente espacio físico en la cabina para el manejo de las cartas. Al respecto, se ha contrastado la importancia de mantener un estricto orden de almacenamiento en la cabina para poder acceder a los gráficos de forma rápida.

Los dispositivos que portan cartas digitales resuelven parte de las limitaciones anteriores -luminosidad, filtrado de datos, variación dinámica de escala, etc.-. Sin embargo, los soportes físicos empleados -dimensiones, peso, tamaño, reflectividad y propiedades capacitivas de la pantalla, interfaz de opciones, etc.- no suele estar ideado para el uso en tareas aeronáuticas. Por el contrario -y salvo el 
tamaño y los molestos reflejos de las pantallas de los modelos más veteranos-, la ergonomía de los modos de operación de los displays instrumentales se muestra en todo momento muy adecuada.

8. ¿Es adecuado el volumen y síntesis de información que suministran?

En líneas generales, las cartas en papel no se adecúan correctamente cuando en determinadas zonas de representación existe una acumulación de información; su solución en forma de fichas separadas provoca también un problema de ergonomía por la falta de continuidad entre los documentos. En el caso de los displays de navegación, es muy adecuada la síntesis que hacen de la información, pero en el caso de los grandes alcances se acumula demasiada información en pantalla y se tornan ilegibles. Finalmente, en el caso de las cartas digitales, no existe una estandarización en cuanto a la gestión y visualización de la información; esto provoca que el piloto se deba de responsabilizar de la jerarquización y filtrado de la información, provocando distracciones en las labores de navegación -efecto head-down-

9. ¿Es adecuada la representación gráfica de los diversos fenómenos?

En el estudio se han manifestado dos casos sintomáticos; en las cartas en papel, existe una falta de conexión entre los accidentes geográficos que sirven para dotar de conciencia situacional al piloto de vuelo visual en zonas interiores - hidrografía, vías de comunicación, etc.- y su representación gráfica en las cartas, condicionada esta última por el resto de representaciones y datos, cuya acumulación provoca ruido en el mensaje. En el caso de los displays de navegación-especialmente en los más antiguos-, la representación de la orografía del terreno es claramente insuficiente.

Las frecuencias con las que los pilotos reconocen dificultades de interpretación están en la mayoría de los casos por debajo del 10\%, pero depende mucho tanto del medio -4\% en displays instrumentales- como, sobre todo, de la tipología de piloto -por ejemplo, se alcanza un 14\% en cartas papel en el caso de pilotos instrumentales en vuelos VFR visuales-, o un 13\% en cartas digitales en pilotos instrumentales.

10. ¿Hasta qué punto los problemas de interpretación pueden provocar incidencias relevantes para la seguridad en vuelo?

En el estudio, y pese a detectar porcentajes de ocurrencia cercanos al 10\% en el caso de las cartas papel y digitales, los pilotos han sido parcos en relatar incidencias concretas. 
Bloque IV: En cuanto a los aspectos relacionados con las condiciones ambientales.

11. ¿De qué forma afecta al uso de los formatos el espacio físico disponible en la cabina de mando?

El manejo de las cartas en papel está claramente afectado por la angostura y la falta de lugares de apoyo físico dentro de las cabinas de mando. Incluso, en el caso de cabinas abiertas, el uso de cartografía en papel se torna especialmente problemático por el flujo de aire exterior.

12. ¿Y por las condiciones ambientales exteriores?

En cuanto a las condiciones ambientales, las cartas en papel se hacen difíciles de consultar ante la falta de luz diurna, mientras que en resto de los formatos, son precisamente los reflejos solares los que dificultan en gran medida su lectura. En cuanto a las vibraciones, y a tenor de los resultados del estudio, tanto las cartas en papel como los dispositivos personales de visualización de cartas digitales son afectados, provocando dificultades en la lectura -los pequeños caracteres se muestran ilegibles-.

13. ¿Son habituales las anomalías técnicas de los formatos digitales?

El estudio demuestra que el porcentaje de anomalías técnicas es relativamente pequeño, o al menos la frecuencia no es elevada. Sin embargo el hecho de que puedan producirse, aunque sea muy de vez en cuando, provoca una constante inseguridad en su uso, sobre todo en los dispositivos electrónicos personales.

\subsection{SUMARIO}

En este segundo capítulo se ha alcanzado el objetivo general de descubrir la caracterización la utilización práctica de la información geo-aeronáutica por parte de los pilotos civiles. Previamente a ello:

- Revisión histórica. A través de una revisión de la literatura existente, se ha dado cuenta de la evolución tanto de la información geo-aeronáutica como de la propia cartografía especializada a través de su perfeccionamiento histórico, cotejando esta con el desarrollo paralelo de las capacidades de las aeronaves, la evolución de las técnicas de navegación aérea y la progresiva tecnificación de los sistemas de información de componente visual. 
- Conceptos de navegación aérea. Se han descrito tanto los procedimientos básicos de navegación que se encuentran recogidos de forma gráfica en la cartografía aeronáutica la sectorización que autoridades regulatorias internacionales han aplicado al espacio aéreo. A su vez, se han detallado los procedimientos que deben llevarse a cabo en cada una de las fases en las que se divide un vuelo instrumental.

- Situación actual de la información geo-aeronáutica. Se ha aportado un estado general de la cuestión con respecto a la Información Geográfica Aeronáutica (IGA): expresión gráfica habitual, soportes físicos y tecnológicos, interoperabilidad, etc. Además, se ha justificado la necesidad de dicha información, y se da cuenta del estado de la cuestión de la provisión, publicación e interoperabilidad de datos aeronáuticos.

Finalmente se han descrito someramente los condicionantes externos de la comunicación de información aeronáutica en vuelo, y se ha aportado, a través de un estudio propio, una visión general de la utilización práctica de la Información Geográfica Aeronáutica (IGA) por parte de las tripulaciones de aeronaves civiles españolas. En este orden de cosas:

- Declaración de objetivos y descripción metodológica. Utilizando la encuesta como instrumento de evaluación, se ha llegado a establecer formalmente el propósito del estudio, los aspectos a evaluar, la escala, etc. Como método de recogida de datos se ha ideado la programación de una encuesta on-line auto-conducida con recogida de datos automatizada, con el que se han evaluado un total de 73 ítems o preguntas.

- Empleo y validación del estudio. Se ha aplicado el instrumento propuesto a un universo poblacional concreto y controlado. Como consecuencia, se han recogido un total de 392 participaciones de pilotos civiles, de las cuales se validaron finalmente 253 cuestionarios completados correctamente y en su totalidad. A su vez, se ha comprobado tanto la adecuada representatividad de la muestra como la fiabilidad de la escala de medida aplicada.

- Análisis y discusión de resultados. A través de una metodología de creación automatizada de consultas, se ha logrado evidenciar -entre otras cuestiones- las relaciones generales existentes, los perfiles de tripulaciones, aeronaves y formatos que son habituales en el colectivo de pilotos civiles en España, las preferencias y especializaciones, la adecuación de la representación cartográfica en cada uno de los formatos, así como la influencia de las condiciones ambientales sobre las labores de lectura e interpretación. 


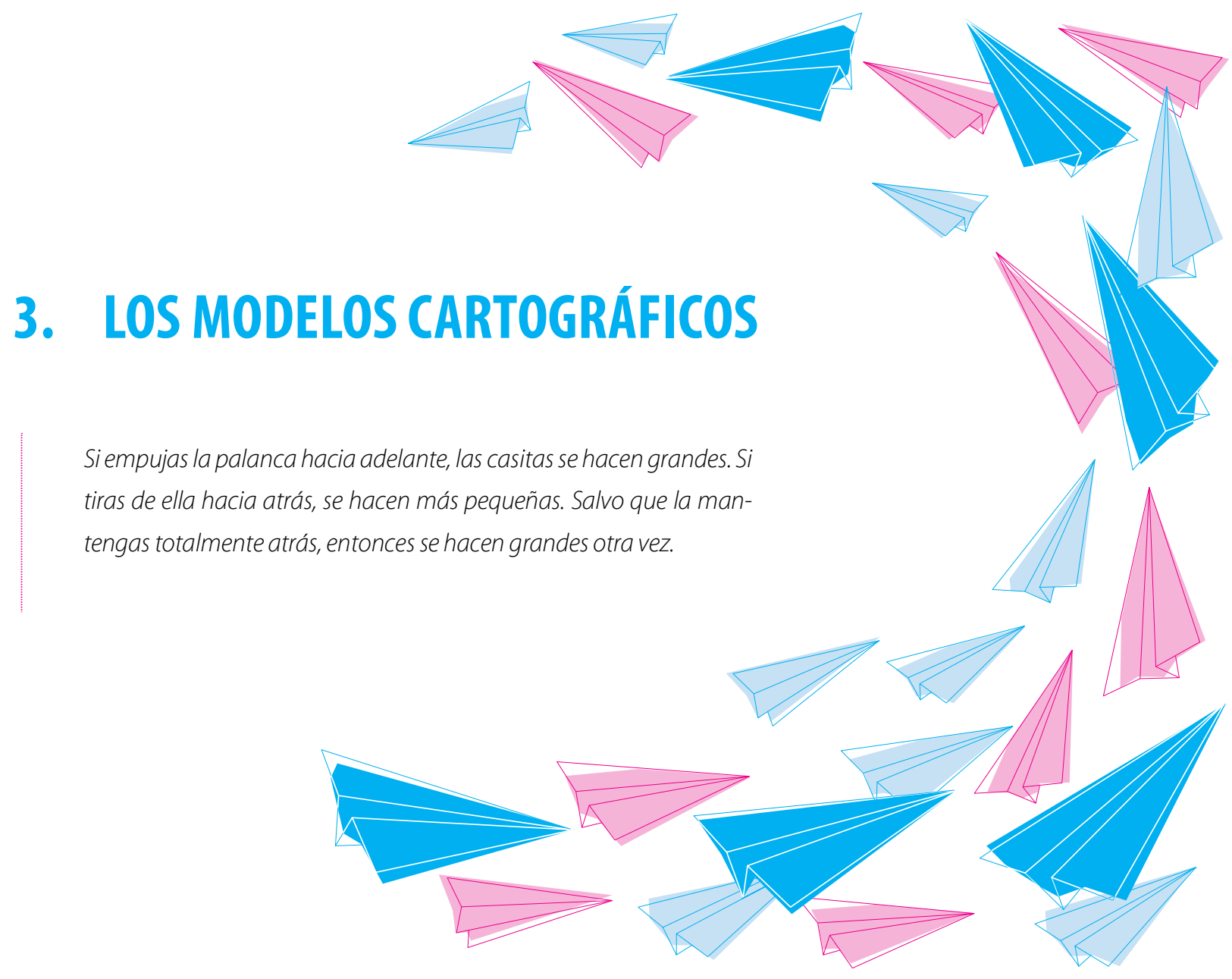

Un mapa -o una carta si está destinada a la navegación- no deja de ser un conjunto de símbolos convencionales que, dispuestos en una determinada formulación, representan diferentes fenómenos de los que ocurren sobre la totalidad del territorio o una parte del mismo. En la disertación realizada en la sección 2.5 -Información geoaeronáutica-, se puso de manifiesto que la principal función de la cartografía aeronáutica es la comunicación de información espacial geográfica y aeronáutica a través de la expresión gráfica. Ciertamente, un modelo cartográfico es una abstracción del mundo real que reduce enormemente su complejidad, permitiéndonos identificar de forma muy sencilla e intuitiva las características esenciales que lo definen, a la vez que obvia detalles de menor importancia que harían de su empleo una actividad ineficiente.

El proceso de construcción de cualquier modelo cartográfico obliga a realizar un esfuerzo de simplificación de la realidad. Para ello el diseñador de la carta, en primera instancia, debe analizar en profundidad esa información, de modo que sea capaz de sintetizarla por medio de distintos convencionalismos. Materializados comúnmente a través de un código de simbolización que garantiza la comunicación con el usuario del mapa, la efectividad del proceso de síntesis se facilita enormemente si se aplica una expresión gráfica lo más clara y precisa posible. De esta manera, y sin sacrificar la precisión de los datos presentados, el usuario de una carta puede llegar a obtener y asimilar con gran agilidad la información necesaria para el desempeño de la navegación. 
Teniendo presente que la motivación de esta tesis doctoral radica -entre otras- en el interés por las innovaciones metodológicas relativas a la ideación eficiente de la expresión gráfica de los modelos cartográficos para la navegación aérea, se ha considerado dedicar este capítulo, fundamentalmente, a tratar la cuestión relativa a la forma y significación del modelo, como necesaria base previa para el posterior estudio de los diferentes aspectos de la eficiencia comunicacional.

En este orden de cosas, creemos necesario subrayar que no pretendemos realizar tabla rasa sobre todo lo ya establecido, refutando así las bases metodológicas de la composición cartográfica. Tampoco es nuestro propósito cuestionar la conveniencia y el rendimiento comunicativo de ediciones cartográficas concretas, tomando finalmente una posible evaluación crítica como punto de partida del proceso metodológico que desarrollaremos a continuación; si así actuásemos, en nuestro discurso metodológico no cabría entonces afirmar cuestión alguna sobre la bondad o no de la eficiencia comunicacional de las cartas aeronáuticas, porque en realidad lo estaríamos haciendo de tal o cual edición cartográfica concreta, y no de una generalidad, como es nuestra verdadera pretensión.

Por todo lo anterior, en este capítulo proponemos realizar un proceso de estereotipado, fijado mediante el descubrimiento de pautas o tendencias repetidas de las especificaciones simbólicas comunes de un conjunto finito pero homogéneo y característico de ediciones OACI mundiales. Este proceso deberá conducir finalmente a la deducción de uno o varios modelos compositivos estereotipados ${ }^{121}$, que serán tomados como elementos de partida para el estudio evaluativo de eficiencia.

Teniendo en cuenta todas estas matizaciones metodológicas, este tercer capítulo -Los modelos cartográficosse va a estructurar de la siguiente manera: En la sección 3.1 -Estandarizaciones y recomendaciones- se da cuenta de las normativas y recomendaciones internacionales que, en el momento actual, son de aplicación a la cartografía aeronáutica. En la sección 3.2 -Grafismo de la información aeronáutica- se consigna una breve síntesis teórica de los conceptos de representación y simbolización aplicada al ámbito aeronáutico, analizando a continuación la estructura compositiva y semántica y el nivel de abstracción simbológica que es habitual en las cartas requeridas para cada tipo de reglas de vuelo existentes. A continuación, y previa declaración de las conclusiones de un estudio preliminar crítico en referencia a las características de las ediciones $\mathrm{OACl}$, en la sección 3.3 -Ediciones características- se declararan de forma razonada las restricciones que van a ser aplicadas al resto de la investigación, identificando justificadamente a partir de ellas un conjunto homogéneo y característico de ediciones de cartas aeronáuticas de distintas regiones y continentes. Finalmente, en la sección 3.4 -Evaluación y estereotipado- se deducirán mediante una metodología propia las especificaciones simbólicas que caracterizan de forma particular a cada una de las ediciones seleccionadas son objeto de análisis, cuya evaluación concluye con una propuesta sintetizada de composición y simbología estereotipada. La deducción de este conjunto de pautas y tendencias constituirá la necesaria base para el posterior estudio de los diferentes aspectos

${ }^{121}$ Con el término estereotipo, nos referimos a modelos cartográficos o cartas cuyo conjunto de pautas de simbolización de fenómenos geográficos y aeronáuticos -los cuales serán inferidos a lo largo de este capítulo- atienda a un común transversal y repetido en una mayor parte de las ediciones mundiales, tratando así de minimizar en lo posible la existencia de sesgos individuales o no característicos. 
de la eficiencia comunicacional. Como conclusión, en la sección 3.5 -Sumario- se presentará la oportuna síntesis de las cuestiones tratadas a lo largo de las secciones de este capítulo.

\subsection{ESTANDARIZACIONES Y RECOMENDACIONES}

Para conseguir que las operaciones aéreas sean seguras es esencial contar en todo momento con una fuente actual, completa e irrefutable de información para la navegación; las cartas aeronáuticas son un medio adecuado para suministrar esta información de manera manejable, condensada y coordinada (ICAO, 2012a). Por la propia naturaleza de la navegación aeronáutica, el mundo de la aviación exige mapas significativamente diferentes a los utilizados en el transporte de superficie. No solo deben facilitar información en dos dimensiones -aspecto habitual en la mayor parte de los mapas de transportes-, sino que también deben ser capaces de representar sistemas de servicios de tránsito aéreo en tres dimensiones.

En la mayoría de los segmentos aeronáuticos, los mapas aeronáuticos se toman como referencia básica para la planificación, el control de tránsito aéreo y la navegación. Entre otras características, deben facilitar una interpretación rápida y clara; esta exigencia viene impuesta por el continuo y progresivo cambio que se produce en las necesidades operacionales de las mismas: mayores velocidades de las aeronaves, mayor gama de altitudes de operación, creciente congestión del tránsito aéreo, etc. (SENASA, 2008). Además se considera que, con frecuencia, la fatiga del piloto es causa probable de errores de navegación y, en consecuencia, un factor que predispone al accidente (ICAO, 1990). Una carta precisa, bien delineada y fácil de leer en diversas condiciones de iluminación, tanto natural como artificial, reduce la tensión que acompaña al vuelo en condiciones atmosféricas poco propicias (SENASA, 2008).

\subsubsection{El Anexo 4 del Convenio de Aviación Civil Internacional}

Tal y como establece el Convenio sobre Aviación Civil Internacional (ICAO, 2006a), cada Estado contratante se compromete, en la medida de lo posible, a adoptar y aplicar las normas y demás métodos y reglas de operación que se recomienden o establezcan continuamente en aplicación del convenio ${ }^{122}$. Como se adelantó en 1.1.2 - Normalización y transición al entorno digital-, las directrices de producción y difusión de cartografía aeronáutica son recogidas formalmente, en el denominado Anexo 4 del Convenio de Aviación Civil Internacional (AN/4) (ICAO, 2009a). En él quedan definidos una extensa serie de especificaciones acerca de la cobertura, el formato, la identificación y el contenido de la carta, incluyendo la simbología normalizada y el color ${ }^{123}$. El objetivo es satisfacer la debida uniformidad y coherencia imprescindibles en el suministro de cartas aeronáuticas,

${ }^{122}$ El Consejo de la OACl adoptó por primera vez las normas y métodos recomendados originales en 1948.

${ }^{123}$ Desde la adopción de la primera edición, que incluía las especificaciones de siete tipos de cartas de la OACl, se han ido sucediendo hasta 53 enmiendas para actualizar el Anexo y dar cabida a los rápidos adelantos de la navegación aérea y la tecnología cartográfica. 
ya que sus editores deben garantizar su calidad y su validez como método de transmisión de una información crítica para la seguridad.

Teniendo como base este documento normativo, a continuación se presentan las necesidades que OACl demanda que sean atendidas (ICAO, 2009a), las cuales a su vez justifican una serie de requisitos normativos que deben ser aplicados por los editores a la hora de confeccionar sus colecciones de cartas. Algunos de estos requisitos son los siguientes:

- En cada tipo de carta se debe proporcionar la información correspondiente a su función y en su diseño se deben observar distintos principios relativos a factores humanos que aseguren su uso óptimo.

- En cada tipo de carta se debe proporcionar la información apropiada a la fase correspondiente del vuelo, con el fin de asegurar la operación segura y pronta de la aeronave.

- La presentación de la información debe ser exacta, exenta de distorsiones y confusiones, inequívoca y legible en todas las circunstancias normales de operación.

- Los colores, las tintas y el tamaño de los tipos empleados deben ser tales que el piloto pueda leer e interpretar fácilmente la carta en diversas condiciones de iluminación natural y artificial.

- La forma de presentar la información debe permitir que el piloto la adquiera en un tiempo razonable, compatible con su carga de trabajo y las circunstancias operacionales.

- La presentación de la información proporcionada en cada tipo de carta debe facilitar la transición de una carta a otra, según la fase concreta del vuelo.

Estos requisitos y otras normas y métodos recomendados son de obligada aplicación en todas las cartas aeronáuticas auspiciadas por $\mathrm{OACl}$, salvo que se indique otra cosa en las especificaciones de la carta correspondiente. Existen, además, unos factores básicos de índole cartográfico que también deben atenderse en el diseño de una carta aeronáutica. Entre ellos:

- Uso de una proyección común.

- Selección de escalas y unidades de medidas -pies, millas náuticas y metros- con valores fácilmente comprensibles.

- Selección de las elevaciones/alturas y otra información relativa al terreno, construcciones y datos aeronáuticos, que faciliten la transición de una carta a otra.

- Publicación simultánea de cartas conexas, tanto cartas nuevas como revisiones. 
- Datos aeronáuticos que deberán ser incluidos en las propias cartas.

Además de especificar los datos aeronáuticos que deberán ser incluidos en cada tipología de cartas normalizada -ver 2.5.4 La publicación- el Anexo 4 del Convenio en vigor señala una serie de normas y recomendaciones generales de confección para todas las cartas: título y denominación, información general a disponer, sistemas de referencia, unidades de medida, escala y proyección, fecha de validez de la información aeronáutica, simbología, ortografía de nombres geográficos, abreviaturas, fronteras políticas, colores, relieve, zonas prohibidas, restringidas o peligrosas, espacios aéreos ATS, declinación magnética, tipografía, etc.

Por último, la OACl dedica apéndices particulares a las normas anteriores, destinados a ampliar la información de determinados aspectos cartográficos:

- Distribución de notas marginales.

- Símbolos cartográficos OACl.

- Guía de colores.

- Guía de tintas hipsométricas ${ }^{124}$.

- Índice y disposición de las hojas de la carta aeronáutica mundial OACI-1:1.000.000.

- Requisitos de calidad de los datos aeronáuticos.

Si nos interesamos por condicionantes meramente semiológicos ${ }^{125}$, el Anexo 4 define una serie de normas y recomendaciones simbológicas de aplicación para toda la producción de cartas OACl de los países firmantes del convenio. Esta especificación asigna un identificador numérico correlativo a cada uno de los símbolos considerados -hasta un total de 177-y los categoriza temáticamente, agrupándolos en topográficos, hidrográficos, construcciones, aeródromos [Figura 3-1], radioayudas, servicios de tránsito aéreo [Figura 3-2], obstáculos y símbolos adicionales. Junto a la especificación de forma correspondiente, también se adjunta una guía para el uso de la variable color y adicionalmente una guía de tintas hipsométricas para la representación del relieve [Figura 3-3].

${ }^{124}$ El empleo de tintas hipsométricas en una carta trata de representar el relieve del terreno por medio de superficies coloreadas según su elevación. La relación entre los colores empleados y los rangos de altitudes se expresan en una tabla presentada en la leyenda (A. H. Robinson, Morrison, Muehcke, Kimerling, y Guptill, 1995).

${ }^{125}$ La cartografía aeronáutica es una forma de transmisión de un tipo de información espacial temática; describe y representa los fenómenos geo-aeronáuticos a través de la construcción de una estructura comunicativa basada en la ideación de un conjunto coordinado de símbolos y signos que tratan de traducir gráficamente dichos fenómenos a través de determinados convencionalismos y leyes (Moya y Bernabé, 2011). 


\begin{tabular}{|l|ll|l|}
\hline 84 & Civil & Terrestre & \\
\hline 85 & Civl & Hidro & \\
\hline 86 & Miltar & Terrestre & \\
\hline 87 & Miltar & Hidro & (2) \\
\hline
\end{tabular}

\begin{tabular}{|l|l|l|}
\hline 88 & Mixto, civil y militar Terrestre \\
\hline 89 & Mixto, civil y militar Hidro \\
\hline 90 & $\begin{array}{l}\text { Aeródromo de emergencia o } \\
\text { aeródromo sin instalaciones }\end{array}$ \\
\hline 91 & $\begin{array}{c}\text { Aeródromo abandonado o } \\
\text { cerrado }\end{array}$ \\
\hline
\end{tabular}

\begin{tabular}{|l|l|c|}
\hline 92 & Anclaje resguardado & t \\
\hline 93 & $\begin{array}{l}\text { Aeródromo utlizado en las cartas } \\
\text { en las que no es necesario } \\
\text { indicar la clasificación del } \\
\text { aeródromo, p.ej., Cartas de } \\
\text { navegación en ruta }\end{array}$ & ¿े. \\
\hline 94 & $\begin{array}{l}\text { Helipuerto } \\
\text { Nota. Aeródromo para uso } \\
\text { exchusivo de helicóoteros }\end{array}$ & H \\
\hline
\end{tabular}

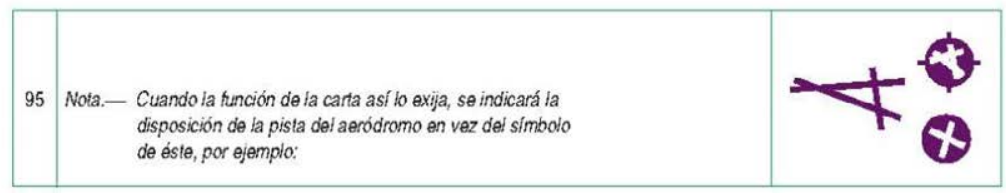

Figura 3-1: Símbolos de aeródromos-OACl, extracto. (ICA0, 2009a)

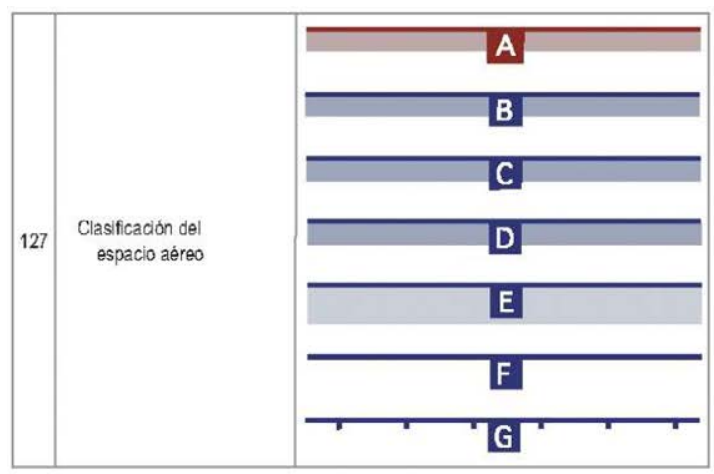

Datos aeronáuticos en forma abreviada que deben utilizarse asociados con los simbolos de clasificación del espacio aéreo:

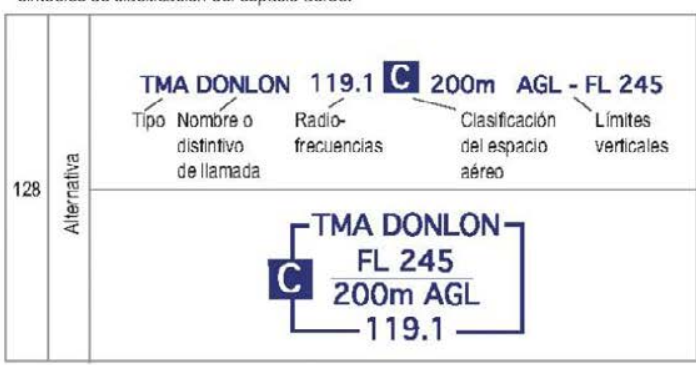

\begin{tabular}{|c|c|c|c|}
\hline \multirow[t]{2}{*}{129} & $\begin{array}{l}\text { Espacio aéreo restringido } \\
\text { (Zona prohibida, restringida o peligrosa) }\end{array}$ & Limite común a dos zonas & 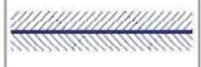 \\
\hline & \multicolumn{3}{|c|}{ 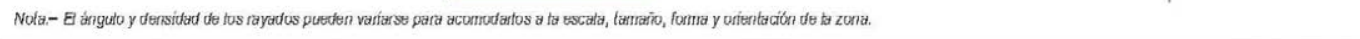 } \\
\hline 130 & Frontera internacional cerrada al paso de ae & Oa través de un corredor aéreo. & $-4=4-6$ \\
\hline
\end{tabular}

Figura 3-2: Símbolos de clasificación y restricciones del espacio aéreo. (ICA0, 2009a) 


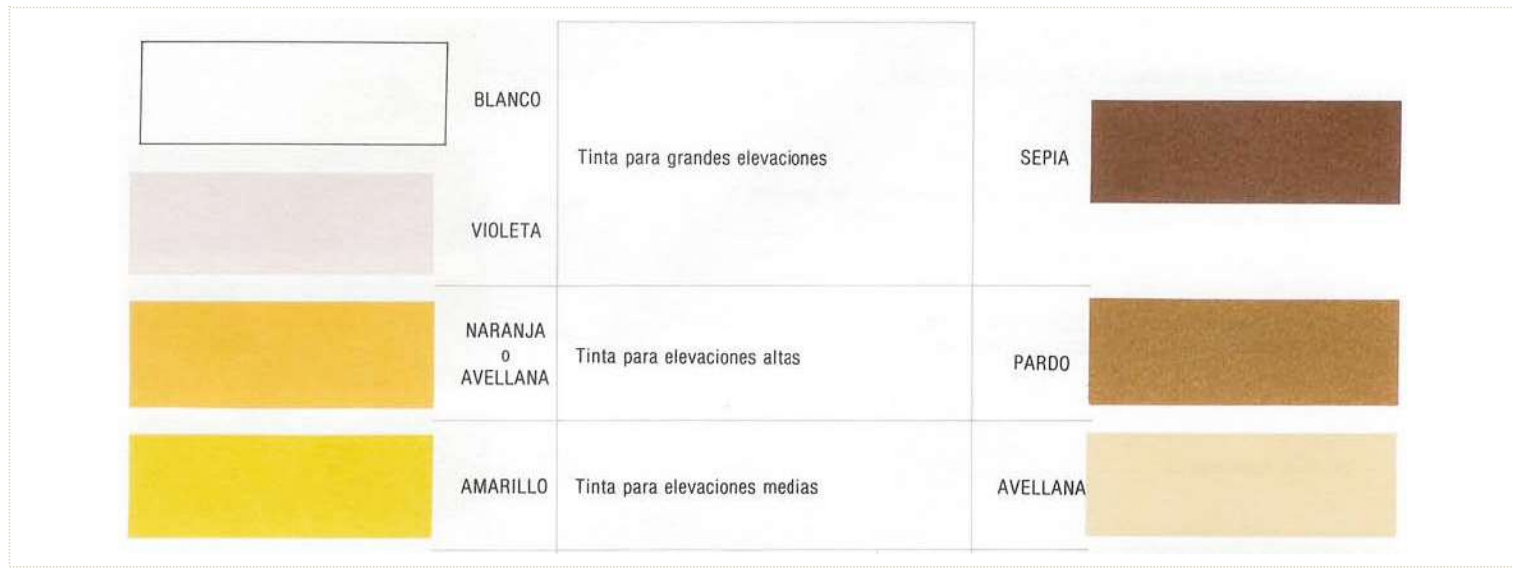

Figura 3-3: Guía de color-0ACl: tintas hipsométricas, extracto. (ICA0, 2009a)

\subsubsection{Otros documentos $\mathrm{OACl}$ de orientación y ayuda}

A la hora de afrontar el diseño y producción de cartas también es de aplicación el denominado Manual de Cartas Aeronáuticas (8697-AN/889/2) (ICAO, 1992), publicación ${ }^{126}$ en la que se orienta y ayuda a los estados a poner en práctica las normas y métodos recomendados del Anexo 4. Además de facilitar a los Estados -así como a todos aquellos que intervienen en la producción, divulgación y uso de cartas aeronáuticas- orientación sobre los aspectos de la cartografía aeronáutica que no sean de técnicas cartográficas elementales, con el manual reseñado la OACl pretende en particular lo siguiente:

- Ayudar a los organismos gubernamentales, así como a los no gubernamentales de cartografía, en la aplicación uniforme de las disposiciones del Anexo 4.

- Fomentar al máximo la eficacia de organización y administración de los servicios que proporcionan cartas aeronáuticas.

- Ayudar a los Estados contratantes en la instrucción del personal responsable de la producción de cartas aeronáuticas.

Paralelamente, el Manual de entrenamiento de Factores Humanos (9683-AN/950) (ICAO, 1990, 1998a) sintetiza diversos principios de factores humanos -comprensión de las capacidades y limitaciones humanas previsibles y su aplicación- que resultan de particular aplicación en lo que a usabilidad y diseño simbólico se refiere. Si bien en

${ }^{126}$ Ideado para dar mejor cumplimiento a la Recomendación $n^{0}$ 11/1 de la Conferencia Departamental de Servicios de Información Aeronáutica y de Cartas Aeronáuticas de 1966, indica que debiera leerse junto con las últimas ediciones de los documentos OACI Anexo 4 - Cartas Aeronáuticas, Anexo 15 - Servicios de Información Aeronáutica, Doc. 8126 - Manual para los servicios de información aeronáutica y Doc. 7192 - Manual de instrucción, parte E-3 - Personal de los servicios de información aeronáutica (ICA0, 1992). 
este documento apenas se realiza referencia alguna a la cuestión del diseño cartográfico, del capítulo dedicado a la ergonomía puede deducirse que una carta aeronáutica, al ser entendida como un soporte lógico, es un medio a través del cual el elemento humano interacciona para obtener información vital. En consecuencia, se deduce que un diseño inadecuado desde el punto de vista ergonómico y cognitivo puede dar lugar a representaciones susceptibles de provocar retrasos y errores de lectura e interpretación. En el capítulo 4. - La eficiencia comunicacional-se presentará más información al respecto.

\subsubsection{Las directrices particulares en el ámbito digital}

Los requisitos generales de utilización citados en el Anexo 4 son de aplicación independientemente del medio utilizado -papel o digital-, por lo que la función asignada a la presentación electrónica de cartas es totalmente análoga a la que deben realizar las cartas tradicionales en formato papel: permitir en base a la presentación de la información requerida las tareas de planeamiento y observación de rutas y de navegación. ICAO (2009a) considera que con el uso del formato electrónico esta función puede llegar a alcanzarse con mucha mayor eficacia; en consecuencia, en el capítulo 20 del anexo -titulado Presentación electrónica de Cartas Aeronáuticas $O A C l$ - se particularizan determinadas directrices ${ }^{127}$ relacionadas con las posibilidades básicas de la representación multimedia.

Aun siendo las especificaciones comunes a lo que se puede esperar de cualquier aplicación electrónica de mapas, la OACI también aporta en el mismo documento la necesidad de características adicionales sobre el soporte físico de la presentación: tamaño efectivo, capacidad, visibilidad, luminosidad, etc. Sin embargo, a tenor de la lectura realizada, podemos concluir que las características adicionales aportadas son exiguas e indeterminadas con respecto a las condiciones particulares de una cabina de pilotaje ${ }^{128}$ en términos de factores humanos ${ }^{129}$. En cuanto a la especificación de simbología, tampoco se hace especial distinción al respecto de una posible equivalencia o versión específica de un mismo símbolo bajo formato papel y electrónico, respectivamente.

${ }^{127}$ Por ejemplo se dispone que, aunque la información básica o indispensable para un vuelo seguro debe ser siempre visible, debe ofrecerse la posibilidad de representar otro tipo de información o datos a petición -uso de capas-. De igual forma se podrá variar manualmente la zona de la carta visualizada, su escala y, en los casos en los que no se utilice cartografía estática, la zona representada podrá variar automáticamente acorde con la posición real de la aeronave (ICAO, 2009a).

${ }^{128}$ La variación de la luminosidad interior, la distancia relativa a la pantalla, la usabilidad en condiciones de atención a distintas tareas de navegación, el uso de pantallas táctiles como medio de interacción, etc. serían algunas de ellas.

${ }^{129}$ Mediante la observancia de las circunstancias especiales que caben esperar al hacer uso de la presentación electrónica en cabina. 
Fuera del ámbito de la $\mathrm{OACl}$, destaca el trabajo normativo del Comité de cartas aeronáuticas de SAE International (SAEG-10) ${ }^{130}$, el cual tutela bajo el documento denominado Electronic Aeronautical Symbols (ARP 5289) (SAE, 1997) diversas recomendaciones para símbolos de uso habitual en cartas aeronáuticas. Este documento se diferencia de la especificación OACl en que, además de estar mucho más enfocado a la observancia de los factores humanos, cada especificación individual de símbolo recomendado es acompañada con la representación de los que son utilizados en la realidad tanto por los principales productores de cartas en papel y digital como por los constructores de la industria aeronáutica, en el caso de las pantallas ND.

\subsubsection{El nuevo contexto de servicios y aplicaciones}

Situados ya en 2015, las recomendaciones OACl para el ámbito de la producción de cartografía aeronáutica se encuentran ciertamente sobrepasadas; así lo atestigua el ya referido y vigente a todos los efectos Manual de Cartas Aeronáuticas (8697-AN/889/2) (ICAO, 1992), datado originalmente en año 1987 y que da cuenta de técnicas de producción cartográfica analógicas y totalmente desfasadas. De igual forma, el ámbito tecnológico que aún describe el anexo 4 -cuya última edición data de 2009-, está a día de hoy plenamente superado por los planes de trabajo que pretenden conseguir una interoperabilidad de datos aeronáuticos mundial. Al respecto, cabe destacar el plan denominado genéricamente Transición de AIS a AIM, cuyo objetivo es que toda la información aeronáutica, incluida la que contienen actualmente las distintas AIP, se almacene en forma de conjunto de datos normalizados e interoperables, que podrá consultarse desde diversas aplicaciones de usuario (Bossman, 2011; EUROCONTROL, 2006b; ICAO, 2008a). Una vez desplegada en su totalidad la iniciativa' ${ }^{131}$, las aplicaciones del usuario final ya no dependerán exclusivamente de la estructura y formato de los datos; estas tendrán capacidad de acceder a diversas fuentes de datos, para así transformarlos y coordinarlos con otros libremente en orden a presentarlos al usuario final mediante el correspondiente proceso cartográfico tal y como éste lo requiera, indistintamente del formato portador -papel, digital, NDs o EFBs- (ICAO, 2009b).

La libertad emanada de la posibilidad de crear e integrar nuevos servicios de análisis y visualización de información aeronáutica que se nutran de datos propios o de terceros, entraría en conflicto con la rigidez de las especificaciones de simbología $\mathrm{OACl}$, que no tienen capacidad de contemplar nuevas necesidades tanto tecnológicas como simbólicas. Un ejemplo sintomático es la aplicación AWE (Spirkovska y Lodha, 2003), una de las primeras propuestas de adición de información meteorológica en tiempo real sobre una cartografía para

${ }^{130}$ SAE International es una asociación global de ingenieros y expertos técnicos relacionados con las industrias aeroespacial, automotriz y de vehículos comerciales. Su labor se centra, fundamentalmente, en el desarrollo de estándares de adopción voluntaria.

${ }^{131}$ Según ICAO (2013), la aplicación del plan AIS-AIM supondrá a nivel legislativo la adición en 2016 de tres nuevos capítulos al Anexo 15-Servicios de información Aeronáutica-y la publicación de nuevos procedimientos, procesos, formatos y especificaciones técnicas en forma de requerimientos PANS-AIM -procedures for Air Navigation Services-. 
vuelo visual. Mediante distintos artificios simbólicos ${ }^{132}$ trata de codificar sobre una carta aeronáutica al uso información meteorológica relativa a las condiciones actuales de nubes, visibilidad y vientos en diferentes capas de altitud.

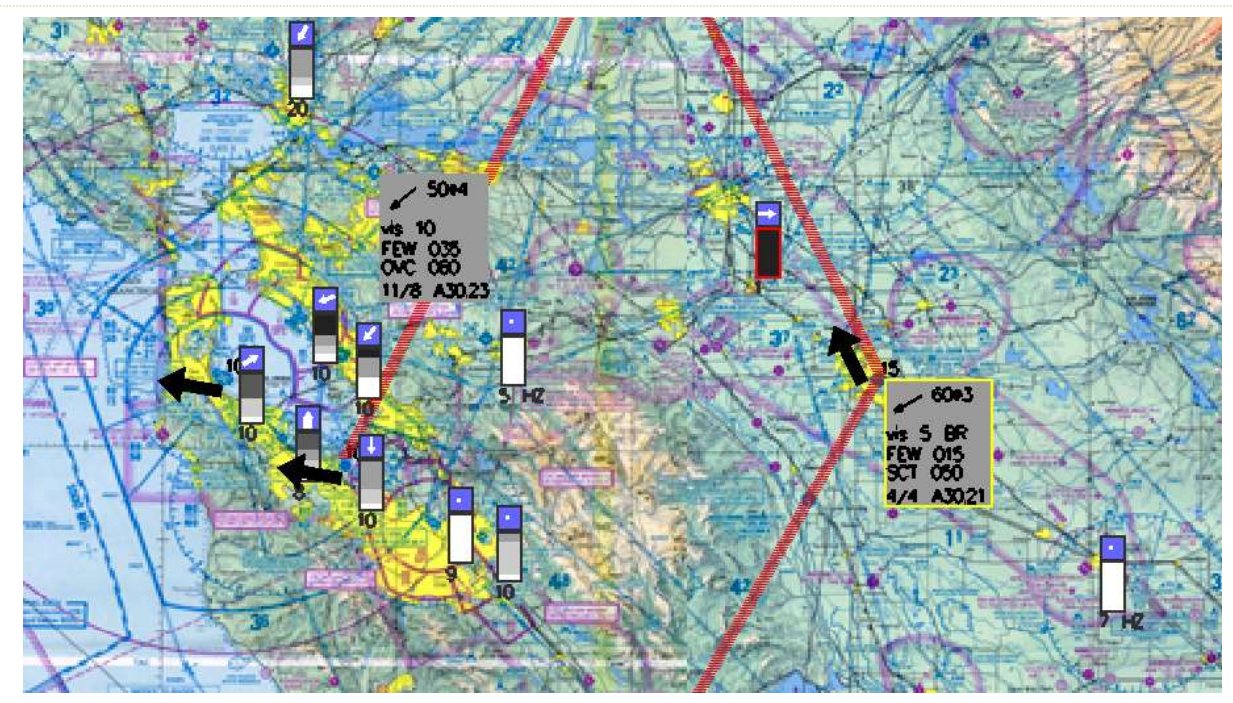

Figura 3-4: Aplicación AWE de información meteorológica aeronáutica basada en símbolos dinámicos (Spirkovska y Lodha, 2002)

El resultado [Figura 3-4] es una cartografía digital capaz de proporcionar una gran cantidad de datos relevantes sobre una representación bidimensional pero que, sin embargo, adolece de una correcta integración con la información aeronáutica sobre la que se sitúa -ocultamiento, falta de unicidad y semántica simbológica, etc.- ni parece lograr una mejora en la comprensión de los datos meteorológicos, ya que los símbolos multivariables dinámicos propuestos se alejan en demasía tanto de los aeronáuticos como de los utilizados habitualmente en los mapas meteorológicos al uso por todos conocidos.

El progresivo acercamiento a una estandarización que maximice las capacidades de los nuevos formatos, así como el nuevo contexto de servicios y aplicaciones es de máxima actualidad. Esta necesidad está siendo recogida por numerosos grupos de interés desde distintos enfoques: la aplicación del concepto de Infraestructuras de Datos Espaciales (IDE) para la producción de cartas aeronáuticas digitales propuesta por el Comité de Cartas Aeronáuticas del Instituto Panamericano de Geografía e Historia (IPGH) (IPGH, 2009), y de forma singular el empleo del estándar de Descriptores de Capas de Estilo (SLD) para los símbolos OACI del Grupo de Trabajo en el Dominio de la Aviación de la OGC (Bossman, 2011), así como el estado del arte realizado por el Centro VOLPE acerca de los símbolos aeronáuticos utilizados por la industria (Yeh y Chandra, 2008). También se trabaja

${ }^{132}$ Sectorización de rectángulos y triángulos con codificación dinámica de colores de relleno y borde color en los bordes, flechas con orientación y tamaño acorde con los datos de entrada, etc. 
en la publicación, por parte de OACl, de una serie de nuevos requisitos técnicos (SARPS) y textos de orientación relacionados con la presentación electrónica de cartas (ICAO, 2008a).

\subsection{GRAFISMO DE LA INFORMACIÓN AERONÁUTICA}

La función básica de las cartas aeronáuticas ${ }^{133}$ es la comunicación de información espacial geográfica y aeronáutica a través de la expresión gráfica, simplificando la realidad por medio de distintos convencionalismos gráficos. Este proceso comunicativo -realizado a través de la ideación de un código de simbolización- se facilita enormemente al tratar de procurar una expresión gráfica de significante clara y precisa, es decir, que no dé pie a ambigüedades de comprensión del significado por parte del lector. De esta manera, y sin sacrificar la precisión en la georreferenciación de los datos presentados, al leer una carta el usuario puede llegar a comprender y obtener con la mayor agilidad y seguridad posible la información necesaria y libre de error para sus labores de navegación.

Para facilitar la comprensión de la información desplegada en una carta, en su diseño se realiza un proceso de simplificación. Este proceso consiste en lo siguiente:

- Una elección básica de proyección y escala que ayuden a mostrar el fenómeno ${ }^{134}$.

- La clasificación de las características que se vayan a representar, reuniéndolas en grupos que presenten características muy similares ${ }^{135}$.

${ }^{133}$ Uno de los requisitos primarios para todo acceso a la información aeronáutica es la posibilidad de visualizar y representar los datos a los que va a tenerse acceso. La forma más efectiva para representar este tipo de información es a través de mapas -cartas, si están destinadas a la navegación-, conjunto de símbolos convencionales que, dispuestos en una determinada apariencia, representan diferentes fenómenos de los que ocurren sobre toda o una parte del territorio.

${ }^{134}$ Por ejemplo, una carta en proyección Lambert a escala 1:1.000.000 permite medir rumbos y distancias con facilidad pero, además, representar todo el espacio aéreo sobre la Península y las islas Baleares y Canarias con gran detalle y sin que su tamaño sea excesivamente grande para poder manejarla con cierta soltura.

${ }^{135}$ Sirvan de ejemplo las zonas prohibidas, restringidas y peligrosas; al agruparlas bajo una misma simbología, quedan separadas así del resto de los espacios aéreos y se identifican con un color visualmente llamativo que incite a una especial atención por parte del piloto. 
- Una generalización que facilite en lo posible la lectura, perdiendo cada objeto sus características personales, unificándose con todos los de su clase ${ }^{136}$.

\subsubsection{La representación}

Los fenómenos geográficos son manifestaciones de hechos que ocurren dinámicamente sobre la superficie del planeta. La norma ISO 19117, que trata de la representación de la información geográfica (ISO, 2012), proporciona una metodología aplicable a cualquier base de datos para generar representaciones gráficas para cada una de las apariciones de fenómenos geográficos -como ríos, montañas, lagos, etc.- descritos en estas bases, incluidas las aeronáuticas. Esto se realiza por medio de la vinculación de variables gráficas -tonos, tamaños, valores, texturas, etc.- a los atributos espaciales -punto, línea, área, etc.- propios de los objetos geográficos descritos en un catálogo. Sin embargo, la norma no proporciona descripción geométrica alguna de una simbología, ni tampoco concreta ningún tipo de estandarización gráfica de los fenómenos geográficos, por lo que a continuación trataremos de sistematizar la cuestión.

Con frecuencia una cantidad importante de objetos cartográficos, conteniendo cada uno su propio valor, hace virtualmente imposible replicar la variabilidad de los valores por medio de símbolos igualmente numerosos. Es necesario algún tipo de agrupamiento, de clasificación de los valores de la variable.

Así, y según Cauvin, Escobar, y Serradj (2010), los hechos y las entidades del territorio -de carácter más permanente- pueden representarse en un mapa de acuerdo a tres características: las dimensiones del fenómeno o entidad, su escala de medida y su distribución sobre la superficie del territorio.

La elección de alguno de los métodos disponibles para ello no es neutra, y tendrá un impacto importante sobre el resultado final. Tanto la elección de la escala -y por tanto el nivel de simplificación y generalización que mostrará el mapa-, como la elección de la proyección -y por tanto sus deformaciones-, condicionan la validez de la elección de un método u otro para la discretización de la variable en intervalos (Moya, Bernabé, y Escobar, 2012). En el anexo 9.2.1 -Representación de los fenómenos geográficos en relación con sus características- se presenta una completa información adicional al respecto.

${ }^{136}$ Como muestra de ello, sobre una carta se puede observar que antenas de telecomunicaciones, grandes rascacielos y las chimeneas de las centrales térmicas pierden sus características personales para unificarse en una clase denominada obstáculos, la cual-en determinadas ediciones como la recomendada por OACl-se representa con un símbolo único y común. 


\subsubsection{La simbolización}

La simbolización es un proceso de simplificación y abstracción que clasifica y jerarquiza los fenómenos geográficos para facilitar su visualización y comprensión.

Un símbolo es una representación convencional de algo, -por ejemplo, las banderas son uno de los símbolos que identifican a los Estados-. La naturaleza tan dispar de los fenómenos condiciona de manera directa la forma en la que los fenómenos o elementos deben ser representados por medio de las variables visuales: la posición, la forma, la orientación, el tamaño, el color, el valor y la textura ${ }^{137}$. Y puesto que el soporte cartográfico papel solo dispone de dos dimensiones espaciales -las dos que permite un plano- solo tendremos a nuestra disposición el punto, la línea y la superficie como elementos de diseño.

Según el criterio de su forma, los símbolos cartográficos pueden clasificarse en: pictóricos -que son descriptivos, evocadores de una imagen reconocible-, geométricos -que son abstractos y generalmente no evocan la imagen que representan-, y literales -que son propios de la rotulación cartográfica- (Cauvin et al., 2010). En 9.2.2 -Clasificación de los símbolos aeronáuticos según niveles de abstracción- se ha querido definir y ejemplificar, para el ámbito particular aeronáutico, cada uno de estos niveles.

El diseño de la simbología debe pasar por procesos de evaluación que garanticen la correcta comprensión por parte del usuario, evaluando sus capacidades semánticas -en qué medida el símbolo representa el mensaje-, sintácticas -relaciones entre el conjunto de imágenes-y pragmáticas-la relación entre el símbolo y el usuario- (AIGA, 1981; Dent, 1985).

\subsubsection{Los aspectos operacionales}

En una carta aeronáutica, tanto la estructura compositiva y semántica como el nivel de abstracción simbológica requerida varía de forma sustancial obedeciendo también al tipo de reglas de vuelo -ver 2.2.4 Las reglas de vuelo- al que van destinadas. A continuación, y teniendo también en cuenta determinados aspectos extraídos del estudio realizado en la sección 2.6 -Caracterización del uso práctico de la información-, se realiza un breve cotejo de la cuestión con respecto a las funciones operaciones a las que puede ir destinada cada carta.

${ }^{137}$ Por variables visuales se entiende a todos aquellos estímulos que la percepción visual discrimina como diferentes, diferencias que constituyen la unidad mínima para la representación y lectura de la información a través de nuestro sentido de la vista. 
a) Cartas de vuelo visual.

La cartografía utilizada para respaldar este tipo de navegación ${ }^{138}$ debe representar las características geográficas del área circundante que puedan reconocerse fácilmente desde el aire, además de la posición precisa de obstáculos, elevaciones del terreno y zonas restringidas del espacio aéreo. En una carta destinada a vuelo visual se utilizan con profusión los símbolos pictóricos o descriptivos, es decir, aquellos que muestran una imagen figurativa, fácil de recordar y universalmente reconocible. Debido al realismo con el que muestran la imagen que quieren evocar, se utilizan en aquellas ocasiones en las que sea necesaria en pleno vuelo una lectura rápida, directa y universal. Ejemplo de ello son los símbolos dedicados a construcciones o que pueden suponer un obstáculo para la navegación: antenas, depósitos, fábricas y parques eólicos, etc. En determinadas ocasiones, estos símbolos suelen ocupar un gran espacio en el mapa, y por lo tanto una baja precisión situacional: es el caso de los símbolos pictóricos que son utilizados para clasificar los campos de vuelo en función de su especialización.

b) Cartas de vuelo instrumental.

La gran diferencia de la cartografía destinada a vuelo instrumental ${ }^{139}$, con respecto a la visual, es que pierde la representación detallada de elementos geográficos visibles en favor de aspectos no tangibles relacionados tanto con la estructura del espacio aéreo como de los procedimientos de navegación normalizados: aerovías, rumbos, distancias, límites de altitud, frecuencias, etc. Para acometer la correspondiente abstracción simbólica de aspectos plenamente operacionales se recurre tanto a símbolos geométricos o abstractos como a símbolos literales. En el caso de los símbolos abstractos, generalmente no son evocadores de la imagen que representan, aunque a veces puedan recordar vagamente la forma del objeto original en cuestión -radiofaro, VOR-, es por ello que necesitan de una leyenda que explique su significado. Al poseer una estructura geométrica, disponen de un centro fácilmente reconocible por lo que poseen un elevado grado de precisión en su situación sobre la carta, lo que es crítico al describir procedimientos operacionales, en mayor medida cuanto más cercana esté la instrucción simbolizada al terreno.

Otra categoría de símbolos de uso extensivo en las cartas destinadas a vuelo instrumental es la que está compuesta por letras y/o números -símbolos literales-, muy adecuada en una cartografía pensada para extraer sin lugar posible a equívoca interpretación una ingente cantidad de atributos operacionales: denominaciones, frecuencias, límites de altitud, etc. En las cartas aeronáuticas es habitual aplicar símbolos literales a los fenómenos superficiales de una carta-concretamente en los espacios aéreos-, ya que se tiende a evitar el uso de rellenos

${ }^{138}$ Recordemos que, bajo las denominadas Reglas de Vuelo Visual (VFR), el vuelo se realiza mediante técnicas de navegación autónomas, en las que el piloto es capaz de orientarse en el espacio por sus propios medios y sin ayudas externas (Moya y Bernabé, 2011).

${ }^{139}$ Alternativamente existen las denominadas Reglas de Vuelo Instrumental (IFR), bajo las cuales el control de la aeronave se realiza con el apoyo de una estructura exterior (radioayudas, sistemas GNSS, sistemas ILS para el aterrizaje de precisión, etc.), debiendo atender tanto a la lectura de los instrumentos como a las indicaciones de los Servicios ATS (Moya y Bernabé, 2011). 
de color para no interferir en la lectura de elementos puntuales y lineales. Si bien la propia forma cerrada de la superficie delimita su ámbito de ocurrencia, existen problemas de lectura e identificación cuando este tipo de espacios comparten límites o se solapan entre sí, algo muy habitual en las Áreas de Control Terminal (TMA) de los grandes aeropuertos. Este último problema lo comparten indistintamente cartas de vuelo visual e instrumental.

\subsection{EDICIONES CARACTERÍSTICAS}

La obligación de aplicar en las cartas aeronáuticas auspiciadas por OACl los requisitos y otras normas y métodos recomendados desgranados anteriormente, puede llevar a presuponer que los productos cartográficos finales editados por los distintos países poseen una apariencia homogénea y similar. Muy al contrario, un primer cotejo de las series de cartas editadas por las distintas AIS muestra una llamativa disparidad de aspecto formal y estético. Este confuso escenario conectaría con una de las cuestiones centrales de la tesis, la cual versa sobre el estudio de la afección que, para la bondad comunicativa del modelo cartográfico ${ }^{140}$, puede suponer una errónea formulación de la forma y ordenación de los objetos simbólicos que lo componen.

Para abordar la cuestión de hasta qué punto son distantes entre sí las formulaciones gráficas ofrecidas por las distintas AIS, se ha presumido conveniente identificar justificadamente un listado finito y característico de cartas aeronáuticas dentro del conjunto total de ediciones AIS mundiales, listado que posteriormente es sometido a un análisis pormenorizado.

A priori, los criterios de selección de ediciones características dentro del conjunto mundial pueden ser múltiples, y además todos ellos con un cierto grado de subjetividad: identificar una serie de rutas aéreas internacionales y recopilar la cartografía necesaria para su navegación, determinar la producción de los AIS de varios países con peso económico en el ámbito aeronáutico de cada una de las cinco regiones OACl de forma equilibrada, elegir ediciones entre las AIS que faciliten su descarga de la Web, etc. La incertidumbre acerca del criterio que resultase más aconsejable se ha resuelto mediante una exploración previa que se describe a continuación.

${ }^{140}$ En nuestra argumentación, entendemos una carta aeronáutica como un modelo sintetizado de la realidad que rodea a un piloto. 


\subsubsection{Análisis preliminar de ediciones $0 \mathrm{ACl}$}

Previamente a la selección final de ediciones características, se desarrolló una activad académica que, basada en el primero de los criterios anteriormente señalados -planeamiento de rutas-, sirvió como primera aproximación al problema. Así, y en el marco de la docencia de la asignatura de Geoinformación para la Navegación Aérea -Máster universitario en Ingeniería Geodesia y Cartografía de la UPM, curso 2012-, se propuso a los alumnos una práctica denominada 'recopilación online de información aeronáutica'. Realizada por grupos, consistió en compilar, interpretar y realizar un análisis crítico de la información cartográfica necesaria para realizar diversos recorridos aéreos indicados previamente ${ }^{141}$. Una vez que los alumnos compilaban los documentos cartográficos necesarios, debían completar el correspondiente cuestionario ${ }^{142}$.

Incluso para su simple propósito de exploración previa, esta primera experiencia no resultó satisfactoria. Así, el método de selección de recorridos previos no resultaba forzosamente ligado a la facilidad de obtención de la cartografía pertinente por medios propios -y gratuitos. Tampoco a criterios de edición cartográfica que garantizasen una recopilación mínimamente homogénea, característica y de interés semiológico. Igualmente, el análisis realizado por los alumnos, aunque estuvo en todo momento conducido a través de un formulario cerrado, resultó superficial y poco aprovechable desde el punto de vista de la investigación.

Coetáneamente, y por medio de un estudio indagatorio propio -es decir, sin recurrir al análisis de terceros-, se analizaron las series cartográficas oficiales de un total de 12 países de distintas regiones y continentes: Argentina, Australia, Colombia, Ecuador, España, Estados Unidos, Francia, Holanda, Islandia, Italia, Marruecos y Reino Unido ${ }^{143}$.

${ }^{141}$ A cada grupo le fue asignado previamente dos recorridos concatenados, combinando recorridos de vuelo visual e instrumental, así como pequeños aeródromos y grandes aeropuertos. Los alumnos debían acudir, preferentemente, a las sedes electrónicas de las AIS de los países sobre los que se desarrollaban los recorridos teóricos propuestos.

${ }^{142}$ El cuestionario trataba de abarcar un amplio conjunto de indicadores de logros: a) conocer la estructura y documentos que componen la Publicación de Información Aeronáutica que edita distintos AIS mundiales y aprender a clasificar el conjunto de cartas aeronáuticas según su uso en las distintas fases de vuelo, b) alcanzar a confeccionar un plan de vuelo a partir de la información extraída de la AIP y, alternativamente, de un catálogo interoperable de información aeronáutica y razonar el porqué de la existencia de las distintas Reservas del Espacio Aéreo, clasificándolas además de acuerdo a sus limitaciones espacio-temporales, c) realizar un análisis crítico de la situación actual de la provisión de datos geo-aeronáuticos que ofrecen los distintos los Servicios de Información Aeronáutica mundiales y d) descubrir las debilidades semiológicas de las cartas actuales y diseñar simbologías alternativas a las estandarizadas según el Anexo 4 de $0 \mathrm{ACl}$.

${ }^{143}$ Para la elección de cada serie concreta influyó en gran medida la facilidad de acceso a las cartas desde las distintas Web oficiales, ya que en muchos casos se requiere un registro autorizado e incluso la invocación de la 
Se realizaron distintas valoraciones y ensayos, des de la recopilación encadenada de documentos entre distintas series -con la intención de crear diversos planes de vuelo y ejecutarlos en un simulador de vuelo ${ }^{144}$-, hasta el análisis gráfico entre cartas de una misma tipología pero editadas por AIS distintas. Las valoraciones realizadas -de tipo cualitativo- se gestionaron a través de una sencilla puntuación basada en escalas numéricas de tipo Likert -desde 1, nada adecuado, hasta 5, totalmente adecuado-.

La aplicación de estas escalas de evaluación atendió al intento de recoger una valoración preliminar de diversos factores, tales como el cumplimiento de la especificación de símbolos OACl recogida en el Anexo 4, los elementos dispuestos sobre la cartela de cada carta si esta existiese -tipo, forma, situación, predominancia, etc.- la presencia o no de leyenda, la adecuación del tamaño de los símbolos y textos del documento, el nivel densidad de la información en especial sobre grandes zonas aeroportuarias y la manera en la que era resuelto el problema de la saturación gráfica, entre otros.

También se realizaron -para cada una de las fuentes accedidas- estimaciones subjetivas acerca de la calidad de la edición y el diseño desde el punto de vista meramente estético, así como una recopilación de símbolos que, aunque indicaran características recogidas en la especificación OACl, su apariencia simbólica se alejase en cierta medida de la indicada por el propio Anexo 4.

Aunque hubiese sido posible tanto plantear una mayor profundidad en el análisis, así como aplicar instrumentos de evaluación más rigurosos, de la exploración previa desarrollada se extrajeron una serie de conclusiones relevantes, las cuales se sintetizan a continuación:

- Se comprobó que las ediciones analizadas pueden agruparse de forma evidente entre a) la producción de las AIP cuya edición final apenas difiere de la fase de compilación en CAD/GIS -España, Islandia, Italia, Ecuador, Marruecos-y b) con respecto a aquellas publicaciones AIP que, por el contrario,

tenencia en vigor de, al menos, una licencia PPL de piloto privado. En otros países, la cartografía aeronáutica oficial se ofrece previo pago directo o por suscripción.

${ }^{144}$ La generación de planes de vuelo resultó un instrumento especialmente útil para observar la continuidad simbólica entre diferentes series, tipos y escalas. Así, se intentó valorar si la transición de lectura entre unas series y otras resultaba cómoda, si los símbolos de fenómenos equivalentes en distintas escalas eran análogos -o por el contrario variaba significativamente la aplicación de variables visuales, especialmente la forma-, etc. 
trabajan y cuidan más la edición final y el aspecto simbólico de sus series -Estados Unidos, Francia, Reino Unido, Holanda, Colombia- ${ }^{145} 146$.

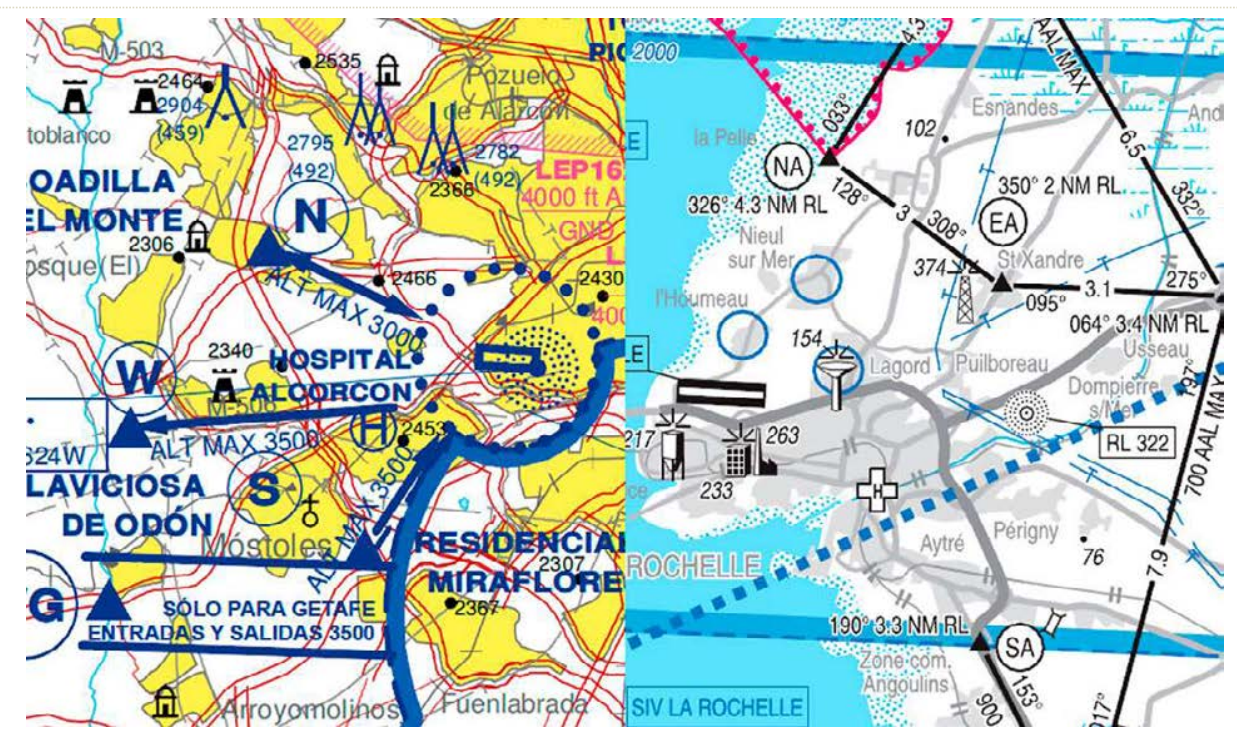

Figura 3-5: Comparativa simbológica entre cartas de aproximación visual (VAC) españolas y francesas (Moya, Siabato, y Bernabé, 2012)

- Se evidenció que, en determinadas AIP -Estados Unidos, Francia-, se tiende a usar un número de símbolos significativamente superiores a los indicados en el Anexo $4^{147}$. Al mismo tiempo, en el caso de los fenómenos que sí están recogidos en él, en ocasiones son codificados mediante símbolos cuyo diseño es desemejante con respecto a lo indicado en la especificación OACl.

${ }^{145}$ Tal y como se ejemplifica en [Figura 3-5], además de ser más adecuadas para facilitar una buena comunicabilidad cartográfica, las ediciones que poseen un cuidadoso diseño cartográfico tienden a adecuarse mejor al problema de la elevada densidad de datos en determinadas áreas, gracias a una estudiada observancia de la aplicación de las variables visuales.

146 Una circunstancia habitual que debe resolver el diseño cartográfico es lograr localizar rápidamente un mismo lugar, ruta o punto significativo de la misma en dos series distintas -por ejemplo en las series de salida y ruta, o de descenso y aproximación-. Al respecto, se evidenció que cuanto más cuidado está el aspecto simbólico de las series - grosores de líneas, rotulación, uso del color, etc.-, mayor es la facilidad de transición visual entre documentos, aunque la diferencia de escalas entre estos sea acusada.

${ }^{147}$ Tal es el caso de las cartas de Estados Unidos, cuya especificación de simbología tanto para series VFR como IFR es completa y extensa, recogiendo una gran cantidad de símbolos no contemplados en el Anexo 4 [Figura 3-6]. Todo ello se traduce en unas cartas de elevada calidad simbólica, con una razonable coherencia en su construcción y jerarquía de reconocimiento simbólico -dimensión sintáctica-, y una notable calidad en la rotulación, cuyo diseño además es homogéneo con el resto de los componentes gráficos que configuran la carta. 
- Mientras que en el caso de las ediciones de países que mantienen un alto grado de concordancia con la especificación OACl -independientemente de su calidad de edición- la comprensión genérica de la simbología que portan se evidencia relativamente sencilla -Argentina, España, Islandia, Marruecos-, no ocurre así en el caso de las ediciones más alejadas de la norma reseñadas anteriormente.
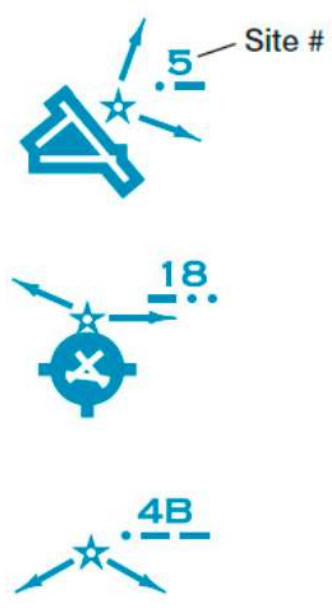

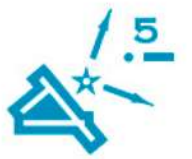

18

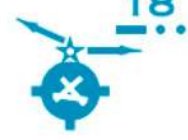
ANGOO ROAMS

\section{WATSY}

Comblned

VHF - LF / MF

Figura 3-6: Algunos de los símbolos de cartas FAA/NACO no contemplados por OACI (Moya, Siabato, et al., 2012)

En orden a perfeccionar el análisis preliminar, las conclusiones anteriores se cotejaron con las características semiológicas, de usabilidad y de eficiencia deducidas en 2.6 -Caracterización del uso práctico de la información148, especialmente para el formato de cartas en papel. De la exploración previa podemos deducir, en síntesis, que tanto el grado de intensidad en la edición a partir del conjunto de datos CAD/SIG de origen, como el grado

${ }^{148}$ Algunas de estas características requeridas son la velocidad en la búsqueda de la información, la representación de los límites de velocidad, altitud y la segmentación del espacio aéreo, la adecuación de la representación orográfica y de obstáculos, la interpretación de zonas con gran densidad simbológica y las propiedades de orientación general en el entorno. 
de concordancia con la especificación de símbolos OACl afectan significativamente a la eficiencia comunicacional, es decir, a las propiedades de síntesis de la información, legibilidad del lenguaje gráfico, y comprensión del mensaje -entre otras- del modelo cartográfico ${ }^{149} 150$.

\subsubsection{Las restricciones aplicadas a la investigación}

Desde un punto de vista puramente metodológico, es ineludible destacar la formidable dificultad que supone desarrollar un completo análisis comparativo de un conjunto de propiedades de eficiencia comunicacional entre distintas ediciones de ámbito internacional.

Se ha comprobado que el cumplimiento de las especificaciones simbólicas OACI no impide una evidente disparidad de aspecto formal y estético en lo que respecta al grafismo de las cartas aeronáuticas. Adicionalmente, para alcanzar un análisis integral de comunicabilidad del modelo, no entra únicamente en juego la mera especificación simbólica de cada una de las ediciones a comparar ${ }^{151}$, sino que, a nuestro juicio, también deberían ser considerados otros múltiples aspectos cartográficos ${ }^{152}$.

Adicionalmente ya han sido definidos y analizados en esta tesis, de forma integral, al menos tres tipos de contenedores físicos de información cartográfica -ver 2.5.5 Los formatos-. Éstos, a su vez, son susceptibles de presentar significativas particularidades con respecto a la eficiencia en la que transmite el mensaje al usuario, lo

${ }^{149}$ Según el análisis preliminar realizado, las ediciones de cartas que se alejan de la especificación OACl actual se mostraron más comunicativas que las restantes, y además sus propiedades de calidad y velocidad de lectura se mostraron, aparentemente, mejores, siendo más eficientes para resolver los problemas generales de diseño cartográfico aeronáutico -en especial, la densidad de datos y transición entre series-. Por el contrario, al alejarse de la norma y añadir una gran cantidad de símbolos particulares, la codificación simbólica se torna más difícil de recordar, no tanto por un mal diseño como por el elevado número total de símbolos y de categorizaciones puestas en juego. A nuestro parecer, esto aumenta en gran medida la posibilidad de confusión o equivocación en la lectura, lo cual no deja de ser un riesgo en un entorno en el que la seguridad es un aspecto crítico.

${ }^{150}$ En el caso de las cartas que más se ciñen a las recomendaciones OACI, en la mayoría de los casos analizados no es necesaria siquiera una leyenda simbológica a poco que se tenga costumbre en la lectura de cartas aeronáuticas.

${ }^{151}$ La simbología de un conjunto de ediciones de cartas aeronáuticas sería razonablemente comparable a partir del cotejo de la especificación simbólica particular de cada una de las series $\mathrm{OACl}$ que, a su vez, componen cada edición a comparar.

${ }^{152}$ Algunos de ellos son: la manera práctica en la que el código simbólico es aplicado, la cantidad de datos incorporados, las escalas, encuadres e información marginal que usualmente definen cada una de las series de forma particular, la forma de solape y la transición simbólica entre distintas series/escalas, el propósito mismo de cada una de las series, etc. 
que complica aún más un análisis comparativo -ver 2.6.11 Evaluación de características semiológicas, de usabilidady de eficiencia-.

Por todo lo anterior, para identificar justificadamente un listado finito y característico de cartas aeronáuticas dentro del conjunto total de ediciones AIS mundiales, se propone aplicar una serie de restricciones metodológicas. Esta decisión va a permitir acotar de forma sustancial el alcance de la investigación ${ }^{153} \mathrm{y}$, de modo adicional, reducir sustancialmente el nivel de incertidumbre en el análisis. En consecuencia:

- Para eliminar en la investigación la incertidumbre sobre el impacto de las consideraciones físicas y ergonómicas que puedan afectar a la comunicabilidad de la información, de aquí en adelante se considerará únicamente el formato papel ${ }^{154}$.

- Para abordar en la investigación la enorme diversidad en el diseño y contenido de las distintas series OACl de cartas -impuesto a partir de la clase de información que proporcionan cada una de ellas-, de aquí en adelante se considerarán únicamente las Cartas de Aproximación Visual - OACI ${ }^{155}$.

Precisamente, las Cartas de Aproximación Visual (VAC) pueden considerarse como una serie cartográfica de carácter transversal, ya que son conocidas indistintamente tanto por pilotos de perfil visual como instrumental $^{156}$. Adicionalmente, su elección para esta investigación está especialmente alineada con el interés por indagar en profundidad en las causas semiológicas de los problemas detectados en cuanto a la velocidad de búsqueda de información, la correcta representación cartográfica de límites de velocidad, altitud, sectorización,

${ }^{153}$ Como muestra de lo que podría suponer un análisis completo de las ediciones cartográficas de tan sólo 10 países, se deberían considerar al menos una muestra o carta por cada una de las series $\mathrm{OACl}$, lo que supondría incorporar 170 cartas como conjunto de datos de entrada.

154 La justificación reside en que los condicionamientos físicos y ergonómicos -factores humanos- que pueden influir en la comunicabilidad del mensaje que portan son razonablemente conocidos y controlables, prácticamente idénticos entre las distintas series. En definitiva, el papel no presenta la enorme disparidad de fabricantes, pantallas y especificaciones físicas y técnicas características de los formatos de cartas digitales y displays de navegación, desarrollados en el capítulo anterior.

${ }^{155}$ El capítulo 12 del Anexo 4 del Convenio de Aviación Civil Internacional (AN/4) (ICAO, 2009a) está dedicado íntegramente a especificar la forma en la que, a través de las cartas VAC, se proporcionará a las tripulaciones de vuelo información que les permita pasar de las fases de vuelo en ruta y de descenso a las de aproximación hasta la pista de aterrizaje prevista mediante referencia visual. En esta investigación, para cualquier consideración acerca del contenido, alcance y demás características de la información geo-aeronáutica dispuestas en las cartas VAC, este será el documento de referencia, adoptando por tanto sus indicaciones.

${ }^{156}$ Las cartas VAC de aproximación visual presentan una razonable homogeneidad de tamaños y escalas entre ediciones, y su propósito y la información que deben portan es común a todas ellas. Adicionalmente para la investigación presentan la ventaja de que en ellas, por razones de propósito y escala, confluyen en un mismo documento la representación detallada de información aeronáutica con la realidad puramente geográfica -orografía del terreno, vías de comunicación, construcciones, etc.- 
orografía, obstáculos, etc., así como a la adecuación del volumen y densidad simbológica que usualmente portan las cartas. La valoración del impacto que provocan estos problemas, sin entrar en las causas que los originan, ha sido sintetizada en 2.6.11 -Evaluación de características semiológicas, de usabilidad y de eficiencia-

\subsubsection{Listado de ediciones características}

Declaradas ya las restricciones que van a ser aplicadas, el siguiente paso consiste en identificar justificadamente un listado finito y característico de cartas aeronáuticas VAC, dentro del conjunto total de ediciones AIS mundiales. El estudio semiológico de la especificación simbólica de este conjunto de series servirá, a posteriori, para generar una serie de cartas visuales estereotipadas con las que poder trabajar. Aunque no cabe duda que la elección de ediciones va a atender a razones subjetivas, se ha querido en todo caso considerar una serie de criterios con los que se pretende precisamente dar al conjunto extraído el marchamo de representativo:

- Criterio simbólico: equilibrio de publicaciones con una fisonomía y aspecto de tipo CAD con respecto a producciones que posean una trabajada edición simbólica. Además se buscará un equilibrio entre ediciones que usualmente incorporen una elevada densidad de información con respecto a otras cuya carga de datos sea, en conjunto, más limitada.

- Criterio geográfico: equilibrio de ediciones entre los países que componen las distintas regiones OACl ${ }^{157}$, y entre estos, preferencia por los países tanto de nuestro entorno europeo más inmediato como los que posean peso económico y significancia en el contexto internacional ${ }^{158}$.

- Criterio funcional: preferencia por las ediciones en formato PDF / vectorial, y que sean directamente accesibles a través de los portales Web de las diferentes AIS, para asegurar la uniformidad del formato en las ediciones que serán comparadas.

- Seleccionar no más de 15 - 18 ediciones cartográficas para su análisis completo.

${ }^{157}$ Con el fin de facilitar el planeamiento e implementación de los servicios básicos para el transporte aéreo, la OACl dispone de una serie Planes de Navegación Aérea (ANP) regionales (ICAO, 2012b). Las distintas regiones en las que OACl las tiene establecidas son las siguientes: África-Océano Indico (AFI), Asia (ASIA), Caribe (CAR), Europa (EUR), Oriente Medio (MID), Norte América (NAM), Atlántico Norte (NAT), Pacífico (PAC) y Sudamérica (SAM).

${ }^{158}$ Finalmente no ha sido posible atender de una manera más adecuada el criterio del balanceo geográfico, puesto que una parte de los países ha delegado la producción de su responsabilidad en agencias privadas, cuyos productos únicamente pueden adquirirse previo pago de una elevada cantidad, o bien mediante suscripción -es el ejemplo de Reino Unido y de Alemania-. Por otra parte existen determinados países que consideran la información aeronáutica una materia sensible para sus intereses de seguridad nacional requieren, para permitir el libre acceso a la cartografía, demostrar un interés legítimo, como por ejemplo la filiación al colectivo de pilotos -el caso de Arabia Saudí y otros-. 
El listado final de países cuyas ediciones han sido consideradas para la investigación es el siguiente:

\begin{tabular}{|ll|}
\hline Región OACI & Países incluidos \\
\hline África-Océano Indico (AFI) & $\begin{array}{l}\text { Marruecos, Asecna África -Mauritania, Mali, Níger, Chad, } \\
\text { Congo, Gabón, Camerún, Costa de Marfil, Senegal, etc.- }\end{array}$ \\
\hline Asia (ASIA) / Pacífico (PAC) & Corea del Sur, Nueva Zelanda \\
\hline Caribe (CAR) & México \\
\hline Europa (EUR) & España, Francia, Holanda, República Checa, Rusia, Suiza \\
\hline Oriente Medio (MID) & Israel \\
\hline Norte América (NAM) & Estados Unidos \\
\hline Atlántico Norte (NAT) & Islandia \\
\hline Sudamérica (SAM) & Brasil, Chile, Colombia \\
\hline
\end{tabular}

Tabla 3-1: Listado de ediciones características seleccionadas.

A continuación se ejemplifican algunas de las numerosas cartas VAC evaluadas con diversos extractos significativos de 12 de las 17 ediciones consideradas en el estudio:

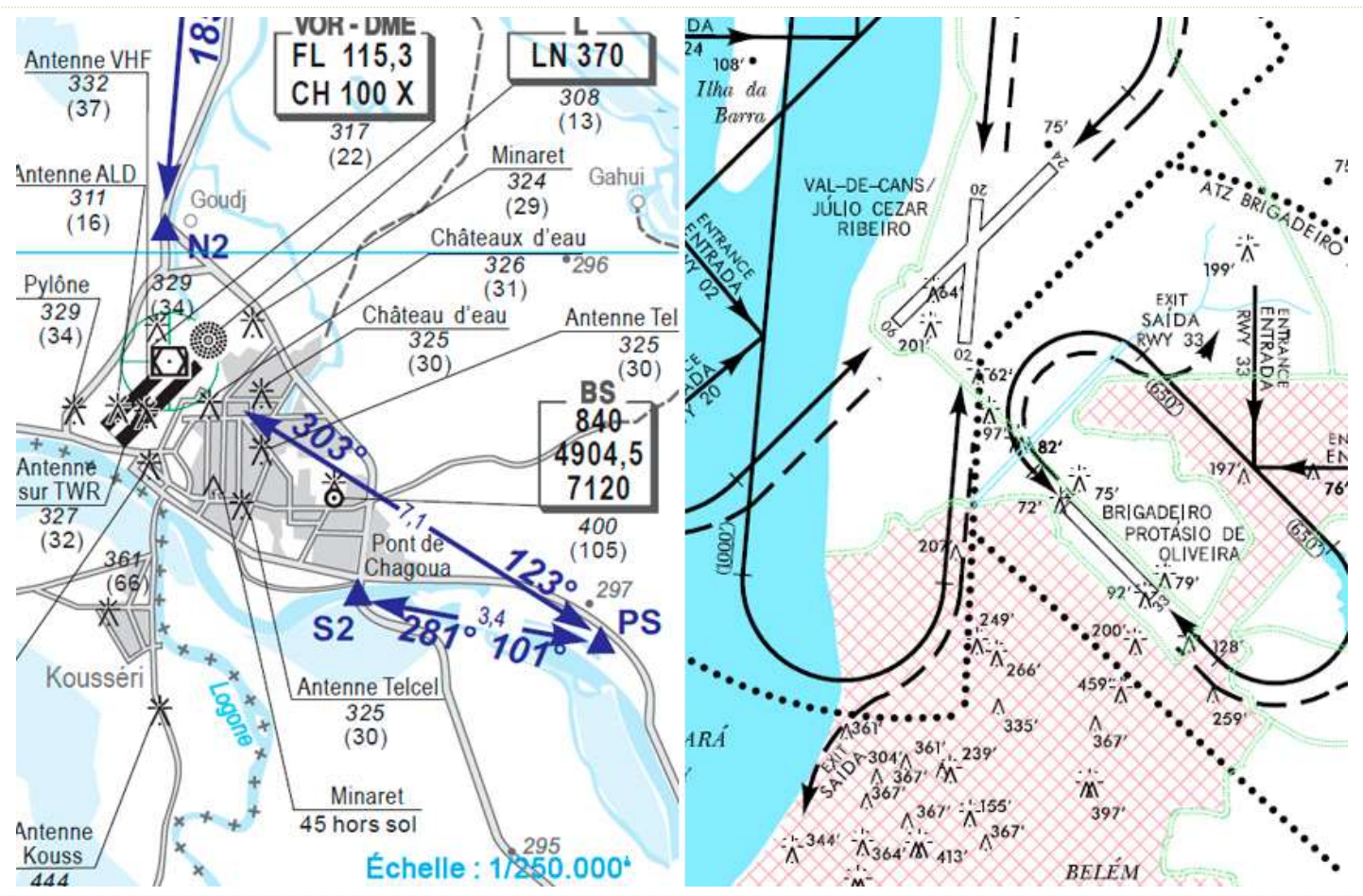

Figura 3-7: Extractos cartas VAC. a) N'Djamena-FTTJ (Asecna/Chad), b) Belém-SBBE (Brasil). 

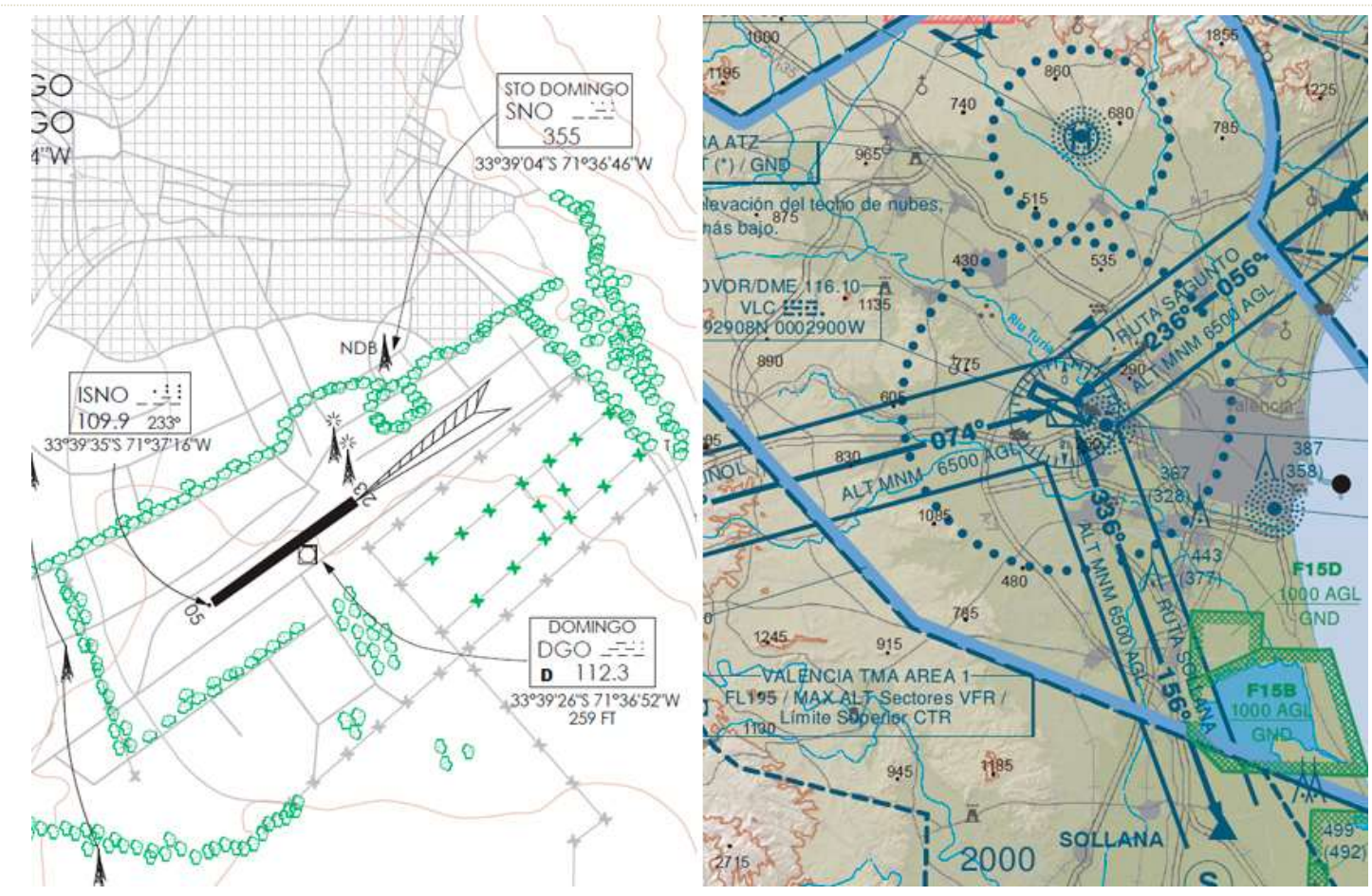

Figura 3-8: Extractos cartas VAC. a) Curicó-SCIC (Chile), b) Valencia-LEVC (España).

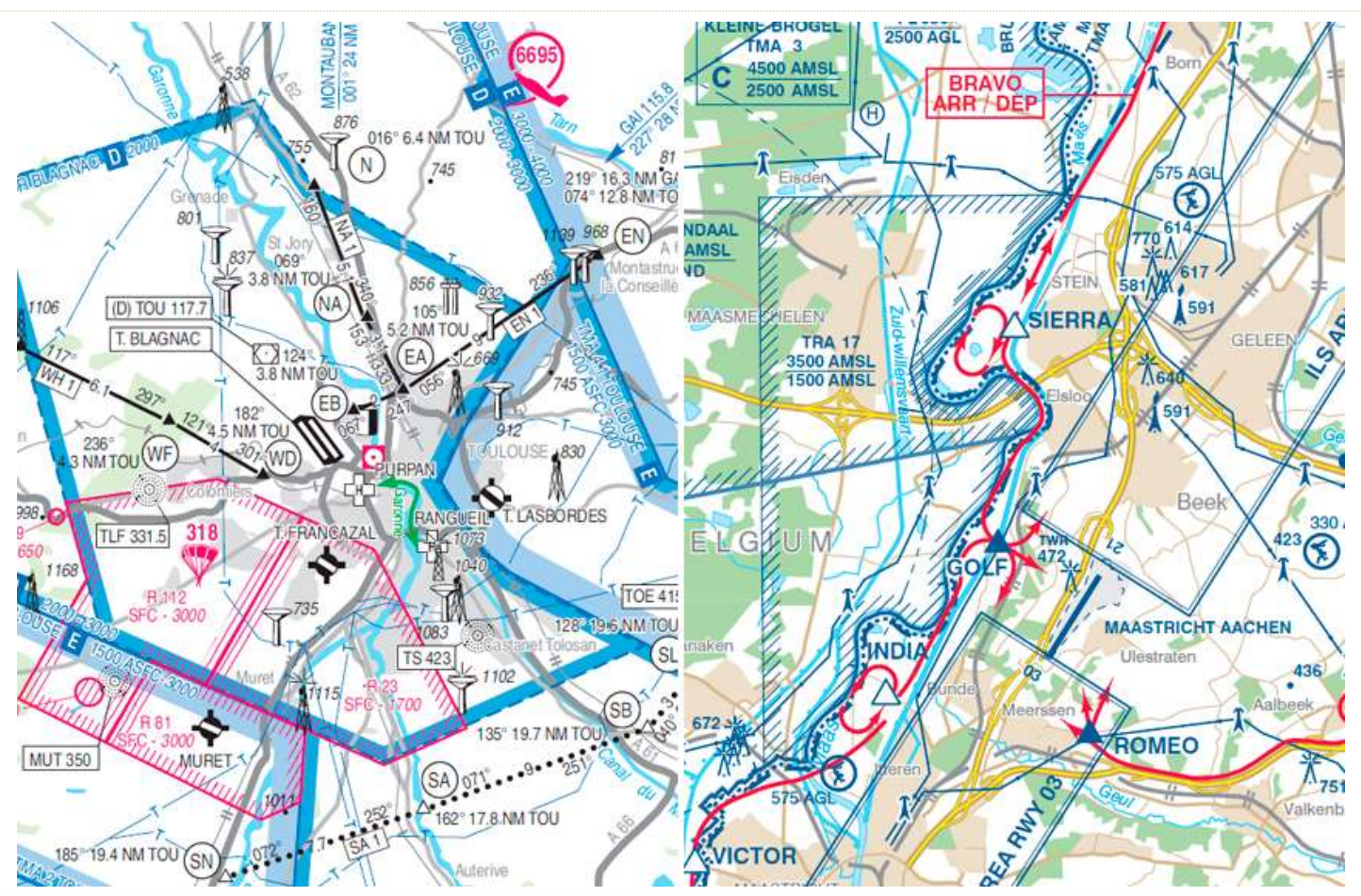

Figura 3-9: Extractos cartas VAC. a) Toulouse-LFBO (Francia), b) Maastricht-EHMK (Holanda). 


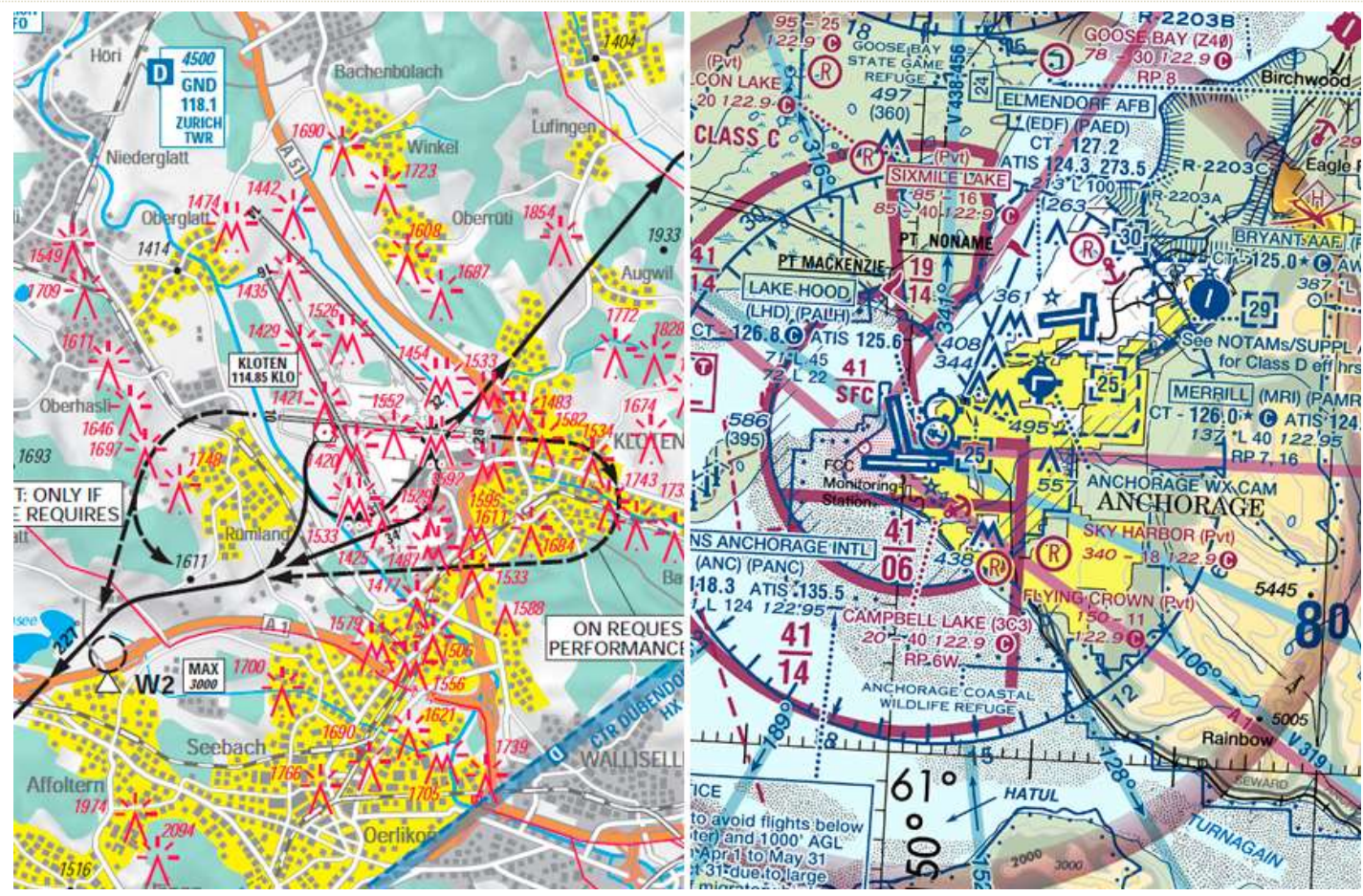

Figura 3-10: Extractos cartas VAC. a) Zúrich-LSZH (Suiza), b) Anchorage-PANC (USA).

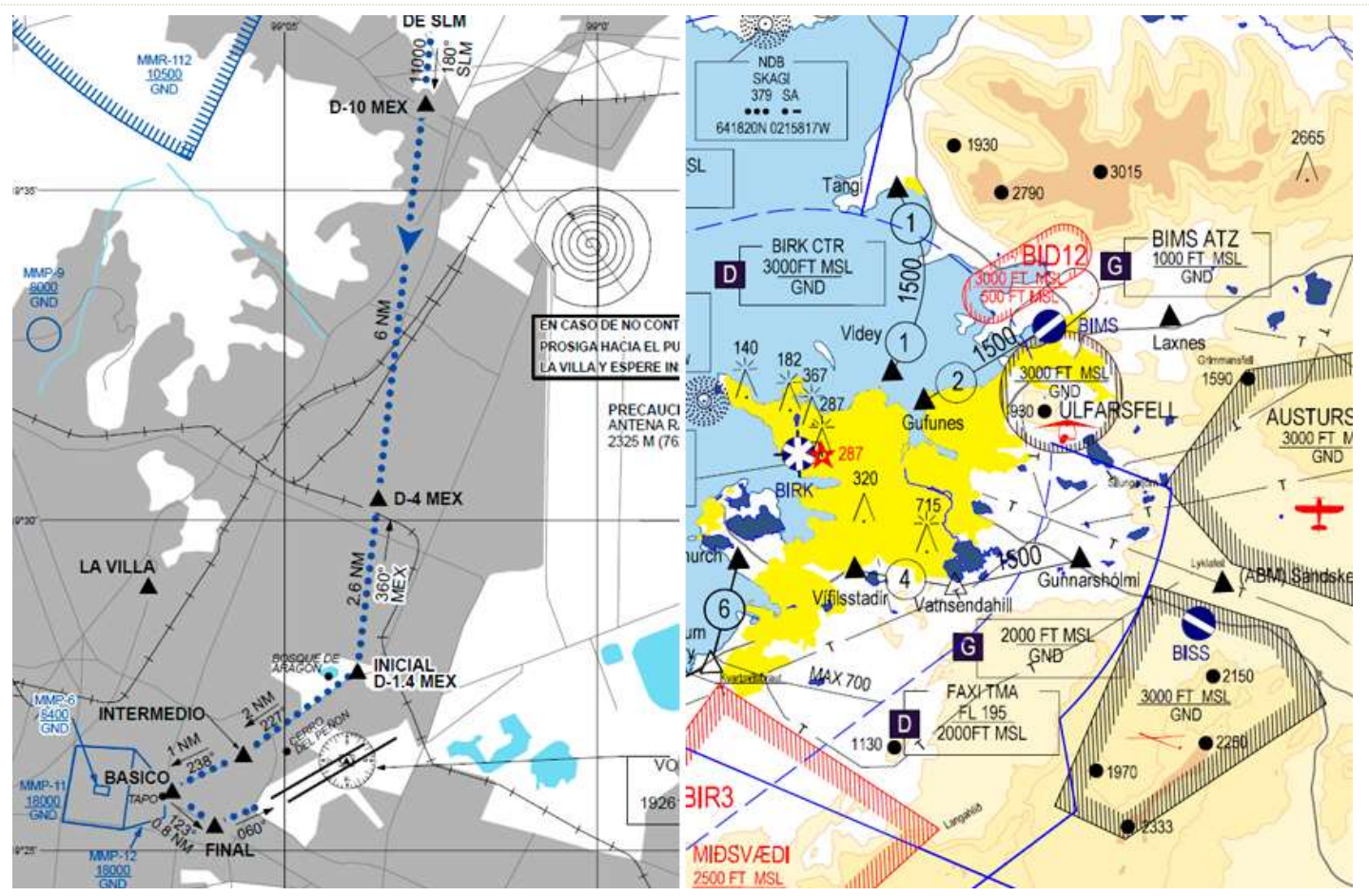

Figura 3-11: Extractos cartas VAC. a) México DF-MMMX (México), b) Reykjavik-BIRK (Islandia). 


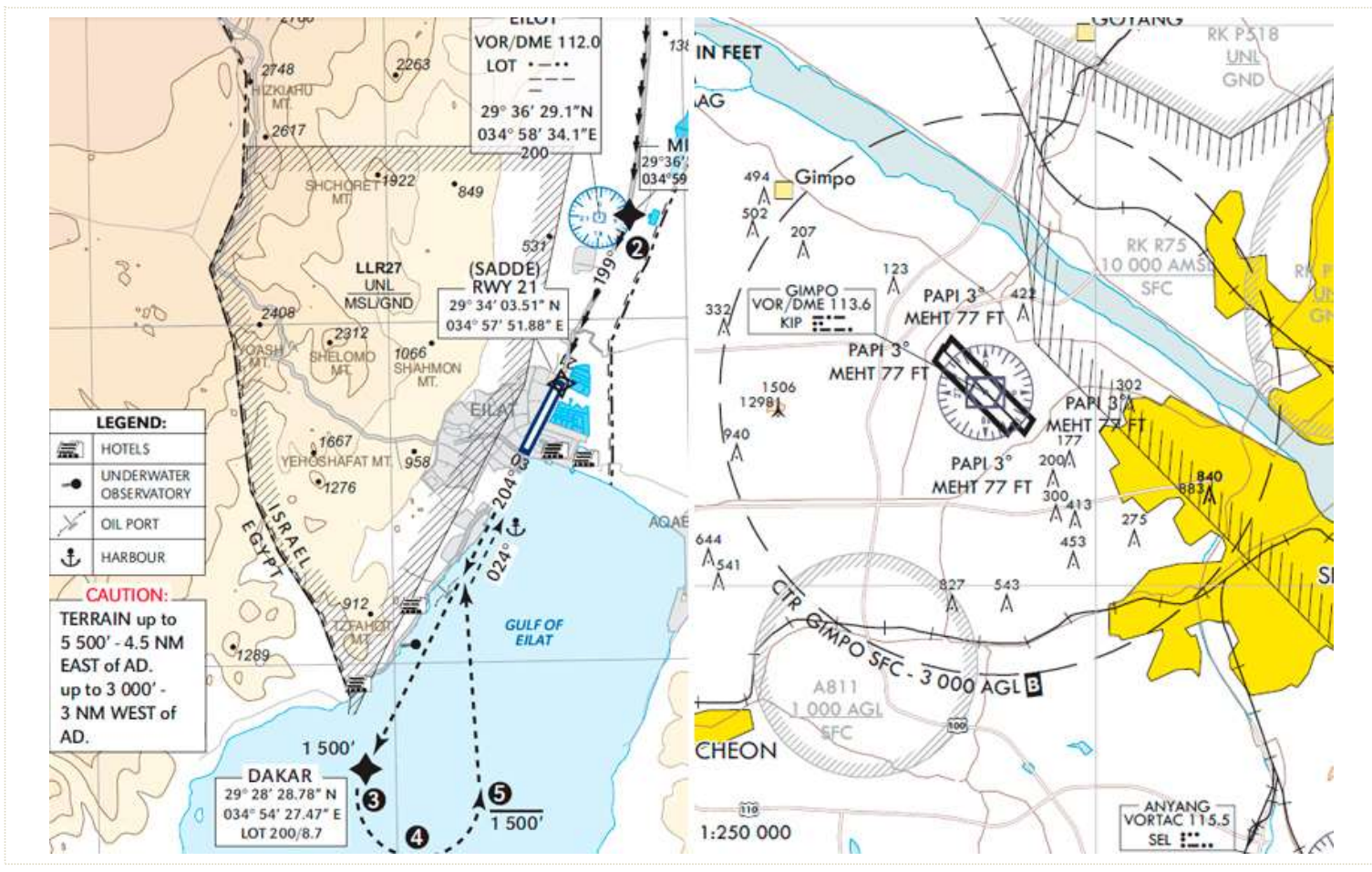

Figura 3-12: Extractos cartas VAC. a) Eilat-ETH (Israel), b) Seúl-RKSS (Corea del Sur).

\subsection{EVALUACIÓN Y ESTEREOTIPADO DE TENDENCIAS}

\subsubsection{El análisis de especificaciones simbólicas}

Una vez declaradas las restricciones, y elegidas de forma razonada el conjunto de ediciones características, el siguiente paso consiste en examinar cómo la OACl, en su normativa, considera y representa los fenómenos geográficos y aeronáuticos en relación con sus características ${ }^{159}$ y, además, qué niveles de abstracción simbólica recomienda para cada uno de ellos.

${ }^{159}$ Por su incidencia directa, es imperativo atender la escala a la que el fenómeno va a ser considerado en la representación. Para las cartas VAC, la OACI especifica que la escala no debería ser menor de 1:500 000, siendo preferible una escala de 1:250 000 ó 1:200 000 . 
Para ello se ha acudido a la especificación simbólica sita en el Anexo 4 del Convenio de Aviación Civil Internacional (AN/4) (ICAO, 2009a), y se han seleccionado -del total de 177 fenómenos/símbolos indicados- los fenómenos que pueden, bajo nuestro criterio, estar presentes como información en las Cartas de Aproximación Visual - OACl, comúnmente denominadas cartas VAC. Así, se han considerado 9 grupos temáticos, y un total de 59 fenómenos, repartidos de la siguiente manera:

\begin{tabular}{|ll|}
\hline Grupo temático & No de fenómenos \\
\hline T1. Topografía & 6 \\
\hline T2. Hidrografía & 11 \\
\hline T3. Construcciones / 3.1 Zonas edificadas & 4 \\
\hline T3. Construcciones / 3.2 Ferrocarriles & 3 \\
\hline T3. Construcciones / 3.3 Autopistas y carreteras & 6 \\
\hline T3. Construcciones / 3.4 Varios & 8 \\
\hline T4. Aeródromos & 3 \\
\hline T5. Radioayudas para la navegación & 7 \\
\hline T6. Clasificación del espacio aéreo & 2 \\
\hline T7. Restricciones del espacio aéreo & 1 \\
\hline T8. Obstáculos & 5 \\
\hline T9. Varios & 3 \\
\hline
\end{tabular}

Tabla 3-2: Agrupación temática de los fenómenos susceptibles de ser representados en las cartas VAC.

Para cada uno de los fenómenos considerados, se analiza la consideración que la especificación simbólica de $\mathrm{OACl}$ hace de sus características dimensionales, de su escala de medida y de su distribución sobre el territorio. A su vez, también se identifica la tipología gráfica del símbolo propuesto por OACl para dicho fenómeno.

En 9.3.1 -Análisis de caracterización OACI de fenómenos y abstracción simbólica- se presenta el análisis realizado, en el cual se aplica un código visual propio para identificar cada uno de los parámetros estudiados [Figura 3-13]. A su vez, los resultados de este estudio se han sintetizado de forma gráfica en [Figura 3-14], distinguiendo los fenómenos en aeronáuticos -grupos temáticos T4 a T8- y geográficos -resto de grupos-, respectivamente. 


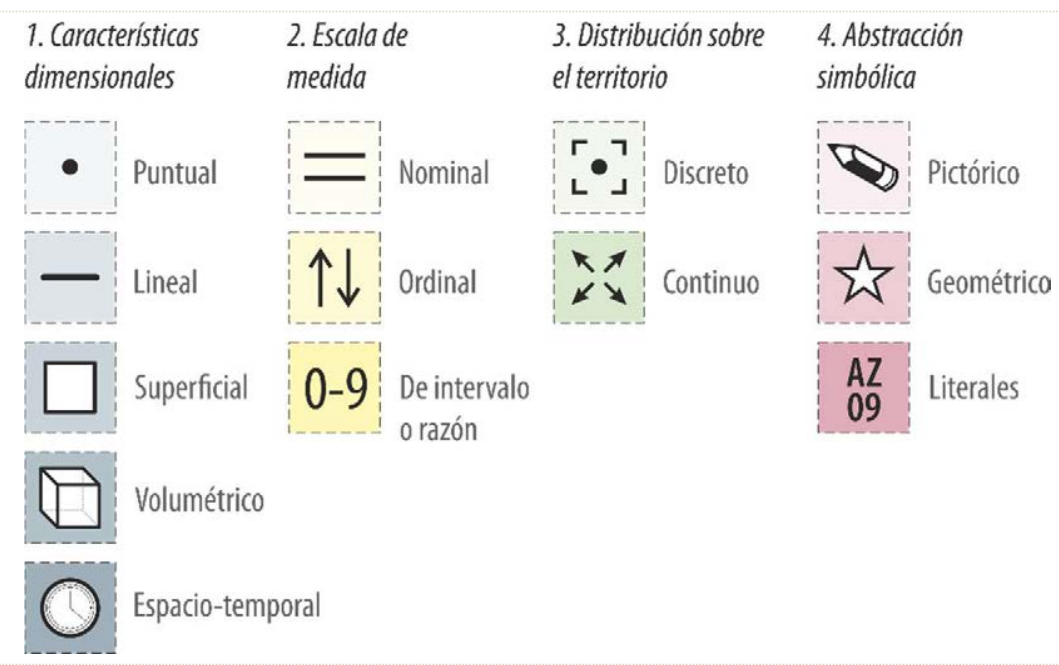

Figura 3-13: Código utilizado para el análisis de la caracterización 0ACI de fenómenos y abstracción simbólica (figura propia)

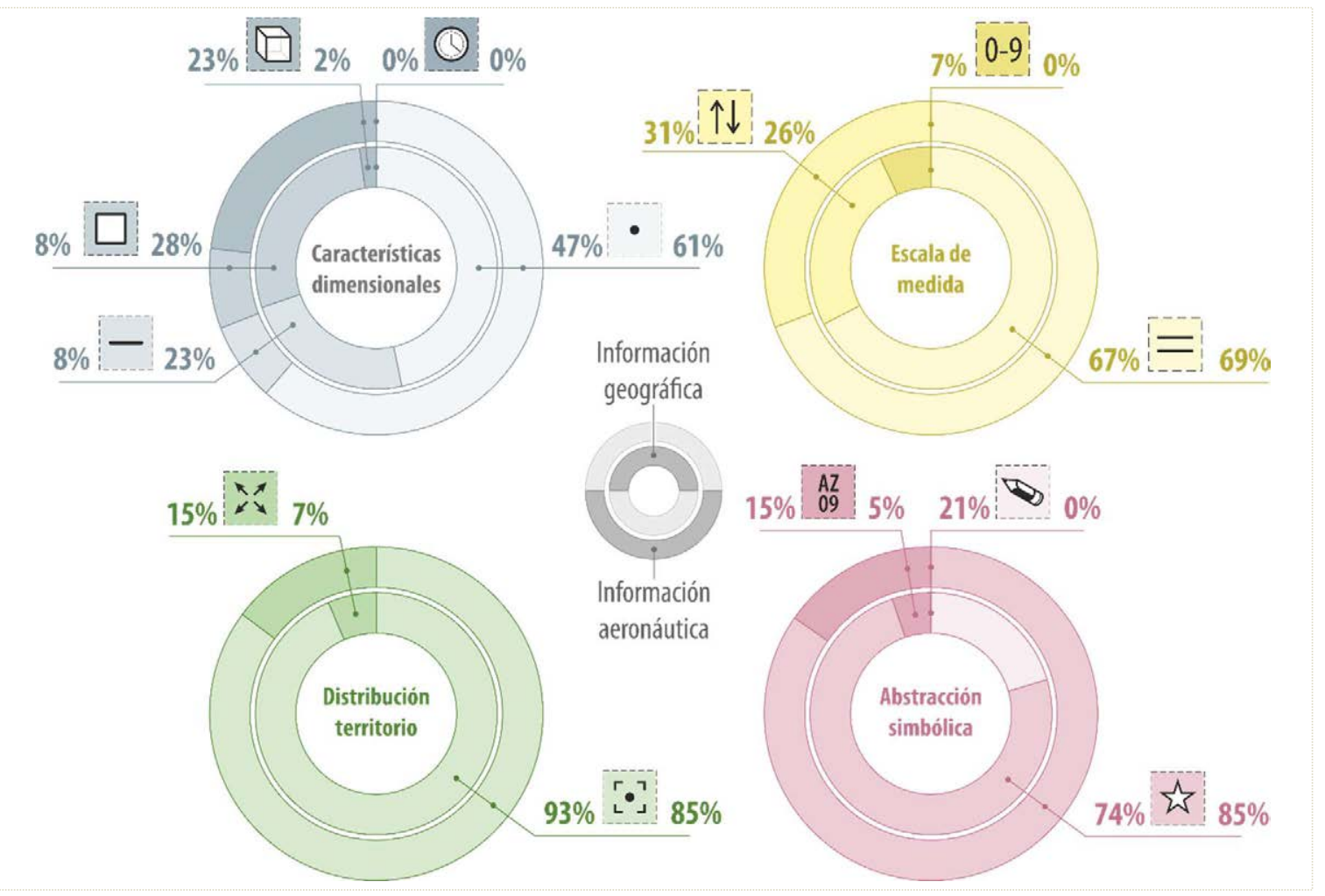

Figura 3-14: Síntesis de los resultados del análisis de la caracterización OACI de fenómenos y abstracción simbólica (figura propia). 
De forma resumida, se puede concluir lo siguiente:

- En cuanto a las características dimensionales de los fenómenos potencialmente representables en las cartas VAC, en el caso de los estrictamente geográficos tienen una presencia mayoritaria los fenómenos puntuales -aproximadamente la mitad-, mientras que los fenómenos lineales y superficiales tienen una presencia aproximadamente ecuánime de un 25\% cada uno de ellos. Los fenómenos volumétricos tienen una presencia muy exigua. Por el contrario, en el caso de la información estrictamente aeronáutica, toman más predominancia los fenómenos puntuales, mientras que los fenómenos lineales y superficiales, aunque conservan su equilibrio, bajan drásticamente su presencia, no llegando al 10\% en cada caso. Por último, son los fenómenos volumétricos los que toman una fuerte presencia, representando una cuarta parte del total.

- En el caso de la escala de medida de la información geográfica, la caracterización de la información se evidencia bastante equivalente entre fenómenos geográficos y aeronáuticos. Dos terceras partes corresponderían a fenómenos nominales, y el resto a fenómenos ordinales. En el caso concreto de la información geográfica tiene una pequeña presencia los fenómenos que pueden considerarse poseedores de una escala de intervalo, siendo esta presencia nula en el caso de los elementos aeronáuticos.

- Al analizar la caracterización de la distribución de la información sobre el territorio, nuevamente nos encontramos con una notable similitud entre la información geográfica y aeronáutica, con una presencia abrumadora de los elementos de carácter discreto. Los fenómenos que pueden considerarse como continuos y con presencia en todo el territorio alcanzan un 7\% en el caso de los elementos geográficos, mientras que la presencia de los considerados como aeronáuticos dobla esta proporción.

- Finalmente, sí se observa una llamativa diferencia en la forma de simbolizar la información en las cartas VAC, puesto que en el caso de los fenómenos geográficos los símbolos pictóricos representan una cuarta parte del total, mientras que este método de abstracción no aparece en la información aeronáutica que puede ser mostrada. En ambos casos, la abstracción geométrica es mayoritaria -representando dos tercios del total-, mientras que la existencia de símbolos literales es muy reducida en el caso de la información geográfica -apenas un 5\%-, mientras que en el caso aeronáutico este porcentaje se triplica.

Una vez han sido caracterizados los fenómenos, se ha procedido a cotejar la simbología de las cartas VAC de cada una de las series cartográficas características elegidas en 3.3.3 -Listado de ediciones características- con respecto a la especificación simbólica de OACl. La intención de este cotejo es tratar de mensurar el cambio o diferencia existente en cada uno de los símbolos analizados con respecto a la especificación recomendada de $\mathrm{OACl}$, sin pretender esta vez, como se hizo en 3.3.1-Análisis preliminar de ediciones OACl-, discernir o enjuiciar en modo alguno si una simbología es mejor o más adecuada que otra. 
Se han encontrado múltiples dificultades para realizar un cotejo homogéneo de las series características analizadas, puesto que las especificaciones simbólicas declaradas por cada país en sus correspondientes AIP atienden, en general, al conjunto total de tipologías y escalas ${ }^{160}$, y no al vuelo visual en particular ${ }^{161}$, por lo que en muchas ocasiones existen incongruencias a la hora de declarar la forma de simbolizar fenómenos en las escalas habituales de las cartas VAC. A su vez, en el análisis de las especificaciones simbólicas declaradas en cada AIP, se han encontrado casuísticas de todo tipo ${ }^{162} 163164$, las cuales han dificultado sobremanera el lograr alcanzar un cotejo homogéneo entre países.

Regresando a la toma en consideración del objetivo de identificar tendencias o rasgos de edición afines entre las distintas producciones mundiales características, para alcanzar el propósito de mensurar individualmente las diferencias existentes entre cada uno de los símbolos identificados en las series características de cartas VAC y la especificación recomendada por $\mathrm{OACl}$, se ha llegado a establecer una escala de grados en términos de intensidad de la diferencia. Esta escala, dimensionada en niveles del 1 al 4 , se ha definido de la siguiente manera:

${ }^{160}$ En ninguna de las ediciones consultadas se indica una simbología recomendada para cada una de las series identificadas en 2.5.4 -La publicación-, o bien mediante algún criterio de escala, salvo en los casos de las cartas de obstáculos y en algunos casos en las propias cartas VAC.

${ }^{161}$ Salvo en el caso de Francia y Estados Unidos, no han sido encontradas especificaciones referidas en exclusiva a las cartas VFR-usualmente indicadas en los denominados manuales VFR-, por lo que se ha acudido como criterio general a procurar que los símbolos extraídos de las cartas tomadas como ejemplo se circunscriban a los declarados en la especificación que consta en el manual AIP de cada país - usualmente en la sección 2 de tablas y códigos que se encuentra contenido en la parte denominada Generalidades (GEN)-.

${ }^{162}$ Así, existen casos en los que se reproduce exactamente -como una copia literal- la especificación simbólica OACl de su Anexo 4 -el caso de Colombia-, otros que respetan aproximadamente el esquema de grupos temáticos -el caso de España, Marruecos, etc.-, y finalmente otros países cuya especificación simbólica está desordenada frente al esquema de $\mathrm{OACl}$-el caso de Chile-, o bien amplía de forma evidente las casuísticas de la forma en la que van a quedar representados los fenómenos a grandes escalas -el caso de la República Checa, Suiza, etc.-

${ }^{163}$ No siempre los símbolos que aparecen en la especificación se corresponden con los finalmente simbolizados en las cartas. También existen casos en los que símbolos básicos, usualmente los que atienden a las capas geográficas, no aparecen en la especificación simbólica declarada en la AIP, como por ejemplo en el caso de las VAC de Chile.

${ }^{164}$ En otras ocasiones se han detectado -para una misma producción-, diferentes ediciones, teniendo algunos países parte de sus cartas en una edición más antigua y en vías de sustitución, y otras en una edición más reciente y con una simbolización distinta -el caso de Corea del Sur, España, Israel, República Checa, etc.-. Los cambios de escala dentro de las propias series VAC nacionales también es una circunstancia habitual. 
- Un primer nivel -en el análisis identificado en color verde- distingue los símbolos que se ajustan totalmente a la especificación de $\mathrm{OACl}$, aunque puede admitirse una discrepancia en el caso de la variable visual valor-obscuridad relativa de un relleno-.

- El siguiente nivel -en color amarillo- distingue los casos en los que el cambio es poco significativo, y está asociado a la variable visual del color -denominada tono-.

- Un tercer nivel -en color naranja- distingue los casos en los que la divergencia entre especificaciones es, para el símbolo estudiado, significativa, afectando también a la variable visual textura.

- Por último, y en un cuarto y último nivel -en color rojo-, se señalan las diferencias extremas, las cuales afectan a la variable visual forma o bien a la propia abstracción simbólica del elemento.

Junto con la clasificación de la intensidad de la diferencia, las variables que dan pie a catalogar a los elementos en la escala propuesta -forma, valor, color, textura y tono- también son identificadas mediante un código visual propio [Figura 3-15].

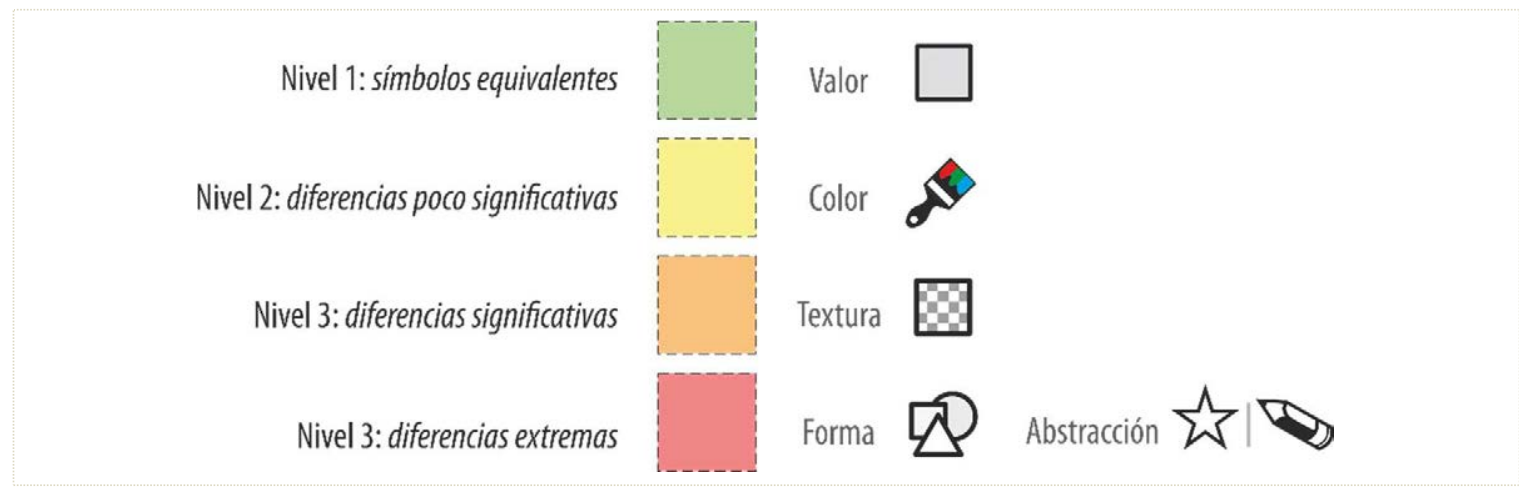

Figura 3-15: Código utilizado para el análisis del cambio o diferencia existente en cada uno de los símbolos analizados con respecto a la especificación recomendada de $\mathrm{OACl}$ (figura propia).

Como ejemplo del análisis realizado, en 9.3.2 -Cotejo gráfico de diferencias entre la simbología de ediciones características y la especificación OACl- se ejemplifica, para el caso de los 5 países europeos seleccionados, la metodología de escala de grados propuesta. A su vez, en 9.3.3 -Análisis de tendencias existentes en la simbolización de las ediciones características-puede consultarse las conclusiones completas, deducidas a partir del cotejo metodológico de las 17 series de cartas VAC características.

Además de obtener una valoración del grado de adopción de las especificaciones de simbología propuestas por $\mathrm{OACl}$ en su Anexo 4, se ha logrado sintetizar una serie de tendencias de simbolización que, respeten en mayor o menor medida las recomendaciones de $\mathrm{OACl}$, pueden considerarse como representativas y transversales en el conjunto de las ediciones analizadas. Estas tendencias se declaran, de forma sintetizada, en la TTabla 3-3]. 


\begin{tabular}{|c|c|}
\hline Tipologías & Tendencias constatadas \\
\hline $\begin{array}{l}\text { Forma de los sím- } \\
\text { bolos geográficos } \\
\text { puntuales }\end{array}$ & $\begin{array}{l}\text { 1. Se respeta absolutamente la forma simbólica de las radioayudas. } \\
\text { 2. Los elementos de orientación se tornan pictóricos, y se representan más fenó- } \\
\text { menos que los recomendados por OACl, teniendo además un sesgo cultural. } \\
\text { 3. Se mezclan la identificación genérica de obstáculos con la representación de } \\
\text { elementos puntuales nominales -construcciones varias-. } \\
\text { 4. No se simbolizan puentes de carretera, y cuando se hace es en escalas grandes } \\
\text { y con su forma real y no simbólica. } \\
\text { 5. Las turbinas eólicas se representan asiduamente. } \\
\text { 6. Se simboliza con elementos pictóricos zonas asociadas a actividades aeronáuti- } \\
\text { cas. }\end{array}$ \\
\hline $\begin{array}{l}\text { Forma de los sím- } \\
\text { bolos geográficos } \\
\text { lineales }\end{array}$ & $\begin{array}{l}\text { 1. Se respeta absolutamente la forma de los símbolos hidrográficos. } \\
\text { 2. Se respeta la forma de los ferrocarriles, pero adoptando una simbología nomi- } \\
\text { nal, y no ordinal -no se identifican el número de vías-. } \\
\text { 3. En las carreteras se aplica una jerarquía ordinal acompañando la doble línea } \\
\text { con el uso de rellenos de color. No se simbolizan los caminos. } \\
\text { 4. El estilo de línea ondulada de los trazados de alta tensión se cambia por un es- } \\
\text { tilo simple y rectilíneo. }\end{array}$ \\
\hline $\begin{array}{l}\text { Forma de los sím- } \\
\text { bolos geográficos } \\
\text { superficiales }\end{array}$ & $\begin{array}{l}\text { 1. Las zonas arbóreas se representan con rellenos de color, renunciando a ser } \\
\text { acompañados con su símbolo pictórico nominal. } \\
\text { 2. Se respeta el símbolo pictórico de las zonas pantanosas. } \\
\text { 3. Se respetan los rellenos de color las zonas de aglomeración urbana -si bien } \\
\text { existe un número no desdeñable de series que utilizan un tramado o textura-. } \\
\text { 4. Dentro de las aglomeraciones urbanas, las zonas concretas de edificación no } \\
\text { suelen simbolizarse. }\end{array}$ \\
\hline $\begin{array}{l}\text { Forma de los sím- } \\
\text { bolos geográficos } \\
\text { volumétricos }\end{array}$ & $\begin{array}{l}\text { 1. Una cierta mayoría opta por simbolizar el relieve mediante una combinación } \\
\text { de curvas de nivel y tintas hipsométricas de intervalo. } \\
\text { 2. Si además se incorporan sombreados, se aplican de forma ligera y con elevada } \\
\text { luminosidad. } \\
\text { 3. Los rellenos de color de las zonas arbóreas quedan incompatibilizados con el } \\
\text { uso de las tintas hipsométricas. }\end{array}$ \\
\hline $\begin{array}{l}\text { Aplicación del } \\
\text { resto de las varia- } \\
\text { bles visuales }\end{array}$ & $\begin{array}{l}\text { 1. Se aplica de forma extensiva el uso de distintas combinaciones de valor para } \\
\text { minorar visualmente determinadas capas de información geográfica, y especial- } \\
\text { mente en el caso de los elementos hidrográficos y de comunicaciones. } \\
\text { 2. El suavizado de la intensidad del tono mediante la variación del valor apenas } \\
\text { afecta a los elementos aeronáuticos. }\end{array}$ \\
\hline
\end{tabular}


3. Se generaliza el uso de tres tonos de color, siendo dos de ellos los característicos tonos negro y azul de la especificación de OACI.

4. Si la carta tiene un estilo gráfico de tipo CAD/GIS, el tercer tono suele ser de la gama de los colores terrosos, mientras que si la carta está simbolizada de una forma más concienzuda se tiende a adoptar el tono magenta para combinarlo con los dos tonos tradicionales.

5. A los elementos de la capa aeronáutica se les puede aplicar un único tono -bien sea negro o azul-, o bien una combinación de dos tonos para separar visualmente dos conjuntos de elementos de la misma capa entre sí.

6. La especificación de color de los espacios aéreos de OACl es respetada, si bien en el caso de las zonas P, R y D se observa la utilización de cualquiera de los tres tonos combinatorios e, incluso, de un cuarto -verde-.

Tabla 3-3: Pautas y tendencias estereotipadas de la caracterización simbológica del conjunto de ediciones características (elaboración propia).

\subsubsection{La composición de modelos de simbología estereotipada}

El Diccionario de la Real Academia Española presenta como tercera definición del término estereotipar ${ }^{165}$ la de fijar mediante su repetición frecuente un gesto, una frase, una fórmula artística, etc. (RAE, 2001). Precisamente, en este tramo de la investigación hemos querido inferir formulaciones y estructuras simbológicas transversales al conjunto de ediciones de cartas mundiales, mediante la identificación de rasgos y elementos comunes que minimicen en lo posible la existencia de sesgos individuales o no representativas.

Así, del análisis anterior se ha logrado sintetizar una serie de pautas o tendencias repetitivas [Tabla 3-3] que, combinadas entre sí, nos permiten finalmente establecer de forma básica uno o varios modelos de representación transversales y estereotipados, sin entrar a valorar todavía la conveniencia de la combinatoria simbólica inferida. Estas tendencias serán a continuación aplicadas a dos distintos conjuntos de datos, a través de la metodología detallada en las siguientes páginas.

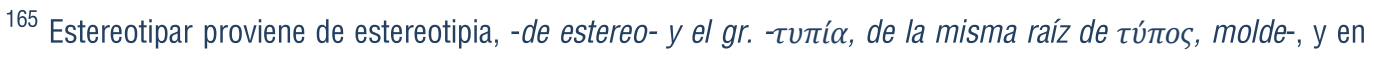
imprenta hace referencia al procedimiento para reproducir una composición tipográfica, que consiste en oprimir contra los tipos un cartón especial o una lámina de otra materia que sirve de molde para vaciar el metal fundido que sustituye al de la composición. Si bien, estereotipia también puede ser definida como la repetición involuntaria e intempestiva de un gesto, acción o palabra, que ocurre sobre todo en ciertos dementes. 
- Elección de conjuntos de datos de partida. Se han tomado como modelos de partida las Cartas de Aproximación Visual (VAC) de Bourdeaux Merignac (LFBD) y Madrid Cuatro Vientos (LECU), respectivamente. Realizadas por distintas oficinas, los dos modelos representan campos de vuelo inmersos en zonas urbanas con una cierta complejidad.

- Particularidades de los conjuntos de datos. Así, el primero de ellos -carta de Burdeos- se caracteriza por una extensión de datos relativamente homogénea, una densidad de datos media y una capa de información aeronáutica compleja, en la que se deben realizar distintos circuitos visuales reglados para alcanzar el campo de vuelo, todo ello dependiendo del punto de aproximación inicial que sea tomado. Por el contrario, el segundo de ellos -carta de Madrid- destaca por una enorme densidad de datos representados, aunque por el contrario la capa de información aeronáutica es relativamente sencilla.

Para su elección se consideró un aspecto de calidad supuesta inferida, el cual se comenta con mayor detalle en 5.1.2 -El marco de evaluación y los niveles de abstracción simbólica-. De forma resumida hemos asumido que, a priori, las cartas de edición francesa parten con una gran reputación de calidad por parte de los pilotos mientras que, por el contrario, las de edición española son ampliamente criticadas. La consideración de extremos no deja de ser un medio de validación interno de la propia metodología de estereotipado propuesto puesto que, a priori, la composición de simbología estereotipada aplicada a la carta de Madrid Cuatro Vientos debería mejorar con claridad la eficiencia comunicacional de la original; por el contrario, debería empeorarla en el caso de aplicación al modelo francés.

A continuación, se presenta un extracto de ambas cartas [Figura 3-16]. Para su referencia, las composiciones originales de ambas cartas -realizadas por las AIS francesa y española respectivamente- pueden encontrarse en 9.3.4 -Propuesta de composición cartográfica estereotipada: datos de partida-. A simple vista es evidente la significativa diferencia de simbolización existente entre ambas cartas. Ciertamente la aplicación de una formulación estereotipada debería concluir con una unificación de su aspecto visual.

- Homogeneización de escala. A los conjuntos de datos se les aplicó -en orden a posibilitar su comparación- una homogeneización de escala, para que esta coincidiera en ambos modelos. Para ello, y al ser la escala de la carta de Cuatro Vientos algo más pequeña, a esta última le fue aplicada un recorte y un posterior escalado, hasta resultar coincidente con el encuadre de la carta de Burdeos.

- Reclasificación de elementos. Atendiendo a los grupos temáticos identificados en [Tabla 3-2], los fenómenos presentes en cada uno de los conjuntos de datos se han reclasificado en capas de información, para su posterior simbolización.

- Simbolización estereotipada. Finalmente, y siguiendo las pautas y tendencias estereotipadas de ediciones características analizadas en 9.3.3 -Análisis de tendencias existentes en la simbolización de las ediciones características- y sintetizadas en [Tabla 3-3], se ha procedido a la simbolización de las capas de información, a través de una única especificación simbólica para ambos conjuntos. 


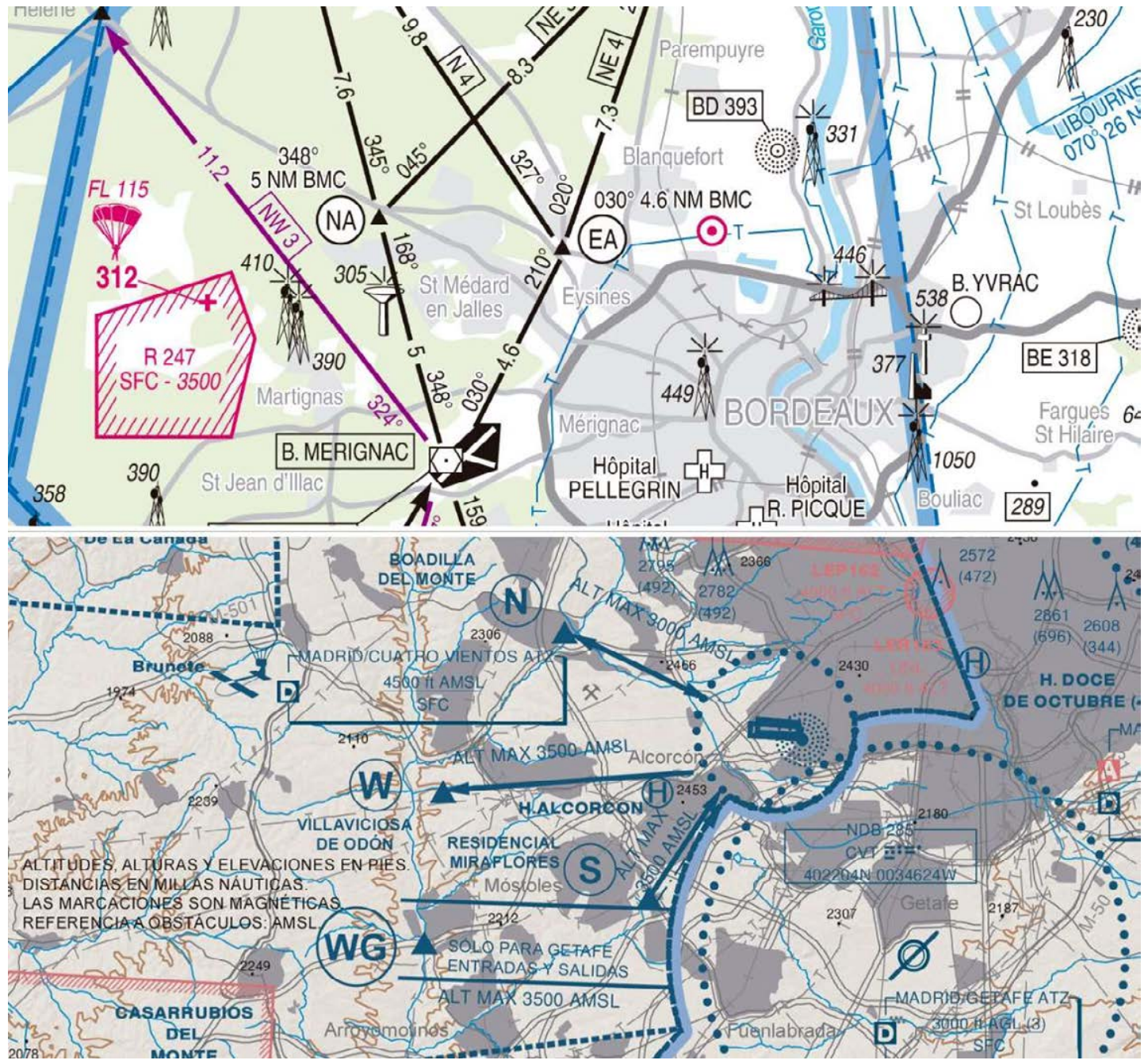

Figura 3-16: Carta de Aproximación Visual (VAC) de Bourdeaux Merignac (LFBD) -arriba- y carta de Aproximación Visual (VAC) de Madrid Cuatro Vientos (LECU) -abajo-. Cartas originales. (SIA, Francia y AENA, España).

Las primeras capas de información en simbolizarse fueron las correspondientes al mapa base ${ }^{166}$, incluyendo las capas de vegetación, hidrografía y construcciones -zonas edificadas, ferrocarriles, autopistas y carreteras-, etc. En [Figura 3-17] se presenta un extracto de cada uno de los conjuntos de datos, en referencia a las capas base.

${ }^{166}$ No se ha considerado la capa de relieve, ya que en el caso de la carta VAC de Burdeos no estaba disponible. En consecuencia, y para asegurar el cotejo homogéneo, en el caso de la carta VAC de Cuatro Vientos se ha prescindido del relieve de sombreado y tintas hipsométricas, así como de las curvas de nivel, no así de los puntos de cotas, que también lo definen, aunque no de forma satisfactoria. 


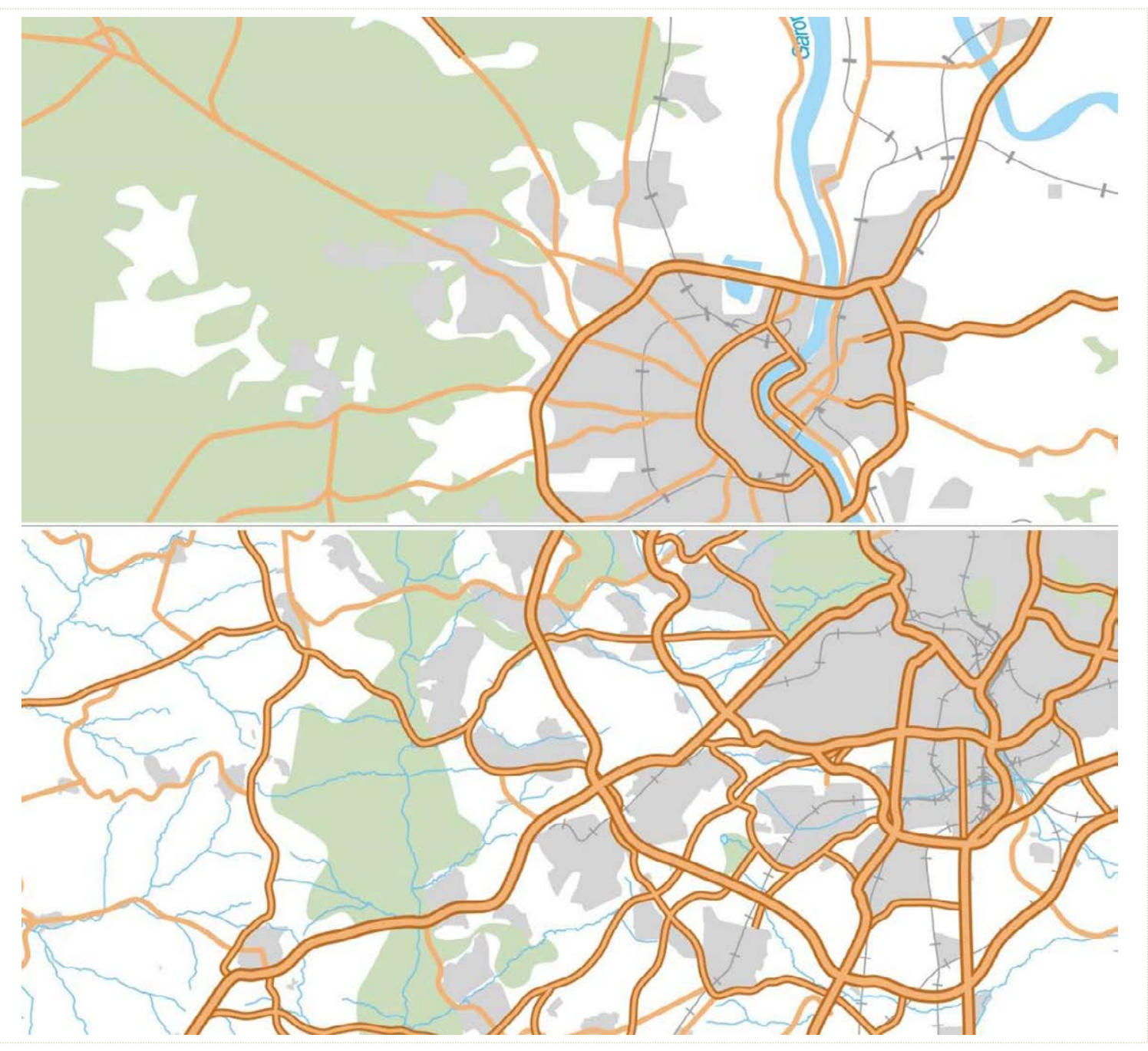

Figura 3-17: Capas de información base ya estereotipadas de la carta VAC de Burdeos (LFBD) -arriba- y de la carta VAC de Madrid Cuatro Vientos (LECU) -abajo- (figura propia).

En el caso concreto de la carta de Cuatro Vientos existe de origen una mala generalización de datos en las capas base ${ }^{167}$, lo que provoca ruido y una densidad visual que puede evitarse. En consecuencia, y como tarea adicional, se optó por generalizar ligeramente las capas de construcciones, hidrografía, y ferrocarriles. De igual forma se actuó a posteriori con la capa de tendidos eléctricos, simplificando los nudos que llegan a las subestaciones eléctricas.

${ }^{167}$ EI AIS de AENA utiliza para compilar el mapa base la Base Cartográfica Nacional (BCN). Sin embargo sobre esta base no realiza revisión ni generalización alguna, perdiendo así la oportunidad de particularizar la información a la estrictamente necesaria para la orientación en vuelo [Figura 9-46]. Esta aparente dejadez aumenta la densidad de información dispuesta sobre la carta, ya de por sí saturada. 


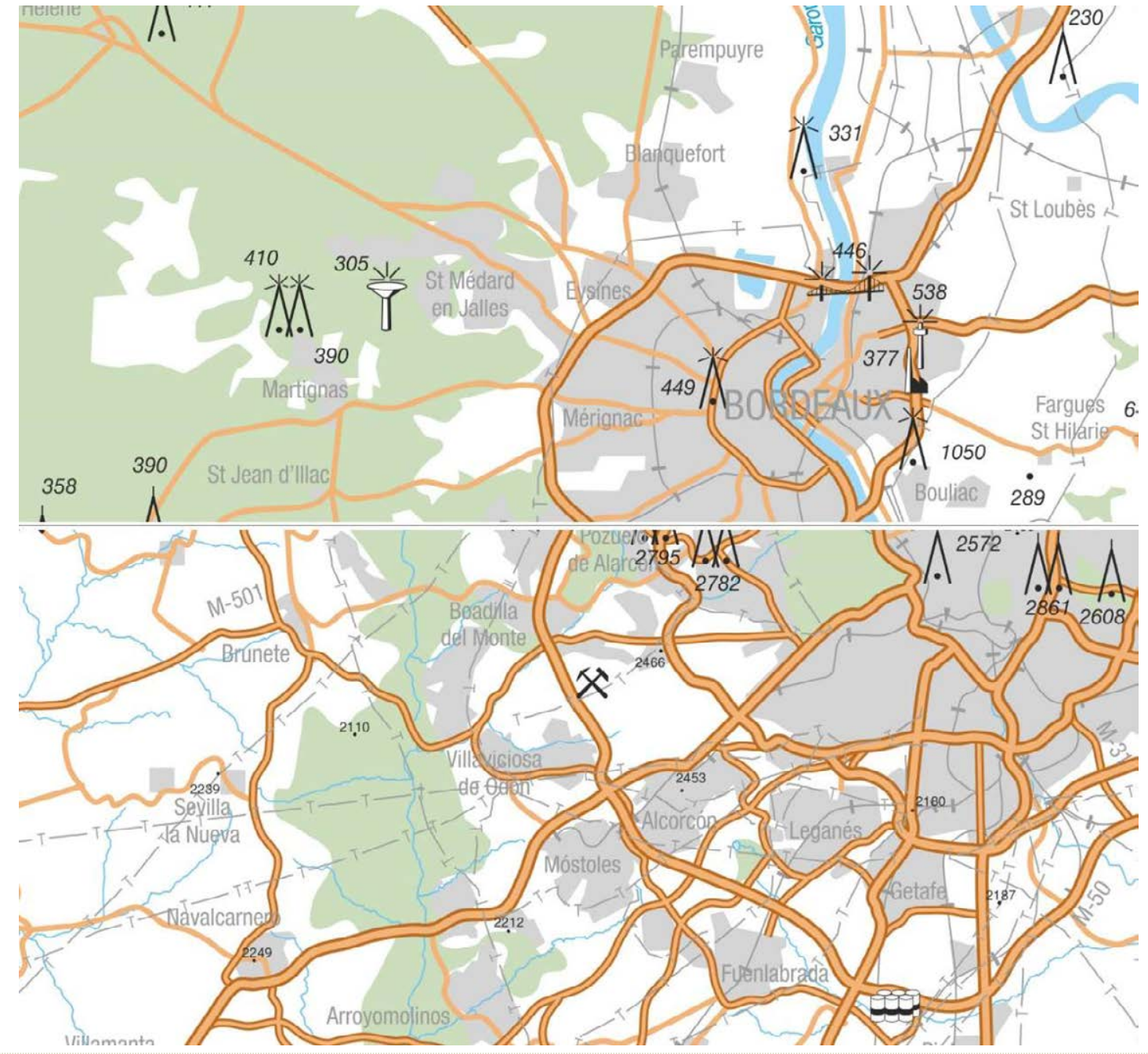

Figura 3-18: Adición de nuevas capas con simbolización estereotipada. Arriba carta VAC de Burdeos (LFBD), y abajo carta VAC de Madrid Cuatro Vientos (LECU) (figura propia).

Una vez realizada la generalización y agregada la rotulación de los topónimos, el siguiente paso consistió en añadir sobre el mapa base las capas de construcciones varias -para la orientación-, tendidos eléctricos, y obstáculos aeronáuticos específicos, incluyendo la rotulación de sus cotas [Figura 3-18]. De igual forma, se siguieron las tendencias de simbolización constatadas, con especial atención en este paso a la simbología puntual que se superpone al grupo de las capas base. 


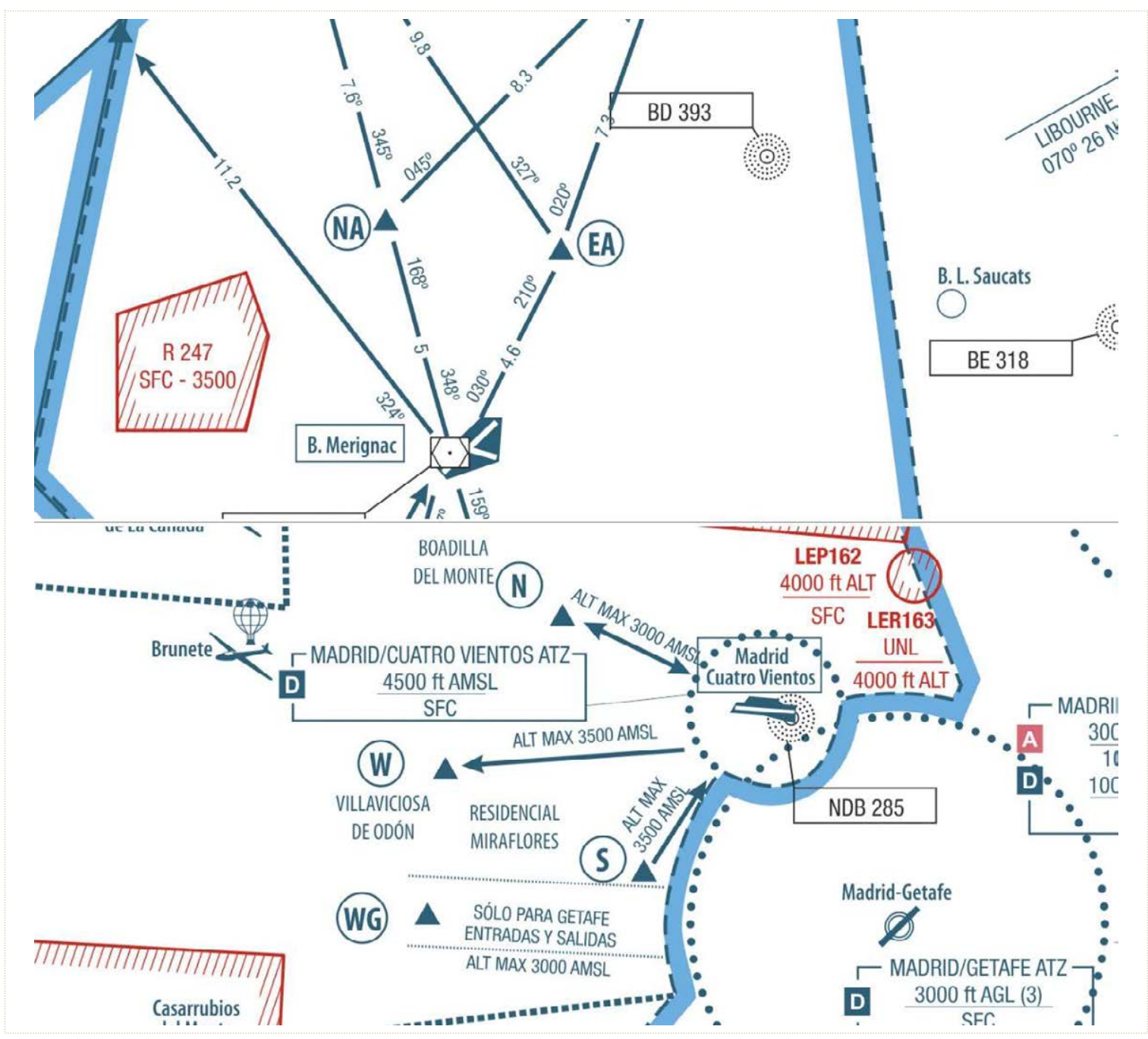

Figura 3-19: Capas de información aeronáutica con simbolización estereotipada. Arriba carta VAC de Burdeos (LFBD), y abajo carta VAC de Madrid Cuatro Vientos (LECU) (figura propia).

Añadidas las capas de información aeronáutica -clasificación y restricciones del espacio aéreo, circuitos de aproximación, etc.- [Figura 3-19], finalmente se compilaron los documentos finales estereotipados, de los que se presentan sendos extractos para su cotejo en [Figura 3-20]. 


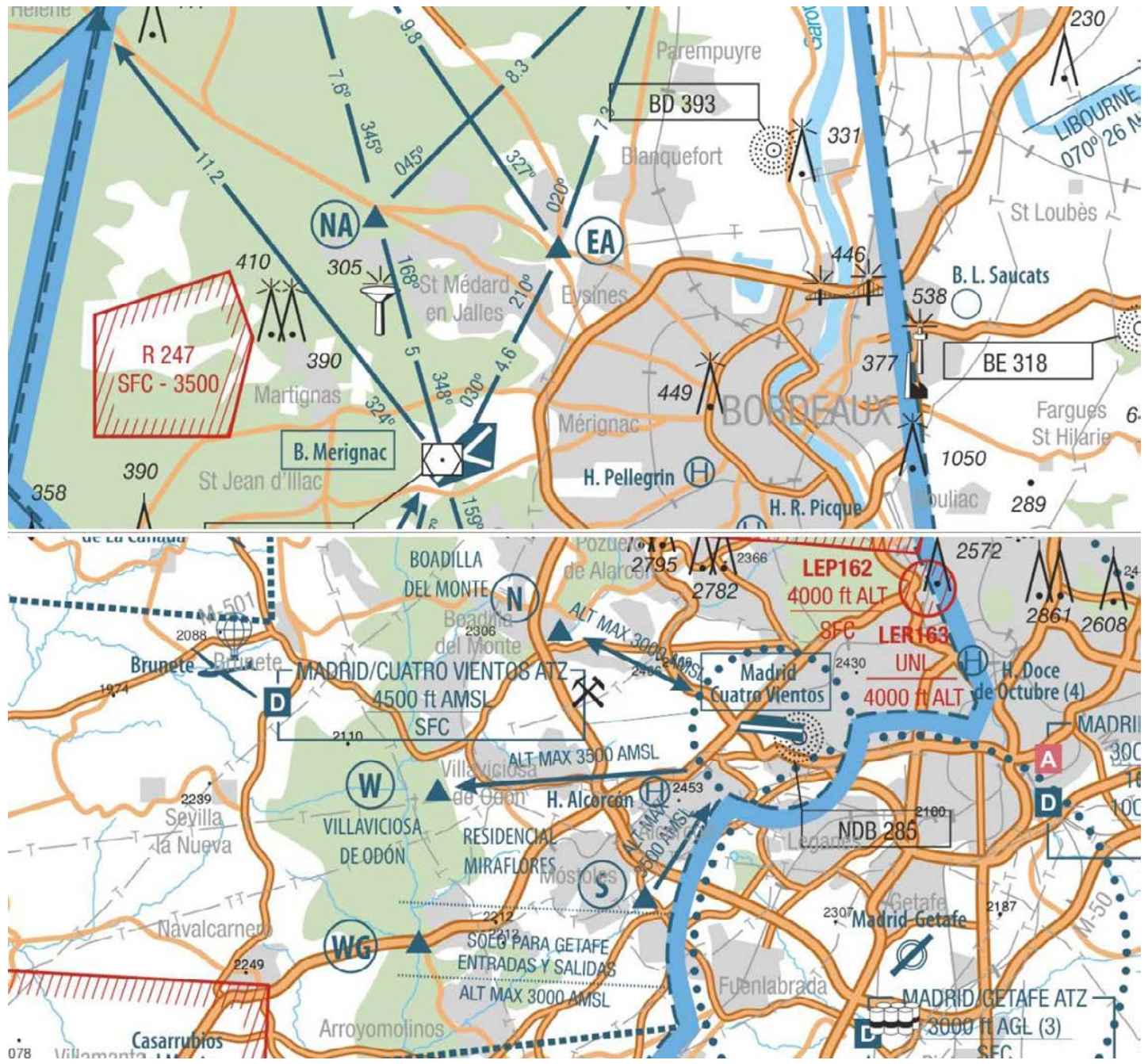

Figura 3-20: Extractos de los modelos de simbología estereotipada propuestos. Arriba carta VAC estereotipada de Burdeos (LFBD), y abajo carta VAC estereotipada de Madrid Cuatro Vientos (LECU) (figura propia).

Los prototipos de cartas completas que se proponen como síntesis de composición y simbología estereotipada del conjunto de ediciones características mundiales pueden encontrarse para su análisis en 9.3.5 -Propuesta de composición cartográfica estereotipada: modelos finales- 


\subsection{SUMARIO}

En este tercer capítulo se ha alcanzado el objetivo de concretar un conjunto limitado de cartas estereotipadas modelo sobre las que poder aplicar el tercer objetivo específico. Previamente a ello:

- Revisión de estándares. A través de una revisión de normas y métodos recomendados en vigencia, se han revisado y sintetizado las estandarizaciones internacionales que son de aplicación a la cuestión. En particular, se presentan las necesidades demandadas por $\mathrm{OACl}$, y se identifican una serie de requisitos normativos que los editores deben de asumir a la hora de confeccionar sus colecciones de cartas. Adicionalmente, se han presentado una serie de directrices particulares en el ámbito digital, así como del nuevo contexto de servicios y aplicaciones circunscrito al plan mundial de transición de AIS a AIM.

- Métodos de representación cartográfica. Se ha aportado una síntesis teórica de las metodologías de representación de la información en un mapa, de acuerdo sus las características de dimensionalidad, escala de medida y distribución, y simbolización respectivamente, aportando una caracterización en el caso concreto de la información aeronáutica. A su vez, se han definido y ejemplificado, para el ámbito particular aeronáutico, los posibles niveles de abstracción simbólica, cotejando esta cuestión en particular con respecto a las funciones operaciones a las que puede ir destinada cada carta.

- Cumplimiento de la normativa y aspecto estético. A través del análisis de las series cartográficas de un total de 12 países de distintas regiones y continentes, se cotejado el grado de cumplimiento de las normas y métodos recomendados de $\mathrm{OACl}$, analizando tanto series destinadas a vuelo visual como a vuelo instrumental. Este análisis ha tratado de recoger una valoración preliminar de diversos factores, entre otros el cumplimiento de la especificación de símbolos OACl, la adecuación del tamaño de los símbolos y textos del documento, la manera en la que se resuelve el problema de la saturación gráfica en áreas de elevada densidad de información, etc. Adicionalmente se ha alcanzado una serie de estimaciones subjetivas generales acerca de la calidad y el diseño estético de las ediciones mundiales.

Sintetizadas las conclusiones obtenidas, se ha declarado de forma razonada las restricciones que van a ser aplicadas al resto de la investigación, considerado únicamente las ediciones en formato papel o imprimible y, dentro de estas, únicamente las Cartas de Aproximación Visual (VAC). A partir de esta restricción metodológica, se ha identificado justificadamente un conjunto homogéneo y característico de ediciones de cartas aeronáuticas de distintas regiones y continentes. 
Para ello se ha atendido a 3 distintos criterios -simbólico, geográfico y funcional-, seleccionando un total de 17 países o entidades regionales cuyas ediciones han sido consideradas como características. Tomando como base este conjunto, se ha aplicado la siguiente metodología:

- Representación y abstracción simbólica de OACl. Se han considerado un total de 59 fenómenos de información geo-aeronáutica susceptibles de ser representados VAC, agrupados a su vez en un total de 9 grupos temáticos. Para cada uno de los fenómenos anteriores, se ha analizado la consideración que la especificación simbólica de OACl hace de sus características dimensionales, de su escala de medida y de su distribución sobre el territorio. También se ha identificado la tipología gráfica del símbolo propuesto por OACl para cada uno de ellos.

- Verificación de diferencias. Se ha mensurado individualmente el cambio o diferencias existentes entre cada uno de los símbolos identificados en las series características de cartas VAC y la especificación recomendada por $\mathrm{OACl}$, con el objetivo de descubrir tendencias o rasgos coincidentes en el conjunto de ediciones características. Para ello se ha propuesto aplicar una escala de grados en términos de intensidad de la diferencia, lo que permite valorar metodológicamente el grado de adopción de las especificaciones de simbología propuestas por OACl en su Anexo 4.

- Deducción de tendencias representativas. Se ha logrado sintetizar un listado concreto de pautas y tendencias de simbolización que pueden considerarse como representativas y transversales en el conjunto de las ediciones características analizadas. Las tendencias estereotipo se han declarado, de forma sintetizada, mediante un listado de 23 tendencias constatadas, agrupadas a su vez en un total de 5 tipologías o características.

- Propuesta de composición estereotipada. Finalmente, aplicando las especificaciones del listado anterior, se ha concluido con una propuesta sintetizada de composición y simbología estereotipada, aplicada a dos conjuntos de datos -cartas VAC en vigor- de dos productores distintos -SIA de Francia y AlS de España- 


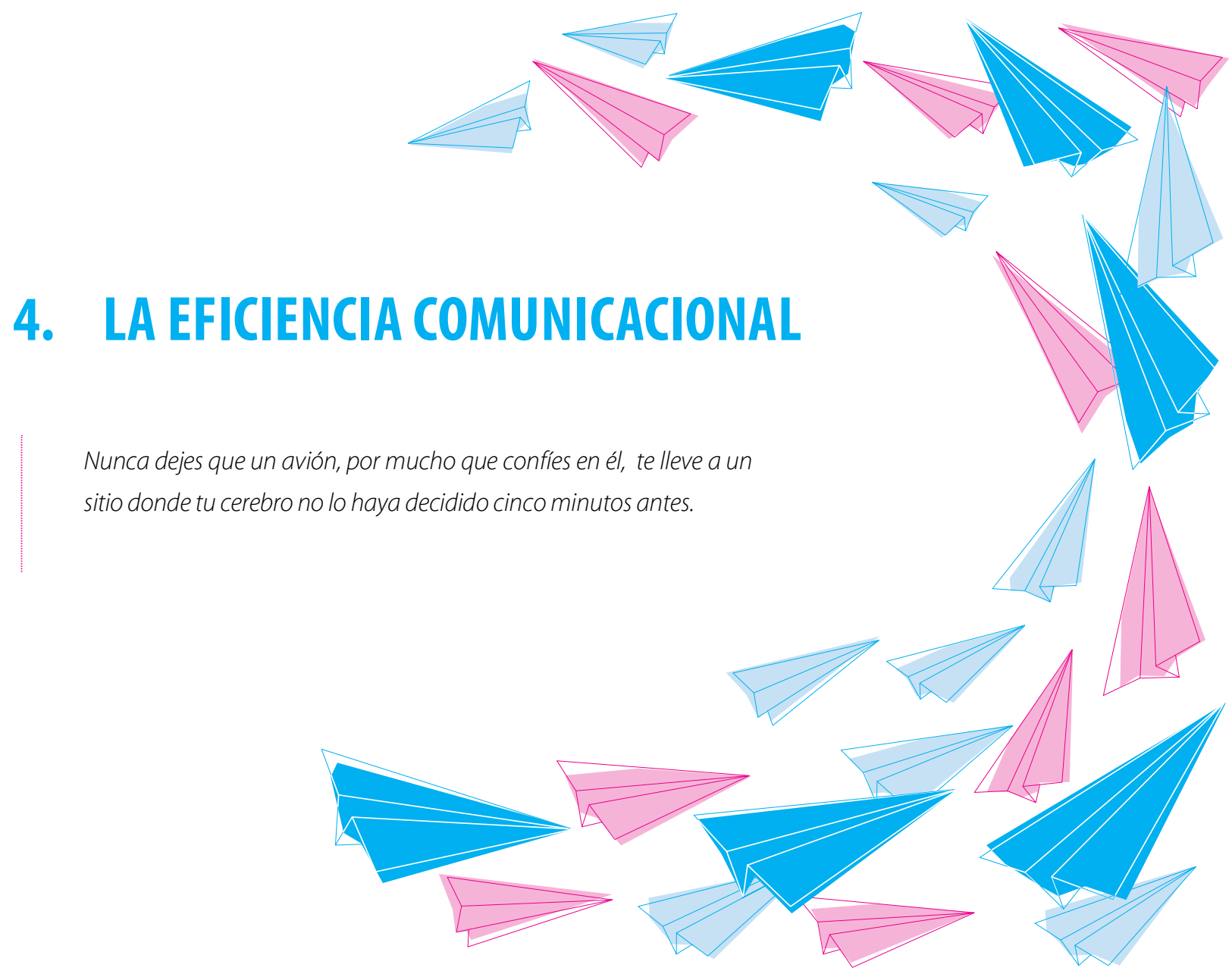

En el año 1982, el metro de Madrid renovó por completo su identidad gráfica aplicando criterios semiológicos modernos. Esta decisión cambió radicalmente la manera en la que, hasta entonces, se informaba al viajero por medio de la comunicación gráfica. El equipo interdisciplinar responsable, liderado por el diseñador Arcadi Moradell, creó una nueva señalética de pasillos y estaciones -hasta entonces anárquica y no sujeta a libro de estilo alguno- en la que la tipografía utilizaba primordialmente las letras minúsculas, planteó desterrar los números romanos para designar líneas e identificó a cada una de ellas con un tono de color diferente. Todo ello dentro de una imagen gráfica uniforme, coherente y en la que los distintos elementos eran compatibles entre sí, independientemente de si estaban situados en directorios, trípticos o cartelerías. También se publicó un plano esquemático de la red basada en esta nueva identidad gráfica. Creación del reconocido diseñador madrileño Alberto Corazón, venía a paliar las enormes carencias y la falta de criterios de los planos anteriores editados por la compañía.

En la primavera de 2007 la Comunidad de Madrid tomó la decisión de sustituir la última edición del plano esquemático señalado anteriormente, obra de Juan de la Mata ${ }^{168}$, por un nuevo diseño del que fue responsable el ilustrador Rafael Sañudo. Su propuesta obviaba conscientemente la identidad corporativa consolidada

${ }^{168}$ Si bien el diseño original del plano esquemático de 1982 - que recogía la nueva identidad gráfica de Metro- es obra de Alberto Corazón, hasta 2007 Metro de Madrid tenía encomendadas las labores de racionalización compositiva y actualización al estudio de Juan de la Mata. 
desde hacía 25 años, e introdujo todo tipo de elementos cuestionables, como una tipografía poco legible -que además se aplicaba con un uso dominante de las mayúsculas-, la auto imposición de no utilizar líneas diagonales en la representación de la red, el uso de la forma circular en los extremos de las líneas en vez de la tradicional cuadrada, el uso de puntos de colores en las correspondencias, etc. La prensa escrita se hizo rápidamente eco del gran revuelo social provocado por el cambio, y realizaron acopio de opiniones a favor y en contra, tanto desde el mundo profesional de la comunicación como desde el ámbito de los usuarios.

Se ha traído ese ejemplo aquí, ajeno a la aeronáutica, para mostrar cómo la valoración del nivel de expresividad y de comunicabilidad de un artefacto gráfico es una cuestión compleja y que puede ser abordada desde distintos puntos de vista. Uno de ellos lo aporta la semiología gráfica, que estudia los elementos del lenguaje visual tal y como lo definió el cartógrafo francés Jacques Bertin (1977), pionero de su teorización. Así, un análisis semiológico del cumplimiento de la gramática visual portada por un modelo cartográfico puede resultar un método adecuado para valorar si cumple o no adecuadamente su propósito de transmitir información en base a la cual se crea. En el caso introducido como ejemplo, se realizaron notables análisis al respecto por parte de Muñoz Román (2007) y De Córdoba (2011), los cuales vinieron a demostrar que, comparativamente, la propuesta de Sañudo cometía distintos errores en el diseño del lenguaje gráfico y, en consecuencia, transmitía peor la información que el plano clásico al que pretendía sustituir.

Otra metodología para evaluar esa cuestión es la realizada mediante encuestas y entrevistas con expertos y usuarios -evaluación de satisfacción-. Dada la transcendencia social que adquirió el cambio, las crónicas de la época recogieron opiniones enconadas: desde el entusiasmo de Alberto Corazón -es magnífico, gráficamente muy inteligente y afronta los problemas de comunicación de forma muy interesante desde el punto de vista estético(ADN, 2007) hasta el más absoluto rechazo de una gran parte de los usuarios consultados -engendro, bobalicón e innecesario fueron algunos de los calificativos recogidos- (EIPaís, 2007). El propio Rafael Sañudo aseguró que había comprobado la utilidad del nuevo plano con mucha gente, incluida su suegra y sus alumnas de 'bridge' (sic). El plano fue retirado 6 años más tarde (ElPaís, 2013), lo que significó la vuelta, aunque actualizado, del modelo tradicional concebido en los años 80.

Existe otro modo desde el cual afrontar el problema, y es acudir a la observación directa y espontánea de los usuarios en el uso del plano, es decir, desde el dominio de la percepción visual y de la cognición humana. Son precisamente estas capacidades las que establecieron en mayor o menor medida los principios de la semiología gráfica y sus reglas gramaticales. A título personal podemos decir que resultaba sorprendente contemplar discretamente a los turistas que hacían uso de los planos de Sañudo ubicados en el interior de los vagones, adheridos en los laterales de las puertas de salida. Así, mientras que anteriormente a 2007 los viajeros leían el plano clásico sujetos a los pasamanos y a una relativa distancia del mismo, con el plano de Sañudo se observaba un comportamiento muy significativo de su mala calidad comunicacional: un número significativo de usuarios realizaban la lectura valiéndose del dedo índice sobre el plano, con el que recorrían físicamente líneas y transbordos, incapaces de extraer recorridos únicamente de forma visual. 
En el caso de los planos de transporte urbano, la peor consecuencia de una deficiente comunicabilidad-como ocurrió el caso planteado- puede ser la pérdida de tiempo al llegar al destino por una ruta más larga que el recorrido óptimo. En el caso de las cartas aeronáuticas, un diseño inadecuado es un factor de riesgo que, si se dan las circunstancias, puede añadirse a las causas de un incidente o peor aún, de un accidente aéreo.

El interés de esta tesis es plantear una metodología que permita realizar un análisis de la eficiencia comunicacional de los modelos de cartografía aeronáutica desde el punto de vista de las habilidades, limitaciones y otras características humanas relevantes. En consecuencia, este cuarto capítulo -La eficiencia comunicacional- se va a estructurar de la siguiente manera: En la sección 4.1 -Factores humanos en la comunicación cartográfica- se identificarán las implicaciones de factores humanos clave, en cuanto a comunicación cartográfica se refiere, a partir de una revisión bibliográfica específica. En la sección 4.2 -Ergonomía de la comunicación visual-se desgranarán de forma sintetizada los conceptos de comunicación, ergonomía cognitiva e incertidumbre gramatical de la imagen, todos ellos de aplicación en la investigación de modelos cartográficos. En la sección 4.3 -Evaluación comunicacional- se repasarán algunas de las metodologías propuestas por otros autores para la evaluación de los sistemas de comunicación visual y, de forma extensiva, las técnicas de seguimiento ocular, aportando su concepto, avances recientes, así como las bondades y limitaciones de su aplicación concreta para el análisis de la eficiencia comunicacional cartográfica. Finalmente, en la sección 4.4 -La propuesta metodológicase propondrá una metodología de análisis que permita valorar la eficiencia de unas ediciones frente a otras. Como se obró en los anteriores capítulos, se dedicará la sección 4.5 -Sumario- a sintetizar las cuestiones tratadas a lo largo del presente.

\subsection{FACTORES HUMANOS EN LA COMUNICACIÓN CARTOGRÁFICA}

El elemento humano es la parte más flexible, adaptable y valiosa del sistema aeronáutico, pero también es la más vulnerable a las influencias que pueden afectar negativamente a su comportamiento. A través de los años, tres de cada cuatro accidentes han sido el resultado de comportamientos humanos considerados menos que óptimos (ICAO, 1998b).

En el ámbito aeronáutico se ha indagado profusamente en el conocimiento de los Factores Humanos (HF). Concepto definido como un conjunto de habilidades, limitaciones y otras características humanas relevantes para el diseño de objetos y sistemas (R. R. Gray, Rogers, y Hewitt, 2007), representa un dominio de importancia capital, donde los efectos de la tecnología y la creciente complejidad situacional en el ámbito aeronáutico fuerzan al individuo responsable -piloto, controlador, etc.- a enfrentarse constantemente a situaciones comprometidas. Un cúmulo encadenado de decisiones inadecuadas puede hacer peligrar seriamente la seguridad propia y la del resto de los usuarios del espacio aéreo. 


\subsubsection{El modelo conceptual de los factores humanos}

El área de conocimiento relacionada con el concepto de error humano y sus implicaciones en el ámbito aeronáutico se estudia actualmente a partir del 'modelo conceptual de los factores humanos', propuesto por Edward en 1972 -modelo SHEL-, y modificado posteriormente por Hawkins ${ }^{169}$-modelo SHELL-en 1975 (ICAO, 1998b). La premisa básica de este último modelo es la relevancia del ser humano como centro de referencia [Figura 4-1]. Reconoce que la persona posee una serie de limitaciones que inciden en el desempeño de tareas, exigiendo por tanto al resto de componentes del modelo una acomodación rigurosa con el fin de maximizar la ergonomía, es decir el estudio de la eficiencia de las personas en sus ambientes de trabajo. Es el ambiente, la máquina, quién ha de acomodarse al hombre y nunca al contrario como ocurrió en los comienzos de la aviación (Hawkings, 1987).

S-Software soporte lógico (procedimientos, simbología...)

$\mathrm{H}$ - Hardware equipo (máquina)

\section{E-Environment} ambiente

L - Liveware (human) elemento humano

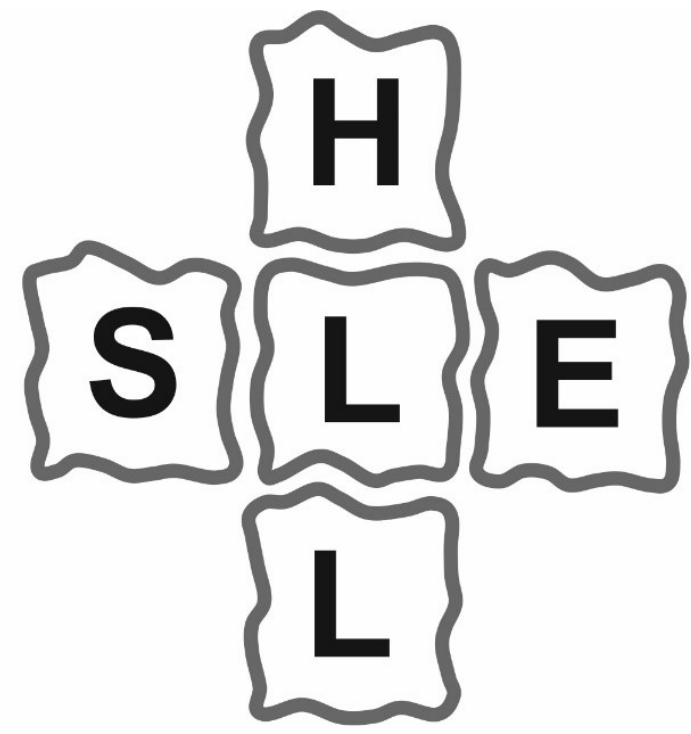

Figura 4-1: Modelo SHEL modificado por Hawkings ${ }^{170}$ (ICA0, 1998b).

Dentro de las cuatro interfaces del modelo de Hawkings -relaciones entre los 5 elementos que lo componen-, es de interés particular la relación 'humano-soporte lógico'. Esta abarca al ser humano y a los aspectos no físicos del sistema, tales como los procedimientos, la presentación general de manuales y listas de verificación, la simbología y los programas de ordenador (ICAO, 1998b). Cada una de las interfaces del modelo SHEL tiene un potencial de error cuando existe desajuste entre sus componentes: en la interfaz reseñada, pueden producirse

${ }^{169}$ Hawkins instó la necesidad de añadir otro elemento humano -liveware- al modelo original de Edward, situándolo además en el centro del sistema para ilustrar las interacciones entre este y cada uno de otros cuatro sistemas

${ }^{170}$ El que los bloques -interfaz- de este modelo encajen o no, reviste tanta importancia como las características de los propios bloques, El hecho de que no encajen puede dar lugar a errores humanos (ICA0, 1998b). Por ello, en el esquema de Hawkings, los bloques son representados por bordes ásperos y lobulados. 
errores al buscar información vital, cuando la documentación y las cartas son confusas, engañosas o excesivamente recargadas de elementos.

Por otra parte, en el capítulo 2 del Anexo 4 al Convenio sobre Aviación Civil Internacional de la ICAO-OACl se estipulan que en el diseño de cada tipo de carta 'se observarán los principios relativos a factores humanos que aseguren su uso óptimo', siendo el Manual de instrucción sobre factores humanos (Doc 9683) el texto de orientación que debe ser aplicado (ICAO, 2009a). Si bien el manual de instrucción sobre factores humanos en vigor de ICAO (1998b) presenta los principios básicos sobre ergonomía -examinando para ello las capacidades humanas que deben tenerse en cuenta en el diseño de equipos, pantallas de visualización y condiciones de estrés ambiental de relevancia-, no desgrana directrices y recomendaciones específicas para el diseño de la representación gráfica de fenómenos geoespaciales en relación a la correcta observación de los factores humanos. Esta carencia ha querido ser abordada como parte de la investigación propuesta.

\subsubsection{Las implicaciones de los errores de edición, lectura e interpretación}

Llegado este momento, cabría preguntarse hasta qué punto un error de lectura o interpretación de una carta de navegación podría ser el responsable de un accidente. Según Reason (1997), los errores pueden ser abordados bajo dos puntos de vista:

- Desde el punto de vista de las personas, el enfoque se centra en los actos no seguros -violaciones de los protocolos y procedimientos- de los individuos situados en la primera línea de responsabilidad, como médicos, cirujanos, pilotos, etc. Se considera que estos actos inseguros derivan de procesos mentales como la falta de atención, de motivación, la negligencia y la imprudencia. Los seguidores de este enfoque tienden a tratar los errores como cuestiones morales, asumiendo que este tipo de cosas les suceden a las malas personas. Según esta hipótesis moral denominada 'de justicia universal', un accidente provocado por una mala interpretación de una carta les sucederá sólo a pilotos conflictivos con una personalidad indudablemente irreflexiva, temeraria, etc.

- Desde el punto de vista de los sistemas -defendida por Reason-, el enfoque consiste en asumir que los seres humanos somos falibles y los errores son esperables, incluso en las mejores organizaciones. Los errores son vistos como consecuencias en lugar de causas, que tiene sus orígenes no tanto en la perversidad de la naturaleza humana como en diversos factores sistémicos, como 'trampas' en el lugar de trabajo o errores de organización en los procesos que dan lugar a las mismas. Así surge el concepto de contramedidas, basadas en el supuesto de que a pesar de que no se puede cambiar la condición humana, podemos cambiar la atmósfera y las condiciones bajo las cuales los seres humanos funcionan. Todas las tecnologías peligrosas poseen barreras y salvaguardas, y la aviación desde 
que Alfonso Chapanis ${ }^{171}$ abrió la vía del estudio de factores humanos en los sistemas complejos de pilotaje -ver 2.5.2 El ambiente- se caracteriza también por ello. Así, cuando un evento adverso ocurre, lo importante no es quién ha cometido el error, sino cómo y por qué las defensas fallaron.

La mañana del 19 de febrero de 1985, un Boeing B727 se estrelló ${ }^{172}$ contra ladera noreste del monte Oiz provincia de Bizkaia-. El accidente se desencadenó cuando el aparato de la compañía Iberia, procedente de Madrid-Barajas, perdió la mayor parte del ala izquierda al impactar contra un soporte de antenas de EiTB -la televisión autonómica vasca- en condiciones de visibilidad reducida al inicio de la maniobra de aproximación al aeropuerto de Bilbao-Sondika.

Trasladando las conclusiones del informe final (España, 1985) al razonamiento de Reason, desde el punto de vista de las personas la culpable del accidente -el avión volaba 300 metros por debajo de la altitud recomendadafue evidentemente la tripulación -enfrascada además en una en una pueril conversación en pleno estrés operativo acerca del retraso en el cobro de sus nóminas-. Así, el copiloto al mando en ese momento (PF) ${ }^{173}$, tuvo una excesiva confianza en el sistema de alerta de altitud -interpretando incorrectamente sus avisos- cometiendo, además, un error de lectura del altímetro de tambor del Boeing B727 174 175. Sin embargo, desde el punto de vista de los sistemas, los errores cometidos por la tripulación no lograron ser aislados por las diferentes salvaguardas, entre otras la supervisión de la maniobra por parte del piloto (PNF), la comprobación de la existencia de obstáculos

${ }^{171}$ Desde una perspectiva histórica, Chapanis fue un autor fundamental para el campo de la ingeniería de factores humanos durante su período de gestación y crecimiento entre la Segunda Guerra Mundial y la década de 1980. Su trabajo está acreditado como pieza clave del estado actual de la comprensión de la conducta humana en el contexto de la innovación tecnológica y el diseño de sistemas, no sólo en aviación (Joyce y Pew, 2010).

172 Todos los ocupantes del aparato, 141 pasajeros y 7 tripulantes, fallecieron en el accidente.

${ }^{173}$ Antes del comienzo de un vuelo comercial típico, el comandante de la aeronave decide cuál de los dos pilotos tendrá la responsabilidad directa de volar la aeronave para el vuelo completo o para determinadas partes como el descenso/aproximación y aterrizaje. Así, la persona que pilota se convierte en el 'piloto que vuela' (PF) para ese tramo, mientras que su compañero se convierte en el 'piloto que no vuela' (PNF) y en ese papel debe monitorear las acciones de gestión de vuelo y control de aeronaves del PF y llevar a cabo tareas de apoyo, de comunicaciones y el registro de lista de lectura (CAA, 2013).

174 De acuerdo a estudios referenciados (España, 1985), diferentes pilotos comentaron acerca del altímetro de tambor que 'la ventanilla es una complicación en el instrumento y es bastante pequeña, muy a menudo requiere una doble mirada y apartar la atención de la aguja. Otros instrumentos requieren solamente un único punto de atención visual para comprenderlo y no apartar, retrasar o complicar la comprobación de los instrumentos' o que 'las lecturas erróneas parecen ocurrir siempre a baja altitud, cuando la atención está dividida entre más actividades'.

${ }^{175}$ Tras el accidente, Aviación Civil recomendó sustituir los altímetros de tambor y aguja por otros modelos que evitasen los errores de lectura. 
a través de la cartografía -ni el monte Oiz ni la antena de televisión cercana a su cima figuraban en la carta de aproximación del aeropuerto- ${ }^{176}$, etc.

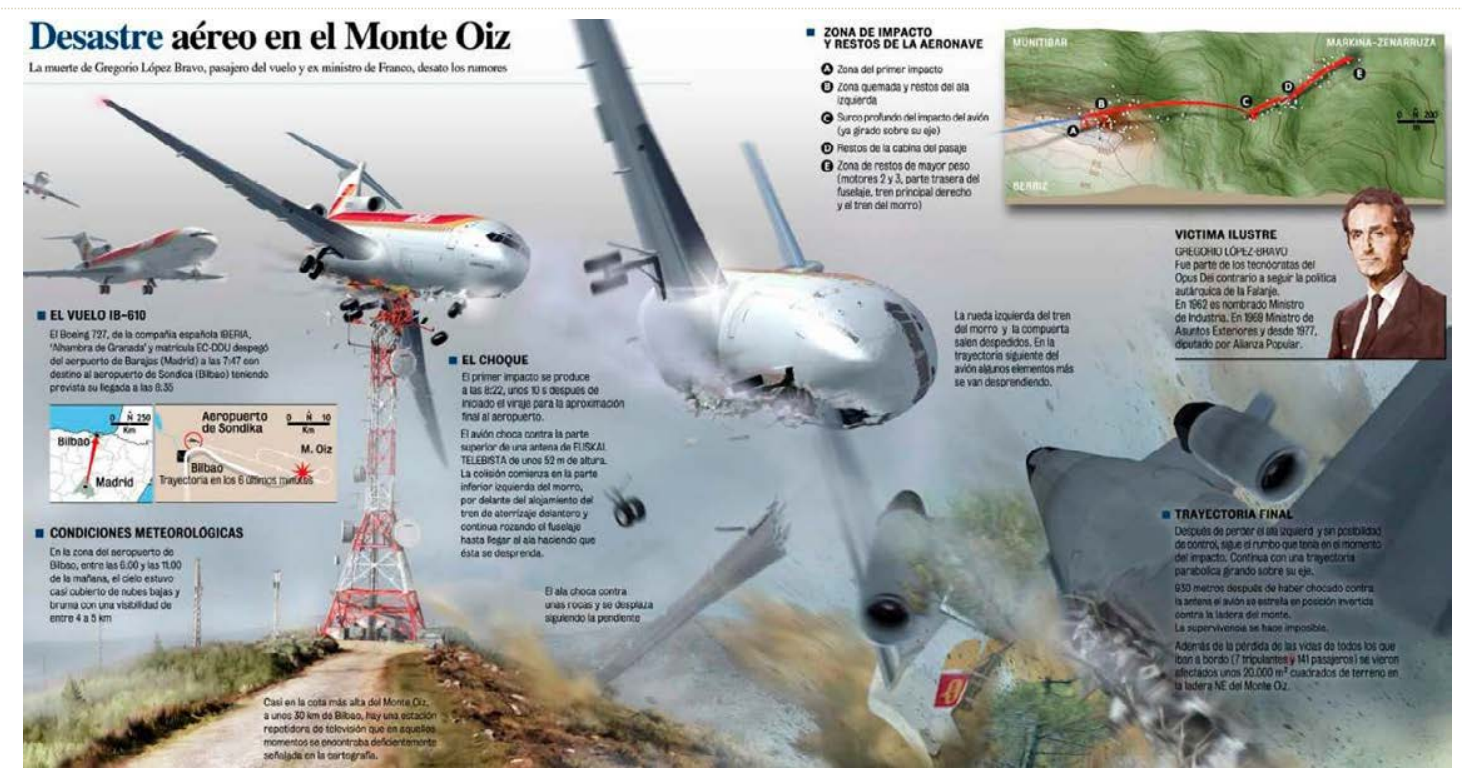

Figura 4-2: Infografía del accidente del Monte Oiz de 1985 (De Velasco y Alonso, 2008).

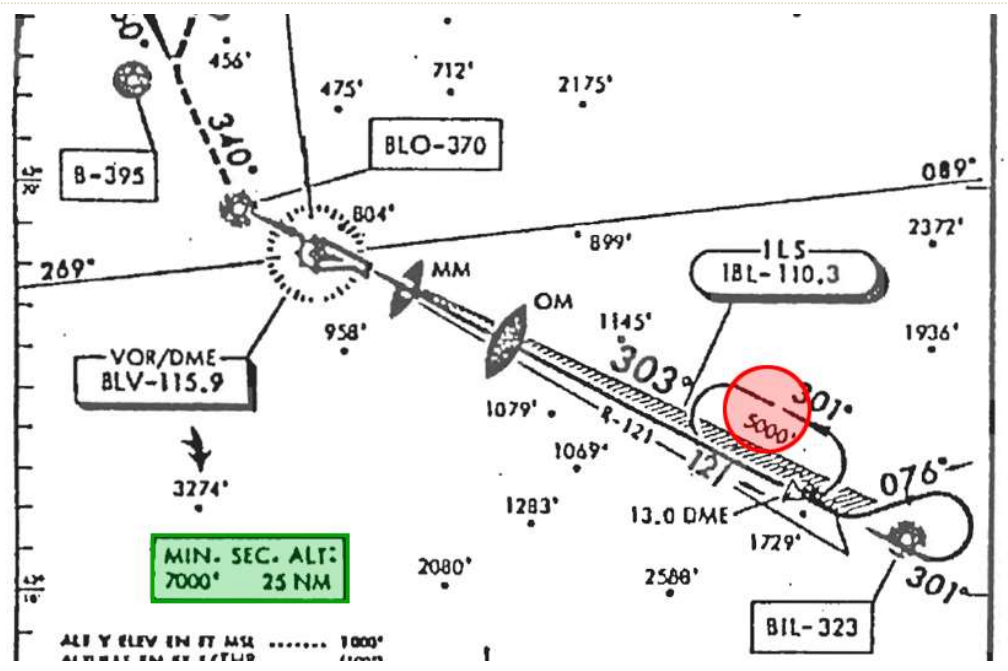

Figura 4-3: Extracto de la carta de Aproximación por Instrumentos - OACl / ILS RWY 30 del Aeropuerto de Bilbao editada en Julio de 1984- supuestamente utilizada por la tripulación accidentada (España, 1985; Iberia, 1985). Se indica en rojo la posición aproximada del Monte 0iz-3.386 pies de altura, no representado- y la representación de la Altitud Mínima del Sector (MSA).

${ }^{176}$ Entre las diferentes recomendaciones emitidas una vez investigado el accidente, se instó a las autoridades aeronáuticas competentes a que acelerasen el proceso de actualización de las cartas aeronáuticas, de acuerdo con la normativa del Doc. 8168 de $\mathrm{OACl}$ en vigor. 
Si bien el soporte de antenas de televisión -de 54 metros de altura- sobrepasaba en 28 metros la cota máxima del monte, era precisamente la cima del monte Oiz el obstáculo determinante para calcular la altitud de seguridad del área de protección de la maniobra de aproximación. Esta cima, de 1.026 metros de altura -3.386 pies, era la más elevada de la zona comprendida en las cartas oficiales en vigor en 1985 y, al igual que la antena, no aparecía representada: como consecuencia, tampoco figuraba en las cartas utilizadas por los pilotos de Iberia [Figura 4-3] o de otras compañías ${ }^{177}$.

Ante tales circunstancias cabría preguntarse hasta qué punto pudo influir en el accidente la ausencia de la antena o de la cima en la carta, o bien -si ambos fenómenos hubiesen estado representados- la evidente mala redacción y representación de la orografía [Figura 4-4] [Figura 4-5] con respecto a los límites de seguridad en la senda de descenso.

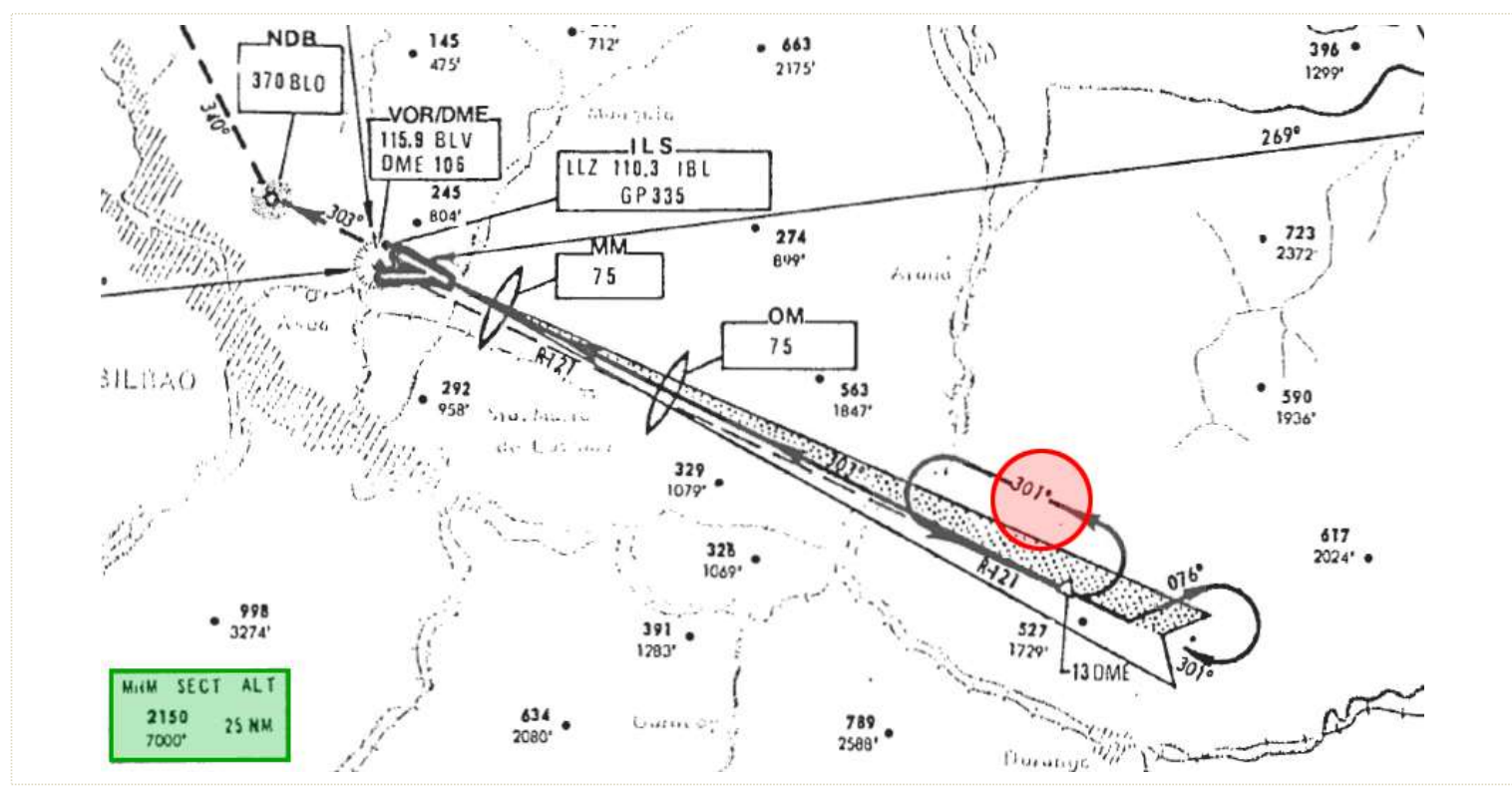

Figura 4-4: Extracto de la carta de Aproximación por Instrumentos - OACI / ILS RWY 30 del Aeropuerto de Bilbao editada en Noviembre de 1981- del Servicio de Información Aeronáutica -actual AIS de Aena- y que era oficial en el momento del accidente (España, 1985). Se indica en rojo la posición aproximada del Monte Oiz, de 3.386 pies de altura -no representado- y la representación de la Altitud Mínima del Sector (MSA).

177 La Administración estaba informada de esas circunstancias y, por este motivo, la propia Dirección General de Aviación Civil envió tan sólo un mes antes del accidente una propuesta de nueva carta, fechada en diciembre de 1984, en la que se incluye el Oiz y se incrementaban en 350 metros las alturas mínimas de seguridad de vuelo (EIPaís, 1985). 


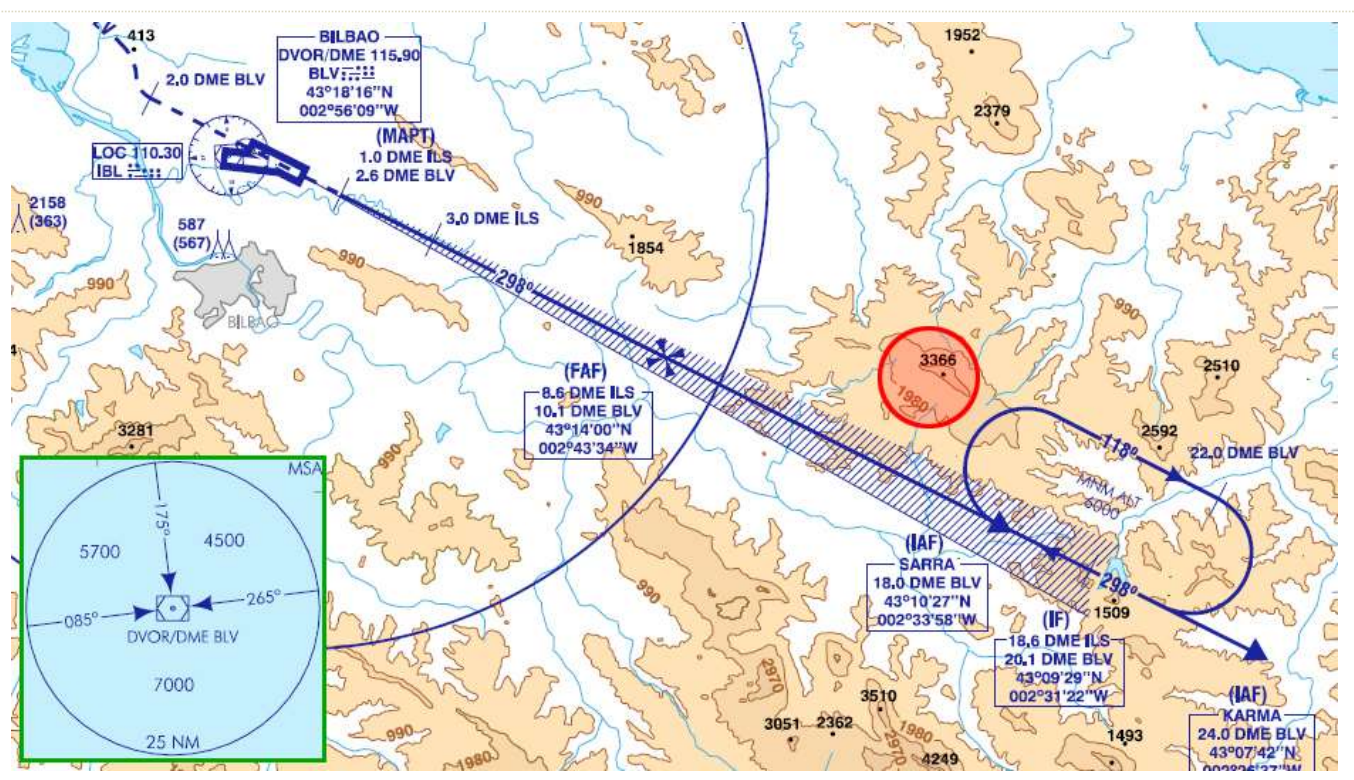

Figura 4-5: Extracto de la carta de Aproximación por Instrumentos - OACI / LOCZ RWY 30 del Aeropuerto de Bilbao, que es oficial en la actualidad (Aena, 2013a). Se indica en rojo la posición del Monte Oiz y la representación de la Altitud Mínima del Sector (MSA).

Para tratar de explicar de forma general la posible causalidad de los accidentes en aviación, ingeniería y asistencia sanitaria, el propio James Reason propuso en 1990 el denominado 'modelo del queso suizo' (Reason, 1990). En este modelo, cada sistema posee distintas barreras que separan la exposición del desenlace y los riesgos de las pérdidas. Sin embargo, cada barrera -representada en forma de lonchas de queso- tiene fallos o agujeros -como caracteriza al queso Emmental-, cuya posición varía aleatoriamente, de modo que el accidente ocurre cuando se alinean fatalmente al menos un agujero por cada barrera.

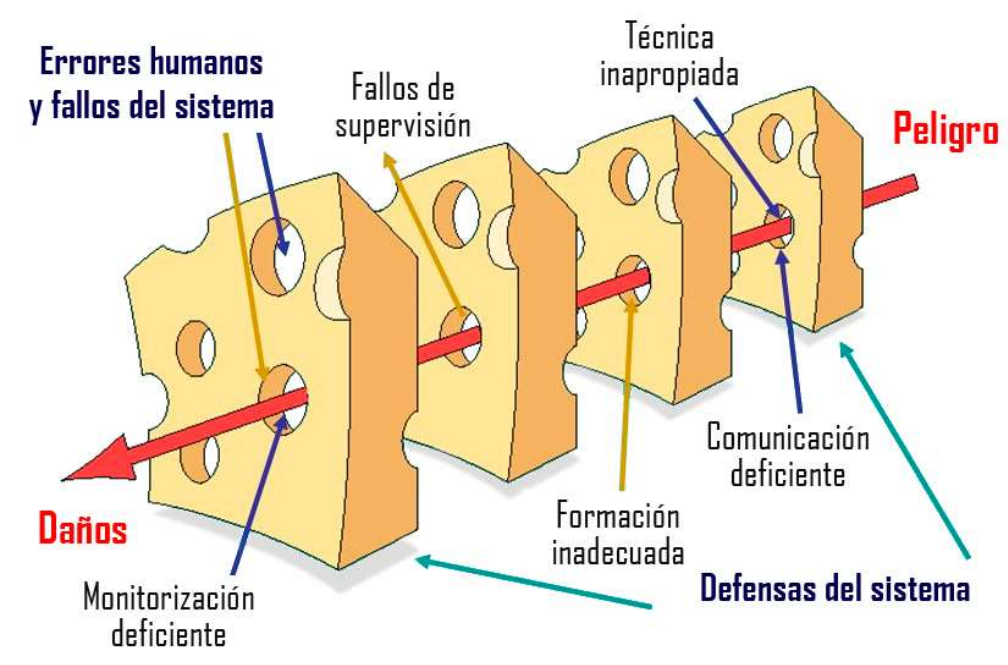

Figura 4-6: Modelo de error humano denominado 'del queso suizo'. Adaptado de (Reason (1990), 2000)). 
En resumen, el riesgo no está en que aparezca un fallo en el sistema, sino que concurran varios simultáneamente. Por ejemplo, en el accidente reseñado, se produjeron determinado número de fallos activos -que se cometieron al estar la tripulación en contacto directo con el sistema- y fallos pasivos provocados por las condiciones latentes. Precisamente este tipo de fallos residentes -generalmente ocultos- tienen relación con el diseño del sistema, por ejemplo con el diseño del sistema de información geográfica propio de las cartas de aproximación utilizadas.

Cotejando el modelo de Reason con las conclusiones oficiales, podemos deducir que se produjo una comunicación deficiente del modelo cartográfico -puesto que no aparecía indicado ni la cima del monte ni la posición de la antena en los alrededores, que lo superaba en altura-, una técnica inapropiada -puesto que la representación orográfica en la carta a base de puntos de cota carecía de la función comunicativa de las curvas de nivel y la expresividad visual de las tintas hipsométricas-, y fallos de supervisión -puesto que en el proceso de trazabilidad y revisión de los datos en la producción cartográfica no detectó, hasta poco antes de producirse el accidente, que la cota más elevada indicada tenía 998 metros de altura, y no los 1.026 metros del monte Oiz, que además ni siquiera estaba representado-.

A este compendio de fallos de índole cartográfica se le unieron otros muchos -más determinantes- como la monitorización deficiente de la altitud y el error de lectura en el altímetro de tambor-activos-, la falta de asepsia en cabina -pasivos-, etc.

\subsubsection{Los componentes y factores implicados en la lectura de cartas}

En el año 2007, un grupo de investigadores adscritos a la Administración Federal de Aviación de los Estados Unidos con experiencia en varias disciplinas a la ciencia y los métodos de Factores Humanos, completó y puso en marcha el programa de enseñanza denominado 'FAA Human Factors Awareness Course' (R. R. Gray et al., 2007). Ideado para fomentar la comprensión de la función y la contribución de los factores humanos en el desarrollo del sistema de la FAA, está estructurado alrededor de una adaptación ${ }^{178}$ del modelo de factores humanos de David Meister, el cual realiza una ideación de cómo los seres humanos y los sistemas interactúan (Meister, 1971).

Presentado de forma esquemática en [Figura 4-7], el modelo adoptado por la FAA para la formación de su personal muestra un típico flujo de información entre los humanos y las máquinas, divididos a su vez en diversos componentes de un sistema.

${ }^{178}$ Entre otros aspectos, Gray y otros autores de la FAA añadieron al modelo original de Meister (1971) las influencias ambientales sobre la interacción 'humano-máquina'. 


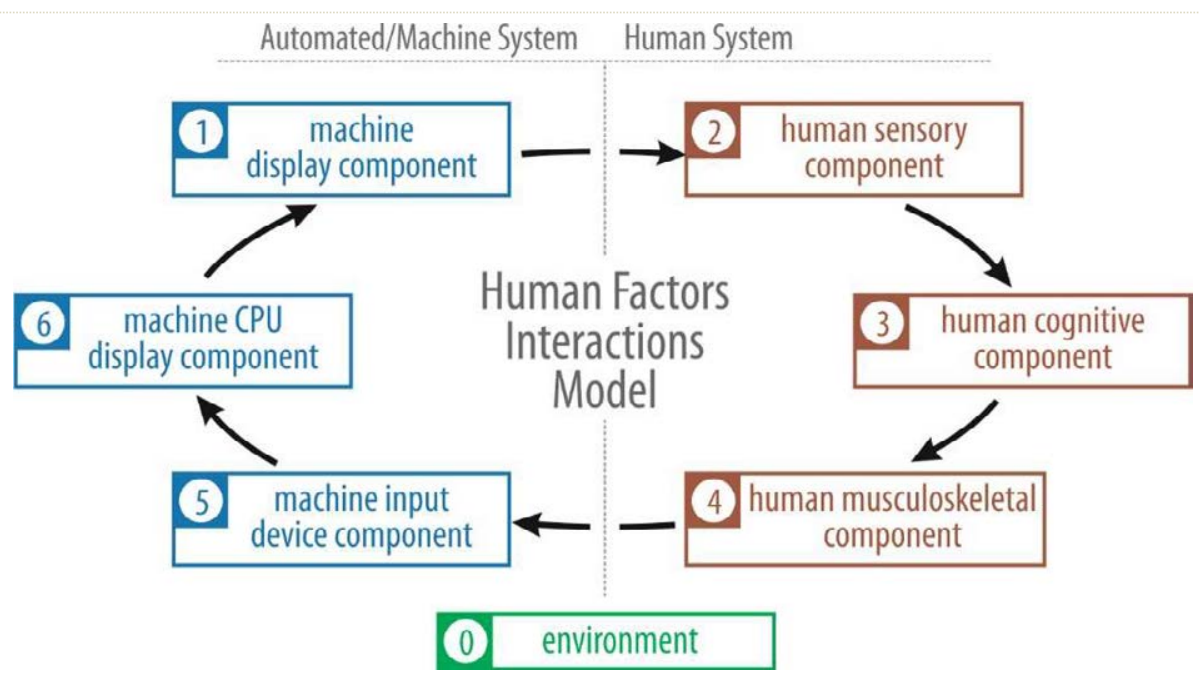

Figura 4-7: Modelo de interacción de factores humanos de Meister (1971) adaptado para funciones de formación en la FAA (figura propia a partir de (R. R. Gray et al., 2007)).

En la [Tabla 4-1] se desgranan, para cada componente identificado, los factores generales implicados en el sistema.

\begin{tabular}{|ll|}
\hline Componentes & Factores implicados \\
\hline [0] - Ambiente & lluminación, nivel de ruido, calidad del aire, vibración, clima. \\
\hline $\begin{array}{l}\text { [1] - Componente de salida de } \\
\text { 'la máquina' }\end{array}$ & $\begin{array}{l}\text { Suministra la respuesta: [a] Visual, [b] auditiva, [c] táctil... } \\
\text { Consultas iniciales. }\end{array}$ \\
\hline $\begin{array}{l}\text { [2] - Componente sensorial hu- } \\
\text { mano }\end{array}$ & Visión, oído, tacto, olfato, gusto. \\
\hline $\begin{array}{l}\text { [3] - Componente cognitivo } \\
\text { humano }\end{array}$ & $\begin{array}{l}\text { Atención, memoria de corto y largo plazo, procesamiento de la infor- } \\
\text { mación, toma de decisiones, inicio de la acción. }\end{array}$ \\
\hline $\begin{array}{l}\text { [4] - Componente musculo-es- } \\
\text { quelético humano }\end{array}$ & $\begin{array}{l}\text { Coordinación motora, desempeño de la acción, manipulación de } \\
\text { objetos. }\end{array}$ \\
\hline $\begin{array}{l}\text { [5] - Componente de disposi- } \\
\text { tivo de entrada de 'la máquina' }\end{array}$ & $\begin{array}{l}\text { Receptor de datos a través de: [a] sensores, [b] controles, interrupto- } \\
\text { nocimiento de voz. }\end{array}$ \\
\hline
\end{tabular}


[6] - Componente CPU de 'la maquina'
Procesos de datos: programación, procedimientos, almacenado de datos, recuperación de datos, transmisión de la respuesta.

Tabla 4-1: Componentes y factores implicados en el modelo adaptado de Meister (1971) (R. R. Gray et al., 2007).

Tomando en consideración los contenedores o formatos de información geo-aeronáutica evaluados en 2.5.5 -Los formatos-, se comprueba que el proceso de comunicación cartográfica está presente en todos los componentes del sistema presentado. De esta manera los autores, desde el punto de vista particular de los sistemas electrónicos de visualización de datos, formulan una serie de factores y consideraciones deducidos a través del modelo modificado de Meister. Desde la óptica de nuestra investigación estos factores, que son presentados en 9.4.1 - Factores humanos de interés desde el punto de vista de los sistemas electrónicos de visualización de datos, deben ser indispensablemente tomados en cuenta en el diseño y aplicación de la comunicación cartográfica a través de los formatos de soporte electrónico ya analizados tales como los displays de navegación (ND) y las cartas aeronáuticas digitales.

Por el contrario, y teniendo en cuenta las restricciones metodológicas de la tesis que fueron enunciadas en 3.3.2 -Las restricciones aplicadas a la investigación-, si nos referirnos exclusivamente al tercero de los formatos evaluados -el formato papel-, comprobamos la existencia de un problema conceptual: la carta en papel, una vez trazada e impresa, no es una máquina con la que el ser humano pueda interactuar completamente, es decir, de forma totalmente biunívoca. Tampoco los autores parecen hacer mención expresa a esta circunstancia -ni para el caso específico de la cartografía aeronáutica ni para casos análogos como el de la documentación en papel, como listas de chequeo en cabina, etc.-.

Pese a esta circunstancia, una carta en papel puede considerarse formalmente un sistema de comunicación, ya que presenta todos los elementos necesarios para que sea considerada así -emisor, receptor, lenguaje o protocolo de transmisión, mensaje y canal o medio- (Galeano, 1998; McLuhan y Fiore, 1988; Shannon, 1948), por lo que debería ser posible analizar este formato a través del modelo de la FAA -aunque sea con ciertas limitaciones. Por todo lo anterior, en este punto de la investigación planteamos tratar de caracterizar a una carta aeronáutica en papel como un sistema de comunicación perteneciente al 'lado de la máquina', aunque desde el punto de vista práctico no lo sea.

Bajo este enfoque metodológico, en la [Tabla 4-2] se identifican y aportan algunos de la relaciones y factores de interés que, en el proceso de lectura cartográfica, proponemos que sean consideradas dentro del modelo de formación de la FAA, si así fuese particularizado para nuestro campo concreto de estudio. 


\begin{tabular}{|c|c|}
\hline Componentes & Factores y/o relaciones de interés \\
\hline [0] - Ambiente & $\begin{array}{l}\text { 1. Gama e intensidad de iluminación general en cabina. } \\
\text { 2. Fuentes de reflejos de luz. } \\
\text { 3. Intensidad y frecuencia del movimiento típica de las vibraciones causadas por } \\
\text { turbulencias. } \\
\text { 4. Calidad del aire y temperatura en el puesto de mando. }\end{array}$ \\
\hline $\begin{array}{l}\text { [1] - Componente } \\
\text { de salida de 'la } \\
\text { máquina' }\end{array}$ & $\begin{array}{l}\text { 1. Tamaño de la ficha o carta. } \\
\text { 2. Densidad y semiótica del sistema de signos y textos desplegado. } \\
\text { 3. Impresión en B/N o en color. } \\
\text { 4. Método y calidad de la impresión de las tintas. } \\
\text { 5. Pliegues, dobleces, textura del papel, etc. }\end{array}$ \\
\hline
\end{tabular}

[2] - Componente 1. A través de la visión -con la que se percibe radiación electromagnética de longitusensorial humano des específicas- se adquiere la información codificada en forma gráfica.

2. A través del tacto se recibe, en el caso de turbulencias, la sensación de movimiento.

[3] - Componente 1. El piloto centra su atención cognitiva en el proceso de orientación.

cognitivo hu- $\quad 2$. Recuerda cómo interpretar una carta y orientarse a través de ella -memoria a mano largo plazo-.

3. Extrae y memoriza datos concretos para el procedimiento a ejecutar-memoria a corto plazo-.

4. En el caso de una visión borrosa, evalúa la distancia al documento. En el caso de una visión movida, evalúa la intensidad y frecuencia de las vibraciones. En el caso de reflejos de luz sobre la carta, evalúa su intensidad y procedencia.

5. Procesa la información portada por el mensaje cartográfico.

6. Decide sobre la acción o acciones a tomar.

7. Ordena la acción motriz -respuesta- sobre los mandos del avión para realizar el procedimiento de vuelo, sobre la propia carta para iterar la búsqueda de información o bien para aplicar medidas correctoras -distancia, reflejos, vibraciones-, etc.

\section{[4] - Componente 1. El piloto sostiene la carta frente a él.}

musculoesquelé- $\quad$ 2. Cambia el punto central de la visión para buscar e interpretar otros datos.

tico humano 3. Modifica la distancia, el ángulo de visión y aplica pequeños movimientos a la carta, para tratar mejorar la nitidez de los gráficos más pequeños, evitar la incidencia directa de luz parásita, y compensar el temblor propio de las vibraciones y turbulencias, respectivamente.

4. Realiza anotaciones a mano sobre la carta. 


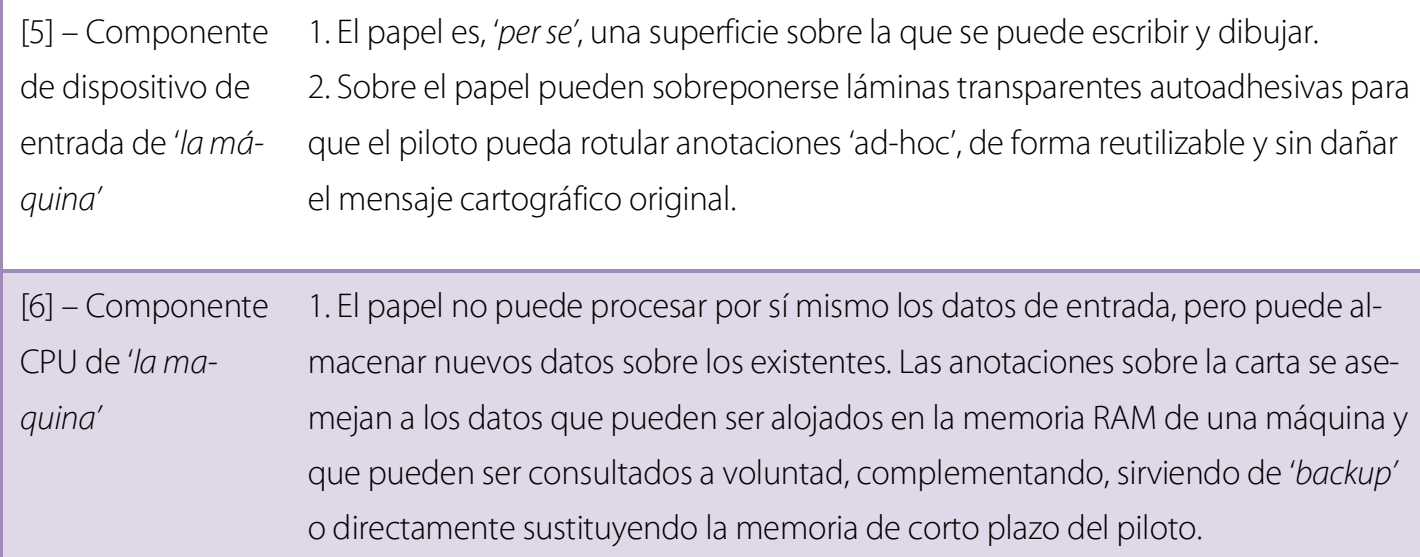

[6] - Componente 1. El papel no puede procesar por sí mismo los datos de entrada, pero puede alCPU de 'la ma- macenar nuevos datos sobre los existentes. Las anotaciones sobre la carta se asequina' mejan a los datos que pueden ser alojados en la memoria RAM de una máquina y que pueden ser consultados a voluntad, complementando, sirviendo de 'backup' o directamente sustituyendo la memoria de corto plazo del piloto.

Tabla 4-2: Componentes y factores implicados en la interacción de un piloto con una carta aeronáutica en formato papel (elaboración propia).

Al objeto de nuestra investigación, son de nuestro interés los componentes sensorial y cognitivo humano, respectivamente. Por ello, en 9.4.2 -Conceptos fundamentales de factores humanos aplicados a la representación visual- se extraen del programa de formación de la FAA y se declaran determinados conceptos, nociones y consideraciones prácticas de factores humanos que pueden ser de aplicación directa en los ensayos de percepción visual que serán realizados a posteriori.

\subsubsection{Listado de conceptos de eficiencia comunicacional}

A continuación se lista una síntesis de los conceptos seleccionados, en orden a facilitar su uso como parte de los requisitos de mejora para la optimización, desde el punto de vista de los factores humanos, de cualquier tipo de modelo cartográfico.

- Existe una enorme variabilidad en la visión humana, debido a casusas genéticas, lesiones, enfermedades y factores de edad.

- El sistema de visión humano se rige por percepción de cantidades relativas de luz, mediante la comparación de áreas, objetos y cambios en la luz ambiental. En fotometría, los términos relacionados con la percepción humana son el brillo -percepción de la luz proveniente de una fuente propia- y la luminosidad -percepción de la luz reflejada-. Cuanto mayor sea el contraste de luminosidad, mayor será para el sistema de visión humano la legibilidad del mensaje gráfico. 
- En el ojo las diferentes longitudes de onda se refractan de forma distinta, por lo que en la percepción se tienden a crear efectos estereoscópicos cuando se combinan determinados colores. Por este motivo, en la comunicación visual deben evitarse -entre otras- combinaciones superpuestas de azul y rojo, además del uso del azul puro en textos, líneas y símbolos sobre fondos negros.

- En las cartas impresas en papel, el sistema de color que debe ser considerado es de tipo sustractivo: el papel blanco es la luz, difiriendo en claridad u obscuridad las tintas dispuestas sobre ella.

- El sistema de visión humano se muestra más hábil distinguiendo tonos cromáticos que valores de gris. Además, el color es una variable visual que se procesa de forma temprana en el cerebro.

- El color puede ser descrito en términos de sus tres componentes: tono -término identificador-, valorcantidad de luz reflejada-y saturación -pureza o intensidad del color-. Existe un conjunto de 12 tonos básicos ampliamente aceptados: blanco, negro, rojo, verde, amarillo, azul, marrón, rosa, naranja y gris. Se añade el cyan para considerar su uso en pantallas electrónicas.

- Aunque el ojo humano puede diferenciar entre 8 y 12 millones de colores, el sistema visual humano, al funcionar por comparación, presenta limitaciones para identificar colores particulares de forma aislada. Para codificar información que debe ser leída rápidamente, el número de colores a utilizar debe limitarse a entre 5 y 10 . Se recomienda tan sólo entre 4 y 5 si se quiere atender a usuarios que puedan presentar una deficiente visión del color.

- Con el uso correcto del color se puede hacer destacar uno o varios elementos gráficos, o bien agruparlos, identificar patrones o distinguir áreas. Por el contrario, un uso incorrecto puede generar escenarios de confusión y errores.

- Aunque el color es un potente elemento de codificación, se recomienda utilizar otros mecanismos redundantes, en especial la forma; con ello se refuerzan determinados procesos de atención y se da cabida a usuarios cuya visión del color es deficiente. En el caso de pequeños símbolos, la redundancia es especialmente necesaria: incluso personas con visión normal pueden tener dificultades para distinguir algunos colores, en especial el azul en condiciones exigentes o la diferenciación entre el blanco y el amarillo.

- Existen formas simples y colores que son procesados y reconocidos por los sistemas de percepción con gran rapidez-procesos de atención temprana-, ya que son reconocidos de forma automática antes que la propia atención consciente. Si la información se codifica aprovechando esta característica se facilitará su rápida comprensión.

- Los elementos procesados tempranamente se basan en los principios de la Gestalt, que explican el origen de las percepciones a partir de los estímulos. Se reconocen un total de 13 reglas. Algunas de ellas son los principios de proximidad, continuidad, cierre y similitud. 
- Se considera que una característica es preatentiva -procesada automáticamente de forma tempranasi puede ser reconocida, dentro de un conjunto de elementos distractores, en menos de 10 milisegundos. La simetría, el color, el tamaño y la forma son algunas de ellas, pero cuando se combinan entre sí se debe de evitar la creación de condiciones de búsqueda combinada, para así no perder la ventaja de la atención temprana.

- En orden a incorporar texto de manera efectiva a una representación gráfica, deben de considerarse diversos atributos, como el contraste de luminosidad entre caracteres y fondo, el tamaño y forma de los caracteres y la selección de colores que se aplican al texto y al fondo. También toma importancia el espaciado de caracteres, palabras y líneas.

- La legibilidad de un texto es función del contraste y la cantidad de luz ambiental, pero también del tamaño de la fuente: los símbolos y textos de tamaño pequeño requieren más luminosidad y contraste para ser distinguidos correctamente. Por otra parte, un tamaño excesivo puede ser difícil de leer, lo que reduce su impacto.

- Para asegurar la legibilidad del texto, el tamaño óptimo de los caracteres dependerá de la posición del usuario en relación a la visualización, en términos de ángulo visual y distancia de visualización. Por ejemplo, estando la altura óptima de símbolos y caracteres entre 20 y 22 minutos de arco, con una altura de 18 la legibilidad comienza a disminuir; debe evitarse todo tamaño por debajo de 16.

- Un texto escrito en letras mayúsculas es más difícil de leer que el mismo escrito en minúsculas. Estas últimas, al ser más distintivas entre sí, ayudan a la percepción a través de la variable forma. La combinación de mayúsculas y minúsculas aumenta la velocidad de lectura y reduce el tiempo de búsqueda. La tipografía cursiva está especialmente contraindicada en las pantallas digitales, por su peor resolución.

- Las representaciones pictóricas o gráficas, con respecto al texto, reducen la necesidad de leer y analizar. Símbolos e iconos debe basarse en conceptos familiares, de manera que cualquier usuario pueda deducir con facilidad su significado.

\subsection{ERGONOMÍA DE LA COMUNICACIÓN VISUAL}

En el contexto de esta tesis doctoral el concepto de comunicación se define, según el Diccionario de la Real Academia Española, como la transmisión de señales mediante un código común al emisor y al receptor (RAE, 2001). Asimismo, y como se declaró en 3.2 -Grafismo de la información aeronáutica-, la función básica de las cartas aeronáuticas es la comunicación de información espacial geográfica y aeronáutica a través de la expresión gráfica, simplificando la realidad por medio de distintos convencionalismos gráficos. 


\subsubsection{La comunicación y la ergonomía cognitiva}

La comunicación está intrínsecamente relacionada con los dominios de la ergonomía y los factores humanos $^{179}$, que a su vez se reconocen como disciplinas científicas que abordan el entendimiento de las interacciones entre los seres humanos y otros elementos de un sistema (IEA, 2015). El ideario de la ergonomía es hacer compatibles esos elementos con las necesidades, capacidades y limitaciones de las personas.

Ergonomía y comunicabilidad son procesadas y evaluadas por otro campo profesional que corresponde a la ergonomía cognitiva (Correa, 2010), definida como la disciplina científica que estudia los aspectos conductuales y cognitivos de la relación entre el hombre y los elementos físicos y sociales del ambiente, cuando esta relación está mediada por el uso de artefactos (Cañas y Waerns, 2001; Salmerón, Fajardo, y Cañas, 2004). Con respecto al uso de estos artilugios, según Wickens, Lee, Liu, y Gordon-Becker (2003) los dispositivos de presentación de información -displays en su acepción inglesa- son típicamente definidos como artefactos hechos por el hombre diseñados para apoyar la percepción de variables relevantes del sistema y facilitar el ulterior procesamiento de la información.

El sistema cognitivo humano posee unos recursos de procesamiento limitados, que deben ser distribuidos entre los diferentes componentes del sistema cognitivo de procesamiento (Perurena y Moráguez, 2013), por lo que la ergonomía cognitiva se centra así en especificar y ofrecer recomendaciones de adaptación del diseño de soportes de información -entre ellos las construcciones visuales- a ciertas características del usuario tales como los procesos de input perceptivo -detección, clasificación, reconocimiento de patrones, etc.-, el procesamiento cognitivo central -memoria, razonamiento, resolución de problemas, etc.-, y los procesos perceptivo-motores, estos últimos relacionados con los sistemas de respuesta y ejecución (Romero, 2006).

\subsubsection{La incertidumbre gramatical de la imagen}

La sintaxis de la imagen ${ }^{180}$ es, en el proceso de composición de la comunicación visual, el paso más importante en la resolución del problema visual (Filippis, 2007). En el contexto de la alfabetidad visual ${ }^{181}$, sintaxis significa la disposición ordenada de partes o elementos que componen el lenguaje visual (Dondis, 1985). Dondis Ilega

${ }^{179}$ Según Cañas and Waerns (2001), el término ergonomía se ha usado intercambiándolo con el término de factores humanos por razones históricas y geográficas: mientras que factores humanos era el nombre que se le daba a esta disciplina en Estados Unidos, ergonomía fue el nombre que se le dio en Europa. Sin embargo, actualmente podemos considerarlos como sinónimos.

${ }^{180}$ En gramática, la sintaxis es la parte que enseña a coordinar y unir las palabras para formar las oraciones y expresar conceptos. (RAE, 2001).

${ }^{181}$ La alfabetidad significa que todos los miembros de un grupo comparten el significado asignado a un cuerpo común de información (Pérez-Bermúdez, 2000). 
a definir uno a uno estos elementos visuales: punto, línea, contorno, color, textura, escala, dimensión y movimiento. No existe un consenso generalizado sobre cuáles son los elementos constitutivos de la imagen y del alfabeto visual; autores como Bamford (2003) proponen considerar la sintaxis visual de un modo más amplio, e incluyen un mayor número de elementos como: la luz y las sombras, la composición, el movimiento, la profundidad, el color, la perspectiva, la línea, los contornos, el tono, la escala, el tamaño relativo, la armonía, el contraste, el énfasis el ritmo, la simplificación, la metáfora o el fondo. En todo caso, aun definidos los elementos del alfabeto visual sigue en pie el problema de cómo abordar el proceso de composición con inteligencia y saber cómo afectarán las decisiones compositivas al resultado final (Dondis, 1985).

Dondis (1985) afirmó que el modo visual no describe sistemas estructurales absolutos, por lo que en medios complejos visuales existe la incertidumbre de lograr un significado compartido entre el emisor y el receptor del mensaje. En el lenguaje oral y escrito, la sintaxis significa la disposición ordenada de palabras en una forma y una ordenación apropiadas: se definen unas reglas y lo único que hemos de hacer es aprenderlas y usarlas inteligentemente (Dondis, 1985). Pero en el contexto de la alfabetización visual no existen reglas absolutas, sino cierto grado de comprensión de lo que ocurrirá en términos de significado, si disponemos las partes de la visualización de determinada forma para obtener una organización y una orquestación de los medios visuales (Filippis, 2007).

Los resultados de las decisiones compositivas marcan el propósito y el significado de la declaración visual, pero además tienen fuertes implicaciones sobre lo que recibe el usuario (Bamford, 2003). En consecuencia, los componentes visuales que participan en la comunicación cartográfica deben concatenarse de forma coherente y adecuada, en orden a facilitar una óptima velocidad de lectura e interpretación del mensaje. La clave está en conducir de forma planificada - a través de una combinación visual convenida por el comunicador- el estímulo o estímulos apropiados en la percepción ${ }^{182}$ que provoquen al lector reacciones cognitivas esperadas (Cañas y Waerns, 2001) que, a su vez, puedan dotar al mensaje de una mayor y más efectiva fuerza interpretativa.

Trasladando el concepto de incertidumbre gramatical de la imagen a la línea metodológica de la tesis doctoral, podemos concluir lo siguiente: una vez acopiada en la investigación el entendimiento de las fortalezas y limitaciones humanas del procesamiento de la representación visual -ver 4.1.4 Listado de conceptos de eficiencia comunicacional-, así como identificados los componentes visuales que participan en la comunicación cartográfica, gozamos de la capacidad de formular combinaciones visuales que provoquen reacciones cognitivas más nítidas y eficientes que las de partida. Esta aseveración se alinearía finalmente con la hipótesis planteada en la tesis-ver 1.2.1 Hipótesis-, puesto que propone por una parte la existencia de interferencias en la percepción provocadas por un ajuste no adecuado de la formulación gráfica para cada nivel de significado, y por otra una

${ }^{182}$ El estímulo pertenece al mundo exterior y produce un primer efecto o sensación en la cadena del conocimiento. Esta sensación es de orden cualitativo; es energía física, mecánica, térmica, química o electromagnética que excita 0 activa un receptor sensorial. Por el contrario, la percepción pertenece al mundo interior, al proceso psicológico de la interpretación y al conocimiento de las cosas y los hechos (Correa, 2010, 2011). 
mejora a través del ajuste de la manera en la que han sido combinadas las variables visuales en el modelo original.

Dado que siempre existirá un grado de incertidumbre a la hora de lograr un significado compartido entre el emisor y el receptor del mensaje, no se trataría tanto de alcanzar una serie de reglas absolutas, como de alcanzar un cierto grado de mejora con respecto a la eficiencia comunicacional del modelo de partida -ver 3.4 Evaluación y estereotipado de tendencias-. Quedaría entonces únicamente por despejar la incógnita de cuál sería la metodología apropiada para mensurar -de forma preferentemente cuantitativa- la mejora de las cualidades comunicacionales entre el modelo cartográfico de partida y el alcanzado, en términos de velocidad, claridad y cantidad de información que puede ser percibida y procesada con respecto al desempeño humano óptimo.

\subsection{EVALUACIÓN COMUNICACIONAL}

Desde un punto de vista cercano al de los sistemas de información electrónicos de uso masivo -sobre todo de tipo on-line y web-, se coloca el foco de atención en el adecuado diseño de la interacción, definiendo así los aspectos técnicos de uso de la aplicación y evaluando las consideraciones y principios estándares de uso de un sistema interactivo. Conocidos y de uso extendido para esta cuestión son las 10 heurísticas ${ }^{183}$ o principios básicos de usabilidad de Nielsen, propuestos por el propio autor para ser tenidos en cuenta en el momento de confeccionar un diseño de interacción (Marky Nielsen, 1995; Nielsen, 1994). En cambio la comunicabilidad se acerca más al campo concreto del desarrollo del diseño de la información, área disciplinar que se centra en trabajar en la forma de articular el texto y la información con la imagen (Correa, 2010).

\subsubsection{Las metodologías de evaluación de los sistemas de comunicación}

Según la clasificación de Hom (1998), la evaluación heurística de Nielsen está integrada -junto con otras treinta identificadas por el autor- en los denominados métodos de evaluación, los cuales permiten obtener una idea del estado de los sistemas de comunicación ${ }^{184}$ según la experiencia de usuario. El conjunto de métodos, técnicas o protocolos de evaluación pueden agruparse bajo tres epígrafes generales (Perurena y Moráguez, 2013), según su tipología:

a) Métodos de inspección. Emplea el trabajo de expertos cualificados para inspeccionar aspectos de del sistema a evaluar relacionados con la usabilidad, o la propia comunicabilidad.

${ }^{183}$ Una heurística es un conjunto de reglas metodológicas, no necesariamente formalizadas, que sugieren o establecen cómo proceder y qué problemas evitar a la hora de generar soluciones y elaborar hipótesis (Polya, 1945).

184 Usualmente programas, páginas Web, etc. pero también es aplicable a los sistemas de comunicación visual como la cartografía. 
b) Métodos de indagación. Consiste en conversar con los usuarios, mediante la formulación de preguntas, acerca de aspectos relacionados con el sistema, obteniendo así respuestas a preguntas formuladas verbalmente o por escrito mediante encuestas, cuestionarios o entrevistas.

c) Métodos de test. Se trata de que los usuarios trabajen en tareas concretas utilizando el sistema mientras los evaluadores realizan determinadas medidas de las prestaciones para valorar cómo el sistema da soporte a las tareas de los propios usuarios.

A la hora de afrontar la evaluación de la usabilidad o eficiencia comunicacional de un modelo cartográfico podemos acudir de igual forma a alguno de las diversas metodologías de evaluación de sistemas de comunicación existentes, usualmente métodos cualitativos (Eicher y Brewer, 2000). Es interesante en este punto examinar el uso de métodos de evaluación aplicados a la anteriormente citada -ver introducción a 4. La eficiencia comunicacional- comparativa de los planos esquemáticos de Juan de la Mata y Rafael Sañudo [Figura 4-8]. Así, en la época de vigencia de la propuesta de Sañudo se dieron tanto métodos de inspección de expertos (De Córdoba, 2011; Muñoz Román, 2007) como de indagación mediante pensamiento manifestado en voz alta (ADN, 2007; ElPaís, 2007).

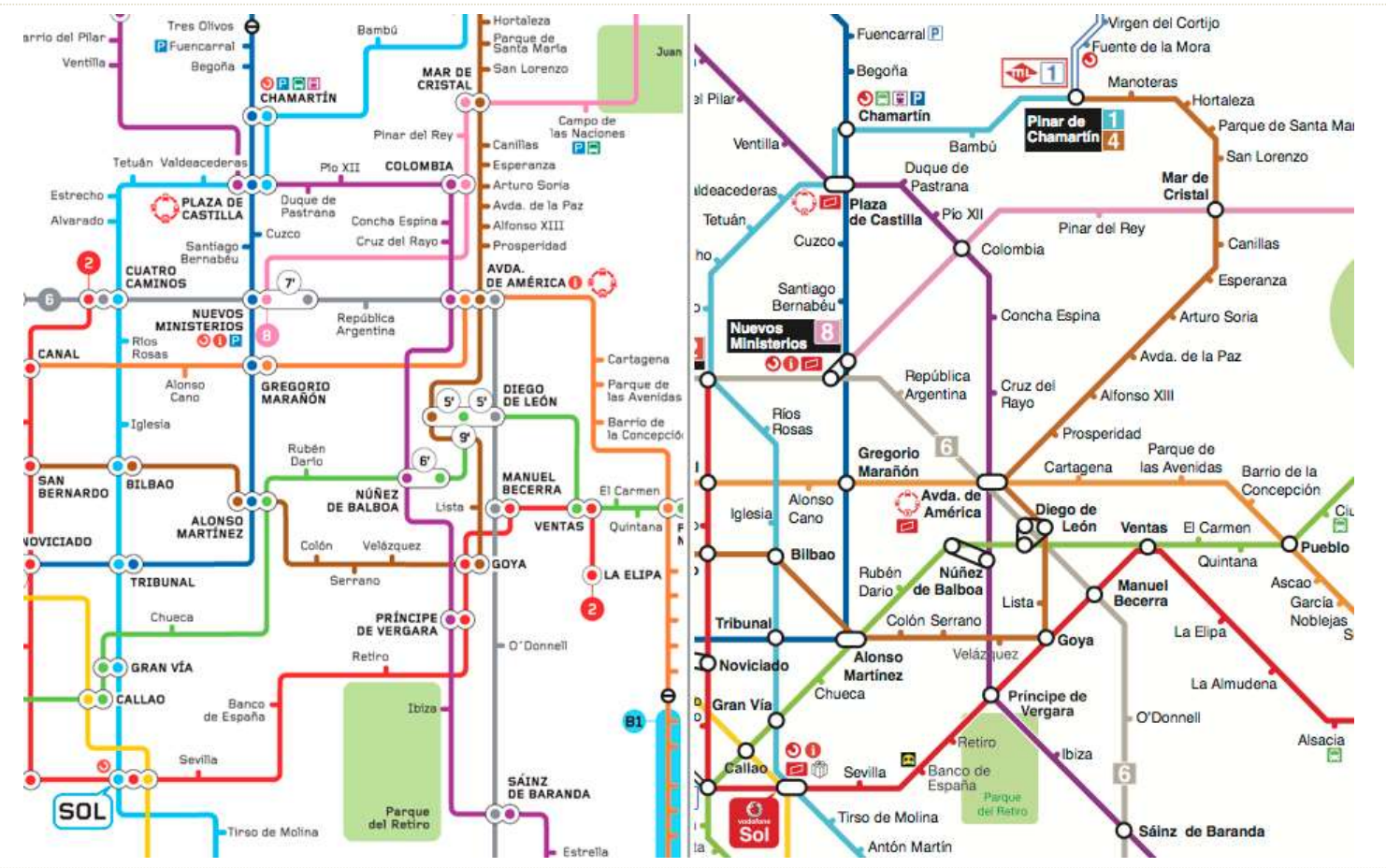

Figura 4-8: Comparativa parcial del plano esquemático del Metro de Madrid. Izquierda plano oficial de Rafael Sañudo (2007-2013) y derecha plano oficial actual (2013-2015), basado en el diseño clásico de Alberto Corazón (Madrid, 2015). 
De igual manera en esta tesis doctoral también se han aplicado distintas metodologías de evaluación para resolver las diferentes preguntas de investigación. Por ejemplo, para resolver la caracterización del uso práctico de la información aeronáutica por parte de los pilotos civiles -ver 2.6 Caracterización del uso práctico de la información- se ha optado por realizar una evaluación de tipo indagatoria, trasladando a usuarios habituales del sistema -pilotos- diferentes cuestiones acerca de las relaciones generales con los formatos de información, representación e interpretación, condicionantes ambientales, etc. Por el contrario, para resolver la evaluación y estereotipado de tendencias simbólicas de la cartografía mundial -ver 3.4 Evaluación y estereotipado de tendencias-, se ha optado por una metodología de inspección mediante listas de comprobación, sin participación alguna de usuarios.

Para nuestra propia elección de una metodología de evaluación de la eficiencia de modelos cartográficos descartaremos los métodos de pensamiento manifestado ${ }^{185}$-think aloud- de usuarios; aunque sus comportamientos y comentarios en el uso del sistema a evaluar contribuye a veces al análisis del problema, sus expresiones acostumbran a ser ambiguas, poco concretas o incluso diferir en ciertos aspectos de sus pensamientos (Ericsson, 1993). Del mismo modo, también nos alejaremos los métodos de inspección, puesto que hemos planteado abordar aspectos de la ergonomía cognitiva y de la provocación tanto de estímulos como de respuestas a los mismos. Si bien la inspección sistemática por parte de expertos semiólogos y de factores humanos puede acercarnos a nuestro propósito, las técnicas tradicionales de evaluación no permiten mensurar de forma empírica y cuantificable factores como la velocidad de lectura, qué elementos atraen la atención visual con más fuerza o el papel que pueden jugar determinados elementos distractores, entre otros.

Dentro de los métodos de test, han ido apareciendo a lo largo del tiempo diversas técnicas y tecnologías que tratan de extraer conclusiones evaluativas con un menor grado de incertidumbre. Una de ellas es la del seguimiento de ojos o 'eye-tracking'.

\subsubsection{La atención visual y el seguimiento de ojos}

El concepto de seguimiento de ojos, o eye-tracking, hace referencia a un conjunto de tecnologías que permiten monitorizar y registrar la forma en la que una persona explora visualmente una determinada escena o imagen (Goldberg y Wichansky; Hom, 1998; Young y Sheena, 1975), en concreto en qué áreas fija su atención, durante cuánto tiempo y qué orden sigue en su exploración visual (Hassan y Herrero, 2007; Hassan y Ortega, 2009).

${ }^{185}$ Los test de usuario de pensamiento manifestado o en voz alta -think aloud- tradicionales, en los que se le plantea una tarea a un usuario y se le invita a pensar en voz alta, son muy útiles para detectar muchos de los problemas de usabilidad de un sistema de información (Nielsen y Landauer, 1993). Una vez detectados, un experto puede analizar las causas y proponer una o varias soluciones para resolverlos. 
Como señala en su trabajo Jacob (1991), el estudio del movimiento ocular comenzó a finales del siglo XIX ${ }^{186}$, aunque es a partir de la década de los 70 del siglo XX cuando la investigación acerca del movimiento ocular se expandió rápidamente, en particular la asociada al estudio de la lectura de documentos (Rayner, 1998; Young y Sheena, 1975). Actualmente la tecnología de eye-tracking está reservada principalmente a tareas de investigación y de desarrollo de productos, aunque se espera que su rápida evolución la permita llegar a convertirse en interfaz de uso cotidiano en dispositivos de consumo (Villanueva, 2010).

Cuando el ser humano observa una escena cualquiera, sus ojos se mueven entre los distintos puntos que llaman su atención, recreando con la suma de ellos una imagen cerebral de la escena (Nielsen y Pernice, 2009). Al respecto, el sistema de eye-tracking puede proporcionar la evidencia objetiva y cuantitativa de los procesos relacionados con la visión y la percepción, midiendo el movimiento de los ojos y la atención al realizar otra tarea independiente.

Aunque existen diversos modelos que estudian los movimientos oculares complejos, para investigaciones realizadas mediante tecnologías de eye-tracking es suficiente (Villanueva, 2010) con modelar el movimiento mediante dos conceptos: fijación y movimientos sacádicos. Nielsen y Pernice (2009) definen de forma sucinta la fijación como el momento en el que los ojos permanecen fijos sobre un objeto de forma apreciable, y los movimientos sacádicos como los movimientos oculares que, de forma rápida, se producen entre dos fijaciones. En cada fijación precisa se transmite información al cerebro a través del nervio óptico. En el intervalo entre fijaciones, y al ser el movimiento sacádico muy rápido, el cerebro obvia en gran parte la modulación de información a través del nervio óptico para mostrar una imagen más nítida. La suma continuada de interrupciones de la percepción -asumiendo una media de 3 por segundo- puede llegar a representar alrededor de 90 minutos al día (Irwin, 2003). Pese a ello, se produce lo que se llama enmascaramiento sacádico (Ibbotson, Crowder, Shaun, Price, y Mustari, 2008), fenómeno que impide que se tenga la sensación que momentáneamente se ha interrumpido la trasmisión de información al cerebro ${ }^{187} 188$.

Según Duchowski (2007), dependiendo del tipo de sistema o tarea visual sometida a análisis se pueden distinguir dos vertientes de aplicación de sistemas de eye-tracking: aquella que sirve para interactuar con un sistema electrónico u ordenador-modo activo-y la vertiente de tipo diagnóstico destinada al estudio de la observación

${ }^{186}$ Sin embargo, la primera metodología objetiva de medición de movimiento de ojos utilizando la reflexión corneal es datada en el año 1901 (D. A. Robinson, 1968).

${ }^{187}$ Erdmann and Dodge (1898) demostraron que una persona es incapaz de ver ante un espejo el movimiento de sus propios ojos, sin embargo otra persona sí puede distinguir nítidamente el movimiento.

${ }^{188}$ En la novela titulada 'el curioso incidente del perro a medianoche' (Haddon, 2004), se describe un experimento consistente en leer un texto en una pantalla de ordenador. Si el ordenador detectaba un movimiento sacádico, a través de una cámara, cambiaba el texto de modo que la persona no lo veía realmente, pero sabía que algo extraño había pasado. Los participantes aseguraban que parecía que había cambiado la realidad ante sus ojos. 
-modo pasivo-. La aplicación del eye-tracking al estudio de un mapa o plano cartográfico, o de una composición visual en general, se adecuaría a esta segunda vertiente.

La mayoría de sistemas de eye-tracking se basan en el uso de cámaras que proyectan rayos infrarrojos hacia uno o los dos ojos del participante, infiriendo la zona de la escena visual que el usuario se encuentra atendiendo en cada momento (Duchowski, 2007; Hassan y Herrero, 2007; Hassan, Herrero, y Guerrero, 2010).

Existe una variada gama de dispositivos de este tipo. Su adecuación metodológica depende del propósito de la evaluación. La clasificación más sencilla de dispositivos distingue entre los que son invasivos -los que físicamente entran en con el usuario como lentillas, gafas, cascos, etc.- y los que no. Duchowski (2007) amplía esta clasificación e identifica cuatro categorías de sistemas de seguimiento de ojos: electro-oculografía (EOG) ${ }^{189}$, lentes de contacto / bobinas de búsqueda ${ }^{190}$, foto-oculografía (FOG) o video-oculografía (VOG) ${ }^{191}$, y reflejo de córnea y pupila basada en vídeo ${ }^{192}$.

Esta última es la técnica de seguimiento de ojos moderna más usada en la actualidad (L. González y Velásquez, 2012). El sistema se materializa en un simple ordenador de escritorio al que se asocia un monitor y una cámara de visión infrarroja -usualmente montada debajo del mismo- que hace rebotar sobre la cara del usuario un haz invisible de infrarrojos tipo LED ${ }^{193}$. Un software específico de procesamiento de imágenes localiza e identifica en tiempo real (Poole y Ball, 2005) tanto el reflejo de la córnea -que en el espectro infrarrojo aparece como un disco brillantey bien definido- como el centro de la pupila -mostrado como un pequeño, pero intenso brillo- [Figura 4-9]. A su vez, el propio software calcula mediante trigonometría el lugar hacia donde mira el usuario, identificando la intersección entre la dirección de la vista -virtualmente una línea recta-y el plano del monitor asociado al ordenador (Batista, 2004; Nielsen y Pernice, 2009). A través del uso de esta técnica no intrusiva, es posible

${ }^{189}$ Consiste en la medida de diferencias de potencial eléctrico sobre la piel detectadas por una serie de electrodos colocados alrededor del ojo. Todavía en uso, fue una de las técnicas más utilizadas alrededor de 1970 (Duchowski, 2007).

190 Se fundamente en el contacto físico con el ojo a través de un mecanismo basado en lentes de contacto, sobre la cual se asigna un objeto de referencia mecánico u óptico, como por ejemplo bobinas inductoras (Duchowski, 2007).

191 Esta categoría agrupa una amplia variedad de técnicas que incorporan cámaras o dispositivos de adquisición de imágenes para tratar de determinar el movimiento de los ojos midiendo determinadas características distinguibles -como el centro de la pupila, el contorno del iris o las reflexiones de la córnea- utilizando a posteriori las imágenes obtenidas por estos dispositivos (Duchowski, 2007).

192 Este sistema emplea una técnica de reflexión luminosa corneal denominada Pupil-Centre Corneal Reflection method (PCCR) (Nakazawa y Nitschke, 2012) para establecer un registro continuo de la posición de la mirada del usuario.

${ }^{193}$ La longitud de onda se refleja mucho mejor en la retina que en el resto del ojo, dado que la retina absorbe la luz visible pero refleja la infrarroja. Esto ayuda al dispositivo de eye-tracking a identificar la posición de las pupilas sin demasiado esfuerzo (Nielsen y Pernice, 2009). 
disociar los movimientos oculares de la cabeza, con lo que es posible calcular el punto de atención de los usuarios (Poole y Ball, 2005).
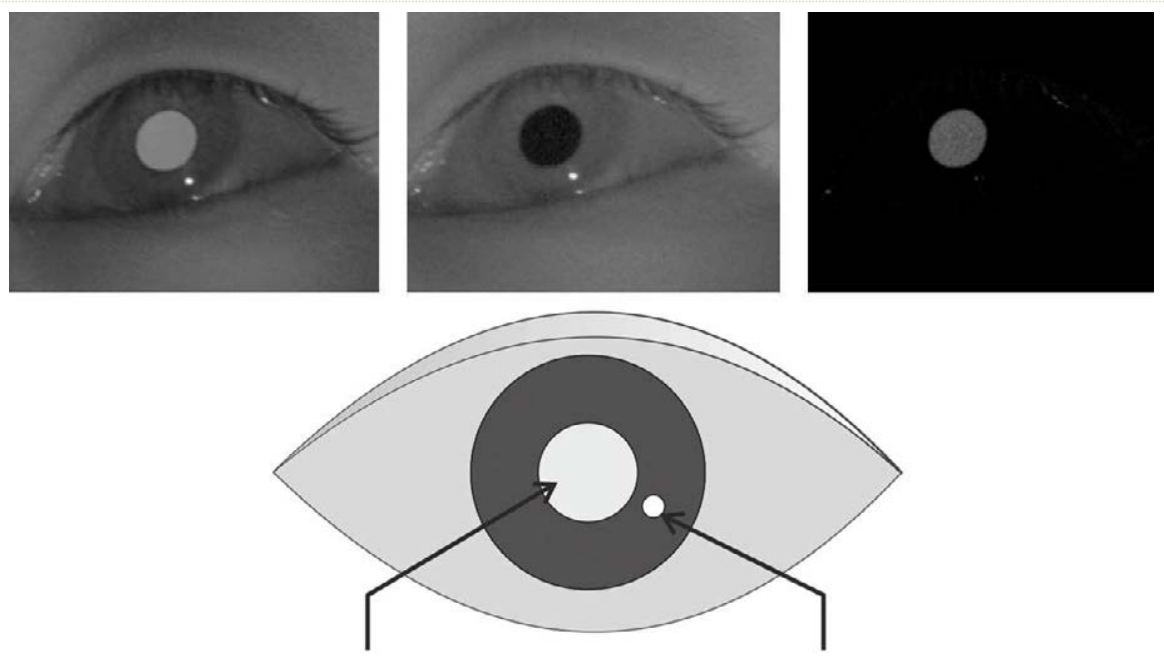

Brillo de la pupila

Reflejo de la córnea

Figura 4-9: Técnica de pupila brillante con infrarrojos - arriba, izquierda-, técnica de pupila oscura ${ }^{194}$-arriba, centroy segmentación de la imagen -arriba, derecha- para la determinación del centro de la córnea y reflejo de la pupila abajo, centro- (Meunier, 2009).

Con respecto al fenómeno de la atención visual, en términos generales podemos distinguir entre la visión foveal ${ }^{195}$-que afecta a una pequeña zona del campo visual y que presenta la mayor agudeza visual posible para el ser humano- y la visión periférica -el resto del campo visual, y que presenta unas propiedades de resolución mucho más reducidas-. De un modo muy simple, al observar una escena a través de la visión periférica, pueden comenzar a detectarse determinadas características preatentivas ${ }^{196}$-ver 4.1.4 Listado de conceptos de eficiencia comunicacional y 9.4.2 Conceptos fundamentales de factores humanos aplicados a la representación visual-. Pese a

${ }^{194}$ La técnica de pupila oscura, alternativa a la de infrarrojos, ilumina el ojo con una fuente situada fuera del eje de la cámara, siendo así la pupila la parte más oscura del ojo en la imagen (Meunier, 2009).

${ }^{195}$ La fóvea es el área de la retina donde se enfocan los rayos luminosos. Se encuentra especialmente capacitada para la percepción del color. Esta área permite, en la dirección donde se dirige la mirada, la visión más precisa de la que es capaz el sistema de visión humana. Su extensión comprende alrededor de $2^{\circ}$ del campo visual (Fairchild, 2013) y menos del $1 \%$ del tamaño de la retina, pero ocupa más del $50 \%$ de la corteza visual en el cerebro (Krantz, 2002).

${ }^{196}$ Schmidtmann, Logan, Kennedy, Gordon, and Loffler (2015) demostraron que la visión periférica posee una precisión algo mayor para detectar formas en la parte inferior del campo visual -zona en la que tenemos las manos, manejamos objetos y por la que nos pueden venir los peligros cuando caminamos-, aunque no encontraron diferencias para distinguir otras propiedades de la imagen. Los autores finalmente concluyen que distinguir con mayor 
que la atención está desconectada de la vista foveal, el sistema visual se posiciona rápidamente en la región en la que se ha detectado esas características, usualmente relacionadas con los principios de la Gestalt. Una vez la fóvea se alinea completamente con la zona concreta de interés, se produce la percepción en alta resolución.

Estas y otras teorías modernas del estudio de los movimientos oculares y la fijación visual se fundamentan en la hipótesis 'ojo-mente' (Just y Carpenter, 1976, 1980). Según esta hipótesis -técnicamente conocida como hipótesis de interpretación inmediata-, no existe una diferencia apreciable entre la información que es objeto de fijación visual y la información que se procesa; es decir, cuando un sujeto está visualizando un objeto dentro de una escena, también está pensando o elaborando información mental de ese objeto -procesamiento cognitivo- en la misma cantidad de tiempo que realiza una fijación ocular a través de la visión foveal. La hipótesis de Just y Carpenter implica que las grabaciones del movimiento ocular pueden proporcionar una traza dinámica de donde se dirige la atención de una persona en relación a una pantalla, mientras que otros aspectos oculares, como las fijaciones, pueden revelar la cantidad de procesamiento que se aplica a los objetos en el punto de mirada (Poole y Ball, 2005). Así, nuestra mirada -o atención visual explícita- se convierte en una ventana a través de la cual se puede explorar qué hay en el sistema cognitivo -mente- (Orenes, 2014).

Por todo lo anterior, la función del eye-tracking no es otra que determinar, sobre la rotación ocular, hacia dónde dirige la persona su visión central -fóvea-, y por tanto qué zona de la escena visual estará siendo percibida más nítidamente en cada momento (Jacob, 1995). Las métricas relevantes a utilizar en los estudios realizados con eye-tracking son inherentes a cada uno individualmente (Goldberg y Wichansky, 2002). Sin embargo, existe un conjunto de métricas comúnmente utilizado en una mayoría de ellos (Jacob y Karm, 2003; Poole y Ball, 2005). En concreto Jacob y Karm (2003), después de analizar un total de 20 estudios realizados con esta tecnología, agrupa las diferentes métricas en los cuatro conceptos más comunes:

- Fijación: una posición del ojo con respecto a la cabeza relativamente estable dentro de un umbral de dispersión -típicamente de 20-, durante una cierta duración mínima -típicamente de 100-200 milisegundos-, y con una velocidad por debajo de cierto umbral -típicamente entre 15-100 por segundo-.

- Duración de la mirada: duración acumulada y media de la localización espacial de una serie de fijaciones consecutivas dentro de un área de interés. Esta métrica usualmente agrupa un conjunto de varias fijaciones cercanas, y puede incluir los cortos espacios de tiempo de los movimientos sacádicos entre fijaciones. El final de la mirada lo marca la primera fijación fuera del área de interés.

- Recorrido: disposición espacial de una secuencia continúa de fijaciones.

precisión la forma de los objetos en la parte inferior del campo visual pudo ser una ventaja evolutiva que ha llegado hasta nosotros, pero que distinguir periféricamente más detalles tuvo demasiado coste y escasas ventajas como para incorporarse a nuestra evolución. 
- Área de interés: área de una pantalla o un entorno visual que es de interés ${ }^{197}$ para el equipo de investigación o de diseño.

A priori, estas métricas nos informan sobre dónde fija la atención el usuario, con qué intensidad y, complementariamente, qué otras zonas pasan desapercibidas. Sin embargo, esta información puede resultar por sí sola insuficiente para inferir por qué ocurre, por lo que la adopción de la hipótesis 'ojo-mente' trata de establecer, de alguna forma, un vínculo entre fijaciones y actividad cognitiva ${ }^{198}$.

Poole y Ball (2005), además de identificar en la literatura científica hasta 22 diferentes métricas derivadas de las 4 generales, asocia interpretaciones de otros autores acerca del significado de determinadas tendencias en los análisis. Hassan y Herrero (2007) indican algunas de ellas:

- Número total de fijaciones: un mayor número de fijaciones revela una menor eficiencia de la búsqueda, lo que puede indicar un problema en el esquema organizativo.

- Número de fijaciones sobre un área de interés: mayor número de fijaciones indica mayor importancia para el usuario.

- Duración de la mirada fija sobre un área de interés: mayor duración indica mayor dificultad para interpretar el contenido del área.

- Densidad espacial de las fijaciones: cuando las fijaciones se concentran en una zona más pequeña indica mayor eficiencia en la búsqueda visual, mientras que si son más dispersas sugieren que la búsqueda está resultando menos eficiente.

- Tiempo transcurrido hasta la primera fijación: cuanto menos tiempo transcurra hasta que el usuario se fije por primera vez en un área de interés, mayor será la capacidad de las propiedades gráficas del área para atraer la atención visual.

En el anexo 9.4.3 -Métricas de seguimiento ocular- se extraen y describen todas ellas, en orden a considerarlas para su aplicación directa en los ensayos de percepción visual que serán realizados a posteriori.

${ }^{197}$ Esta área es definida a priori siempre por el investigador, no por el participante.

${ }^{198}$ Aunque esta relación no es inquebrantable -no siempre atendemos a lo que estamos mirando- ni tampoco inmediata, resulta una relación suficientemente consistente como para extraer conclusiones objetivas sobre los procesos cognitivos que originan o desencadenan las fijaciones (L. González y Velásquez, 2012). 


\subsubsection{Evaluación cartográfica mediante técnicas de eye-tracking}

En el ámbito de las ciencias geográficas y la cartografía, el uso de la metodología de seguimiento de ojos se ha incrementado a partir de 2010 (Opach y Nossum, 2011) ) $^{199}$. Bajo este orden de cosas, existen numerosas referencias de autores que se sirven de las técnicas de eye-tracking para sus investigaciones. Los enfoques de los estudios realizados son diversos, aunque existe un nexo de unión común a todos ellos centrado en el análisis de la usabilidad de los mapas, en el sentido más amplio del término; no solo se abordan las cuestiones semánticas y de comunicabilidad, sino también los interfaces de usuario que implican a muchos de los sistemas de información geográfica actuales, como los geoportales Web.

Al respecto de esta última cuestión, los autores Goldberg y Kotval (1999) centraron su interés en evaluar la metodologías basadas en eye-tracking para validad, a su vez, la usabilidad y eficiencia de los interfaces de ordenador ${ }^{200}$. Argumentaban que, aun constando un amplio bagaje anterior de estudios acerca del seguimiento de ojos, existía una necesidad de mayor definición y evaluación de las métricas que hasta entonces se estaban aplicando. Posteriormente Çöltekin, Heil, Garlandini, y Fabrikant (2009) y Çöltekin, Fabrikant, y Lacayo (2010) avanzaron en el estudio sistemático ${ }^{201}$ de las estrategias visuales que caracterizan a los usuarios al utilizar interfaces altamente interactivas. En concreto, utilizando técnicas de seguimiento de ojos se quiso averiguar si la velocidad visual de los usuarios puede ser caracterizada por secuencias específicas de eventos de interacción en pantalla y, en consecuencia, si el estudio de las estrategias de los usuarios podría emplearse para mejorar en los interfaces el diseño de la interacción.

En el caso de la evaluación de modelos cartográficos, es posible realizar una distinción entre los estudios que tratan exclusivamente los estímulos como representaciones estáticas y aquellos que abordan los estímulos dinámicos -mapas animados y mapas multiescenario-, junto con los interfaces de aplicaciones asociados. Opach y Nossum (2011) disertaron acerca de la conveniencia de las tecnologías eye-tracking como metodología de evaluación para mapas animados como estímulo ${ }^{202}$, mientras que Ooms, Fabrikant, Çöltekin, y De Maeyer

${ }^{199}$ Opach and Nossum (2011) deducen que la razón principal para este incremento del interés por el uso del eyetracking es un mayor desarrollo del hardware y software de seguimiento ocular.

${ }^{200}$ Para aportar mayor conocimiento, pusieron a prueba 50 colecciones de interfaces de usuario mediante distintas agrupaciones de herramientas e iconos -implicando así interfaces buenos y malos-. Con la participación de 12 voluntarios, evaluaron la longitud de las secuencias de fijaciones y la duración del movimiento de sus ojos, deduciendo que no existían grandes diferencias en la interpretación de herramientas e iconos, pero sí en la efectividad de las búsquedas sobre cada uno de los grupos.

${ }^{201}$ Consiste en un enfoque de evaluación genérica que combina teoría y recogida dirigida de datos basados en un análisis de la similitud de secuencias (Çöltekin et al., 2010).

${ }^{202}$ Para ello llevaron a cabo un estudio con 10 participantes sobre dos cartografías, una que contenía animaciones semi-estáticas y otra con animaciones complejas. Los autores concluyeron con la validez como herramienta del eye-tracking, aunque recomendaron limitar la complejidad del estímulo en orden a facilitar el análisis. También 
(2014) explicaban que, por restricciones de la tecnología, a menudo los estudios sobre mapas interactivos ${ }^{203}$ se aproximan mediante animaciones predeterminadas, o bien cargando automáticamente una serie de imágenes estáticas que simulan la interactividad real; esto limita la inferencia de comportamientos o niveles de interactividad de los usuarios, que deben ser capaces de ejecutar tareas en los mapas interactivos como lo harían normalmente ${ }^{204}$.

Centrándonos exclusivamente en la evaluación de mapas estáticos, Brodersen, Andersen, y Weber (2002) evaluaron la usabilidad de los mapas topográficos a través de una combinación de metodologías: pensamiento manifestado -think aloud-, seguimiento ocular, seguimiento del movimiento de la cabeza, entrevistas estructuradas y análisis de vídeo de la conducta no verbal. En este caso, el eye-tracking era una metodología más en la combinación. A través de la participación de 10 voluntarios, examinaron la relación entre la complejidad percibida y el comportamiento cognitivo. Los autores concluyeron que los resultados eran prometedores para futuros estudios, en especial para evolucionar un software cuyo objetivo era permitir observar los movimientos oculares sincronizados con el habla.

Posteriormente es de destacar el trabajo de Popelka, Brychtova, y Brus (2012a), en el que se constata que, hasta entonces, las tecnologías y los métodos de seguimiento ocular no se utilizan plenamente en el ámbito de la información geográfica, a pesar de sus grandes posibilidades en la cartografía. En el caso de su aplicación para lograr una mejor composición gráfica, la dificultad radica precisamente en cómo definir conceptos como 'buena usabilidad', o 'buena composición'. Por ejemplo, si el usuario debe ser capaz de interpretar el contenido del mapa correctamente y con precisión, una correcta interpretación del mensaje cartográfico -pero que lleve demasiado tiempo en la lectura- no puede considerarse como un indicio de una elevada usabilidad del mapa. Desde un punto de vista a futuro, los autores esperan que la investigación cartográfica con métodos de seguimiento ocular contribuirán considerablemente a razonar y redactar, desde una base empírica un elevado número de normas e instrucciones para la creación de mapas, universalizando su lenguaje ${ }^{205}$.

En (Brychtova, Popelka, y Dobesova, 2012) se concretan las posibilidades del uso del eye-tracking en la evaluación de la percepción y facultades cognitivas del usuario, y también en la interpretación de los principios cartográficos. Se argumenta que, por su propia naturaleza, las normas cartográficas existentes en referencia a la composición, estructuración, optimización, etc. sufren un considerable grado de subjetividad, por lo que los

identificaron como limitación la relativa exactitud de las grabaciones y sobre todo los métodos de análisis asociados.

${ }^{203}$ En concreto, los autores citan los trabajos de S. Fabrikant, Rebich-Hespanha, Andrienko, Andrienko, and Montello (2008) y de 0oms, De Maeyer, Fack, Van Assche, and Witlox (2012).

${ }^{204}$ Por ejemplo, es usual que los usuarios realicen zoom y panning sobre los mapas digitales, lo que provoca que estas interacciones causen cambios en la extensión y el nivel de detalle del estímulo Ooms, Coltekin, et al. (2014).

${ }^{205}$ Adicionalmente, permitirá a los investigadores relacionados con la información geográfica alcancen mejores y más valiosos resultados en sus trabajos (Popelka et al., 2012a). 
cartógrafos deben evaluar los mapas de acuerdo a la percepción del usuario y sus facultades; esto implica un gran esfuerzo para objetivar los procesos de creación de los mapas. Subsiguientemente el uso del eye-tracking permite transponer los principios cartográficos a meras hipótesis, que pueden tratar de ser confirmadas mediante esta metodología ${ }^{206}$.

Todo lo anterior se ejemplifica un trabajo posterior (Vondrakova y Popelka, 2014) en el cual se describe de forma amplia e integral el uso de la tecnología de seguimiento ocular en el análisis de diversas tareas cartográficas, siempre desde el punto de vista de la eficiencia de la transferencia de información que el mapa provee al usuario. Así, se realizan diversos experimentos individuales relativos al uso de fuentes y etiquetas de texto, uso de colores, métodos de visualización, etc.

Una significativa muestra del incremento que ha experimentado el desarrollo del hardware de seguimiento de ojos es la reciente aparición de pequeños dispositivos low-cost que, basados en la reflexión luminosa corneal, facilita la innovación de la interactividad de dispositivos portátiles mediante el seguimiento visual, pero también facilita el acceso de este tipo de dispositivos a los investigadores. Al respecto, Popelka y Brychtova (2015) realizaron un estudio comparativo entre las capacidades del hardware profesional SMI Red 250 -de uso habitual en su laboratorio de seguimiento ocular ${ }^{207}$ para las investigaciones anteriormente reseñadas-, y el hardware de bajo coste EyeTribe, un sencillo dispositivo auspiciado en 2014 por una start-up tecnológica de la ITUniversity de Copenhague. Pese a que las características del hardware profesional son indudablemente superiores con respecto al dispositivo low- $\cos ^{208}$, las diferencias no impiden el uso del dispositivo de bajo coste para estudios generalistas [Figura 4-10].

${ }^{206}$ Los autores también enumeran los indicadores o métricas usuales en los análisis de seguimiento de ojos, mencionándolos a través de tres estudios en el ámbito de la cartografía. Por ejemplo, en este trabajo el Análisis de Áreas de Interés (AOI) es identificado como un indicador de especial utilidad en la cartografía como medio para evaluar las diferentes partes en las que se compone un mapa -leyendas, escalas, los propios fenómenos geográficos y temáticos representados, etc.-.

${ }^{207}$ El laboratorio pertenece al Departamento de Geoinformática de la Univerzita Palackého, en Olomouc -República Checa-.

${ }^{208}$ El hardware profesional SIM Red 250 se caracteriza por una precisión de $0,4^{\circ}$ y soporta 60,120 y $250 \mathrm{~Hz}$ de barrido, mientras que el hardware de bajo coste EyeTribe posee una precisión en un rango de $0,5^{\circ}-1^{\circ}$ y soporta 30 y $60 \mathrm{~Hz}$ (Popelka y Brychtova, 2015). 


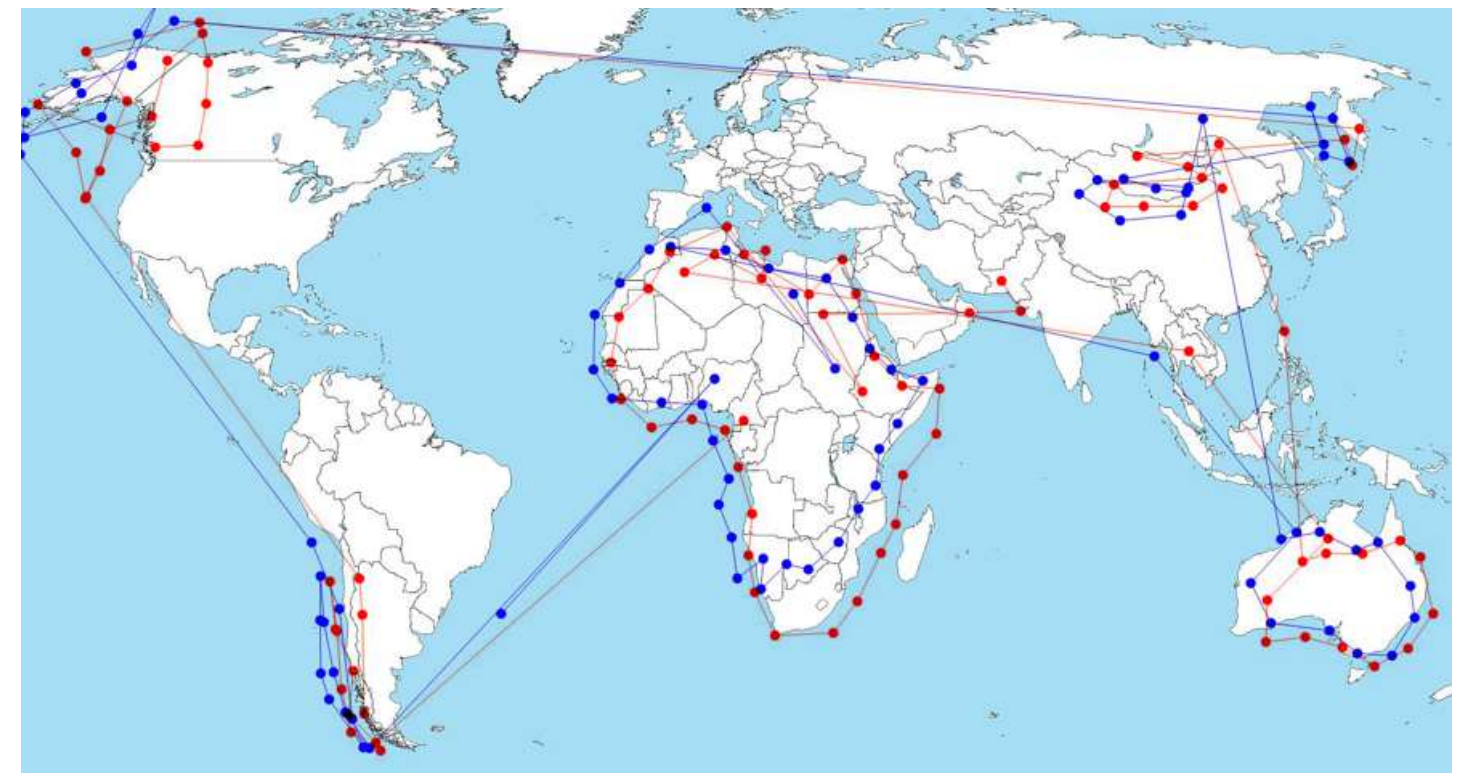

Figura 4-10: Comparativa de recorridos y fijaciones sobre un mismo mapa estático a través de un dispositivo de seguimiento ocular SIM Red 250 -en rojo-y un dispositivo EyeTribe -en azul-. En ambos casos se utilizó una frecuencia de muestreo de $60 \mathrm{~Hz}$ (Popelka y Brychtova, 2015).

Por último, se desea reseñar una reducida pero diversa serie de trabajos específicos que, dentro de la evaluación de modelos cartográficos estáticos a través del seguimiento ocular, tratan sobre aspectos concretos y específicos, en oposición a los citados anteriormente -que poseen un punto de vista más generalista sobre la temática-. La intención es mostrar la gran cantidad de aspectos cognitivos, semánticos y de comunicabilidad cartográfica que pueden ser abordados mediante esta técnica.

- Dimensionalidad de la representación cartográfica. Los anteriormente referidos Popelka, Brychtova, y Brus (2012b) trataron de averiguar qué tipos de visualización -2D ó 3D- prefieren los usuarios al realizar búsquedas de información geográfica -considerando asícada representación como un tipo de estímulo diferente-. A destacar que se encontraron algunos resultados no esperados: aunque las investigaciones de otros autores de referencia indican que un recorrido visual más largo implica una búsqueda menos eficiente (Goldberg y Wichansky, 2002), en todos los casos del experimento realizado el grupo de usuarios con un perfil de expertos en cartografía presentaban recorridos más largos que el perfil de usuarios noveles.

- Legibilidad de imágenes satélite. Los autores Dong, Liao, Roth, y Wang (2014), enfocaron su investigación en la mejora de legibilidad de los mapas Web, en concreto en las imágenes de satélite que son usualmente utilizadas como base cartográfica. Así, registraron los movimientos oculares de 20 participantes mientras realizaban tareas de búsqueda sobre determinadas áreas de interés. Estas 
áreas estaban situadas sobre imágenes sin modificar y otras procesadas mediante determinadas rutinas. Combinando análisis cualitativo y cuantitativo, evidenciaron una mejor eficacia en las tareas propuestas sobre las imágenes tratadas, en concreto en las áreas visualmente más complejas.

- Colory tamaño de fuentes. Brychtova y Coltekin (2014) analizaron empíricamente ${ }^{209}$ la influencia que supone, para el rendimiento de visualización y las estrategias de búsqueda en los mapas, la variación de la distancia -con respecto al usuario-, el color y el tamaño de las fuentes. A través del estudio se pudo concluir, entre otras cosas, que cuando las diferencias de tono de color se hacen más evidentes, las diferencias relativas a tiempos de finalización de tareas se vuelven más significativos estadísticamente, demostrando que una mayor diferencia tonal mejora la legibilidad de los mapas. Por otra parte, también demostraron que un tamaño de fuente intermedio entre las muestras analizadas conduce a una búsqueda más eficiente.

- Distinción entre visualizaciones atentas y difusas. K. Krejtz, Duchowski, y Coltekin (2014) proponen una métrica avanzada consistente en distinguir, en el proceso de visión, qué visualizaciones son focalizadas y precisas, y en cuáles la atención es difusa y meramente ambiental ${ }^{210}$. Para ello se basan en el denominado coeficiente $K^{211}$, que recoge la relación temporal entre la duración de las fijaciones y la amplitud sacádica. El experimento asociado a este estudio compara el comportamiento de búsqueda visual sobre diferentes representaciones geográficas de dos ciudades -Ámsterdam y Barcelona. El análisis posterior sugiere a los autores grandes diferencias en las estrategias cognitivas implicadas en las búsquedas visuales. una búsqueda rápida sobre un estímulo menos complejo puede provocar una búsqueda ambiental más temprana, más larga o con una gran oscilación en la atención, lo que posiblemente indique aburrimiento. Por el contrario, un estímulo más complejo puede requerir a posteriori mayor atención focal en la búsqueda, posiblemente indicando un mayor interés.

- Simbolización de superficies temáticas. Kiik (2015) centra su atención en la simbolización temática de fenómenos superficiales que, situados en primer plano, pueden ocultar la información posicionada debajo de ellos. En el estudio realizado con técnicas eye-tracking, se pidió a 32 participantes expertos con conocimientos cartográficos que resolvieran diferentes tareas de lectura, todo ello en un experimento controlado. Se pusieron en juego cuatro técnicas de simbolización para superficies temáticas - líneas de contorno, transparencias de tonos de color, patrones e iconos- y se comprobaron empíricamente en 16 áreas del mapa físico. A partir de los datos de movimiento ocular comprobaron que el

${ }^{209}$ A través del seguimiento ocular se estudiaron métricas clásicas de rendimiento, como la eficacia -éxito y precisión-, eficiencia -tiempo de respuesta y de tareas-, y las métricas de eye-tracking ya explicadas.

${ }^{210}$ La atención ambiental está caracterizada por unas fijaciones relativamente cortas, seguidas por amplios movimientos sacádicos. Por el contrario, una atención focalizada está definida por fijaciones largas seguidas por sacadas de una amplitud pequeña (K. Krejtz et al., 2014).

${ }^{211}$ Un coeficiente $K>0$ indica una visualización focalizada, mientras que un coeficiente $K<0$ sugiere una visualización ambiental (I. Krejtz, Szarkowska, Krejtz, Walczak, y Duchowski, 2012). 
tiempo de reacción y la calidad de la inferencia del fenómeno eran diferentes en cada uno de las simbologías. Así, para las condiciones creadas en el estudio, los patrones de líneas dieron los mejores resultados: esta simbología supuso las trayectorias de exploración más cortas, pero también la suma de duración de fijaciones más contenida, por lo que cabe interpretar que estímulo asociado a esta simbología lleva a los usuarios a interpretar el fenómeno con mayor facilitad que sus alternativas.

Tanto en el ámbito militar como civil, la metodología de seguimiento de ojos ha tenido un uso intensivo para el estudio de Factores Humanos en el puesto de mando, existiendo numerosas referencias científicas al respecto. Por ejemplo, Flemish y Onken (2000) aplicaron esta técnica para detectar problemas de usabilidad en la gestión de tareas complejas de elevado estrés relacionadas con el combate aéreo. También Robinski y Stein (2013) aplicaron está técnica -combinada con autoevaluaciones y entrevistas- para investigar acerca del trabajo de los pilotos de helicópteros militares ${ }^{212}$, aunque declararon que no se llegó a conclusiones consistentes sobre cómo las técnicas de escaneado visual difieren entre los pilotos con y sin experiencia, en función de las exigencias de la misión.

Con respecto al estudio específico - a través del seguimiento ocular- de la atención visual sobre los distintos formatos de información aeronáutica, en el ámbito civil se pueden encontrar diversos autores de referencia. Graeber y Andre (1999) realizaron una evaluación del comportamiento de la atención visual de los pilotos sobre los mapas electrónicos con movimiento bajo diversos niveles de visibilidad y formación. A su vez, Ottati, Hickox, y Richter (1999) compararon diferentes patrones de exploración ocular sobre diferentes características del terreno durante Reglas de Vuelo Visual (VFR) en busca de implicaciones que ayudaran a la formación de pilotos ${ }^{213}$ y al diseño de mapas electrónicos.

Anders (2001) concretó una serie de escenarios de vuelo realista -en las fases de aproximación y aterrizaje- en un simulador completo de vuelo de un Airbus A330. El investigador asignó sobre la instrumentación una serie de Áreas de Interés (AOI) para proceder a su monitorización [Figura 4-11], y posteriormente sometió a una serie de pilotos voluntarios a medición ocular y de movimientos de cabeza ${ }^{214}$ mientras ejecutaban los escenarios propuestos.

${ }^{212}$ En este estudio, 33 pilotos militares realizaron dos maniobras de aterrizaje diferentes en un simulador de vuelo de helicópteros

${ }^{213}$ Con respecto a la formación, una implicación básica es que los pilotos novatos miraban mucho más hacia el exterior de la aeronave -en busca de puntos de orientación- que los pilotos con experiencia.

${ }^{214}$ Además de realizar el seguimiento ocular de 7 tripulaciones distintas - 14 pilotos- , se realizaron recogidas complementarias de datos mediante grabación de vídeo, cuestionarios y la extracción de los datos del simulador de vuelo, entre otros. 


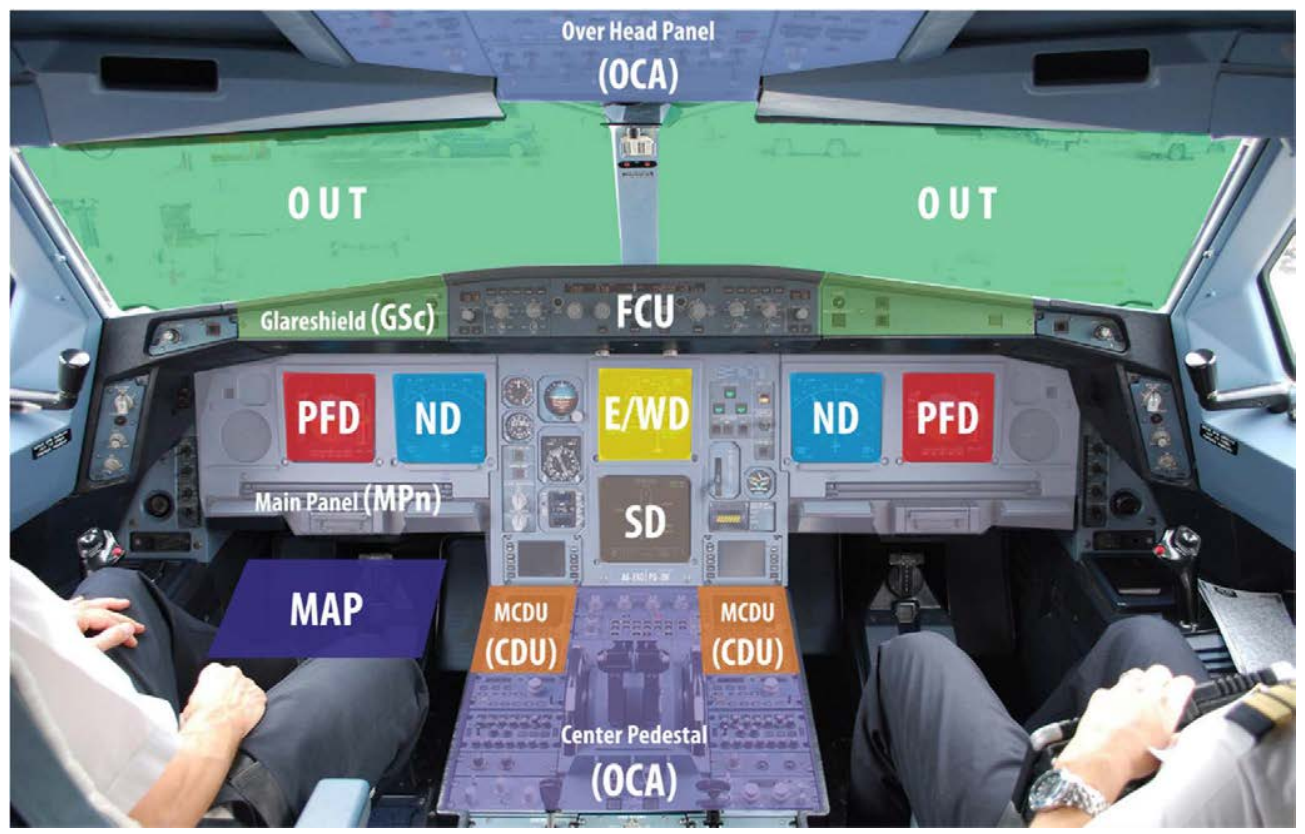

Figura 4-11: Áreas de Interés (A0I) definidas por Anders -en su investigación- en el cockpit de un Airbus A330. Adaptado de (Anders, 2001) sobre fotografía original de (Janco Nagelhout, Airliners.net).

A través de los parámetros descriptivos habituales -duración de fijación de la mirada, recorridos, etc.- se lograron realizar múltiples exploraciones relacionadas con la carga de trabajo mental y la forma de provisión de información, entre ella la relacionada con la conciencia situacional geográfica. Según los resultados preliminares [Figura 4-12], el porcentaje total de atención sobre la Pantalla de Navegación (ND) alcanza algo más del 16\%, mientras que el porcentaje de atención sobre la cartografía tradicional se situó aproximadamente en el 4\%. Con respecto al número de fijaciones, la Pantalla de Navegación (ND) agrupa el 21\% del total de las fijaciones, mientras que la cartografía apenas supone el 0,7\% del total; esta diferencia con respecto al porcentaje de atención de explica por la duración de las fijaciones, que son cortas y numerosas en la consulta de la Pantalla de Navegación (ND), y largas y exiguas en la lectura de $\operatorname{cartas}^{215}$.

Con el paso de los años, la mejora de la tecnología de seguimiento ocular ha resultado ser evidente. Si comparamos el estudio de Anders (2001) con la investigación similar que realizaron Weibel, Fouse, Emmenegger, Kimmich, y Hutchins (2012), se han logrado metodologías no intrusivas, gracias a sistemas de seguimientos de ojos portátiles y muy ligeros -gafas-, que además integran una cámara que permite registrar el campo visual hacia donde observa el piloto, e incluso registrar el sonido ambiente.

${ }^{215}$ En el contexto de la simulación de aproximación y aterrizaje, mientras que la duración media de la fijación de la vista fue de dos segundos para las cartas, sobre los displays de navegación no llegó al medio segundo. 


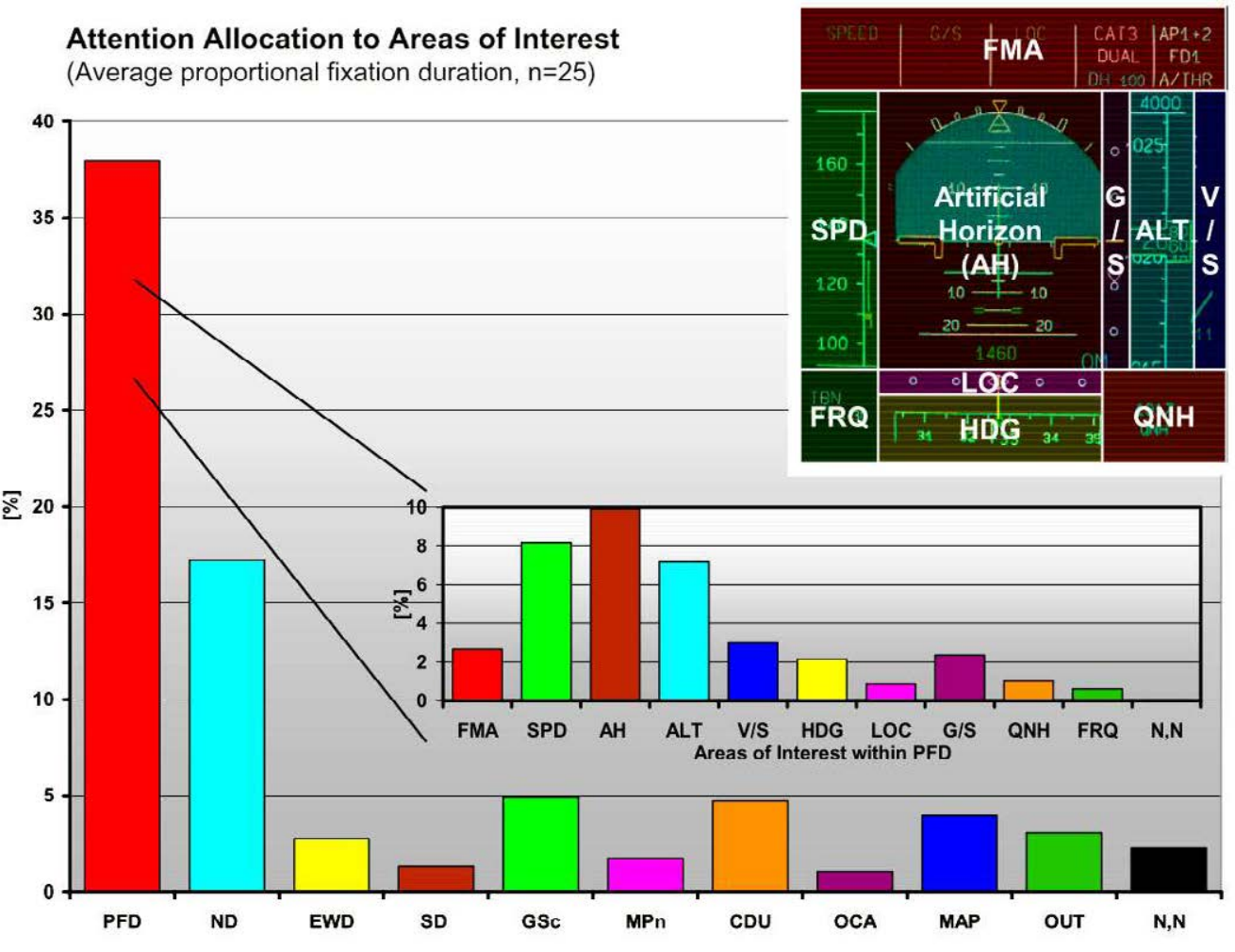

Figura 4-12: Resultado inicial del porcentaje de atención de los pilotos sobre las Áreas de Interés (AOI). Sobre el área de mayor atención-Pantalla Primaria de Vuelo (PFD)-se realiza una segmentación de porcentaje para cada una de sus secciones (Anders, 2001).

\subsubsection{Bondades, incertidumbres y limitaciones}

Pese al atractivo que puede presentar la aplicación de técnicas de eye-tracking en evaluación cartográfica, la mayoría de los autores reseñados en el apartado anterior son todavía cautos y subrayan las incertidumbres y limitaciones metodológicas con las que se han encontrado en sus investigaciones. Así, en las investigaciones anteriores a la llegada de los dispositivos portátiles y low-cost de seguimiento ocular, se indicaba su elevado coste y la dificultad metodológica para realizar investigaciones cognitivas que, además, requería mucho tiempo. También se dudaba que la recopilación de datos fuera realmente útil para todos los cartógrafos (Montello, 2002), mientras que el ya citado Brodersen et al. (2002) advertía que hasta el momento el análisis se centraba en lo que veían los usuarios en el mapa, pero no se analizaban otras cuestiones de inferencia semiológica.

En los trabajos recientes, los autores siguen advirtiendo de distintas incertidumbres. Incluso Ooms (2012), en su tesis doctoral, llega a cuestionar una base fundamental del análisis de seguimiento de ojos, consistente en que existe una relación directa y evidente entre el movimiento de los ojos y la atención de los usuarios. También se indican determinadas advertencias metodológicas, como la realizada por Krassanakis (2013) al respecto 
de que la reacción de los usuarios es más rápida cuando el símbolo buscado se encuentra en la parte central del mapa, y que en los experimentos tienen a buscar en el mapa desde el punto donde se encontraba la respuesta en el mapa anterior, lo que puede interferir en el análisis de resultados cognitivos.

Pese a lo anterior, en diversos trabajos se reconoce la bondad de la técnica para enmarcar estudios de comunicación cartográfica dentro de las múltiples teorías cognitivas existentes, e investigar a los usuarios durante las tareas de lectura de mapas. Por último se sugieren el uso de una combinación de métodos tradicionales de evaluación -inspección e indagación- con el análisis empírico del movimiento ocular, además de aconsejar abordar únicamente pequeños problemas semióticos de usabilidad que, sumados a otros, puedan hacer un todo; al existir un cierto grado de incertidumbre en el análisis, la simplificación de los experimentos es necesaria (Çöltekin et al., 2009).

\subsection{LA PROPUESTA METODOLÓGICA}

Dentro del argumento metodológico de esta tesis doctoral, quedaría únicamente por despejar la incógnita de cuál sería el procedimiento más apropiado para tratar de mensurar las cualidades comunicacionales de un modelo cartográfico -de forma preferentemente cuantitativa-.

Dedicada la segunda parte de este cuarto capítulo a describir y valorar algunos de los métodos de evaluación de los sistemas de comunicación visual, estamos en disposición de diseñar y aplicar una metodología para el análisis y mejora de la eficiencia comunicacional de las cartas aeronáuticas. Puesto que el ámbito de la comunicación cartográfica es enormemente amplio y transversal, trataremos de acotar en lo posible nuestra aportación. Así, proponemos centrar la atención en evidenciar cómo determinadas combinaciones de variables visuales estereotipadas -aplicadas en la simbolización de las distintas capas de información- provocan interferencias en la percepción que, a su vez, obstaculizan la lectura y comunicación de atributos al lector.

Para alcanzar este objetivo, se propone hacer uso de las técnicas de seguimiento ocular, en el convencimiento de su validez para el estudio de percepción visual y la mejora de la expresión gráfica de los modelos cartográficos complejos. Acorde con los principios del eye-tracking, planteamos valorar la mejora de las cualidades comunicacionales -entre un modelo cartográfico de partida y otro modificado- en términos de velocidad, claridad y cantidad de información que se puede ser percibida y procesada con respecto al desempeño humano óptimo.

En consecuencia, aplicaremos el eye-tracking para tratar de transponer determinados principios cartográficos a meras hipótesis, tratando de confirmarlas mediante la interacción con usuarios. En la práctica esto se traduce en identificar un problema semiológico concreto en el ámbito de la cartografía aeronáutica y, aplicando la metodología, tratar de resolverlo o al menos limitar en lo posible su afección. Aprovecharemos también el 
carácter empírico de esta técnica para mensurar la mejora mediante su parametrización numérica -a través de las métricas de seguimiento ocularya presentadas-.

El detallado de la aplicación particular de la metodología y la exposición completa de la evaluación se realizará en el capítulo 5 -La inferencia perceptual-, mientras que se dedicará el capítulo 6 -El ajuste combinatorio- para el correspondiente análisis y la discusión de resultados.

\subsubsection{Localización del ámbito geográfico de evaluación}

En orden a simplificar en lo posible el análisis, se aprovecharán los dos conjuntos de datos de partida identificados en 3.4.2 -La composición de modelos de simbología estereotipada-. Estos conjuntos son las cartas VAC de los aeródromos de Bordeaux Mérignac -Francia-y Madrid Cuatro Vientos -España-, respectivamente. Como se justificó en el apartado reseñado, los dos modelos representan campos de vuelo inmersos en zonas urbanas que presentan una cierta complejidad, la cual se ve reflejada en la composición cartográfica que de ellas realizan cada una de las oficinas nacionales responsables de su redacción.

\subsection{SUMARIO}

En este cuarto capítulo se ha alcanzado el objetivo de examinar las metodologías de análisis de la eficiencia comunicacional de las cartas aeronáuticas, incluida la elección de la más adecuada para el objeto de esta tesis doctoral -la aplicación concreta se realizará en el siguiente capítulo-. Este objetivo se ha resuelto a través de dos enfoques concatenados, siendo el primero de ellos el análisis del conjunto de habilidades, limitaciones y otras características relevantes para el diseño de objetos y sistemas:

- Factores humanos en la comunicación aeronáutica. Con el propósito de identificar las implicaciones de factores humanos clave en cuanto a comunicación cartográfica se refiere, en primer lugar se ha realizado una revisión bibliográfica específica. Para ello se ha indagado de modo específico en el modelo conceptual de factores humanos de Hawkins y el modelo de error humano de Reason, los cuales son utilizados profusamente en el ámbito aeronáutico.

- Errores de edición, lectura e interpretación. Tomando como referencia los modelos conceptuales citados, se ha tratado de deducir los posibles alcances que pueden tener los errores de edición, lectura e interpretación de la cartografía aeronáutica, mediante el análisis de las causas constatadas que desembocaron en el accidente aéreo acontecido en el monte Oiz-provincia de Bizkaia-, en febrero de 1985. 
- Cartas aeronáuticas en papel como sistema de comunicación. A continuación, se analizado el modelo de formación adoptado por la FAA -adaptación del modelo de factores humanos de Meister- para la contribución de los factores humanos en el desarrollo de sistemas propios. Partiendo del mismo, se ha propuesto caracterizar las cartas aeronáuticas en papel como un sistema de comunicación perteneciente al lado de la máquina, particularizado así el modelo de la FAA para nuestro campo concreto de estudio. Bajo este enfoque metodológico, se han identificado y aportado un total de 25 factores y relaciones de interés implicados en la interacción de un piloto con una carta aeronáutica en formato papel, agrupándolos a su vez en los 7 componentes declarados en el modelo modificado de Meister.

Finalmente, y una vez aportado un listado de conceptos de eficiencia comunicacional como parte de los requisitos de mejora para la optimización de cualquier tipo de modelo de comunicación visual, se han estudiado los conceptos de comunicabilidad y ergonomía cognitiva. Estos conceptos han sido igualmente definidos en relación con los aspectos conductuales y cognitivos que gobiernan el vínculo entre el hombre y los artefactos cartográficos.

La segunda parte del capítulo se ha ocupado de las metodologías actuales de evaluación de los sistemas de comunicación gráfica, tratando así de seleccionar una técnica específica y confiable que mejor encaje con el propósito y las necesidades evaluativas de la tesis. En concreto:

- Metodologías de evaluación. Se han identificado una serie de metodologías y técnicas actuales de evaluación de los sistemas de comunicación gráfica y, en especial, las relacionadas con la atención visual y el movimiento ocular, las cuales tratan de extraer conclusiones evaluativas a partir de una medición cuantitativa. De estas se aporta su concepto, avances recientes, así como las bondades y limitaciones de su aplicación concreta para el análisis de la eficiencia comunicacional cartográfica.

- Evaluación de la comunicación cartográfica mediante eye-tracking. Una vez presentados los fundamentos de esta técnica, se ha realizado una revisión bibliográfica específica de autores que se sirven de las técnicas de eye-tracking para sus investigaciones en el ámbito de la aeronáutica, las ciencias geográficas y la cartografía. Al respecto de la evaluación de modelos cartográficos estáticos, se han revisado aspectos concretos y específicos, tales como la dimensionalidad de la representación cartográfica, la legibilidad de las imágenes satélite, el color y el tamaño de las fuentes, la simbolización de elementos superficiales, entre otros.

- Declaración metodológica y ámbito de evaluación. Finalmente se ha declarado en la investigación el propósito de uso de técnicas de seguimiento ocular para el estudio de la percepción visual y mejora de la expresión gráfica de los modelos cartográficos complejos. En concreto, se propone valorar la mejora de las cualidades comunicacionales entre un modelo de partida y su equivalente estereotipado en términos de velocidad, claridad y cantidad de información que se puede ser percibida y procesada con respecto al desempeño humano óptimo. 
